\title{
TWO-PHASE PRESSURE DROP AND PHASE DISTRIBUTION IN A HORIZONTAL TEE JUNCTION
}

\author{
by \\ John R. Buell
}

\begin{abstract}
A thesis
presented to the University of Manitoba

in partial fulfillment of the

requirements for the degree of

Master of Science

in

Mechanical Engineering
\end{abstract}

Winnipeg, Manitoba

(c) John R. Buell, 1992 
National Library

of Canada

Acquisitions and

Bibliographic Services Branch

395 Wellington Street

Ottawa, Ontario

K1A ON4
Bibliothèque nationale

du Canada

Direction des acquisitions et

des services bibliographiques

395 , rue Wellington

Ottawa (Ontario)
Your tile Votreveterence

Ourtife Notre référence
The author has granted an irrevocable non-exclusive licence allowing the National Library of Canada to reproduce, loan, distribute or sell copies of his/her thesis by any means and in any form or format, making this thesis available to interested persons.
L'auteur a accordé une licence irrévocable et non exclusive permettant à la Bibliothèque nationale du Canada de reproduire, prêter, distribuer ou vendre des copies de sa thèse de quelque manière et sous quelque forme que ce soit pour mettre des exemplaires de cette thèse à la disposition des personnes intéressées.
The author retains ownership of the copyright in his/her thesis. Neither the thesis nor substantial extracts from it may be printed or otherwise reproduced without his/her permission.
L'auteur conserve la propriété du droit d'auteur qui protège sa thèse. Ni la thèse ni des extraits substantiels de celle-ci ne doivent être imprimés ou autrement reproduits sans son autorisation. 
TWO-PHASE PRESSURE DROP AND PHASE DISTRIBUTION IN A HORIZONTAL TEE JUNCTION

BY

JOHN R. BUELL

A Thesis submitted to the Faculty of Graduate Studies of the University of Manitoba in partial fulfilment of the requirements for the degree of

MASTER OF SCIENCE

(ㄷ) 1992

Permission has been granted to the LIBRARY OF THE UNFVERSITY OF MANIFOBA to lend or sell copies of this thesis, to the NATIONAL LIBRARY OF CANADA to microfilm this thesis and to lend or sell copies of the film, and UNTVERSITY MICROFILMS to publish an abstract of this thesis.

The author reserves other publication rights, and neither the thesis nor extensive extracts from it may be printed or otherwise reproduced without the author's permission. 


\section{ABSTRACT}

A two-phase-flow apparatus was designed and constructed in order to study the splitting of a two-phase, air-water mixture through a horizontal tee junction with a horizontal branch of equal diameter (37.6-mm I.D.). Generated data consisted of the phase distribution and the pressure drops at the tee junction. Operating conditions were as follows: an inlet pressure of about 1.5 atm, a near-ambient inlet temperature, inlet superficial gas velocities ranging between 2.7 and $41 \mathrm{~m} / \mathrm{s}$, inlet superficial liquid velocities ranging between 0.0021 and $0.181 \mathrm{~m} / \mathrm{s}$, and extraction rates between 0.1 and 0.9 . These inlet flow conditions led to observations of stratified, wavy, stratified-wavy, slug, semiannular, and annular flow regimes at the tee-junction inlet.

The results showed that in general, the phases did not distribute themselves evenly between the branch and the run of the tee junction. The stratified and semiannular data displayed near-even phase distribution. Slug flow data showed a strong preference for the gas phase to flow into the branch. For the majority of the wavy flow data the gas phase preferentially entered the branch and for nearly all of the stratified-wavy flow data the liquid phase preferentially entered the branch. Annular flow data displayed large variations in the distribution of the phases, depending on the inlet superficial liquid velocity. A comparison of the present phase-distribution data and the data of other authors obtained under similar operating conditions generally 
showed good agreement.

The phase-distribution results were presented in a number of ways in order to examine the individual effects of important flow parameters on the phase distribution. The results indicate that as the inlet superficial liquid velocity increased at a fixed inlet superficial gas velocity, there was an increased preference for the gas phase to exit through the branch, irrespective of the inlet flow regime. The effect of the inlet mass flux on the phase distribution appeared to become more significant as the inlet quality was decreased. The effect of the inlet superficial gas velocity on the phase distribution did not result in consistent trends, possibly due to the associated flow regime transitions. These trends in the present data are similar to trends observed by other investigators using different operating conditions and junction geometries.

The phase-distribution data were compared to several phase-distribution models presented in the literature. The model developed by Hwang et al. [19] gave the best overall predictions of the present data; however, the branch quality during slug flow was underpredicted. The phenomenological models developed by Azzopardi and Whalley [6] and Azzopardi [25] performed well in predicting the present annular and semiannular data. The Seeger et al. model [14] underpredicted the branch quality for extraction rates less than 0.5; however, at higher extraction rates the model performed well.

The tee-junction pressure drops were found to depend greatly on the 
inlet flow conditions and the extraction rate. The pressure drops were compared to the predictions of various models given in the literature. For inlet flow regimes other than slug flow, $\Delta \mathrm{P}_{12}$ was predicted best by the separated flow model presented by Fouda and Rhodes [27], with $\left(\mathrm{K}^{\star}{ }_{12}\right)_{\mathrm{S}}$ equal to the single-phase momentum correction factor $\mathrm{K}^{\star}{ }_{12}$. For slug flow, the model presented by Hwang and Lahey [28] gave the best predictions for extraction rates greater than 0.1 ; however, for smaller extraction rates the separated flow model gave the best predictions. In general, $\Delta \mathrm{P}_{13}$ was poorly predicted by existing models. For extraction rates greater than 0.1 , the separated flow model recommended by Saba and Lahey [12] gave the best predictions of the present data; however, for smaller extraction rates the Reimann and Seeger model [26] gave the best predictions. 


\section{ACKNOWLEDGEMENTS}

I would like to acknowledge and thank the many people who have provided assistance over the course of this investigation. Special thanks go to the author's supervisors, Dr. H. M. Soliman and Dr. G. E. Sims, both of whom provided continuous encouragement and guidance which made this work possible. The assistance of Mr. M. Kapitoler and Mr. J. Finken in constructing and maintaining the apparatus is greatly appreciated.

The financial support provided by the Natural Sciences and Engineering Research Council of Canada and the Department of Mechanical and Industrial Engineering, University of Manitoba is gratefully acknowledged. 


\section{TABLE OF CONTENTS}

\section{Page}

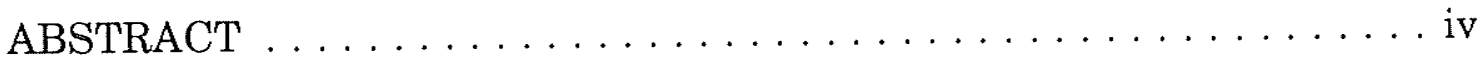

ACKNOWLEDGEMENTS $\ldots \ldots \ldots \ldots \ldots \ldots \ldots \ldots$ vii

LIST OF FIGURES $\ldots \ldots \ldots \ldots \ldots \ldots \ldots \ldots \ldots \ldots \ldots \ldots$

LIST OF TABLES $\ldots \ldots \ldots \ldots \ldots \ldots \ldots \ldots \ldots \ldots \ldots \ldots \ldots$

NOMENCLATURE $\ldots \ldots \ldots \ldots \ldots \ldots \ldots \ldots \ldots \ldots \ldots$ xviii

1. INTRODUCTION $\ldots \ldots \ldots \ldots \ldots \ldots \ldots \ldots \ldots$

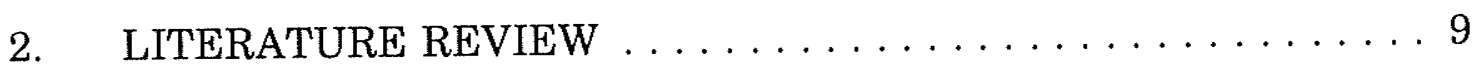

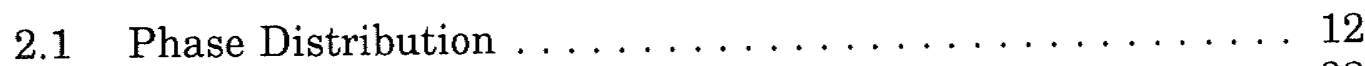

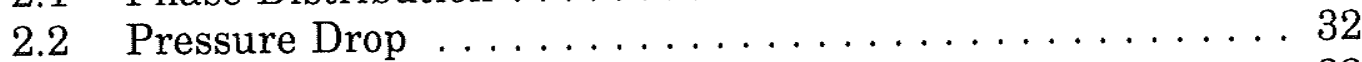

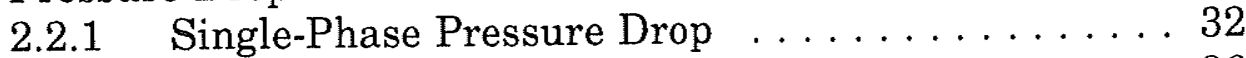

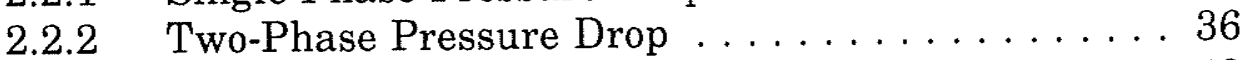

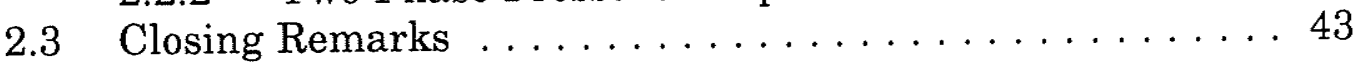

3. EXPERIMENTAL INVESTIGATION $\ldots \ldots \ldots \ldots \ldots \ldots$

3.1 Air-Water Loop $\ldots \ldots \ldots \ldots \ldots \ldots \ldots \ldots \ldots \ldots$

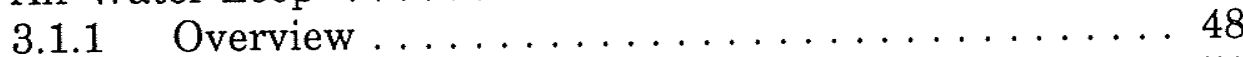

3.1.2 Water Flow Rate Measurement . . . . . . . . . 51

3.1 .3 Mixer ..................... 53

3.1.4 Air Flow Rate Measurement . . . . . . . . . 53

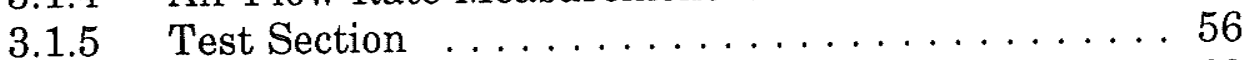

3.1.6 Separation Tanks . . . . . . . . . . . 63

3.1.7 Temperature Measurement . . . . . . . . . 67

3.2 Pressure Measurement . . . . . . . . . . . . . 68

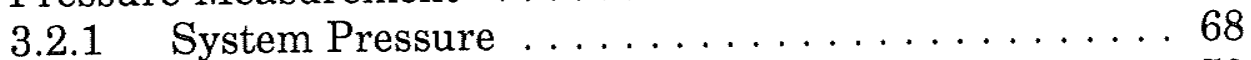

3.2 .2 Pressure Distribution $\ldots \ldots \ldots \ldots \ldots \ldots \ldots$

3.3 Data-Acquisition System . . . . . . . . . . . 71

3.4 System Operation and Data Reduction . . . . . . . . . 72

3.4.1 Two-Phase Flow . . . . . . . . . . . . . . . 72

Start-Up and Steady-State . . . . . . . . . . 72

Recording of Phase-Distribution Data . . . . . . 76

Recording of Pressure-Distribution Data . . . . . 77 
Reduction of Phase-Distribution Data . . . . . . . 81

Reduction of Pressure-Distribution Data . . . . . . 83

Flow Regimes .................. 84

3.4 .2 Single-Phase Flow . . . . . . . . . . . . . 87

Start-Up and Steady-State . . . . . . . . . . 87

Recording and Reduction of Data . . . . . . . 89

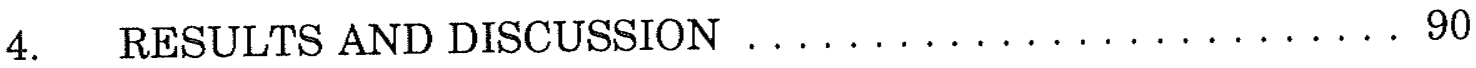

4.1 Data Range ........................ 90

4.2 Presentation of Phase-Distribution Data . . . . . . . 94

4.2.1 Effect of Inlet Superficial Liquid Velocity . . . . . . 94

4.2.2 Effect of Inlet Superficial Gas Velocity . . . . . . 104

$4.2 .3 \quad$ Effect of Inlet Mass Flux . . . . . . . . . . . . . 114

4.2.4 Effect of Inlet Flow Regime . . . . . . . . . . . 123

4.3 Presentation of Pressure-Drop Data . . . . . . . . . 127

4.3.1 Single-Phase Flow . . . . . . . . . . . . . 127

4.3 .2 Two-Phase Flow . . . . . . . . . . . . . . 133

4.4 Experimental Uncertainty . . . . . . . . . . . . 141

4.5 Comparison Between the Present Data and

Existing Models . . . . . . . . . . . . . . . . . . . . . . . 144

4.5.1 Phase-Distribution Data . . . . . . . . . . . 144

Azzopardi and Whalley Model [6] . . . . . . . 144

Azzopardi Model [25] . . . . . . . . . . . . 145

Hwang et al. Model [19] . . . . . . . . . . 147

Seeger et al. Model [14] . . . . . . . . . . . 154

4.5 .2 Pressure-Drop Data . . . . . . . . . . . . . . 156

Data of $\Delta \mathrm{P}_{12} \ldots \ldots \ldots \ldots \ldots \ldots \ldots \ldots \ldots$

Data of $\Delta \mathrm{P}_{13} \ldots \ldots \ldots \ldots \ldots \ldots \ldots \ldots \ldots$

4.6 Comparison of the Present Phase-Distribution 170

Data With Data From Other Authors . . . . . . . . 170

5. CONCLUSIONS AND RECOMMENDATIONS . . . . . . . 183

5.1 Conclusions ....................... 183

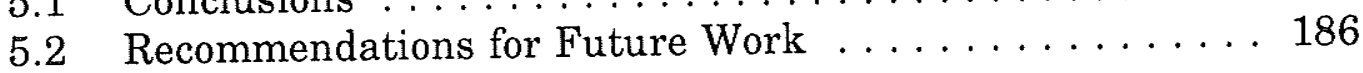

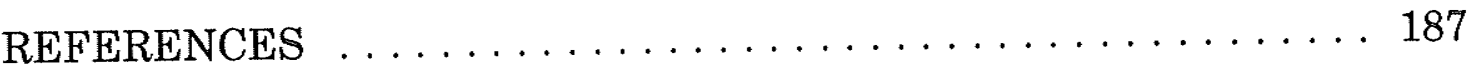

\section{Appendices}

A. CORRECTION FOR EVAPORATION . . . . . . . . . . 191 
B. DETERMINATION OF $\triangle \mathrm{P}_{12}$ AND $\triangle \mathrm{P}_{13}$ FROM THE MEASURED PRESSURE DISTRIBUTION . . . . . . . . . . 213

C. PRESSURE-DROP AND PHASE-DISTRIBUTION DATA . . . . 218

D. SAMPLE PROBLEMS IN MEASURED PRESSURE

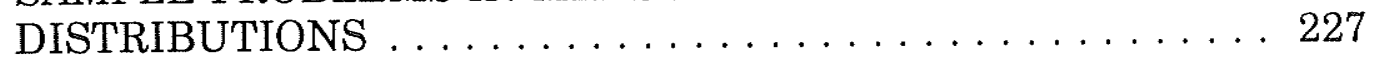

E. ESTIMATES OF EXPERIMENTAL UNCERTAINTY . . . . . . 234 


\section{LIST OF FIGURES}

\section{Figure}

\section{Page}

1.1 Relevant parameters for two-phase flow in a tee junction . . . . . . . . . . . . . . . 3

1.2 (a-b) Methods of presenting phase-distribution data .......4

1.3 An example of the pressure distribution during two-phase flow through a tee junction [present data] . . . . . . . 6

2.1 Schematic diagram illustrating the basis of the Azzopardi and Whalley model [6] for annular flow . . . . . . . 18

2.2 Dividing streamlines for the phase-distribution model of Hwang et al. [19] . . . . . . . . . . . . 25

2.3 (a-b) Control volumes for single-phase pressure-drop models . . 33

2.4 (a-b) Range of inlet conditions for phase-distribution experiments with a horizontal tee junction plotted on the Mandhane et al. [30] flow-regime map . . . . . 45-46

2.5 Range of inlet conditions for pressure-drop experiments with a horizontal tee junction plotted on the Mandhane et al. [30] flow-regime map . . . . . . 47

$3.1 \quad$ Schematic diagram of the experimental facility $\ldots \ldots \ldots 49$

3.2 Schematic diagram of two-phase mixer $\ldots \ldots \ldots \ldots 4$

$3.3 \quad$ Schematic diagram of test section $\ldots \ldots \ldots \ldots \ldots \ldots$

3.4 Construction details of visual section; reproduced from Rubel $[16] \ldots \ldots \ldots \ldots \ldots$. . . . . . . . . . . . 59

3.5 Cross-sectional views of the tee junction; reproduced from Rubel [16] . . . . . . . . . . . . . . . . . . 61

3.6 Isometric view of the tee junction; reproduced from

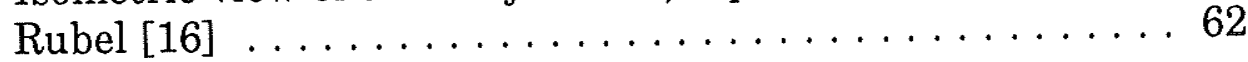

Location of pressure taps $\ldots \ldots \ldots \ldots \ldots \ldots \ldots$ 
3.8 Details of one separation tank $\ldots \ldots \ldots \ldots \ldots$

3.9 Pressure-drop measurement station . . . . . . . . 69

$3.10 \quad$ Schematic diagrams of observed flow regimes $\ldots \ldots \ldots 85$

4.1 The present inlet flow conditions plotted on the Mandhane et al. [30] flow-regime map . . . . . . . . 93

4.2 (a-b) Effect of $\mathrm{J}_{\mathrm{L} 1}$ on the phase distribution for $\mathrm{J}_{\mathrm{G} 1}=2.7 \mathrm{~m} / \mathrm{s}$

4.3 (a-b) Effect of $\mathrm{J}_{\mathrm{L} 1}$ on the phase distribution for $\mathrm{J}_{\mathrm{G1}}=4.3 \mathrm{~m} / \mathrm{s} \ldots \ldots \ldots \ldots \ldots \ldots \ldots \ldots \ldots \ldots \ldots \ldots .9 \ldots \ldots$

4.4 (a-b) Effect of $J_{L 1}$ on the phase distribution for $\mathrm{J}_{\mathrm{G} 1}=10.8 \mathrm{~m} / \mathrm{s} \ldots \ldots \ldots \ldots \ldots \ldots \ldots \ldots \ldots \ldots \ldots \ldots .100 \ldots \ldots$

4.5 (a-b) Effect of $J_{L 1}$ on the phase distribution for

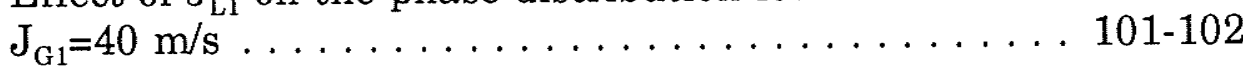

4.6 (a-b) Effect of $J_{G 1}$ on the phase distribution for

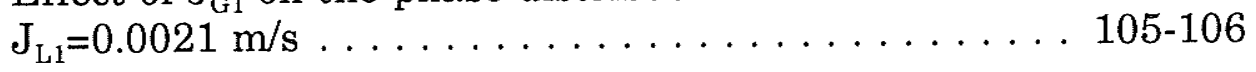

4.7 (a-b) Effect of $J_{\mathrm{G} 1}$ on the phase distribution for

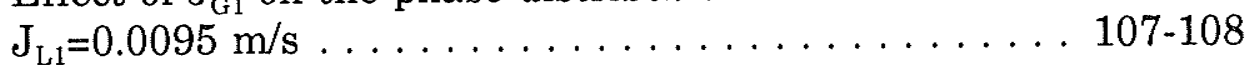

4.8 (a-b) Effect of $J_{G 1}$ on the phase distribution for

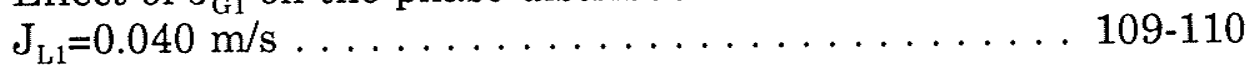

4.9 (a-b) Effect of $J_{G 1}$ on the phase distribution for $\mathrm{J}_{\mathrm{L} 1}=0.180 \mathrm{~m} / \mathrm{s}$

$4.10(a-b)$ Effect of inlet mass flux on the phase distribution for $\mathrm{x}_{1}=10 \%$

$4.11(\mathrm{a}-\mathrm{b})$ Effect of inlet mass flux on the phase distribution for $\mathrm{x}_{1}=32 \%$

$4.12(a-b)$ Effect of inlet mass flux on the phase distribution for $\mathrm{x}_{1}=67 \%$ 
Figure

4.13 (a-b) Effect of inlet mass flux on the phase distribution for $\mathrm{x}_{1}=89 \%$

4.14 Effect of inlet flow regime on the phase distribution for annular and semiannular flow data . . . . . . . . . 124

4.15 Effect of inlet flow regime on the phase distribution for wavy and stratified-wavy flow data . . . . . . . 125

4.16 Effect of inlet flow regime on the phase distribution for slug and stratified flow data $\ldots \ldots \ldots \ldots \ldots \ldots \ldots$

4.17 Pressure distribution during single-phase flow for $W_{3} / W_{1}=0.30 \ldots \ldots \ldots \ldots \ldots \ldots \ldots \ldots \ldots \ldots \ldots \ldots$

4.18 Pressure distribution during single-phase flow for $\mathrm{W}_{3} / \mathrm{W}_{1}=0.70 \ldots \ldots \ldots \ldots \ldots \ldots \ldots \ldots \ldots \ldots \ldots \ldots$

$4.19 \quad$ Single-phase loss coefficient, $\mathrm{K}_{12} \ldots \ldots \ldots \ldots 131$

$4.20 \quad$ Single-phase loss coefficient, $\mathrm{K}_{13} \ldots \ldots \ldots \ldots \ldots$

$4.21 \quad$ Single-phase momentum correction factor, $\mathrm{K}^{\star}{ }_{12} \ldots \ldots \ldots 134$

4.22 Pressure distribution during two-phase flow,

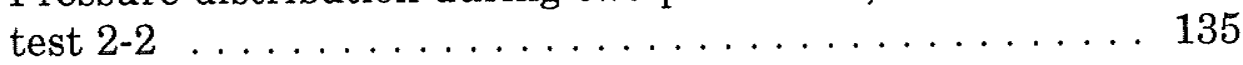

4.23 Pressure distribution during two-phase flow,

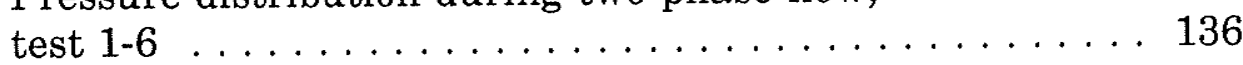

4.24 Pressure distribution during two-phase flow, test $6-3 \ldots \ldots \ldots \ldots \ldots \ldots \ldots \ldots \ldots \ldots \ldots \ldots \ldots \ldots \ldots$

4.25 (a-b) Effect of $\mathrm{J}_{\mathrm{L} 1}$ on the pressure drops for $\mathrm{J}_{\mathrm{G} 1}=11 \mathrm{~m} / \mathrm{s} \ldots \ldots 139$

$4.26(\mathrm{a}-\mathrm{b}) \quad$ Effect of $\mathrm{J}_{\mathrm{L} 1}$ on the pressure drops for $\mathrm{J}_{\mathrm{G} 1}=40 \mathrm{~m} / \mathrm{s} \ldots \ldots 140$

4.27 (a-b) Effect of $\mathrm{J}_{\mathrm{G} 1}$ on the pressure drops for $\mathrm{J}_{\mathrm{L} 1}=0.0095 \mathrm{~m} / \mathrm{s} \ldots 142$

$4.28(a-b) \quad$ Effect of $J_{\mathrm{G} 1}$ on the pressure drops for $\mathrm{J}_{\mathrm{L} 1}=0.180 \mathrm{~m} / \mathrm{s} \ldots 143$ 
4.29 Comparison between the Azzopardi and Whalley model [6] and the present annular and semiannular data . . . . . 146

4.30 Comparison between the Azzopardi model [25] and the present annular and semiannular data . . . . . . . 146

4.31 Inlet flow geometry for stratified flow $\ldots \ldots \ldots \ldots 149$

$4.32 \quad$ Inlet flow geometry for annular flow $\ldots \ldots \ldots \ldots \ldots 151$

4.33 Comparison between the Hwang et al. model [19] for stratified flow and the present stratified, stratified-wavy, wavy, and slug data ................. 153

4.34 Comparison between the Hwang et al. model [19] for annular flow and the present annular and semiannular data ............................. 153

4.35 Comparison between the Seeger et al. model [14] and the present data . . . . . . . . . . . . . . 155

4.36 Homogeneous flow model (HFM) for $\Delta \mathrm{P}_{12}, \mathrm{~K}^{\star}{ }_{12}$ present value . . . . . . . . . . . . . . 160

4.37 Separated flow model (SFM) for $\Delta \mathrm{P}_{12}, \mathrm{~K}^{\star}{ }_{12}$ present value, $\alpha$ using Rouhani correlation $[15] \ldots \ldots \ldots \ldots 160$

4.38 Separated flow model (BM) for $\Delta \mathrm{P}_{12}, \mathrm{~K}^{\star}{ }_{12}=1.0$, $\alpha$ using Rouhani correlation [15] . . . . . . . . . 161

4.39 Reimann and Seeger model [26] (RSM) for $\Delta \mathrm{P}_{12}, \mathrm{~K}_{12}$ present value, $\alpha$ using Rouhani correlation $[15] \ldots \ldots \ldots 161$

$4.40 \quad$ Hwang and Lahey model [28] (HLM2) for $\Delta \mathrm{P}_{12}, \mathrm{~K}^{{ }_{12}}$ present value, $\alpha_{1}$ using Rouhani correlation [15] . . . . 162

4.41 Hwang and Lahey model [28] (HLM1) for $\Delta \mathrm{P}_{12}, \mathrm{~K}^{\star}{ }_{12}$ present value, $\alpha_{1}$ using Zuber-Findlay model [29] . . . . . 162

4.42 Homogeneous flow model (HFM) for $\Delta \mathrm{P}_{13}, \mathrm{~K}_{13}$ present value $\ldots \ldots \ldots \ldots \ldots \ldots \ldots \ldots \ldots \ldots$ 
Figure

4.43 Separated flow model (SFM) recommended by Saba and Lahey [12] for $\Delta \mathrm{P}_{13}, \mathrm{~K}_{13}$ present value, $\alpha$ using Rouhani correlation [15] . . . . . . . . . . . . 166

4.44 Reimann and Seeger model [26] (RSM1) for $\Delta \mathrm{P}_{13}, \mathrm{~K}_{13}$ present value, $\alpha_{1}$ using Rouhani correlation [15], $\mathrm{K}=1.0$

Reimann and Seeger model [26] (RSM2) for $\Delta \mathrm{P}_{13}, \mathrm{~K}_{13}$ present value, $\alpha_{1}$ using Rouhani correlation [15], $\mathrm{K}=1.34$

Ballyk et al. model [18] (BM) for $\Delta \mathrm{P}_{13}, \mathrm{~K}_{13}$ present value, $\alpha$ using Rouhani correlation $[15] \ldots \ldots \ldots \ldots 168$

4.47 Hwang and Lahey model [28] (HLM) for $\Delta \mathrm{P}_{13}, \mathrm{~K}_{13}$ present value, $\alpha_{1}$ using Rouhani correlation $[15] \ldots \ldots \ldots \ldots 168$

4.48 Phase-distribution data of Shoham et al. [21] for stratified flow; reproduced from Shoham et al. [21] . . . . 172

4.49 Phase-distribution data of Shoham et al. [21] for wavy flow; reproduced from Shoham et al. [21] . . . . . 173

4.50 Phase-distribution data of Shoham et al. [21] for annular flow; reproduced from Shoham et al. [21] . . . . 174

4.51 Composite drawing of present wavy and stratified-wavy data, $\mathrm{J}_{\mathrm{G} 1}=4.4$ and $11 \mathrm{~m} / \mathrm{s}$, and the data of Shoham et

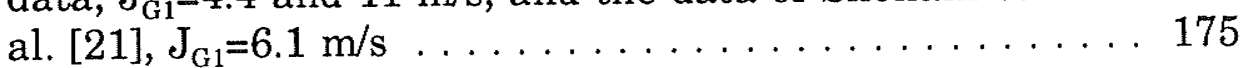

4.52 Comparison between the present wavy and stratified-wavy data and the wavy data of Shoham et al. [21] for

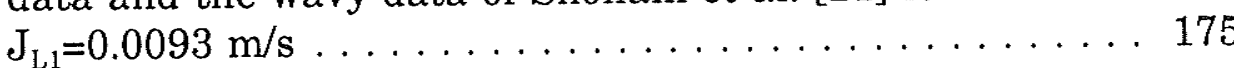

4.53 Comparison between the Hwang et al. model [19] and the data of Shoham et al. [21] . . . . . . . . . . . . . 177

4.54 Comparison between the present data for $J_{\mathrm{L} 1}=0.0094 \mathrm{~m} / \mathrm{s}$ and the data of Rubel et al. [20] . . . . . . . . . . . . 178 
4.55 Comparison between the present data for $J_{G 1}=11 \mathrm{~m} / \mathrm{s}$ and $\mathrm{J}_{\mathrm{L} 1}=0.0092 \mathrm{~m} / \mathrm{s}$ and the data of Rubel et al. [20] . . . . 178

$4.56(\mathrm{a}-\mathrm{b})$ Comparison between the present data and the data of Hong [3] for $\mathrm{J}_{\mathrm{G} 1}=40 \mathrm{~m} / \mathrm{s} \ldots \ldots \ldots \ldots \ldots$

4.57 (a-b) Comparison between the present data and the data of Hong [3] for $\mathrm{J}_{\mathrm{G} 1}=10 \mathrm{~m} / \mathrm{s} \ldots \ldots \ldots \ldots \ldots \ldots \ldots$

A.1 Relevant parameters for the calculation of flow conditions at the mixer outlet $\ldots \ldots \ldots \ldots \ldots \ldots$

A.2 Relevant parameters for the calculation of flow conditions at the tee-junction inlet . . . . . . . . . 198

A.3 Relevant parameters for the calculation of heat transfer to a horizontal tube . . . . . . . . . . . . 200

A.4 Relevant parameters for the calculation of flow conditions in the run . . . . . . . . . . . . 204

B.1 Regression line for run pressure-distribution data . . . . 214

D.1 Pressure distribution for test $7-4 \ldots \ldots \ldots \ldots \ldots 228$

D.2 Pressure distribution for test $4-2 \ldots \ldots \ldots \ldots \ldots \ldots$

D.3 Pressure distribution for test $4-4 \ldots \ldots \ldots \ldots 231$

D.4 Pressure distribution for test $3-2 \ldots \ldots \ldots \ldots \ldots 232$

E.1 Calibration of low-range water turbine meter $\ldots \ldots \ldots 244$

E.2 Procedure for the calculation of $\delta\left(\mathrm{W}_{\mathrm{L} 1 \mathrm{M}}\right) \ldots \ldots \ldots 246$

E.3 Variables required for the calculation of $\delta\left(\mathrm{W}_{\mathrm{GIM}}\right) \ldots \ldots 248$

E.4 Variables required for the calculation of inlet flow conditions . . . . . . . . . . . . . . 250

E.5 Variables required for the calculation of $\delta\left(\mathrm{W}_{\mathrm{G} 2}\right)$
and $\delta\left(\mathrm{W}_{\mathrm{L} 2}\right) \ldots \ldots \ldots \ldots \ldots \ldots \ldots \ldots \ldots \ldots \ldots \ldots \ldots \ldots \ldots \ldots$ 


\section{LIST OF TABLES}

Table

Page

2.1

Summary of Previous Investigations of Two-Phase

Flow in Tee Junctions . . . . . . . . . . . . . 10-11

4.1 Ranges of Operating Conditions for the Two-Phase

Test Runs ........................ . . 91

4.2 Ranges of Operating Conditions for the Single-Phase

Test Runs . . . . . . . . . . . . . . . . . . . 91

4.3 Summary of the Performance of $\Delta \mathrm{P}_{12}$ Models $\ldots \ldots \ldots 9$

4.4 Summary of the Performance of $\Delta \mathrm{P}_{13}$ Models . . . . . . 165

C.1 Two-Phase Pressure-Drop and Phase-Distribution

Data . . . . . . . . . . . . . . . . . . . . 220-223

C.2 Single-Phase Pressure-Drop Data . . . . . . . . . . 224

C.3 Previous Numbering Scheme for Two-Phase

Flow Test Runs . . . . . . . . . . . . . . . . . . . . 225

C.4 Two-Phase and Single-Phase Mass Flow Rates at

the Tee Junction . . . . . . . . . . . . . . . . 226

E.1 Uncertainty Intervals for Reduced Data . . . . . . . . 239-240

E.2 Repeatability of Experimental Data . . . . . . . . . . 259 


\section{NOMENCLATURE}

a Coefficient appearing in the Seeger et al. model [14], defined in equation (2.5)

A Area occupied by a particular phase, $\mathrm{m}^{2}$

$\mathrm{C}_{0} \quad$ Void concentration parameter defined in equation (2.42)

$\mathrm{C}_{2} \quad$ Contraction coefficient for tee-junction run $=\mathrm{A}_{\mathrm{C} 2} / \mathrm{A}_{1}$

$\mathrm{C}_{3} \quad$ Contraction coefficient for tee-junction branch $=\mathrm{A}_{\mathrm{C}} / \mathrm{A}_{1}$

D Diameter, $m$

$\mathrm{E}_{1} \quad$ Entrainment fraction in tee-junction inlet

$\mathrm{F}_{\mathrm{BG}} \quad$ Fraction of gas exiting through the branch

$\mathrm{F}_{\mathrm{BG} \text { crit }} \quad$ Critical value of $\mathrm{F}_{\mathrm{BG}}$, calculated using equation (2.12)

$\mathrm{F}_{\mathrm{BL}} \quad$ Fraction of liquid exiting through the branch

$\mathrm{F}_{\mathrm{S}} \quad$ Fraction of liquid that flows into tee-junction branch from liquid collar, calculated using equation (2.14)

$\mathrm{F}_{\mathrm{SEG}} \quad$ Fraction of liquid film in tee-junction inlet removed from segment

g Acceleration due to gravity $=9.81 \mathrm{~m} / \mathrm{s}^{2}$

G Mass flux, $\mathrm{kg} / \mathrm{m}^{2} \mathrm{~s}$

$h_{L} \quad$ Height of gas-liquid interface, $m$

J Superficial velocity, $\mathrm{m} / \mathrm{s}$

$\mathrm{K} \quad$ Correction factor in equation (2.41)

$\mathrm{K}_{12} \quad$ Single-phase loss coefficient for run, equation (2.19)

$K_{12}^{*} \quad$ Single-phase momentum correction factor for run, equation (2.16) 
$\left(\mathrm{K}_{12}^{*}\right)_{\mathrm{H}} \quad$ Homogeneous flow momentum correction factor for run, equation $(2.27)$

$\left(\mathrm{K}^{\star}{ }_{12}\right)_{\mathrm{S}} \quad$ Separated flow momentum correction factor for run, equation (2.25)

$\mathrm{K}_{13} \quad$ Single-phase loss coefficient for branch, equation (2.19)

n Exponent defined in equation (2.11)

$\mathrm{P} \quad$ Pressure, $\mathrm{Pa}$

$\mathrm{P}_{\mathrm{r}} \quad$ Pressure at tap \#1 (reference pressure), $\mathrm{Pa}$

$\mathrm{P}_{1} \quad$ Extrapolated pressure at tee-junction inlet, $\mathrm{Pa}$

$\mathrm{P}_{2} \quad$ Extrapolated pressure at tee-junction run, $\mathrm{Pa}$

$\mathrm{P}_{3} \quad$ Extrapolated pressure at tee-junction branch, $\mathrm{Pa}$

$\Delta \mathrm{P}_{\mathrm{C} 2 \cdot 2} \quad$ Pressure drop between the throat of a vena contracta in the teejunction run and a location downstream in the run, defined in equation (2.22), $\mathrm{Pa}$

$\Delta \mathrm{P}_{\mathrm{C} 3-3} \quad$ Pressure drop between the throat of a vena contracta in the teejunction branch and a location downstream in the branch, defined in equation (2.22), $\mathrm{Pa}$

$\Delta \mathrm{P}_{12} \quad$ Pressure drop from tee-junction inlet to run, defined in equation (3.12), $\mathrm{Pa}$

$\Delta \mathrm{P}_{13} \quad$ Pressure drop from tee-junction inlet to branch, defined in equation (3.12), $\mathrm{Pa}$

$\Delta \mathrm{P}_{1-\mathrm{C} 2} \quad$ Reversible pressure drop between the tee-junction inlet and the throat of a vena contracta in the tee-junction run, defined in equation (2.21), $\mathrm{Pa}$

$\Delta \mathrm{P}_{1-\mathrm{C} 3} \quad$ Reversible pressure drop between the tee-junction inlet and the throat of a vena contracta in the tee-junction branch, defined in equation (2.21), $\mathrm{Pa}$

Q Volume flow rate, $\mathrm{m}^{3} / \mathrm{s}$

$\mathrm{R} \quad$ Density ratio $=\rho_{\mathrm{L} 1} / \rho_{\mathrm{G} 1}$ 

$R_{G} \quad$ Radius of curvature of gas dividing streamline, $m$
$R_{L} \quad$ Radius of curvature of liquid dividing streamline, $m$
$\mathrm{Re}_{\mathrm{G} 1} \quad$ Superficial gas Reynolds number in the tee-junction inlet
S Slip ratio
V Velocity, $\mathrm{m} / \mathrm{s}$
$\mathrm{V}_{\mathrm{F} 1} \quad$ Mean velocity of liquid film in tee-junction inlet, $\mathrm{m} / \mathrm{s}$
$\mathrm{V}_{\mathrm{G} 1} \quad$ Mean velocity of gas phase in tee-junction inlet, defined in equation (4.4), $\mathrm{m} / \mathrm{s}$
$\mathrm{V}_{\mathrm{L} 1} \quad$ Mean velocity of liquid phase in tee-junction inlet, defined in equation (4.5), $\mathrm{m} / \mathrm{s}$
$\mathrm{V}_{\mathrm{REL}} \quad$ Relative velocity calculated using equation (2.8), $\mathrm{m} / \mathrm{s}$
W Mass flow rate, $\mathrm{kg} / \mathrm{s}$
x Quality, \%

\section{Greek}

$\alpha \quad$ Void fraction

$\delta \quad$ Depth of zone of influence, $m$

$\eta \quad$ Extraction rate $\mathrm{W}_{3} / \mathrm{W}_{1}$

$\theta \quad$ Characteristic angle defined in equation (2.2)

$\rho \quad$ Density, $\mathrm{kg} / \mathrm{m}^{3}$

$\rho_{\mathrm{E}} \quad$ Energy weighted density defined in equation $(2.31), \mathrm{kg} / \mathrm{m}^{3}$

$\rho_{\mathrm{H}} \quad$ Homogeneous density defined in equation (2.28), $\mathrm{kg} / \mathrm{m}^{3}$

$\rho_{\mathrm{M}} \quad$ Momentum weighted density defined in equation $(2.26), \mathrm{kg} / \mathrm{m}^{3}$

$\rho_{\star 1} \quad$ Equivalent inlet density defined in equation $(2.47), \mathrm{kg} / \mathrm{m}^{3}$ 
$\sigma \quad$ Surface tension, N/m

$\varphi \quad$ Two-phase multiplier

$\varphi^{\star} \quad$ Two-phase multiplier defined in equation (2.48)

\section{Subscripts}

C Throat of vena contracta

G Gas phase

$\mathrm{H} \quad$ Homogeneous flow

IRR Irreversible

L Liquid phase

REV Reversible

S Separated flow

$1 \quad$ Side 1 of tee junction (inlet)

$2 \quad$ Side 2 of tee junction (run)

$3 \quad$ Side 3 of tee junction (branch) 


\section{Chapter 1}

\section{INTRODUCTION}

Two-phase flow commonly occurs in many systems in the power and process industries, such as conventional steam power plants, evaporators and condensers of refrigeration systems, boiling-water and pressurized-water nuclear reactors, and a wide variety of chemical and petroleum applications. Quite often, the complex piping networks in these systems require the twophase flow to pass through branching junctions, such as wyes and tees. Until recently, because the behaviour of two-phase flow through dividing junctions was not well understood, a frequent assumption was that the two phases divide evenly at the junction; that is, the quality of the mixture in both legs downstream from the junction are equal to the inlet quality. However, recent observations have shown that this assumption can be significantly in error; that is, in general, branching junctions do alter the distribution of the phases. Certain inlet conditions can lead to single-phase gas (or vapor) flowing in the branch side, while other conditions can lead to single-phase liquid flowing in the branch side. This severe maldistribution of the phases can have a significant effect on the operation and efficiency of any components downstream from the junction. Therefore, it is very important to be able to predict the manner by which the two phases distribute themselves at dividing junctions for different operating conditions. 
Another consideration is the pressure drop the flow experiences as it is split at dividing junctions. Experimental evidence has shown that the pressure drop during two-phase flow can be much greater than during a comparable single-phase flow. Again, predictive models are required for different junction geometries and flow conditions.

Figure 1.1 gives a schematic diagram of a dividing tee junction. The relevant flow parameters are as follows: the inlet, run, and branch mass flow rates $\left(W_{1}, W_{2}\right.$, and $W_{3}$, respectively); the inlet, run, and branch average pressures $\left(\mathrm{P}_{1}, \mathrm{P}_{2}\right.$, and $\mathrm{P}_{3}$, respectively); and the inlet, run, and branch qualities $\left(\mathrm{x}_{1}, \mathrm{x}_{2}\right.$, and $\mathrm{x}_{3}$, respectively). Relevant geometric parameters are the inlet, run, and branch tube diameters $\left(D_{1}, D_{2}\right.$, and $D_{3}$, respectively), and the orientation of the inlet and branch tubes. Another consideration is the properties of the two-phase mixture. The two phases may belong to the same fluid component, such as steam and water, or two distinct components, such as air and water. The extraction rate, given by $\mathrm{W}_{3} / \mathrm{W}_{1}$, is the fraction of the total inlet flow that is withdrawn through the branch.

Figure 1.2(a) illustrates one method that has been used to present phase-distribution data. The ordinate in this figure is the ratio of branch quality to inlet quality $\left(\mathrm{x}_{3} / \mathrm{x}_{1}\right)$, and the abscissa is the extraction rate $\mathrm{W}_{3} / \mathrm{W}_{1}$. Line $\mathbf{A B}$ represents the limiting case where only gas is diverted into the branch $\left(x_{3}=1\right)$ and all of the liquid and some gas flows in the run. Curve BC represents another limiting case where only single-phase liquid flows into the 


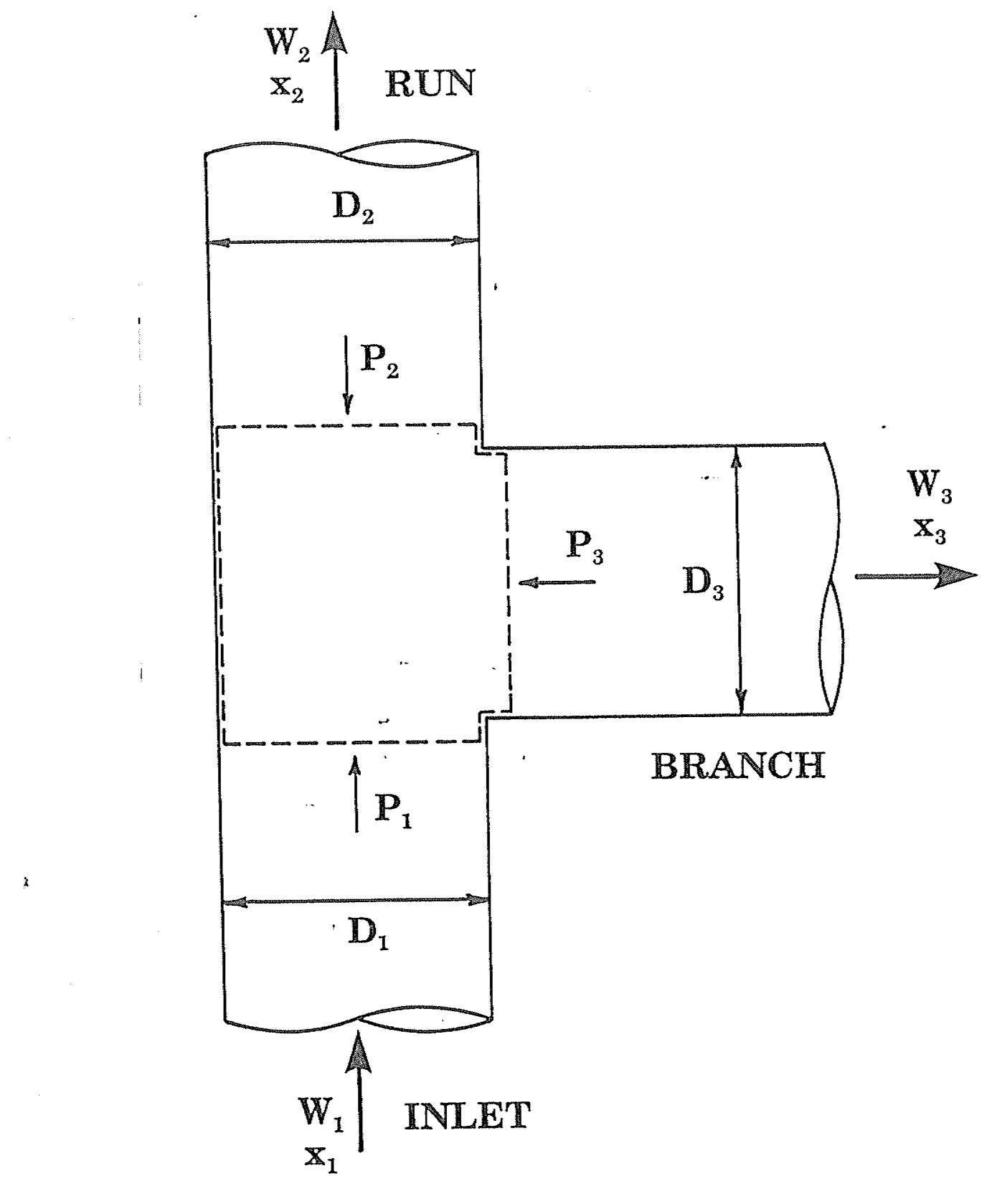

Figure 1.1 Relevant parameters for two-phase flow in a tee junction 


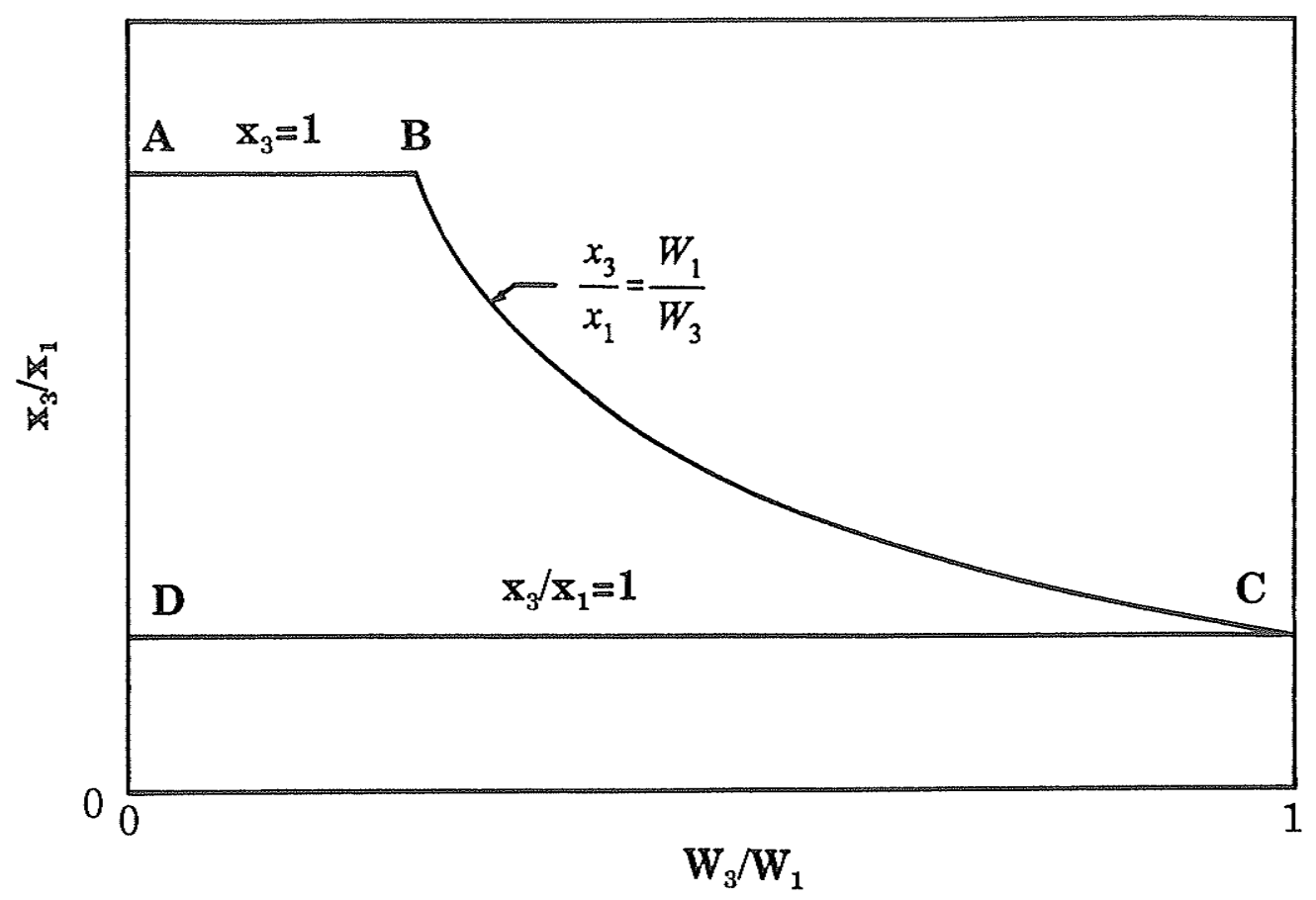

(a)

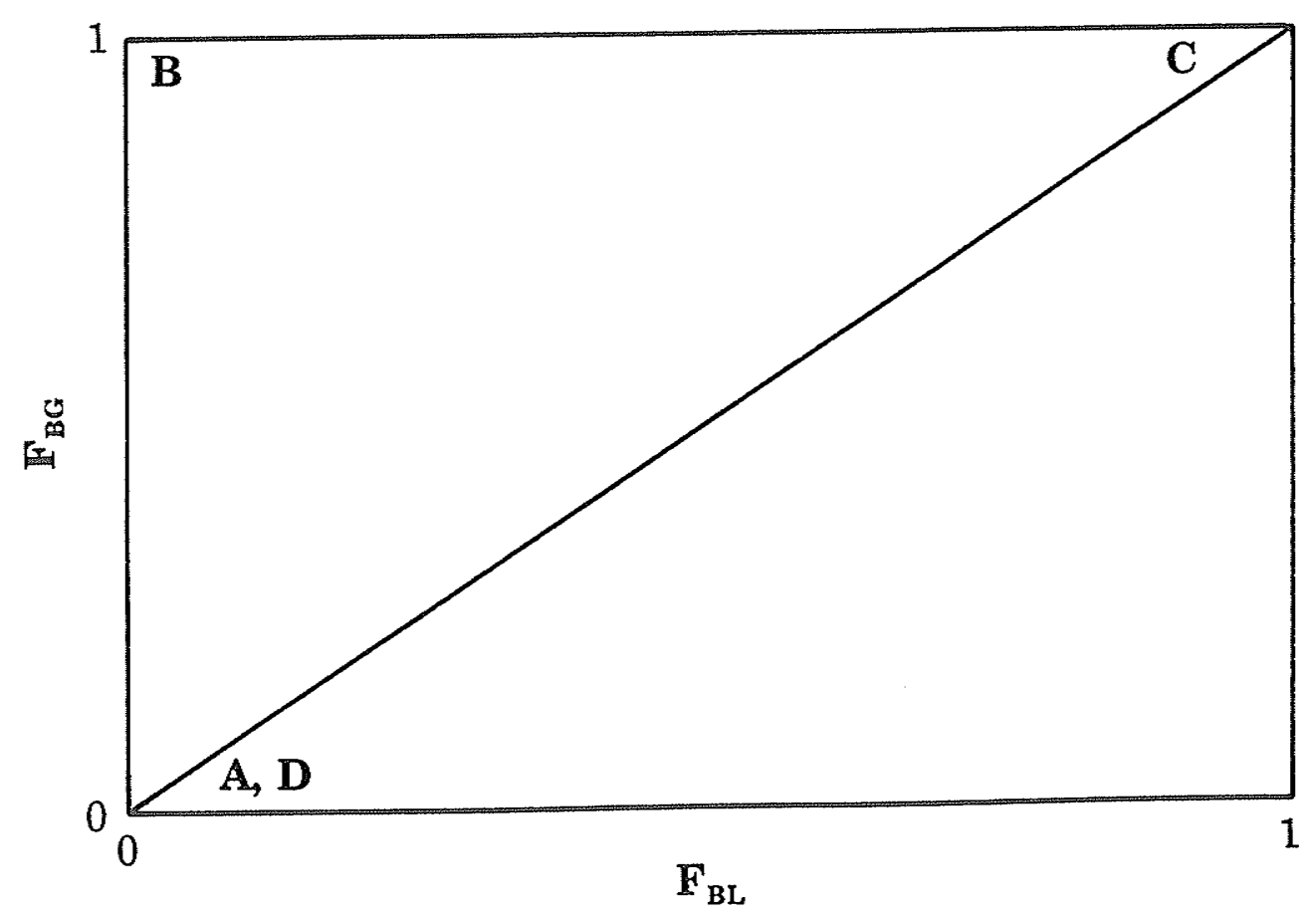

(b)

Figure 1.2 Methods of presenting phase-distribution data 
run $\left(x_{2}=0\right)$ and all of the gas and some liquid is diverted into the branch. A mass balance on the gaseous phase yields the following equation for this curve: $\mathrm{x}_{3} / \mathrm{x}_{1}=\mathrm{W}_{1} / \mathrm{W}_{3}$. At point $\mathbf{B}$, single-phase liquid is flowing in the run and singlephase gas is flowing in the branch. Thus, at point $\mathbf{B}$ the tee junction is acting as a perfect phase separator. No data can exist above curve $\mathbf{A B C}$. To remain consistent with previous authors, in the remainder of this thesis curve $\mathbf{A B C}$ will be referred to as the total phase separation curve. Line $\mathbf{C D}$ is the evenphase-distribution line where the branch quality is equal to the inlet quality $\left(\mathrm{x}_{3} / \mathrm{x}_{1}=1\right)$.

Another method that was previously used to present the phasedistribution data is shown in figure 1.2(b). In this figure, the ordinate is the fraction of inlet gas flowing in the branch $\left(\mathrm{F}_{\mathrm{BG}}\right)$ and the abscissa is the fraction of inlet liquid flowing in the branch $\left(F_{\mathrm{BL}}\right)$. The points labelled $\mathbf{A}, \mathbf{B}, \mathbf{C}$, and $\mathbf{D}$ correspond to the same points given in figure 1.2(a).

Figure 1.3 illustrates a typical static pressure distribution for the splitting of a two-phase mixture in a horizontal tee junction. The ordinate in this figure is the static pressure of the two-phase mixture relative to a reference pressure $P_{r}$. The inlet flow is fully developed; therefore, the pressure gradient in the inlet is due to frictional pressure drop only. When the flow is split, both the run and the branch experience a reversible pressure rise due to the deceleration of the flow. At the same time irreversible pressure losses occur. Generally, for the branch, the irreversible pressure drop is greater than the reversible pressure rise, giving a net pressure drop to the branch. For the 


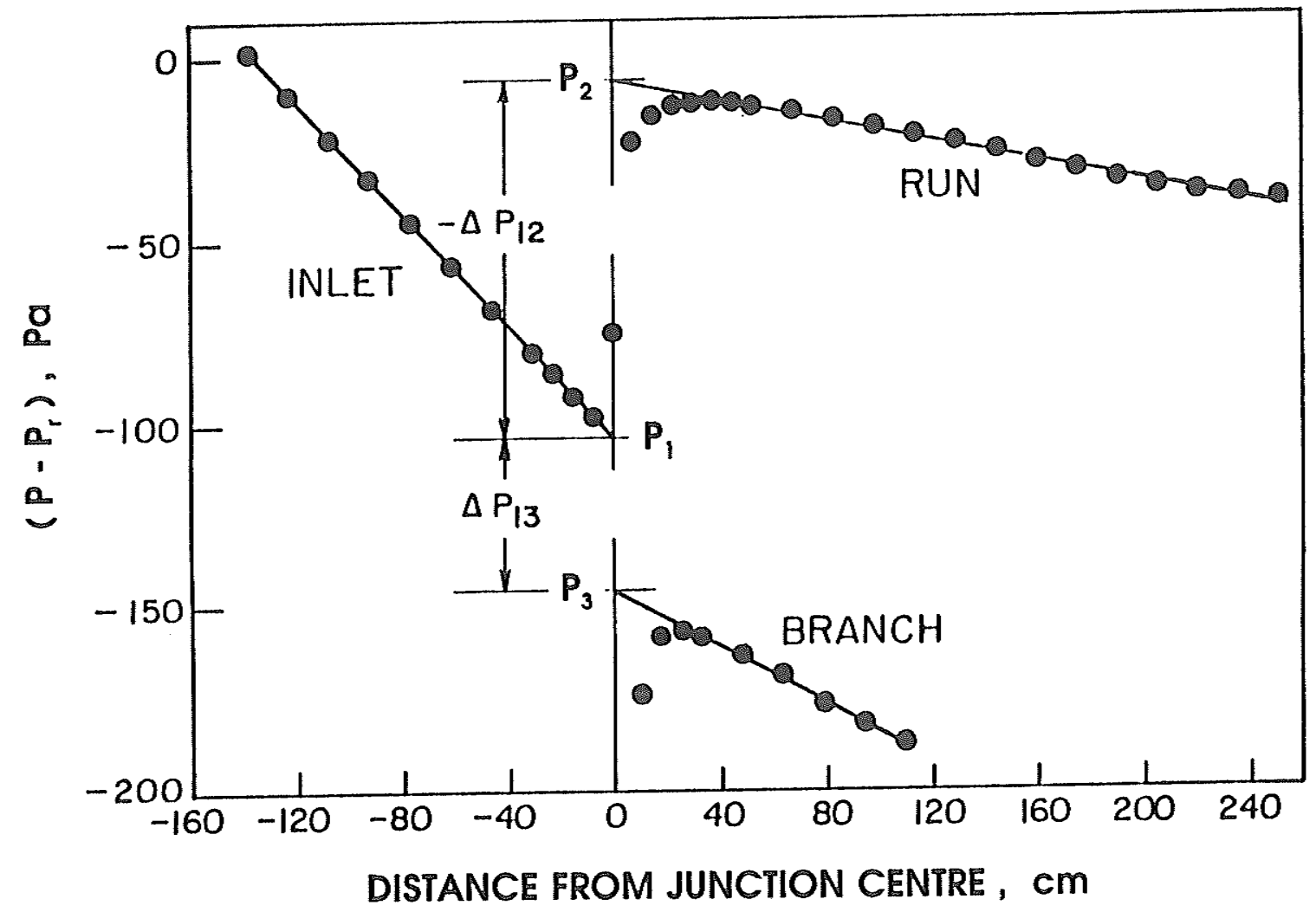

Figure 1.3 An example of the pressure distribution during two-phase flow through a tee junction [present data] 
run, generally the reversible pressure rise is greater than the irreversible pressure drop. Thus, there is a net pressure rise to the run. Some distance downstream from the tee, both the run and branch flows become fully developed again and the pressure gradient there is due to frictional losses only. The junction pressure drops, $\Delta \mathrm{P}_{12}=\mathrm{P}_{1}-\mathrm{P}_{2}$ and $\Delta \mathrm{P}_{13}=\mathrm{P}_{1}-\mathrm{P}_{3}$, are found by extrapolating the fully developed pressure gradients to the tee junction, as shown in figure 1.3.

A great deal of attention has been focused on attempting to develop mathematical models capable of predicting the mixture qualities downstream from tee junctions, as well as the associated pressure drops. Some of these models are claimed to be general (not flow-regime specific) while others are applicable to particular flow regimes. A truly generalized model would have to accommodate any combination of inlet mass flow rate, inlet quality, fluid properties, junction geometry, as well as extraction rate. A review of literature (Chapter 2) indicates that such a model, for the phase distribution or pressure drop, does not exist yet. Although a flow-regime-dependent model would not have to accommodate as wide a range of inlet conditions as a generalized model, none has proven to be adequate. As well, because the associated phenomena are not completely understood, there is no complete agreement amongst researchers as to which parameters must be included in these models.

A fundamental prerequisite to the development of mathematical models capable of predicting the phase distribution and pressure drop, is the availability of a wide range of experimental data against which any proposed 
model can be tested. Unfortunately, only a small amount of phase-distribution data, and even fewer pressure-drop data, have been published. The purpose of the present work, therefore, is to expand the range of experimental data to aid in the understanding of the phenomena and the development of models for phase distribution and pressure drop during two-phase flow through tee junctions.

The following is a list of the specific objectives of the present study:

1. To design and construct a two-phase flow experimental apparatus, capable of generating phase-distribution and pressure-drop data for the flow of airwater mixtures through a horizontal tee junction (inlet and branch lie horizontally), with equal diameter sides (37.6 mm I.D.).

2. To generate phase-distribution and pressure-drop data at about 1.5 atmospheres and ambient temperature, extraction rates between 0.1 and 0.9 , and a range of inlet conditions giving inlet regimes of stratified, wavy, annular, and slug flows.

3. To investigate the influences of inlet superficial gas velocity $\left(\mathrm{J}_{\mathrm{G} 1}\right)$, inlet superficial liquid velocity $\left(\mathrm{J}_{\mathrm{L} 1}\right)$, inlet mass flux $\left(\mathrm{G}_{1}\right)$, and inlet flow regime on the phase distribution and pressure drop through the tee junction.

4. To compare some of the existing phase-distribution and pressure-drop models against the generated experimental data in order to assess their predictive capability at the present conditions.

5. To compare some of the present phase-distribution data to the data published by other authors. 


\section{Chapter 2}

\section{LITERATURE REVIEW}

Table 2.1 gives an overview of the previously published research for twophase flow through tee junctions. Most of the previous data is for air-water flow at low pressure; however, recent studies exist for steam-water flow. For completeness, Table 2.1 summarizes the previous work for all inlet and branch orientations. The rest of this chapter considers only the previous work for tee junctions with horizontal main and branch tubes, except where the results at other orientations are relevant to the present study. Table 2.1 also indicates the previous studies which included tee-junction pressure drops. These studies were performed with elaborate pressure measurements which properly separated the tee-junction pressure drops from the frictional pressure drops. This was done by extrapolating the inlet, run, and branch pressure gradients to the tee junction, as shown previously in figure 1.3. Other studies, such as [1] and [4], only measured the static pressure near the tee junction using a single pressure tap in the inlet, run, and branch. An important parameter in determining the phase distribution and pressure drop is the inlet flow regime. The flow regimes encountered in each of the studies is indicated in Table 2.1. For detailed descriptions of the different two-phase flow regimes encountered in the present study, the reader is referred to Section 3.4.1. 
Table 2.1 Summary of Previous Investigations of Two-Phase Flow in Tee Junctions

\begin{tabular}{|c|c|c|c|c|c|c|c|c|c|c|c|c|}
\hline Authors & \multicolumn{2}{|c|}{ Junction Orientation } & $\begin{array}{c}\mathbf{D}_{1} \\
(\mathrm{~mm})\end{array}$ & $\underset{(\mathrm{mm})}{\mathrm{D}_{3}}$ & $\begin{array}{c}\text { Test } \\
\text { Fluids }^{(1)}\end{array}$ & $\begin{array}{c}\mathbf{P}_{1} \\
(\mathbf{k} \mathbf{P a})\end{array}$ & $\underset{\mathbf{k g} / \mathbf{m}^{2} \mathbf{s}}{\mathbf{G}_{1}}$ & $\begin{array}{l}x_{1} \\
\%\end{array}$ & $w_{3} / w_{1}$ & $\begin{array}{c}\text { Inlet } \\
\text { Flow } \\
\text { Regimes } \\
\end{array}$ & $\begin{array}{l}\text { Phase } \\
\text { Dist. }\end{array}$ & $\begin{array}{l}\text { Press. } \\
\text { Drop }\end{array}$ \\
\hline & & & & & & 150 & $20-030$ & $0-6$ & $0.0-10$ & - & & \\
\hline Tsuyama and Taga [1] & horiz. & horiz. & 23.4 & 23.4 & Aw & 100 & $20-500$ & 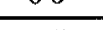 & 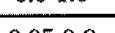 & & & \\
\hline Collier [2] & horiz. & horiz. & 37.6 & 25.4 & $\mathrm{AW}$ & 300 & 136 & $2.1-50$ & $0.05-0.9$ & - & $\mathrm{x}$ & \\
\hline \multirow[t]{2}{*}{ Hong [3] } & \multirow[t]{2}{*}{ horiz. } & $\begin{array}{c}\text { vert. up } \\
45^{\circ} \text { up } \\
45^{\circ} \text { down } \\
\text { vert. down }\end{array}$ & \multirow[t]{2}{*}{9.5} & \multirow[t]{2}{*}{9.5} & \multirow[t]{2}{*}{$\mathrm{AW}$} & 120 & 63 & 63 & \multirow[t]{2}{*}{$0-1.0$} & \multirow[t]{2}{*}{$\begin{array}{l}\text { W } \\
\text { An }\end{array}$} & \multirow[t]{2}{*}{$\mathrm{x}$} & \\
\hline & & horiz. & & & & $120-160$ & $18-126$ & $25-97$ & & & & \\
\hline \multirow[t]{2}{*}{ Johansen [4] } & \multirow[t]{2}{*}{ horiz. } & $\begin{array}{l}\text { vert. up } \\
\text { horiz. } \\
\text { vert. down }\end{array}$ & \multirow[t]{2}{*}{51} & 51 & \multirow[t]{2}{*}{$\mathrm{AW}$} & $250-400$ & \multirow[t]{2}{*}{$7-900$} & \multirow[t]{2}{*}{$0.3-97$} & \multirow[t]{2}{*}{$0.1-1.0$} & \multirow{2}{*}{$\begin{array}{c}\text { St } \\
\text { W } \\
\text { S } \\
\text { AM }\end{array}$} & \multirow[t]{2}{*}{$\mathrm{x}$} & \\
\hline & & horiz. & & 38.1 & & & & & & & & \\
\hline Henry [5] & horiz. & horiz. & 100 & 20 & $\mathrm{AW}$ & 150 & $200-850$ & $4-50$ & $0-0.06$ & An & $\mathrm{X}$ & \\
\hline \multirow[t]{2}{*}{ Whalley and Azzopardi [7] } & vert. & horiz.. & \multirow[t]{2}{*}{31.8} & \multirow[t]{2}{*}{12.7} & \multirow[t]{2}{*}{$\mathrm{AW}$} & 150 & 83-178 & $36-81$ & $0-0.25$ & \multirow[t]{2}{*}{ An } & $\mathrm{X}$ & \\
\hline & horiz. & $\begin{array}{l}\text { vert. up } \\
60^{\circ} \text { up } \\
30^{\circ} \text { up } \\
\text { horiz. } \\
30^{\circ} \text { down } \\
60^{\circ} \text { down } \\
\text { vert. down }\end{array}$ & & & & 250 & 145 & 56 & $0-0.39$ & & & \\
\hline Whalley and Fells [8] & vert. & horiz. & 31.8 & 19 & AW & 150 & $80-180$ & $35-80$ & $0-0.57$ & An & $\mathrm{x}$ & \\
\hline & & & & 6.35 & & & & & & & & \\
\hline Azzopardi and Baker [9] & vert. & horiz. & 31.8 & 12.7 & $\mathrm{AW}$ & 150 & $87-111$ & $9-29$ & $0-0.92$ & $\mathrm{C}$ & $x$ & \\
\hline Azzopardi and Freeman-Bell & vert. & horiz. & 31.8 & 25.4 & $\mathrm{AW}$ & 150 & $83-178$ & $36-81$ & $0.1-0.53$ & An & $\mathrm{x}$ & \\
\hline & & & & 31.8 & & & & & & & & \\
\hline Saba and Lahey [12] & horiz. & horiz. & 38.1 & 38.1 & $\mathrm{AW}$ & 150 & $\begin{array}{l}1355- \\
2711\end{array}$ & $0.1-1.0$ & $0.3-0.7$ & $\begin{array}{l}\mathrm{St} \\
\mathrm{W} \\
\mathrm{S}\end{array}$ & $\mathrm{x}$ & $\mathrm{X}$ \\
\hline
\end{tabular}

(1) $\mathrm{AW}=$ air-water, $\mathrm{SW}=$ steam-water

(2) $\mathrm{DB}=$ dispersed bubble, $\mathrm{An}=$ annular, $\mathrm{AM}=$ annular-mist, $\mathrm{St}=$ stratified, $\mathrm{W}=$ wavy, $\mathrm{S}=\mathrm{slug}, \mathrm{C}=\mathrm{churn}, \mathrm{SA}=\mathrm{semiannular}$ 
Table 2.1 (continued)

\begin{tabular}{|c|c|c|c|c|c|c|c|c|c|c|c|c|}
\hline Authors & $\begin{array}{r}\text { Junctio } \\
\text { Inlet }\end{array}$ & $\begin{array}{l}\text { rientation } \\
\text { Branch } \\
\end{array}$ & $\begin{array}{c}\mathrm{D}_{1} \\
(\mathrm{~mm})\end{array}$ & $\underset{(\mathrm{mm})}{\mathrm{D}_{3}}$ & $\begin{array}{c}\text { Test } \\
\text { Fluids }^{(1)}\end{array}$ & $\underset{(\mathbf{P} P \mathbf{P a})}{\mathbf{P}_{\mathrm{x}}}$ & $\underset{\mathrm{kg} / \mathrm{m}^{2} \mathbf{s}}{\mathrm{G}_{1}}$ & $\begin{array}{l}\mathbf{x}_{1} \\
\%\end{array}$ & $\mathrm{~W}_{3} / \mathrm{W}_{1}$ & $\begin{array}{c}\text { Inlet } \\
\text { Flow } \\
\text { Regrime }\end{array}$ & $\begin{array}{l}\text { Phase } \\
\text { Dist. }\end{array}$ & $\begin{array}{l}\text { Pross. } \\
\text { Drop }\end{array}$ \\
\hline \multirow[t]{2}{*}{$\begin{array}{l}\text { Seeger et al. [14] } \\
\text { Reimann and Seeger [26] }\end{array}$} & \multirow[t]{2}{*}{ horiz. } & horiz. & \multirow[t]{2}{*}{50} & \multirow[t]{2}{*}{50} & $\mathrm{sw}$ & $\begin{array}{l}2400- \\
10300 \\
\end{array}$ & $918-1925$ & $3-36$ & $\begin{array}{l}0.1- \\
0.69\end{array}$ & $\begin{array}{c}\text { An } \\
S\end{array}$ & \multirow[t]{2}{*}{$\mathrm{x}$} & \multirow[t]{2}{*}{$x$} \\
\hline & & $\begin{array}{c}\text { vert. up } \\
\text { horiz. } \\
\text { vert. down }\end{array}$ & & & $\mathrm{AW}$ & $400-1000$ & $500-7500$ & $0.2-32$ & 0.1 .0 & $\begin{array}{c}\text { An } \\
\text { S } \\
\text { DB } \\
\end{array}$ & & \\
\hline Rubel [16] & horiz. & horiz. & 37.6 & 37.6 & SW & $116-207$ & $16.6-50.3$ & $23.3-82.8$ & $0.15-0.80$ & $\begin{array}{c}\text { St } \\
\text { W } \\
\text { SA-W } \\
\text { SA }\end{array}$ & $\mathrm{x}$ & \\
\hline Ballyk et al. [18] & horiz. & horiz. & 25.65 & $\begin{array}{c}25.65 \\
12.3 \\
\end{array}$ & SW & $111-212$ & $400-1200$ & $0-15$ & 0.1 .0 & An & $\mathrm{x}$ & $\mathrm{x}$ \\
\hline $\begin{array}{l}\text { Hwang et al. [19] } \\
\text { Hwang and Lahey [28] }\end{array}$ & horiz. & horiz. & 38 & 38 & AW & 150 & $\begin{array}{l}1350- \\
2700\end{array}$ & $0.2-0.4$ & $0.02 \times 0.95$ & & $\mathrm{x}$ & $\mathrm{x}$ \\
\hline Shoham et al. [21] & horiz. & horiz. & 51 & 51 & $\mathrm{AW}$ & 300 & $12-156$ & $13-97$ & 0.0 .9 & $\begin{array}{l}\text { An } \\
\text { St } \\
\text { W }\end{array}$ & $\mathrm{x}$ & \\
\hline \multirow[t]{4}{*}{ Reimann et al. [22] } & \multirow[t]{4}{*}{ horiz. } & \multirow[t]{3}{*}{$\begin{array}{l}\text { vert. up } \\
\text { horiz. } \\
\text { vert. down }\end{array}$} & \multirow[t]{4}{*}{50} & 4.0 & \multirow[t]{4}{*}{$\mathrm{AW}$} & $480-900$ & $65-4030$ & $1.3-68$ & 0.0 .88 & \multirow{4}{*}{$\begin{array}{l}\mathrm{DB} \\
\mathrm{S} \\
\mathrm{An} \\
\mathrm{St}\end{array}$} & \multirow[t]{4}{*}{$\mathrm{X}$} & \multirow[t]{4}{*}{$\mathrm{X}$} \\
\hline & & & & 10 & & $176-910$ & 60.5630 & $1.3-68$ & $0-1.0$ & & & \\
\hline & & & & 26 & & \multirow[t]{2}{*}{686} & $132-6020$ & $0.4-83$ & & & & \\
\hline & & horiz. & & 50 & & & $87 \cdot 1330$ & 8-76 & $0.07-1.0$ & & & \\
\hline \multirow[t]{4}{*}{ Azzopardi et al. [24] } & \multirow[t]{4}{*}{ horiz. } & \multirow[t]{4}{*}{ horiz. } & \multirow[t]{4}{*}{38.1} & 38.1 & \multirow[t]{4}{*}{$\mathrm{AW}$} & 150 & $42-159$ & 4-73 & $0-0.96$ & \multirow{4}{*}{$\begin{array}{l}\text { An } \\
\text { W } \\
\text { St }\end{array}$} & \multirow[t]{4}{*}{$\mathrm{X}$} & \\
\hline & & & & & & 300 & $42-206$ & $4-89$ & $0-0.92$ & & & \\
\hline & & & & 25 & & 150 & $42-159$ & 4-73 & $0-0.91$ & & & \\
\hline & & & & & & 300 & & $4-89$ & $0-0.99$ & & & \\
\hline
\end{tabular}

(1) AW = air-water, SW = steam-water

(2) $\mathrm{DB}=$ dispersed bubble, $\mathrm{An}=$ annular, $\mathrm{AM}=$ annular-mist, $\mathrm{St}=$ stratified, $\mathrm{W}=$ wavy, $\mathrm{S}=$ slug, $\mathrm{C}=$ churn, $\mathrm{SA}=$ semiannular 


\subsection{Phase Distribution}

One of the earliest experimental investigations was reported in 1959 by Tsuyama and Taga [1]. They obtained data on the pressure drops, using a static pressure tap in each of the inlet, run, and branch, for the flow of an airwater mixture through a tee junction with equal diameter sides (23.4 mm I.D.). For the phase distribution, they only presented visual observations of the flow regimes in the inlet, run, and branch. Their phase-distribution data were classified into three categories: one in which both the branch and run contained a two-phase mixture, one in which the branch contained single-phase liquid, and one in which the run contained single-phase liquid. Conditions which led to each of the three categories were not discussed.

Collier [2] presented the phase-distribution data of St. Pierre for the flow of an air-water mixture in a horizontal tee junction with a 37.6-mm I.D. inlet and run, and a 25.4-mm I.D. branch. The inlet mass flux was constant at 136 $\mathrm{kg} / \mathrm{m}^{2} \mathrm{~s}$, the inlet quality was varied between $2.1 \%$ and $50 \%$, and the extraction rate was varied between 0.05 and 0.9 . The objective was to study the effect of inlet quality on the phase distribution. Almost all of the data showed a preference for the gas phase to enter the branch. For inlet qualities greater than $25 \%$, the data showed a decrease in $\mathrm{x}_{3} / \mathrm{x}_{1}$ over all extraction rates as $\mathrm{x}_{1}$ increased. However, for inlet qualities less than $25 \%$, the data generally displayed an increase in $x_{3} / x_{1}$ over all extraction rates as $x_{1}$ increased. 
Hong [3] presented phase-distribution data for an equal sided $(9.5 \mathrm{~mm}$ I.D.) tee junction with horizontal inlet and branch orientations ranging from vertical upwards to vertical downwards; the gas phase used was air, while the liquids used were viscous and plain water. The inlet mass flux was varied between 18 and $126 \mathrm{~kg} / \mathrm{m}^{2} \mathrm{~s}$, and the inlet quality between $25 \%$ and $97 \%$. These conditions gave rise to wavy and annular flow in the inlet. Hong [3] presented data corresponding to inlet superficial gas velocities $\left(J_{G 1}\right)$ of $9.1,27.4$, and $42.7 \mathrm{~m} / \mathrm{s}$. Liquid viscosities of 1 centipoise for plain water, and 5 and 10 centipoise for water plus hydroxyethyl cellulose were tested. At each inlet superficial gas velocity and liquid viscosity, the inlet superficial liquid velocity $\left(\mathrm{J}_{\mathrm{L} 1}\right)$ was varied between 0.0023 and $0.047 \mathrm{~m} / \mathrm{s}$. Except at low extraction rates, most of the data for the horizontal branch showed a preference for the liquid phase to enter the branch. Generally, for a fixed $J_{G 1}$, an increase in $J_{L 1}$ resulted in an increase in $\mathrm{x}_{3} / \mathrm{x}_{1}$; however, this trend was reversed at lower extraction rates. At a fixed $\mathrm{J}_{\mathrm{L} 1}$, an increase in the $\mathrm{J}_{\mathrm{G} 1}$ resulted in a decrease in $x_{3} / x_{1}$. The effect of increasing liquid viscosity was to decrease $x_{3} / x_{1}$ at fixed $\mathrm{J}_{\mathrm{G} 1}$ and $\mathrm{J}_{\mathrm{L} 1}$. Hong [3] concluded that the inlet flow regime had no clear effect on the phase distribution.

Johansen [4] presented both phase-distribution and pressure-drop data for air-water flow through a tee junction. The junction had a 51-mm I.D. horizontal inlet and run. Two different branch diameters were tested: a 51mm I.D. branch which was oriented vertically upwards, horizontally, and 
vertically downwards, and a 38.1-mm I.D. branch which was oriented horizontally. Inlet superficial liquid velocities of $0.0043,0.122$, and $0.884 \mathrm{~m} / \mathrm{s}$ were tested. At each value of $J_{L 1}$, the value of $J_{G 1}$ was varied between 0.9 and $28 \mathrm{~m} / \mathrm{s}$. At these inlet conditions, inlet flow regimes of stratified, wavy, slug, and annular-mist were observed. Johansen [4] presented the phasedistribution data in terms of $F_{\mathrm{BG}}$ versus the inlet superficial gas Reynolds number, $\mathrm{Re}_{\mathrm{G} 1}$, which is the Reynolds number that the gas phase would have if it flowed alone in the inlet tube. In general, the data showed that as $\mathrm{J}_{\mathrm{L} 1}$ increased, at a fixed $\mathrm{F}_{\mathrm{BG}}$ and $\mathrm{Re}_{\mathrm{G} 1}, \mathrm{~F}_{\mathrm{BL}}$ decreased. This trend, also observed by Hong [3], was attributed to an increase in momentum of the liquid phase as $\mathrm{J}_{\mathrm{L} 1}$ increased. For $\mathrm{J}_{\mathrm{L} 1}=0.0043 \mathrm{~m} / \mathrm{s}$, most of the data showed a preference for the liquid phase to exit through the branch; however, this trend was reversed for higher $\mathrm{J}_{\mathrm{L} 1}$. For the horizontal tee junction, the effect of $\mathrm{Re}_{\mathrm{G} 1}$ variation at fixed $\mathrm{F}_{\mathrm{BL}}$ was found to depend on $\mathrm{J}_{\mathrm{Ll}}$. For $\mathrm{J}_{\mathrm{L} 1}=0.0043 \mathrm{~m} / \mathrm{s}$, the data for constant $\mathrm{F}_{\mathrm{BL}}$ showed a minimum; however, at higher $\mathrm{J}_{\mathrm{L} 1}$ the data for constant $\mathrm{F}_{\mathrm{BL}}$ showed a maximum. This reversal in trend was attributed to a change in inlet flow regime as $\mathrm{J}_{\mathrm{L} 1}$ was increased. Using an energy balance, Johansen [4] related the branch liquid and gas mass flow rates $\mathrm{W}_{\mathrm{L} 3}$ and $\mathrm{W}_{\mathrm{G} 3}$, respectively, to the pressure drop $\Delta \mathrm{P}_{13}$. Using the measured pressure drop $\Delta \mathrm{P}_{13}$, the model predicted values of $\mathrm{W}_{\mathrm{L} 3}$ and $\mathrm{W}_{\mathrm{G} 3}$. Comparison between the measured and predicted values generally showed poor agreement. 
Henry [5] investigated the phase distribution for annular flow through a horizontal tee junction with a 100-mm I.D. inlet and a $20-\mathrm{mm}$ I.D. branch. All tests were carried out using an air-water mixture at near ambient temperature and pressure. The ranges of inlet mass flux and quality were 200 $<\mathrm{G}_{1}<850 \mathrm{~kg} / \mathrm{m}^{2} \mathrm{~s}$ and $4<\mathrm{x}_{1}<50 \%$, respectively. The data covered a narrow range of extraction rates, $W_{3} / W_{1}<0.06$. For a constant $x_{1}$, the results showed that as the extraction rate increased, the branch quality increased monotonically and eventually reached a constant value. The branch flow rate at which the branch quality became constant was approximately proportional to the inlet mass flux. The effect of increasing the inlet mass flux at a constant inlet quality was to decrease the branch quality over all extraction rates. Low inlet mass fluxes resulted in severe maldistribution of the phases with air preferentially entering the branch; however, high inlet mass fluxes resulted in a more even phase distribution. At a fixed inlet mass flux and quality, the branch water flow rate was found to vary approximately linearly with the branch gas flow rate. Finally, as the flow became more homogeneous (dispersed), the value of $x_{3} / x_{1}$ approached unity. Based on his results, Henry [5] proposed an empirical model to predict the branch quality. The model predicted the annular data of Henry [5] and Collier [2] quite well; however, it was less successful in predicting the stratified-wavy data of Collier [2]. Henry [5] suggested caution when using the model at conditions outside those from which it was derived. 
Azzopardi and Whalley [6] published results in 1982 based on the combined studies of Whalley and Azzopardi [7], Whalley and Fells [8], and Azzopardi and Baker [9]. All of these investigations studied the phasedistribution phenomenon using an air-water mixture. Most of the results correspond to vertical upward flow in an inlet tube of $31.8 \mathrm{~mm}$ I.D. with horizontal branch tubes of $6.35,12.7$, and $19 \mathrm{~mm}$ I.D., giving branch-to-inlet diameter ratios of about $0.2,0.4$, and 0.6 , respectively. The pressure used for the experiments was $150 \mathrm{kPa}$ and the ranges of inlet mass flux and quality were approximately $80<\mathrm{G}_{1}<180 \mathrm{~kg} / \mathrm{m}^{2}$ s and $10<\mathrm{x}_{1}<80 \%$, respectively. This gave rise to inlet flow regimes of annular and churn flow. Some experiments used a horizontal inlet tube of $31.8 \mathrm{~mm}$ I.D., with a branch tube of $12.7 \mathrm{~mm}$ I.D. and a test section pressure of $250 \mathrm{kPa}$. This gave rise to an inlet flow regime of annular flow. For inlet flow regimes of annular or churn flow, the results indicated a preference for the liquid to enter the branch. Except at low inlet gas flow rates, the liquid flow rate in the branch was approximately a linear function of the branch gas flow rate. Azzopardi and Whalley [6] suggested that in annular flow, there exists two levels of momentum flux: the liquid film where the momentum flux is low (high density and low velocity), the gas core where the momentum flux is also low (low density and high velocity), and the entrained drops with high momentum flux (high density and high velocity). Therefore, for annular flow it was suggested that liquid from the film has a high probability of being diverted into the 
branch while entrained liquid drops have a high probability of by-passing the branch and flowing into the run. Azzopardi and Whalley [6] compared their vertical annular and churn flow data to the vertical bubbly flow data of Hewitt and Shires. For bubbly flow, Azzopardi and Whalley [6] suggested that the flow can be divided into a liquid layer near the wall with a momentum flux near that of the bubbles, and a liquid core with a much higher momentum flux. Thus, the bubbles and liquid with low momentum flux near the wall would have a higher probability of being diverted into the branch.

Azzopardi and Whalley [6] proposed a geometrically-based phasedistribution model for annular flow. The model assumes that liquid that is diverted into the branch comes only from the liquid film, and that all entrained liquid by-passes the branch and flows into the run. As well, the gas and liquid diverted into the branch come from the same segment of the tube. This segment is characterized by the angle $\theta$ as illustrated in figure 2.1. For the special case of uniform liquid film thickness, the model reduces to

$$
\frac{x_{3}}{x_{1}}=\frac{1}{2 \pi} \frac{W_{1}}{W_{3}}(\theta-\sin \theta) \text {, }
$$

with

$$
\theta=2 \pi \frac{W_{L 3}}{W_{L 1}} \frac{1}{\left(1-E_{1}\right)}
$$

where $E_{1}$ is the mass fraction of inlet liquid which exists as entrained droplets, and $\mathrm{W}_{\mathrm{L} 1}$ is the mass flow rate of liquid in the inlet. 


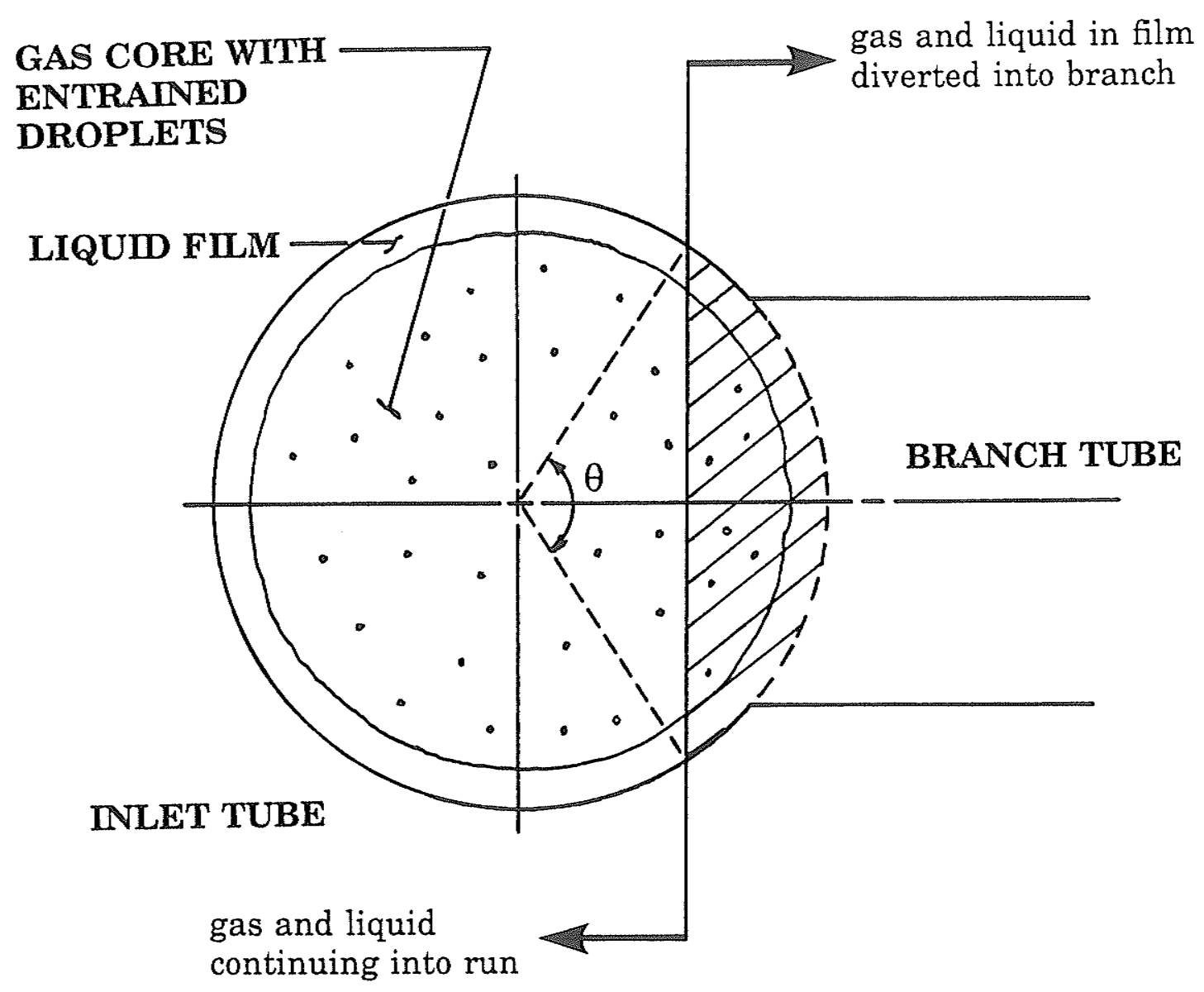

Figure 2.1 Schematic diagram illustrating the basis of the Azzopardi and Whalley model [6] for annular flow 
Later, Azzopardi and Freeman-Bell [10] extended the above data for annular flow in a vertical tee junction to include branch-to-inlet diameter ratios $\left(D_{3} / D_{1}\right)$ of 0.8 and 1.0. These results were also published by Azzopardi [11]. The ranges of test conditions were as follows: air-water mixture at 150 $\mathrm{kPa}, 83<\mathrm{G}_{1}<178 \mathrm{~kg} / \mathrm{m}^{2} \mathrm{~s}, 36<\mathrm{x}_{1}<81 \%$, and $0.1<\mathrm{W}_{3} / \mathrm{W}_{1}<0.53$. These conditions gave rise to annular flow in the inlet. The new results were analyzed together with the previous annular data reported by Azzopardi and Whalley [6]. In general, the combined results showed that as $\mathrm{D}_{3} / \mathrm{D}_{1}$ increases, the branch quality decreases. Azzopardi and Freeman-Bell [10] then proposed a correction factor for the above model which takes into account the diameter ratio $\mathrm{D}_{3} / \mathrm{D}_{1}$. This correction was based on the combined data set covering diameter ratios from 0.2 to 1.0 . The new model consists of equation (2.1) without change, while (2.2) is modified to

$$
\theta=\frac{2 \pi}{1.2\left(D_{3} / D_{1}\right)^{0.4}} \frac{W_{L 3}}{W_{L 1}} \frac{1}{\left(1-E_{1}\right)}
$$

Using the new model, most of the data were predicted within $\pm 30 \%$ with the data for very high inlet qualities deviating most significantly.

Saba and Lahey [12] published results for the phase distribution and pressure drop for air-water flow through a horizontal tee junction with equal diameter sides (38.1 mm I.D.). The values of inlet mass flux used were $\mathrm{G}_{1}=1355,2041$, and $2711 \mathrm{~kg} / \mathrm{m}^{2} \mathrm{~s}$. At fixed $\mathrm{G}_{1}$, inlet qualities of $0.1,0.25,0.5$, 
and $1.0 \%$ were tested. Extraction rates tested were $0.3,0.5$, and 0.7 . These inlet conditions gave rise to inlet flow regimes of stratified, wavy, and slug flow. The results showed that for the entire range of inlet conditions and extraction rates, the air flowed preferentially into the branch. The inlet mass flux was found to have little effect on the phase distribution. Based on their results, Saba and Lahey [12] proposed a mechanistic model. Eight parameters of interest were identified; $\mathrm{x}_{1}, \mathrm{x}_{2}, \mathrm{x}_{3}, \mathrm{~W}_{1}, \mathrm{~W}_{2}, \mathrm{~W}_{3}, \Delta \mathrm{P}_{12}$, and $\Delta \mathrm{P}_{13}$. With three of these parameters specified, five independent conservation equations were required to obtain a solution. The following equations were recommended: mixture continuity equation, vapor-phase continuity equation, mixture linear momentum equation for the branch, mixture linear momentum equation for the run, and the vapor-phase linear momentum equation for the branch. In addition to the above equations, empirical correlations were required to close the set of equations in order to obtain a solution. This model was later shown to be suitable only for extraction rates greater than 0.3 [13].

Seeger et al. [14] reported phase-distribution data for air-water and steam-water flow through an equal-sided (50 $\mathrm{mm} \mathrm{I.D.)} \mathrm{tee} \mathrm{junction.} \mathrm{The}$ steam-water experiments were performed with a horizontal inlet and branch, while the air-water experiments were performed with a horizontal inlet and branch orientations of vertical upward, vertical downward, and horizontal. The inlet mass flux for the air-water experiments varied between 500 and 7500 $\mathrm{kg} / \mathrm{m}^{2} \mathrm{~s}$ at a test section pressure between 0.4 and $1.0 \mathrm{MPa}$. The ranges of inlet 
quality and extraction rate for the air-water experiments were $0.2<\mathrm{x}_{1}<32 \%$ and $0.0<\mathrm{W}_{3} / \mathrm{W}_{1}<1.0$. Over the tested range of inlet mass flux and quality, inlet flow regimes of annular, slug, and dispersed-bubble were observed. The test section pressure ranged between 2.4 and $10 \mathrm{MPa}$ and the inlet mass flux between 918 and $1925 \mathrm{~kg} / \mathrm{m}^{2} \mathrm{~s}$ during the steam-water experiments. This gave rise to inlet flow regimes of annular and slug flow for the steam-water experiments. For the steam-water experiments, the extraction rate and inlet qualities ranged from 0.1 to 0.69 and $3 \%$ to $36 \%$, respectively.

For the horizontal branch (both air-water and steam-water data), $\mathrm{x}_{3} / \mathrm{x}_{1}$ was found to increase rapidly with increasing extraction rate up to a maximum in the vicinity of $\mathrm{W}_{3} / \mathrm{W}_{1}=0.3$. At higher extraction rates, all of the data fell close to the total phase separation curve. For a fixed $\mathrm{J}_{\mathrm{L} 1}, \mathrm{x}_{3} / \mathrm{x}_{1}$ was found to decrease with increasing $J_{\mathrm{G} 1}$, which corresponded to an increasing gas momentum flux. The data also showed that as the test section pressure increased, $x_{3} / x_{1}$ decreased. This also corresponded to an increasing gas momentum flux, due to increased gas density.

Based on the above data, Seeger et al. [14] derived a phase-distribution correlation for each branch orientation. The equation for a horizontal branch is

$$
\frac{x_{3}}{x_{1}}=5 \eta-6 \eta^{2}+2 \eta^{3}+a \eta(1-\eta)^{4}
$$

where $\eta=W_{3} / W_{1}$. The coefficient ' $a$ ' in the above equation is given by 


$$
\mathrm{a}=13.9\left\{\left[\left(\rho_{G l} / \rho_{L I}\right) S_{1}^{2}\right]^{-0.26}-1\right\}
$$

for any flow regime other than dispersed bubble, while $a=14.6$ for dispersedbubble flow. In equation (2.5), $\rho_{\mathrm{G} 1}$ and $\rho_{\mathrm{L} 1}$ are the inlet gas and liquid densities, respectively, while $S_{1}$ is the slip ratio in the inlet which was determined using the correlation developed by Rouhani [15]. This correlation is given by the following equation:

$$
S_{1}=\frac{\rho_{L l}}{\left(1-x_{1}\right)}\left\{\frac{1+0.12\left(1-x_{1}\right)}{\rho_{H 1}}+\frac{V_{R E L}}{G_{1}}-\frac{x_{1}}{\rho_{G 1}}\right\}
$$

where

$$
\rho_{H I}=\left(\frac{x_{1}}{\rho_{G I}}+\frac{1-x_{1}}{\rho_{L I}}\right)^{-1}
$$

and

$$
V_{R E L}=\frac{1.18}{\rho_{L I}^{0.5}}\left\{g \sigma\left(\rho_{L I}-\rho_{G l}\right)^{0.25}\left(1-x_{1}\right) .\right.
$$

It should be noted that for equation (2.8), Seeger et al. [14] omitted the term $\left(1-x_{1}\right)$. Fortunately, for the data of Seeger et al. [14], this term appears to make little difference to the prediction of $\mathrm{S}_{1}$. It will be shown later that, for the present data, this term also has negligible effect on the prediction of $\mathrm{S}_{1}$. Although Seeger et al. [14] presented correlations for other branch orientations, they are not relevant to the present study.

In 1986, Rubel [16] presented phase-distribution data for low-pressure steam-water flow through a horizontal tee junction with equal sides $(37.6 \mathrm{~mm}$ I.D.). The ranges of inlet mass flux, quality, and extraction rates were $16.6<$ 
$\mathrm{G}_{1}<50.3 \mathrm{~kg} / \mathrm{m}^{2} \mathrm{~s}, 23.3<\mathrm{x}_{1}<82.8 \%$, and $0.15<\mathrm{W}_{3} / \mathrm{W}_{1}<0.80$. These conditions gave inlet flow regimes of stratified, wavy, semiannular-wavy, and semiannular. Rubel [16] studied the individual effects of inlet mass flux, inlet quality, inlet flow regime, and inlet superficial liquid velocity on the phase distribution. In general, the results showed that $x_{3} / x_{1}$ was less than unity for stratified flow, greater than unity for most of the wavy flow, and both above and below unity for semiannular flow. For increasing $x_{1}$ at a fixed inlet mass flux, $x_{3} / x_{1}$ was found to decrease, except at the lowest inlet mass fluxes where this trend was reversed. Within a specific inlet flow regime and at a fixed inlet quality, the inlet mass flux appeared to have little effect on the phase distribution. Finally, as $\mathrm{J}_{\mathrm{L} 1}$ increased, the data showed an increasing tendency for the liquid to flow preferentially into the branch.

Ballyk and Shoukri [17] presented results for annular steam-water flow in a horizontal tee junction with a $25.65-\mathrm{mm}$ I.D. inlet tube. Branch tube diameters of 25.65 and $12.3 \mathrm{~mm}$ I.D. were used. The results for the $25.65 \mathrm{~mm}$ I.D. branch were also published in [18]. The ranges of inlet conditions were $400<\mathrm{G}_{1}<1200 \mathrm{~kg} / \mathrm{m}^{2} \mathrm{~s}, 0.0<\mathrm{x}_{1}<15 \%$, and $0.0<\mathrm{W}_{3} / \mathrm{W}_{1}<1.0$. Measurements included the pressure distribution and phase distribution, as well as the void fraction in the inlet, run, and branch. The effects of extraction rate, inlet quality, branch-to-inlet diameter ratio, and inlet mass flux on the phase and pressure distributions were studied. The results showed that at low extraction rates, $x_{3} / x_{1}$ increased rapidly to a maximum value at an extraction rate in the range 0.2 to 0.3 . When the extraction rate was greater than 0.3 , the total 
phase separation curve was approached. An increase in the inlet quality reduced the peak value of $x_{3} / x_{1}$ and increased the extraction rate at which complete phase separation occurred. The effect of inlet mass flux variation at a fixed inlet quality was shown to be less significant than that of inlet quality variation. The smaller branch size resulted in increased phase maldistribution.

Hwang et al. [19] investigated the phase distribution and pressure drops for air-water flow through a tee, a $45^{\circ}$ Y-junction, and a $135^{\circ}$ Y-junction. All three test sections were horizontal, and had equal inlet and branch tube sizes (38 mm I.D.). Three inlet mass fluxes were tested: $G_{1}=1350,2050$, and 2700 $\mathrm{kg} / \mathrm{m}^{2} \mathrm{~s}$. At each value of inlet mass flux, the inlet qualities tested were 0.2 , 0.3 , and 0.4 percent. The extraction rates ranged between 0.02 and 0.95 . It was found that for high extraction rates, nearly complete phase separation occurred, independent of the test section used. For the tee junction, the value of $x_{3} / x_{1}$ reached a maximum at an extraction rate of approximately 0.1 . The $135^{\circ} \mathrm{Y}$-junction gave a higher maximum value of $\mathrm{x}_{3} / \mathrm{x}_{1}$, and this peak occurred at a lower extraction rate. The peak value of $x_{3} / x_{1}$ for the $45^{\circ}$ Y-junction was smaller and it occurred at a higher extraction rate than the tee junction.

Hwang et al. [19] developed an analytical model based on a dividing streamline concept. This model assumes that there is a "zone of influence" for each of the two phases which is bounded by the tube wall near the branch and the appropriate dividing streamline, as shown in figure 2.2. Incoming gas and 


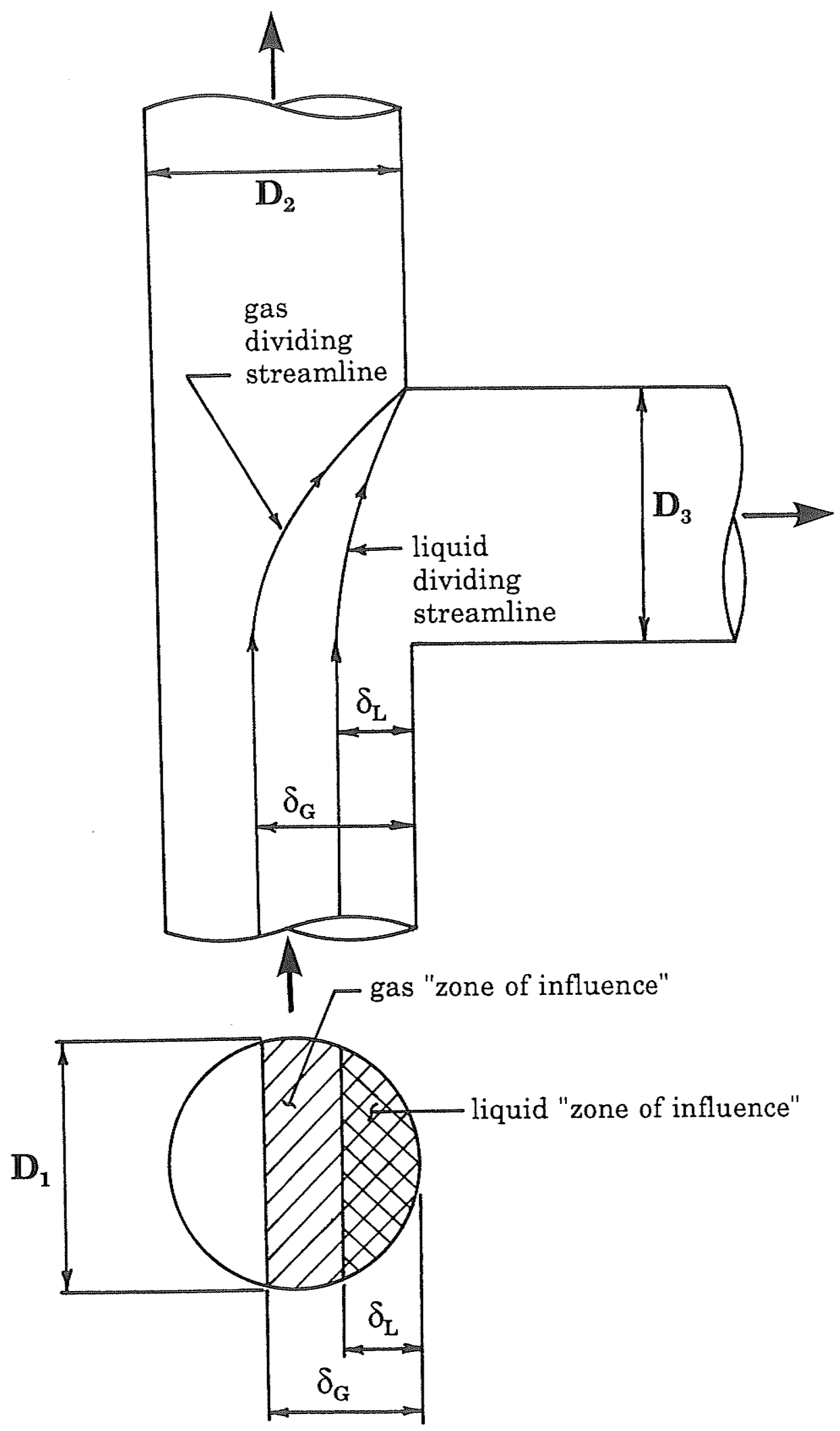

Figure 2.2 Dividing streamlines for the phase-distribution model of Hwang et al. [19] 
liquid must follow curved paths in order to exit through the branch. The model traces the dividing streamlines' paths based on a balance between the dominant forces acting on each phase. This phase-distribution model is valid for any inlet flow regime provided the lateral distribution of the phases in the inlet side of the junction is known. For separated flow (stratified, wavy, or annular), the model simplifies to a balance between centrifugal forces, thus

$$
\frac{\rho_{G I} V_{G 1}^{2}}{R_{G}}=\frac{\rho_{L 1} V_{L 1}^{2}}{R_{L}}
$$

where $R_{G}$ and $R_{L}$ are the radii of curvature of the gas and liquid dividing streamlines, respectively, and $\mathrm{V}_{\mathrm{G} 1}$ and $\mathrm{V}_{\mathrm{L} 1}$ are the mean velocities of the gas and liquid phases in the inlet of the junction, respectively. The radii of curvature were assumed to follow the relation

$$
\frac{R_{G}}{R_{L}}=\frac{\left(8_{L} D_{1}\right)^{n_{L}}}{\left(8_{G} D_{1}\right)^{n_{G}}}
$$

where $\delta_{\mathrm{L}}$ and $\delta_{\mathrm{G}}$ are the depths of the gas and liquid zones of influence, respectively, as shown in figure 2.2. The exponent $\mathrm{n}$ in equation (2.10) was determined empirically from a large data base to be:

$$
n_{k}=5+20 \exp \left[-53\left(8_{k} / D_{1}\right)\right], \quad k=G, L .
$$

Finally, with knowledge of $\delta_{\mathrm{L}}$ and $\delta_{\mathrm{G}}$ as well as the lateral distribution of the liquid and gas phases in the inlet, the branch liquid and gas flow rates can be calculated. Hwang et al. [19] used this model to predict $\mathrm{x}_{3} / \mathrm{x}_{1}$ for stratified, bubbly, and annular flow with very good success. 
Rubel et al. [20] compared their data for steam-water flow in a horizontal tee junction with the model of Hwang et al. [19], the model of Azzopardi and Freeman-Bell [10], and the model of Seeger et al. [14]. For $\mathrm{W}_{3} / \mathrm{W}_{1} \geq 0.4$ and $\mathrm{x}_{1} \geq 40 \%$, the model of Seeger et al. [14] predicted most of the data for $x_{3} / x_{1}$ within $\pm 20 \%$. For the entire range of $x_{1}$ and $W_{3} / W_{1} \geq 0.3$, most of the data for $x_{3} / x_{1}$ were predicted within $\pm 40 \%$. The data were predicted poorly for low extraction rates $\left(\mathrm{W}_{3} / \mathrm{W}_{1}<0.3\right)$. The experimental values of $\mathrm{F}_{\mathrm{BG}}$ for the data points of semiannular flow were compared with predictions using the model of Azzopardi and Freeman-Bell [10]. Although the agreement was poor, it was noted that the model's predictions became increasingly better as the inlet flow approached fully-established annular flow. For the comparison with the model of Hwang et al. [19], the inlet flow regime was assumed to be wavy for all data points. In general, values of $x_{3} / x_{1}$ were predicted within $\pm 30 \%$ for all stratified, wavy, and semiannular flow data.

Shoham et al. [21] reported experimental data for stratified, wavy, and annular flow in a horizontal tee junction with equal sides (51 mm I.D.). The fluids used were air and water. Phase-distribution results were obtained at inlet superficial gas velocities of $2.5,6.1$, and $26 \mathrm{~m} / \mathrm{s}$. Superficial liquid velocities were varied from $0.0029 \mathrm{~m} / \mathrm{s}$ to $0.059 \mathrm{~m} / \mathrm{s}$. The results for wavy flow showed that at the lowest liquid superficial velocities, the liquid preferentially entered the branch. As $\mathrm{J}_{\mathrm{L} 1}$ was increased, $\mathrm{F}_{\mathrm{BL}}$ decreased at a fixed $\mathrm{F}_{\mathrm{BG}}$. At the highest $\mathrm{J}_{\mathrm{L} 1}$, the gas phase preferentially entered the branch. All the data for 
stratified flow indicated a strong preference for the liquid to flow into the run, and for annular flow most of the data showed a preference for the liquid to exit through the branch. This is contrary to the annular flow data of Ballyk and Shoukri [17], who observed that for $\mathrm{W}_{3} / \mathrm{W}_{1}>0.3$, total phase separation was approached. However, the inlet mass flux range tested by Ballyk and Shoukri [17] was much higher than that tested by Shoham et al. [21]. The effect of increasing $\mathrm{J}_{\mathrm{L} 1}$ at a fixed $\mathrm{J}_{\mathrm{G} 1}$ was to increase $\mathrm{F}_{\mathrm{BG}}$ for a fixed $\mathrm{F}_{\mathrm{BL}}$. In fact, at the highest $J_{L 1}$ all of the annular data fell close to the line of even phase distribution. This trend explains the differences in the annular data of Ballyk and Shoukri [17], and Shoham et al. [21].

Shoham et al. [21] developed a flow-regime-dependent model for predicting the phase distribution during stratified and annular flow. The model is based on a suggested splitting mechanism where the preference for the liquid to flow into the branch is controlled by competing inertial and centripetal forces acting on the liquid phase at the tee junction. Reasonable agreement between the experimental data and the prediction of the model was obtained.

Reimann et al. [22] presented results which extended the data of Seeger et al. [14]. The data included a larger range of inlet mass flux and diameter ratios of $1.0,0.52,0.2$, and 0.08 for air-water flow in a horizontal inlet tube of $50 \mathrm{~mm}$ I.D. The wider range of inlet mass flux enabled the addition of stratified flow to be observed in the inlet. For diameter ratios of $0.52,0.2$, and 
0.08 , three branch orientations were tested: vertical upward, horizontal, and vertical downward. For the diameter ratio of 1.0, only a horizontal branch was tested. For the horizontal branch, the results showed in general that as the branch diameter was decreased, the branch quality increased for all $\mathrm{W}_{3} / \mathrm{W}_{1}$.

Azzopardi [23] reported further observations on the phase-distribution phenomenon during annular flow in vertical tee junctions using an equal-sided (31.8 mm I.D.) tee. An air-water mixture was used with inlet conditions similar to those presented by Azzopardi and Whalley [6]. A full range of extraction rates was tested. At low inlet qualities, as $\mathrm{F}_{\mathrm{BG}}$ increased beyond a certain limit, $\mathrm{F}_{\mathrm{BL}}$ increased sharply to almost unity. This occurred over a relatively small change in $\mathrm{F}_{\mathrm{BG}}$ and was attributed to flooding and flow reversal of the liquid which initially flowed past the branch. A modified version of the model given by Azzopardi and Freeman-Bell [10] was presented which accounted for this flow reversal phenomenon. This model agreed well with the experimental data at high liquid flow rates, but underpredicted the fraction of liquid removed through the branch at lower liquid flow rates.

Later, Azzopardi et al. [24] documented results for the splitting of airwater annular, wavy, and stratified flow in a horizontal tee junction. As well, Azzopardi [25] proposed an extension to the model of Azzopardi [23] to include annular flow in horizontal tee junctions. For the experimental results given in [24], a main tube of $38.1 \mathrm{~mm}$ I.D. was used with branch tubes of $38.1 \mathrm{~mm}$ and $25 \mathrm{~mm}$ I.D. The ranges of inlet mass flux, quality, and extraction rate were $42<\mathrm{G}_{1}<206 \mathrm{~kg} / \mathrm{m}^{2} \mathrm{~s}, 4<\mathrm{x}_{1}<89 \%$, and $0.0<\mathrm{W}_{3} / \mathrm{W}_{1}<0.99$, respectively. 
Data were obtained at two different pressures: 150 and $300 \mathrm{kPa}$. Azzopardi et al. [24] studied the individual effects of diameter ratio, gas flow rate, liquid flow rate, gas density, and inlet flow regime on the phase-distribution. In general, for the same inlet conditions, less liquid was removed through the branch (for a fixed $\mathrm{F}_{\mathrm{BG}}$ ) as the diameter of the branch was decreased. Increasing $W_{G 1}$ at fixed $W_{L 1}$ and $F_{B G}$ resulted in an increase in $F_{B L}$. An increase in $\mathrm{W}_{\mathrm{L} 1}$ (at a fixed $\mathrm{W}_{\mathrm{G} 1}$ ) was found to increase the preference for the gas phase to exit through the branch. The inlet flow regime and the testsection pressure were also found to have significant effects on the phase distribution. The data were compared to the predictions of the models of Hwang et al. [19], Shoham et al. [21], and Azzopardi [25]. Best predictions were obtained using the model given by Azzopardi [25].

The new model presented by Azzopardi [25] for annular flow in a horizontal tee junction is similar to the original model by Azzopardi and Whalley [6]. The new model assumes that entrained liquid overshoots the branch into the run, and the gas and liquid diverted into the branch come from the same segment of the inlet tube. An additional mechanism is included in the model to help explain the phase-distribution phenomena at high extraction rates. Azzopardi [24] observed that at low $\mathrm{W}_{\mathrm{L} 1}$, as $\mathrm{F}_{\mathrm{BG}}$ increased beyond a certain critical value, the liquid film at the pipe wall opposite the branch ceased to move axially and formed a collar around the pipe circumference. Azzopardi [24] attributed the stopping of the liquid film to the increase in pressure of the flow as it decelerated into the run. He assumed that some of 
the liquid in the stagnant collar flowed into the branch while the remainder flowed into the run. The following equation was derived to give the critical value of $F_{B G}$ at which liquid film stoppage would first occur:

$$
F_{B G_{c t t}}=0.715-\left[0.493-0.633 \frac{\rho_{L I} V_{F I}^{2}}{\rho_{G I} V_{G l}^{2}}\right]^{0.5} \text {, }
$$

where $V_{G 1}$ and $V_{F 1}$ are the gas and liquid film mean velocities in the junction inlet. Beyond this critical value of $\mathrm{F}_{\mathrm{BG}}$, the liquid film ceases to move axially. $\mathrm{x}_{3} / \mathrm{x}_{1}$ is calculated using (2.1) with $\theta$ given by

$$
\theta=\frac{2 \pi F_{S E G}}{\left(1-E_{1}\right) 1.2\left(D_{3} / D_{1}\right)^{0.4}}
$$

where $\mathrm{F}_{\mathrm{SEG}}$ is the fraction of liquid film removed directly from the segment from which the gas is being removed. The fraction of liquid that flows into the branch from the liquid collar is given by

$$
F_{S}=\left(1-F_{S E G}-E_{1}\right)\left(\frac{F_{B G}^{2}}{1-2 F_{B G}+2 F_{B G}^{2}}\right) \text {. }
$$

Finally, the fraction of branch liquid is the sum of $F_{\mathrm{SEG}}$ and $\mathrm{F}_{\mathrm{S}}$, that is

$$
F_{B L}=F_{S E G}+F_{S} \text {. }
$$

The new model was compared to the horizontal, annular flow data of Hong [3], Shoham et al. [21], and Azzopardi et al. [24]. Comparison with the annular data of Azzopardi et al. [24] generally showed good agreement. The effects of liquid flow rate and diameter ratio were well predicted. At flow rates close to the annular/wavy boundary, the model overpredicted the data due to the 
model's assumption of uniform film flow rate about the periphery of the tube. Agreement with the annular data of Hong [3] was poor, although some trends were properly predicted. It should be noted that the data of Hong [3] were obtained using very small tube sizes (9.5 mm I.D., equal-sided tee junction). In general, the annular data of Shoham et al. [21] were well predicted.

\subsection{Pressure Drop}

To date, no pressure-drop model for two-phase flow in tee junctions has proven adequate for the whole range of inlet conditions. The various models suggested in the literature for two-phase flow are all direct extensions of the models used to predict the pressure drops for single-phase flow. Thus, a brief review of the relevant single-phase models is given next.

\subsubsection{Single-Phase Pressure Drop}

Collier [2] modelled the pressure drops $\Delta \mathrm{P}_{12}$ and $\Delta \mathrm{P}_{13}$ based on a simple momentum balance on the tee junction. For the control volume shown in figure 2.3(a), an axial momentum balance for the control volume with equal inlet and run diameters gives 


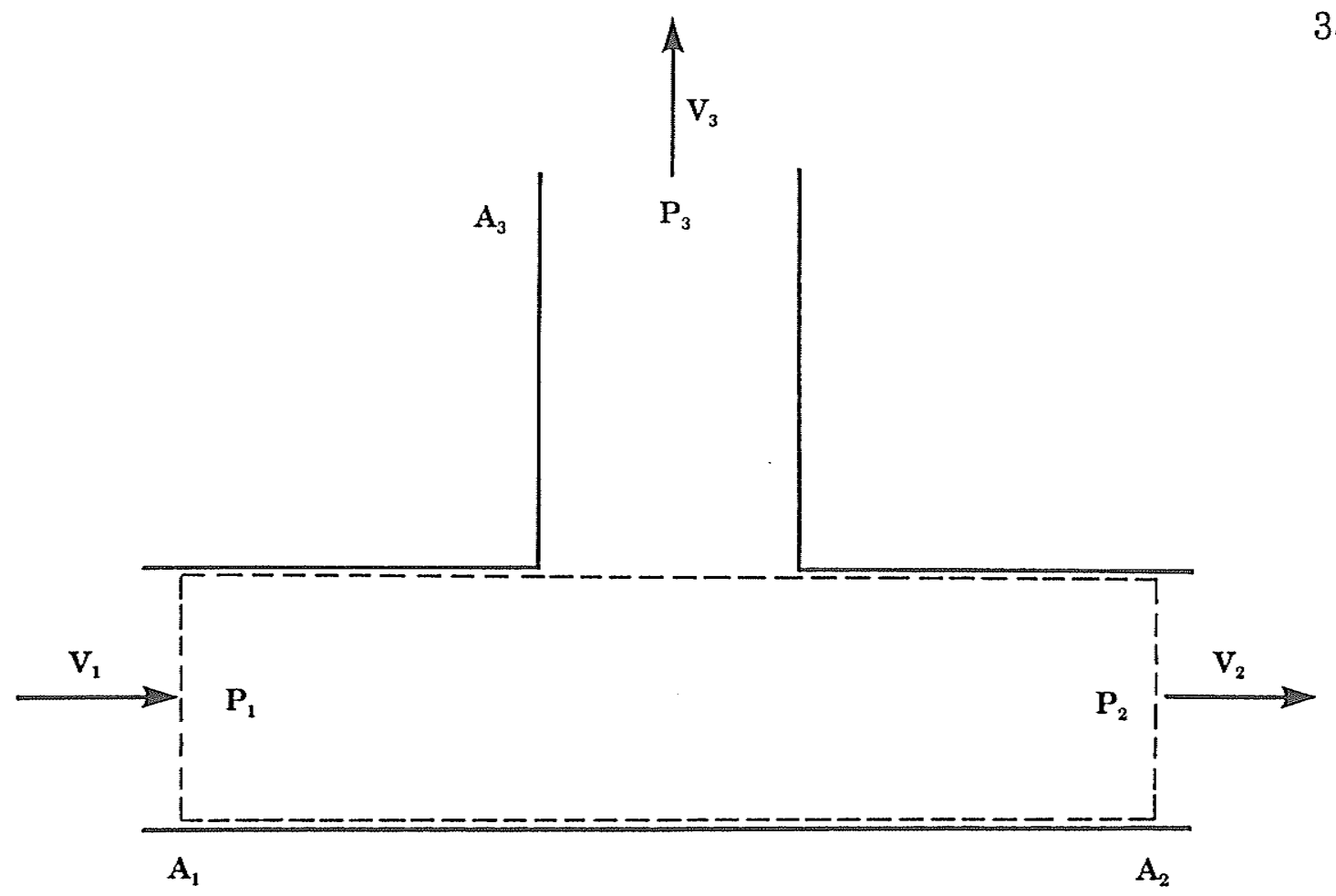

(a)

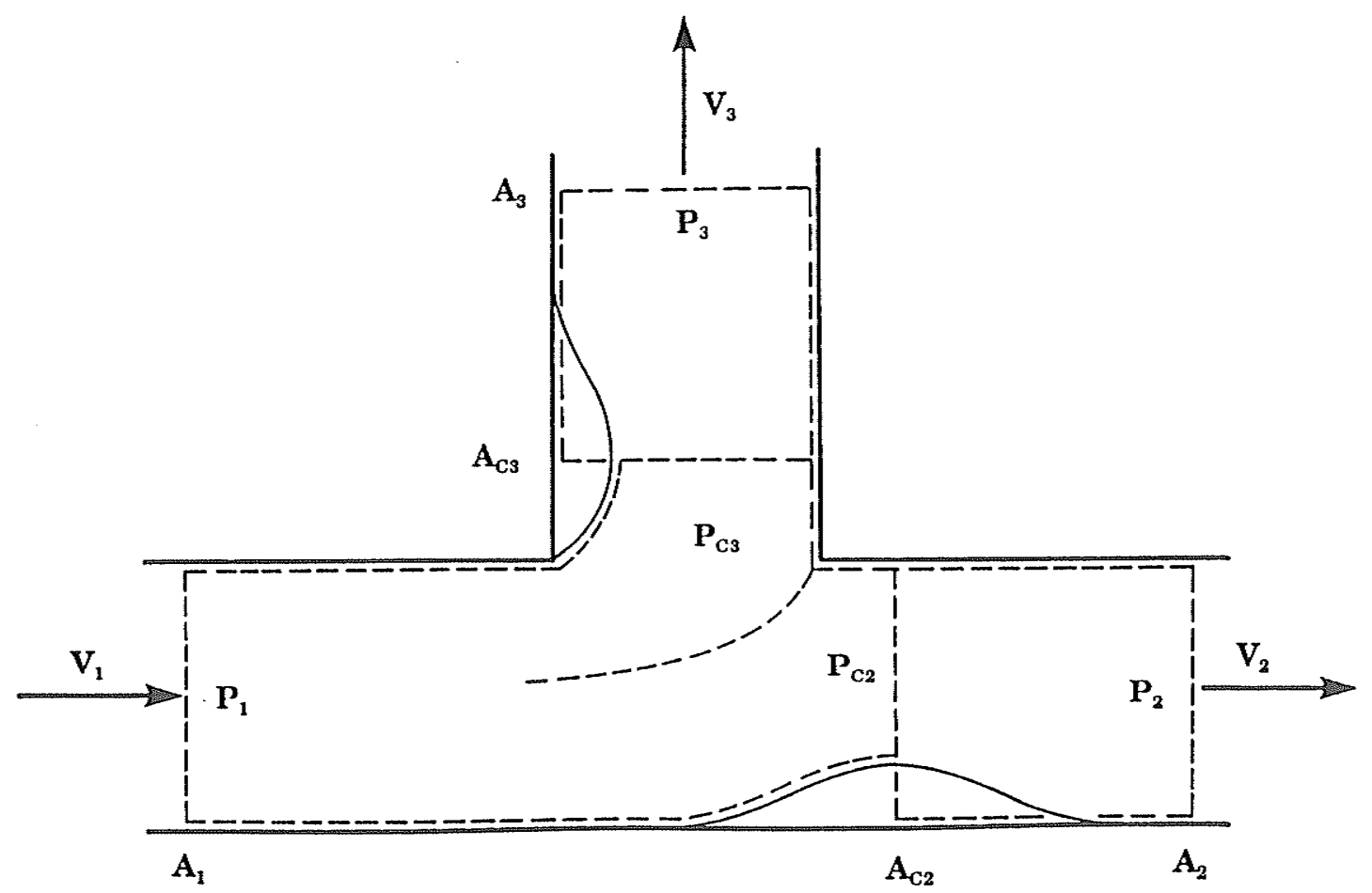

(b)

Figure 2.3 Control volumes for single-phase pressure-drop models 


$$
\Delta P_{12}=P_{1}-P_{2}=K_{12}^{\star}\left(\frac{G_{2}^{2}}{\rho_{2}}-\frac{G_{1}^{2}}{\rho_{1}}\right)
$$

where $P_{1}$ and $P_{2}$ are the inlet and run average pressures, respectively; $G_{1}$ and $\mathrm{G}_{2}$ are the inlet and run mass fluxes, respectively; $\rho_{1}$ and $\rho_{2}$ are the inlet and run densities, respectively; and $\mathrm{K}^{\star}{ }_{12}$ is a correction factor that accounts for forces not considered in (2.16), such as friction and the axial component of momentum exiting through the branch not at a right angle to the inlet and run. To remain consistent with previous authors, in the remainder of this thesis $\mathrm{K}^{\star}{ }_{12}$ will be referred to as the momentum correction factor.

An alternative [2] for modelling the pressure drop $\Delta \mathrm{P}_{12}$, and also used for $\Delta \mathrm{P}_{13}$, is to define

$$
\Delta P_{1 i}=\left(\Delta P_{1 i}\right)_{R E V}+\left(\Delta P_{1 i}\right)_{I R R}
$$

where $i=2$ for the run and $i=3$ for the branch. The reversible component in (2.17) can be obtained from Bernoulli's equation as follows:

$$
\left(\Delta P_{1 i}\right)_{R E V}=\frac{1}{2}\left(\frac{G_{i}^{2}}{\rho_{i}}-\frac{G_{1}^{2}}{\rho_{1}}\right), \quad i=2,3,
$$

where $G_{i}$ is the mass flux in the run $(i=2)$ or branch ( $\left.i=3\right)$. The irreversible component is defined as

$$
\left(\Delta P_{1 i}\right)_{I R R}=K_{1 i}\left(\frac{G_{1}^{2}}{2 \rho_{1}}\right), \quad i=2,3,
$$

where $K_{12}$ and $K_{13}$ are loss coefficients. 
Another model used to predict $\Delta \mathrm{P}_{12}$ and $\Delta \mathrm{P}_{13}$ was presented by Reimann and Seeger [26]. Referring to the control volume given in figure 2.3(b), the pressure drops were defined as

$$
\Delta P_{1 i}=\Delta P_{1-C i}+\Delta P_{C i-i}
$$

where $\Delta \mathrm{P}_{1 \cdot \mathrm{Ci}}$ is the reversible pressure drop between the inlet and the throat of a vena contracta, given by

$$
\Delta P_{1-C i}=\frac{1}{2}\left(\frac{G_{C I}^{2}}{\rho_{C i}}-\frac{G_{1}^{2}}{\rho_{1}}\right), \quad i=2,3,
$$

and $\Delta \mathrm{P}_{\mathrm{C} i \mathrm{i}}$ is the pressure drop between the throat of the vena contracta and a position downstream in the run ( $i=2$ ) or the branch ( $i=3$ ), modelled as a sudden expansion. Thus,

$$
\Delta P_{C H-i}=\frac{G_{i}^{2}}{\rho_{i}}-\frac{G_{i} G_{C l}}{\rho_{i}}, \quad i=2,3
$$

The mass flux at the throat of the vena contracta $\mathrm{G}_{\mathrm{Ci}}$ can be eliminated from equations (2.21) and (2.22) using a conservation of mass equation. Introducing a contraction coefficient $\mathrm{C}_{\mathrm{i}}=\mathrm{A}_{\mathrm{Ci}} / \mathrm{A}_{1}$, setting $\rho_{\mathrm{Ci}}=\rho_{\mathrm{i}}$, and substituting (2.21) and (2.22) into $(2.20)$ yields

$$
\Delta P_{1 i}=\frac{1}{2}\left(\frac{G_{i}^{2}}{\rho_{i}}-\frac{G_{1}^{2}}{\rho_{1}}\right)+\left(\frac{1}{C_{i}}-1\right)^{2} \frac{G_{i}^{2}}{2 \rho_{i}}, \quad i=2,3
$$

where the contraction coefficient is given by 


$$
C_{t}=\left[1+\sqrt{\frac{\rho_{i}}{\rho_{1}}} \frac{G_{1}}{G_{i}} \sqrt{K_{1 i}}\right]^{-1}, \quad i=2,3 .
$$

The parameter $\mathrm{K}_{1 \mathrm{i}}$ represents the single-phase loss coefficients given in equation (2.19). In the above equations, $\mathrm{A}_{\mathrm{Ci}}$ is the cross-sectional area at the throat of the vena contracta, $A_{1}$ is the cross-sectional area of the inlet tube, and $\rho_{\mathrm{Ci}}$ is the density at the throat of the vena contracta.

\subsubsection{Two-Phase Pressure Drop}

Fouda and Rhodes [27] studied two-phase annular flow in a horizontal tee with a vertical branch. The pressure drops $\Delta \mathrm{P}_{12}$ and $\Delta \mathrm{P}_{13}$ were measured using a single pressure tap in each of the inlet, run, and branch. For $\Delta \mathrm{P}_{12}$, Fouda and Rhodes [27] proposed a model that is analogous to the single-phase model given by equation (2.16). Thus,

$$
\Delta P_{12}=\left(K_{12}^{\star}\right)_{S}\left(\frac{G_{2}^{2}}{\rho_{M 2}}-\frac{G_{1}^{2}}{\rho_{M I}}\right),
$$

where $\rho_{\mathrm{Mi}}$ are the momentum-weighted densities given by

$$
\rho_{M i}=\left[\frac{x_{i}^{2}}{\alpha_{i} \rho_{G i}}+\frac{\left(1-x_{i}\right)^{2}}{\left(1-\alpha_{i}\right) \rho_{L i}}\right]^{-1},
$$

with $i=1$ for the inlet and $i=2$ for the run, and $\left(\mathrm{K}^{\star}{ }_{12}\right)_{\mathrm{S}}$ is the separated-flow momentum correction factor. A homogeneous version of equation (2.25) is given by [27]: 


$$
\Delta P_{12}=\left(K_{12}^{\star}\right)_{H}\left(\frac{G_{2}^{2}}{\rho_{H 2}}-\frac{G_{1}^{2}}{\rho_{H 1}}\right),
$$

where $\left(\mathrm{K}^{\star}{ }_{12}\right)_{\mathrm{H}}$ is the homogeneous flow momentum correction factor, and $\rho_{\mathrm{H} 1}$ and $\rho_{\mathrm{H} 2}$ are the inlet and run homogeneous densities, respectively. The homogeneous densities are calculated using

$$
\rho_{H l}=\left[\frac{\left(1-x_{i}\right)}{\rho_{L l}}+\frac{x_{i}}{\rho_{G l}}\right]^{-1}, \quad i=1,2,3
$$

In an extension to the model given by equations (2.17) to (2.19), Saba and Lahey [12] expressed $\Delta \mathrm{P}_{13}$ for two-phase flow as

$$
\Delta P_{13}=\left(\Delta P_{13}\right)_{R E V}+K_{13} \frac{G_{1}^{2}}{2 \rho_{L I}} \varphi
$$

where $\varphi$ is a two-phase loss multiplier for the branch. For separated flow they showed that the above equation becomes

$$
\Delta P_{13}=\frac{\rho_{H 3}}{2}\left[\frac{G_{3}^{2}}{\rho_{E 3}^{2}}-\frac{G_{1}^{2}}{\rho_{E l}^{2}}\right]+K_{13} \frac{G_{1}^{2}}{2 \rho_{L 1}} \varphi_{s},
$$

where $\mathrm{K}_{13}$ is the single-phase loss coefficient based on an inlet liquid mass flux of $\mathrm{G}_{1}, \varphi_{\mathrm{s}}$ is the separated-flow two-phase loss multiplier for the branch; $\rho_{\mathrm{H} 3}$ is the branch homogeneous density, and $\rho_{\mathrm{E} 1}$ and $\rho_{\mathrm{E} 3}$ are the inlet and branch energy-weighted densities, respectively. The energy-weighted densities are defined as follows [12]: 


$$
\rho_{E t}=\left[\frac{\left(1-x_{i}\right)^{3}}{\rho_{L i}^{2}\left(1-\alpha_{i}\right)^{2}}+\frac{x_{i}^{3}}{\rho_{G i}^{2} \alpha_{i}^{2}}\right]^{-1 / 2}, \quad i=1,2,3,
$$

where $\alpha_{i}$ are the void fractions in the inlet, run, or branch. For the two-phase multiplier given in (2.30), Saba and Lahey [12] recommended

$$
\varphi_{s}=\frac{\rho_{L I}}{\rho_{M I}} .
$$

A homogeneous version was obtained by replacing the energy-weighted densities in (2.30) with the appropriate homogeneous densities, giving:

$$
\Delta P_{13}=\frac{\rho_{H 3}}{2}\left[\frac{G_{3}^{2}}{\rho_{H 3}^{2}}-\frac{G_{1}^{2}}{\rho_{H I}^{2}}\right]+K_{13} \frac{G_{1}^{2}}{2 \rho_{L 1}} \varphi_{H} .
$$

For the two-phase loss multiplier given in (2.33), Saba and Lahey [12] recommended $\varphi_{\mathrm{H}}=\rho_{\mathrm{L} 1} / \rho_{\mathrm{H} 1}$, the homogeneous version of (2.32).

For $\Delta \mathrm{P}_{12}$, Saba and Lahey [12] used the model presented by Fouda and Rhodes [27], given by equation (2.25). For the correction factor $\left(\mathrm{K}^{\star}{ }_{12}\right)_{\mathrm{S}}$, Saba and Lahey [12] used $\mathrm{K}^{\star}{ }_{12} / 2$, where $\mathrm{K}^{\star}{ }_{12}$ is a momentum correction factor from single-phase flow. Thus,

$$
\Delta P_{12}=\frac{K_{12}^{\star}}{2}\left(\frac{G_{2}^{2}}{\rho_{M 2}}-\frac{G_{1}^{2}}{\rho_{M I}}\right) .
$$

The parameter $\mathrm{K}^{\star}{ }_{12}$ was calculated using equation (2.16); however, for equation (2.16) Saba and Lahey [12] used the term $\mathrm{K}^{\star}{ }_{12} / 2$ instead of simply $\mathrm{K}^{*}{ }^{*}$. 
Reimann and Seeger [26] derived a model, similar to equation (2.23), for $\Delta \mathrm{P}_{13}$ and $\Delta \mathrm{P}_{12}$ during two-phase flow. The final form of the model is as follows:

$$
\Delta P_{1 i}=\Delta P_{1-C i}+\Delta P_{C i-i}, \quad i=2,3
$$

where $\Delta \mathrm{P}_{1 \cdot \mathrm{Ci}}$ is the reversible pressure change from the inlet to the throat of a vena contracta in the run or branch (given by an energy balance), and $\Delta \mathrm{P}_{\mathrm{Ci}-\mathrm{i}}$ is the pressure change from the throat of a vena contracta to a position downstream in the run or branch (given by a momentum balance). The values of $\Delta \mathrm{P}_{1 \cdot \mathrm{Ci}}$ and $\Delta \mathrm{P}_{\mathrm{Ci-i}}$ are calculated using

$$
\Delta P_{1-C i}=\frac{\rho_{H i}}{2 \rho_{L i}^{2}}\left\{\frac{G_{i}^{2}}{C_{i}^{2}}\left[x_{i} R+S_{C i}\left(1-x_{i}\right)\right]^{2}\left(x_{i}+\frac{1-x_{i}}{S_{C i}^{2}}\right)-G_{1}^{2}\left[x_{1} R+S_{1}\left(1-x_{1}\right)\right]^{2}\left(x_{i}+\frac{1-x_{i}}{S_{1}^{2}}\right)\right\},
$$

and

$$
\Delta P_{C i-i}=\frac{G_{i}^{2}}{\rho_{L i}}\left\{\left[x_{i} R+S_{i}\left(1-x_{i}\right)\right]\left(x_{i}+\frac{1-x_{i}}{S_{i}}\right)-\frac{1}{C_{i}}\left[x_{i} R+S_{C Y}\left(1-x_{i}\right)\right]\left(x_{i}+\frac{1-x_{i}}{S_{C i}}\right)\right\},
$$

where $S_{C i}$ is the slip ratio at the throat of the vena contracta in the run or branch; $S_{i}$ is the slip ratio in the run (i=2) or branch (i=3) downstream of the junction; $S_{1}$ is the slip ratio in the inlet; and $R$ is the density ratio, defined as $\mathrm{R}=\rho_{\mathrm{L} 1} / \rho_{\mathrm{G} 1}$. The contraction coefficients are calculated using

$$
C_{i}=\left[1+\sqrt{\frac{\rho_{H i}}{\rho_{H 1}}} \frac{G_{1}}{G_{i}} \sqrt{K_{1 i}}\right]^{-1}, \quad i=2,3
$$

where $K_{1 \mathrm{i}}$ are the single-phase loss coefficients given in equation (2.19). 
For the prediction of $\Delta \mathrm{P}_{12}$, Reimann and Seeger [26] suggested that the slip ratio in the run vena contracta $S_{C 2}$ should be set equal to unity. This corresponded to the assumption of homogeneous flow at the vena contracta. The slip ratios $S_{1}$ and $S_{2}$ were estimated using the correlation developed by Rouhani [15], given by equations (2.6), (2.7), and (2.8). It should be noted again that for equation (2.8) Reimann and Seeger [26] omitted the term $\left(1-\mathrm{x}_{1}\right)$.

For the prediction of $\Delta \mathrm{P}_{13}$, numerous assumptions were made for $\mathrm{S}_{1}, \mathrm{~S}_{3}$, and $\mathrm{S}_{\mathrm{C} 3}$. The best agreement with air-water flow in a horizontal tee junction was obtained with the assumption of homogeneous flow, therefore $\mathbf{S}_{1}, \mathbf{S}_{3}$, and $\mathrm{S}_{\mathrm{C} 3}$ were all set to unity. Using this assumption, and the following expression for $\mathrm{C}_{3}$ :

$$
C_{3}=\left[1+\frac{Q_{1}}{Q_{3}} \sqrt{K_{13}}\right]^{-1},
$$

where $Q_{1}$ and $Q_{3}$ are the volume flow rates in the inlet and branch, respectively, the model given by (2.35) reduces to (2.33) with the two-phase loss multiplier given by

$$
\varphi_{H}=\frac{\rho_{L I} \rho_{H 3}}{\rho_{H I}^{2}}
$$

A correction factor was suggested by Reimann et al. [22] and Reimann and Seeger [26] for the homogeneous model given by equation (2.33). This correction factor accounted for the deviation of the model from experimental 
data for $\Delta \mathrm{P}_{13}$ at an extraction rate of unity. To compensate for these deviations, the relationship proposed was

$$
\Delta P_{13}=\left(\Delta P_{13}\right)_{R E V}+K\left(\Delta P_{13}\right)_{I R R}
$$

where $\mathrm{K}=1.34$.

Hwang and Lahey [28] presented data for the pressure drops $\Delta \mathrm{P}_{13}$ and $\Delta \mathrm{P}_{12}$ during single-phase and two-phase flow through a tee, $45^{\circ}$ wye, and $135^{\circ}$ wye. All three test sections were horizontal, and had equal inlet and branch tube sizes ( $38 \mathrm{~mm}$ I.D.). The data were compared to various pressure-drop models. For $\Delta \mathrm{P}_{13}$, Hwang and Lahey [28] used the model of Saba and Lahey [12] given by equation (2.30). Best results for this model were obtained assuming homogeneous flow downstream of the junction, that is $\rho_{\mathrm{E} 3}=\rho_{\mathrm{H} 3}$, and $\varphi_{\mathrm{s}}$ given by equation (2.40), the value recommended by Reimann and Seeger [26]. Nearly all the data for $\Delta \mathrm{P}_{13}$ were predicted within $\pm 20 \%$. For $\Delta \mathrm{P}_{12}$, the model presented by Saba and Lahey [12], given by equation (2.34), was recommended with $\rho_{\mathrm{M} 2}=\rho_{\mathrm{H} 2}$. Good agreement was found with more than $95 \%$ of the data predicted within $\pm 25 \%$. To predict the void fraction in the inlet, Hwang and Lahey [28] used the Zuber-Findlay model [29] with an empirical correlation for the void concentration parameter $\mathrm{C}_{0}$, given by

$$
C_{0}=1.10-0.1\left[\rho_{L I} / \rho_{G I}\right]^{-0.0001\left(\rho_{L I} / \rho_{G l}\right)} .
$$

The corresponding slip ratio was then obtained from 


$$
S_{1}=C_{0}+\left(C_{0}-1\right) \frac{\rho_{L l}}{\rho_{G l}}\left[\frac{x_{1}}{1-x_{1}}\right] .
$$

Ballyk et al. [18] obtained pressure-drop data for steam-water annular flow in a horizontal tee junction. They proposed a model for $\Delta \mathrm{P}_{13}$ that is similar to the model presented by Saba and Lahey [12], equation (2.30). The final form of the model is:

$$
\Delta P_{13}=\left(\Delta P_{13}\right)_{R E V}+\left(\Delta P_{13}\right)_{I R R},
$$

where

$$
\left(\Delta P_{13}\right)_{R E V}=\frac{\rho_{H 3}}{2}\left[\frac{G_{3}^{2}}{\rho_{E 3}^{2}}-\frac{G_{1}^{2}}{\rho_{\star 1}^{2}}\right],
$$

and

$$
\left(\Delta P_{13}\right)_{I R R}=K_{13} \frac{\rho_{H 3}}{2} \frac{G_{1}^{2}}{\rho_{\star 1}^{2}} \varphi^{\star} .
$$

The branch energy-weighted density $\rho_{\mathrm{E} 3}$ was defined previously in equation (2.31). The equivalent inlet density $\rho_{\star 1}$ was defined as

$$
\rho_{\star 1}=\left[\frac{\left(1-x_{1}\right)^{2}\left(1-x_{3}\right)}{\rho_{L l}^{2}\left(1-\alpha_{1}\right)^{2}}+\frac{x_{1}^{2} x_{3}}{\rho_{G 1}^{2} \alpha_{1}^{2}}\right]^{-1 / 2}
$$

and the two-phase multiplier $\varphi^{*}$ was obtained empirically from their data as follows: 


$$
\varphi^{*}=-1.37+23.38 \eta-17.00 \eta^{2}+1.12 \eta^{3}, \quad \eta>0.1,
$$

where $\eta$ is the extraction rate $\mathrm{W}_{3} / \mathrm{W}_{1}$. For a given branch-to-inlet diameter ratio, the two-phase multiplier defined above was a unique function of the extraction rate and was independent f the inlet mass flux and the inlet quality. For the pressure change $\Delta \mathrm{P}_{12}$, Ballyk et al. [18] suggested using the separated flow model given by equation $(2.25)$ with the coefficient $\left(\mathrm{K}_{12}\right)_{\mathrm{S}}$ equal to unity. Measured values of the void fractions in the inlet, run, and branch were used in all of the models proposed in [18].

In 1988, Reimann et al. [22] presented results which extended the data of Seeger et al. [14] to include a large range of inlet mass flux and diameter ratios. Pressure-drop data from both of these studies were compared to the predictions of the various pressure-drop models. For $\Delta \mathrm{P}_{12}$, it was concluded that the separated flow model given by equation (2.34) had the highest accuracy in predicting the data for the horizontal branch with $\mathrm{D}_{3} / \mathrm{D}_{1}=1$ and 0.52. The best predictions for $\Delta \mathrm{P}_{13}$ were obtained using the homogeneous model given by equation (2.33) with the two-phase loss multiplier calculated using equation (2.40) and the value of $\mathrm{K}$ in equation (2.41) equal to 1.34 .

\subsection{Closing Remarks}

Based on the above discussion, it is evident that no generalized models have been developed capable of accurately predicting the phase distribution 
and pressure drop through tee junctions. This is a direct consequence of the fact that the relevant phenomena are not completely understood yet.

Since the inlet flow regime is an important parameter, figures $2.4(\mathrm{a})$ and 2.4(b) were developed in order to summarize the range of inlet conditions for previous phase-distribution experiments, and figure 2.5 was developed in order to summarize the range of inlet conditions for previous pressure-drop experiments. In all three figures, the ranges are plotted on the flow regime map of Mandhane et al. [30]. Only experiments with a horizontal tee junction are shown. The flow-regime transition boundaries given in these figures were plotted using the coordinates given by Mandhane et al. [30], without any physical property corrections. The transitions shown are typical for air-water flow in small-diameter pipes (less than $51 \mathrm{~mm}$ ).

Figure 2.5 clearly shows a lack of pressure-drop data for $\mathrm{J}_{\mathrm{L} 1}$ less than $0.07 \mathrm{~m} / \mathrm{s}$. Figures 2.4(a) and 2.4(b) show that some phase-distribution data exist in this region; however, the data of Hong [3] were obtained using a smalldiameter tee junction (9.5 mm I.D.), and the data of Rubel et al. [20] were for steam-water flow. Thus, there is a need for pressure-drop data and new airwater phase-distribution data in the region $J_{L 1}<0.1 \mathrm{~m} / \mathrm{s}$, which corresponds to stratified, wavy, and annular flow. New data in this region would improve our understanding of the phenomena occurring at tee junctions during twophase flow, and would aid in the development of models for the prediction of phase distribution and pressure drop in tee junctions. 


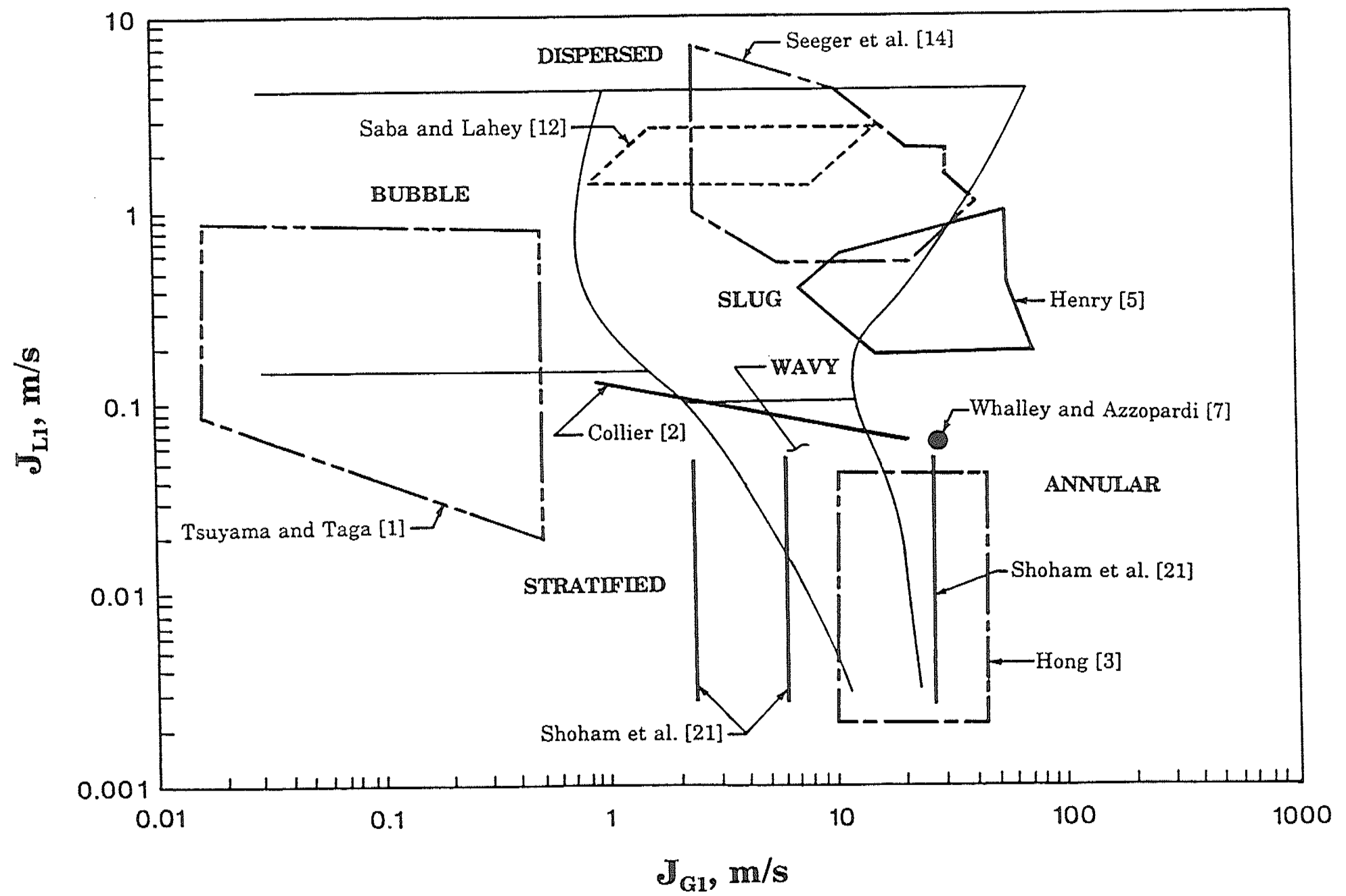

(a)

Figure 2.4 Range of inlet conditions for phase-distribution experiments with a horizontal tee junction plotted on the Mandhane et al. [30] flow-regime map 


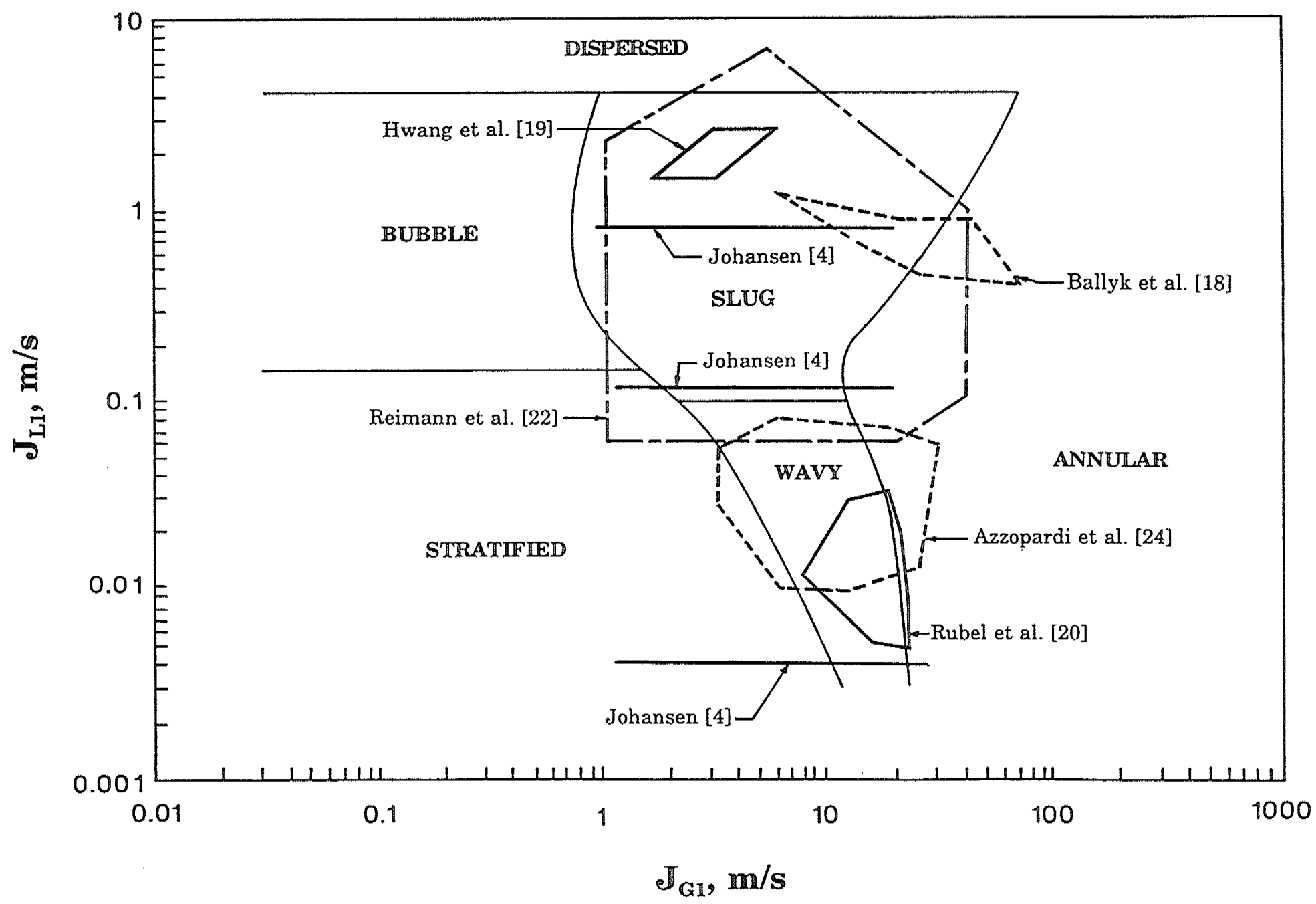

(b)

Figure 2.4 Range of inlet conditions for phase-distribution experiments with a horizontal tee junction plotted on the Mandhane et al. [30] flow-regime map 


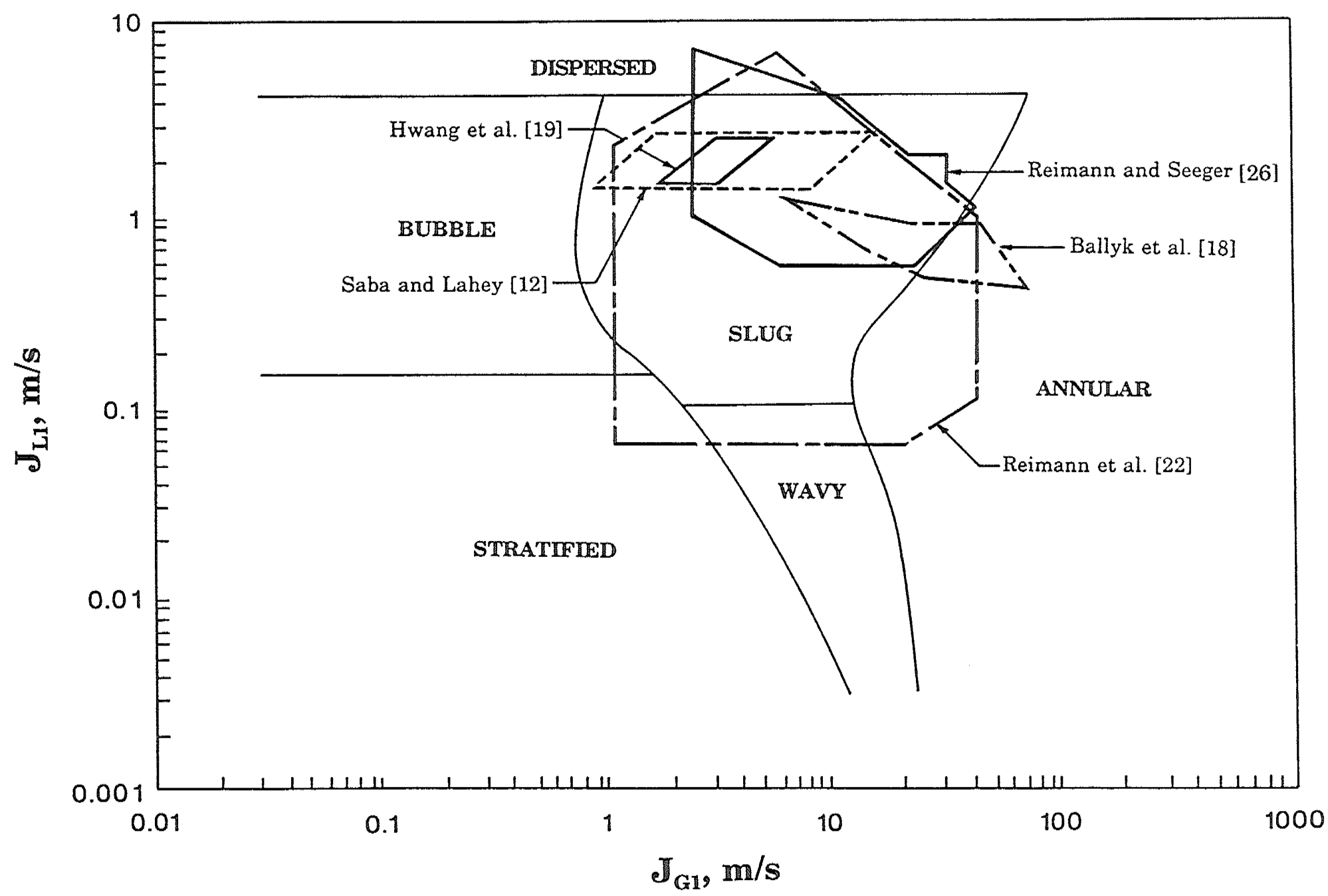

Figure 2.5 Range of inlet conditions for pressure-drop experiments with a horizontal tee junction plotted on the Mandhane et al. [30] flow-regime map 


\section{Chapter 3 \\ EXPERIMENTAL INVESTIGATION}

The objective of the present experimental investigation is to generate phase-distribution and pressure-drop data for two-phase, air-water flow through a horizontal tee junction. The apparatus constructed to obtain these data incorporated a horizontal tee junction with equal inlet, run, and branch tube sizes (37.6 mm I.D.), and was designed for the following operating conditions: air-water mixtures at a pressure of about $150 \mathrm{kPa}$ and near ambient temperature, inlet superficial gas velocities ranging between 2.7 and $41 \mathrm{~m} / \mathrm{s}$, inlet superficial liquid velocities ranging between 0.0021 and $0.181 \mathrm{~m} / \mathrm{s}$, and extraction rates between 0.1 and 0.9 .

\subsection{Air-Water Loop}

\subsubsection{Overview}

The flow loop, which was constructed for this investigation, is shown in figure 3.1. The following paragraph gives a brief description of the flow through the different components of the loop. A more detailed description of the design, construction, and operation of the major components of the loop is given later in this chapter. 


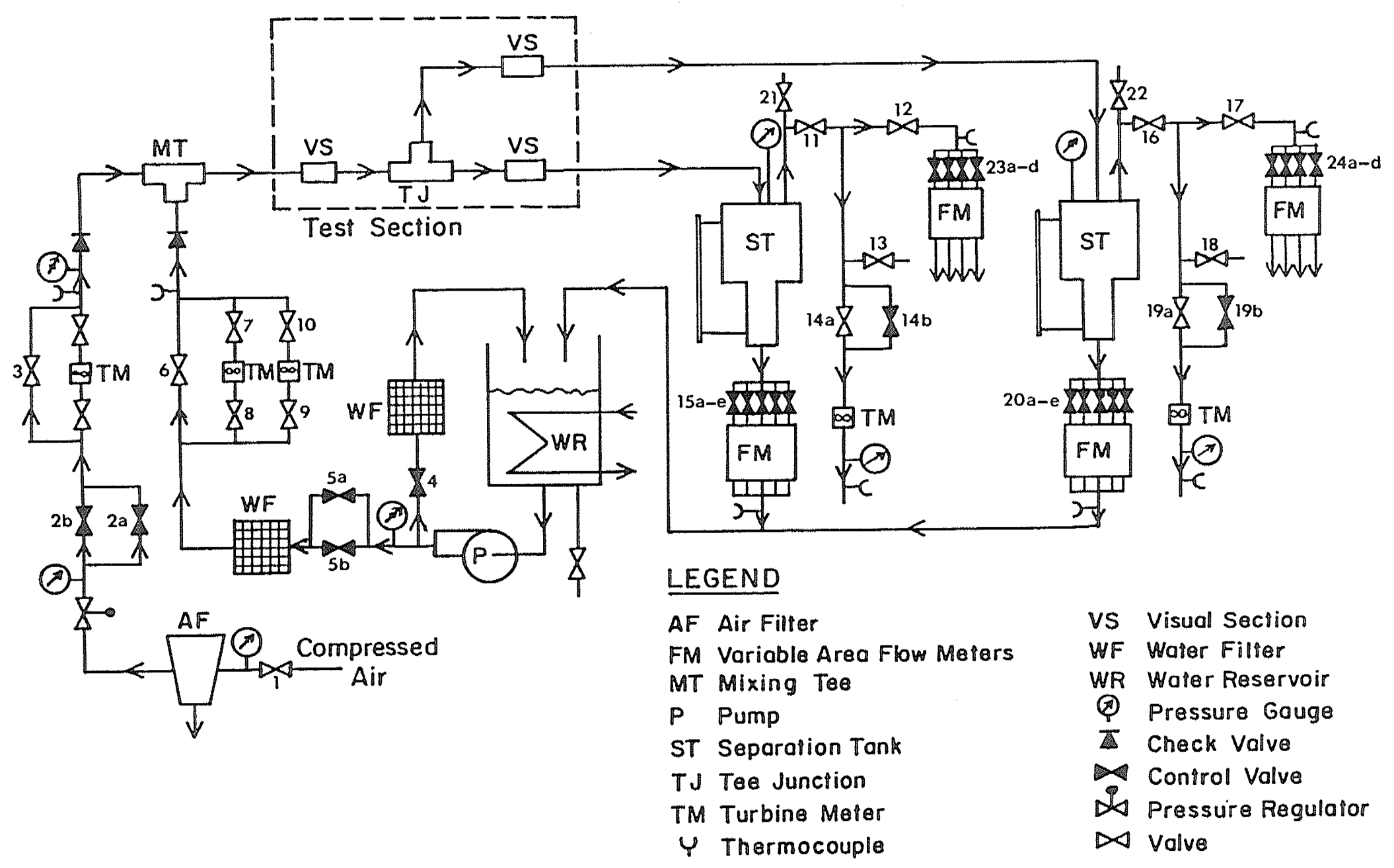

Figure 3.1 Schematic diagram of the experimental facility 
Distilled water used in the system was stored in the water reservoir. Water, fed from the reservoir by a centrifugal pump, was metered by two turbine meters before flowing into the two-phase mixing tee (mixer) where it was mixed with the gas phase (air). Heat absorbed by the water due to flow through the pump and from frictional pressure losses was removed by a heat exchanger installed inside the water reservoir. Air supplied from an air compressor was metered using a single turbine meter before flowing into the mixer. A developing length of 67.5 tube diameters was allowed before the two-phase mixture entered the visual section, and a further 42 tube diameters was provided before entering the branching tee junction. Forty-one pressure taps were located along the test-section inlet, run, and branch in order to map-out the pressure distribution around the tee junction. After the flow patterns in the run and branch were observed through visual sections, each of the two-phase mixtures entered its respective separation tank. The flow rate of liquid from each separation tank was metered using a combination of five rotameters (arranged in parallel) to give individual measurements of the run liquid flow rate $\mathrm{W}_{\mathrm{L} 2}$, and the branch liquid flow rate $\mathrm{W}_{\mathrm{L} 3}$. The two liquid lines then rejoined before returning to the water reservoir. The gas phase exiting each of the separation tanks flowed through its respective throttling valve, used to control both the extraction rate $\mathrm{W}_{3} / \mathrm{W}_{1}$ and the test section pressure, before being metered by either a turbine meter (for high flow rates), or a combination of four variable area flowmeters arranged in parallel (for low flow 
rates). This gave individual measurements of the run air flow rate $\mathrm{W}_{\mathrm{G} 2}$, and the branch air flow rate $\mathrm{W}_{\mathrm{G} 3}$. Both air flows were then discharged to the atmosphere.

\subsubsection{Water Flow Rate Measurement}

The inlet water flow rate $\mathrm{W}_{\mathrm{L} 1}$ was metered using two turbine meters arranged in parallel. Both turbine meters were manufactured by Flow Technology, Inc. The model numbers and flow ranges were as follows:

\section{Model}

FT6-8C1YW-LED-1

FTO-4C1YW-LHC-1

\section{Calibrated Range}

$0.57-18.9 \mathrm{l} / \mathrm{min}(0.15-5.00 \mathrm{GPM})$

$0.076-4.92 \mathrm{l} / \mathrm{min}(0.02-1.30 \mathrm{GPM})$.

Output from each turbine meter was fed into its respective signal converter (Flow Technology, Inc. RC51-1-C-0000-6) which converted the turbine meter output into a 0 to 10 volt $\mathrm{DC}$ signal. These $\mathrm{DC}$ signals were fed into two separate channels in the digital acquisition system.

Both turbine meters were calibrated using a collection tank, scale, and timer. These calibrations agreed very well with the calibrations provided by the manufacturer. Typical deviations of about $\pm 2 \%$ were observed between the present calibrations and the manufacturers calibrations. Maximum deviations of about $\pm 4 \%$ were observed at the lowest flow rates. Therefore, the present calibrations were used in the reduction of all data. 
The water flow rates in the branch and the run were metered using rotameters. Each flow-measurement station consisted of five flowmeters arranged in parallel to give a wide flow-measurement range as follows:

For the run:

\section{Model}

Cole-Parmer, tube number NO82-03ST

Cole-Parmer, tube number FM102-05ST

Cole-Parmer, tube number FM044-40C

Cole-Parmer, tube number NO44-40C

Fisher Porter, 10A3555A

\section{Calibrated Range}

$3.5-46.0 \mathrm{ml} / \mathrm{min}$

$7.6-216 \mathrm{ml} / \mathrm{min}$

$72-1810 \mathrm{ml} / \mathrm{min}$

$99-1900 \mathrm{ml} / \mathrm{min}$

$1140-13400 \mathrm{ml} / \mathrm{min}$

For the branch:

\section{Model}

Cole-Parmer, tube number FM082-03ST

Cole-Parmer, tube number FM102-05ST

Cole-Parmer, tube number FM044-40C

Cole-Parmer, tube number FM044-40C

Fisher Porter, 10A3555A

\section{Calibrated Range}

$0.27-44.7 \mathrm{ml} / \mathrm{min}$

$7.6-216 \mathrm{ml} / \mathrm{min}$

$72-1810 \mathrm{ml} / \mathrm{min}$

$72-1810 \mathrm{ml} / \mathrm{min}$

$1140-13400 \mathrm{ml} / \mathrm{min}$

Thus each flow-measurement station was capable of flow-rate measurement over $13400 \mathrm{ml} / \mathrm{min}$.

All rotameters were calibrated using a collection tank, scale, and timer. Comparison between the present calibrations and the calibrations provided by the manufacturer showed very good agreement. Maximum deviations of approximately $\pm 5 \%$ were observed at the lowest flow rates; however, typical deviations were about $\pm 3 \%$. As well, all rotameters were found to have a 
nearly linear relation between the measured flow rate and the scale reading. As a result, the present calibrations were used in reducing all data.

\subsubsection{Mixer}

A schematic diagram of the two-phase mixer is shown in figure 3.2. The entire mixer was constructed from copper tubing and fittings which were soldered together. Water entering the mixer was injected into the air flow through a large number of 1.6-mm diameter holes. The resulting two-phase mixture then discharged from the mixer and was allowed to become fully developed over a length of 67.5 diameters before entering the visual section.

\subsubsection{Air Flow Rate Measurement}

The inlet air flow rate $\mathrm{W}_{\mathrm{G} 1}$ was metered using a single turbine meter. The air flow rate out of each separation tank was metered by either a turbine meter (for high flow rates), or a bank of rotameters (for low flow rates). All three air turbine meters were Flow Technology, Inc., model number FT-24C1YA-GEA-1, with a flow range of 0.11 to $4.53 \mathrm{~m}^{3} / \mathrm{min}$ ( 3.8 to $160 \mathrm{ACFM}$ ) at atmospheric pressure and ambient temperature. Output from each turbine meter was fed into its respective signal converter (Flow Technology, Inc. RC51-1-C-0000-6) which converted the turbine meter output into a 0 to 10 volt 


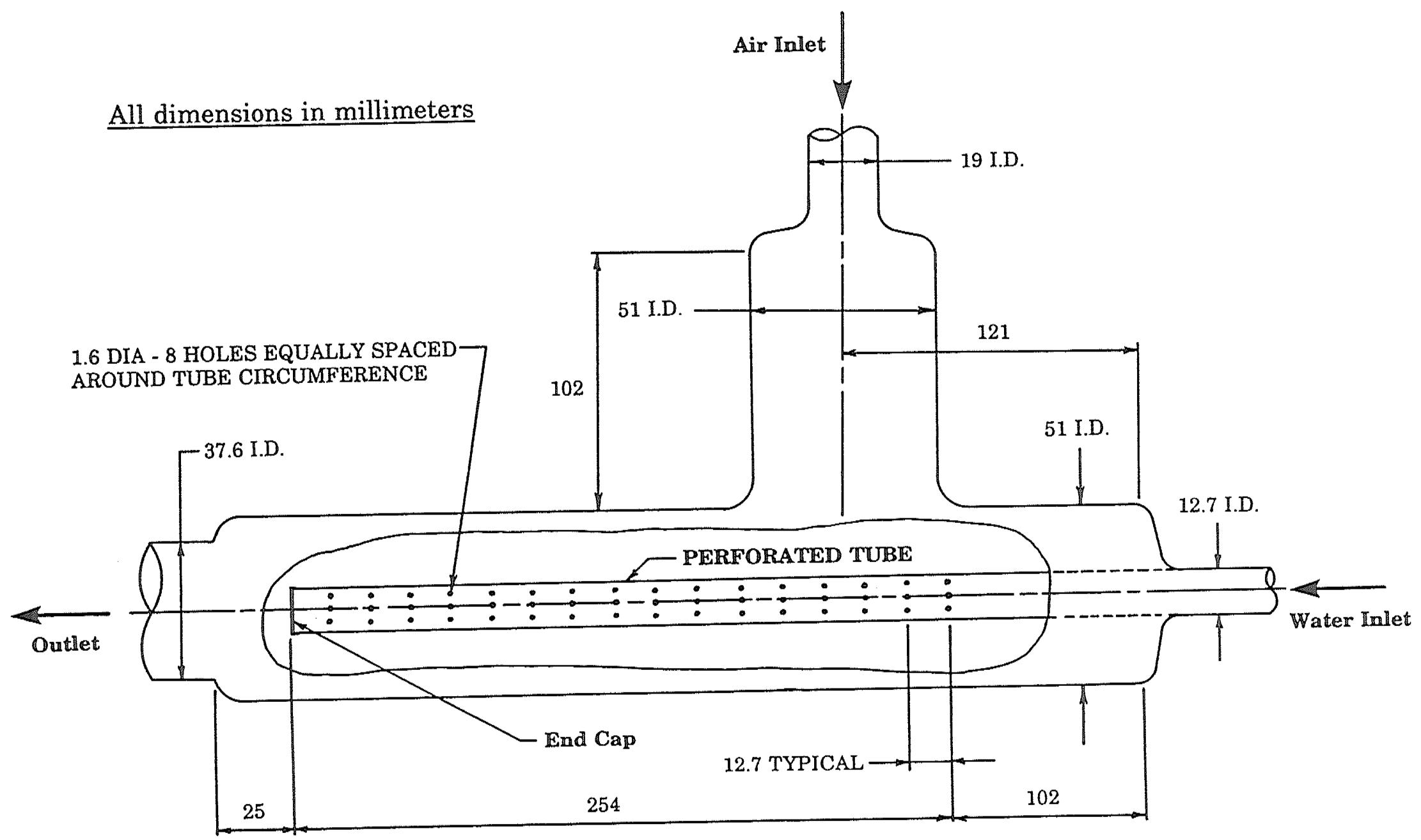

Figure 3.2 Schematic diagram of two-phase mixer 
DC signal. The DC signals were then fed into three separate channels in the digital acquisition system.

Calibrations for the air turbine meters were provided by the manufacturer. As a check, the air turbine meters were calibrated against two air rotameters with calibrations provided by the manufacturer. Rotameters were used since a suitable calibration standard was not available. Due to limitations of the rotameters, the turbine meters could only be calibrated over $1 / 3$ of their range; however, most of the present data fell within this range. For higher flow rates, the present calibrations were extrapolated. It should be noted that for high flow rates the manufacturer also had to extrapolate their calibration. This resulted in little error since the turbine meters are very linear over the top $90 \%$ of their range. The present calibrations were found to deviate at most $7 \%$ from the manufacturers calibrations; however, typical deviations of about $5 \%$ were observed. Using the present calibrations, a mass balance between the air turbine meters gave good results, with a maximum deviation of approximately $\pm 4 \%$. Based on this, the present calibrations were used for all data reduction.

For the measurement of low air flow rates out of either separation tank, a bank of four rotameters (arranged in parallel) was used instead of the turbine meter. Both the run and branch air rotameter banks consisted of the following flowmeters: 


\section{Model}

Cole-Parmer, tube number FM082-03ST $\quad 56-1690 \mathrm{ml} / \mathrm{min}$

Cole-Parmer, tube number FM102-05ST $535-9050 \mathrm{ml} / \mathrm{min}$

Cole-Parmer, tube number FM044-40C $\quad 3.00-64.11 / \mathrm{min}$

Cole-Parmer, tube number FM044-40C 3.00-64.1 1/min.

Thus, with the combination of turbine meter and rotameters, air flow rates from 0.056 to $4530 \mathrm{l} / \mathrm{min}$ could be measured individually out of each separation tank.

All air rotameters were calibrated using a positive-displacement gas flowmeter. A comparison between the present calibrations and the calibrations provided by the manufacturer showed a maximum deviation of approximately $\pm 5 \%$ at the lowest flow rates. Typical deviations of about $\pm 3 \%$ were observed. As well, all of the air rotameters were found to have a nearly linear relation between the measured flow rate and the scale reading. For the reduction of data, the present calibrations were used.

\subsubsection{Test Section}

A schematic diagram of the test section is shown in figure 3.3. The piping used for the construction of the test section was commercial type $\mathrm{K}$ copper tubing with a $37.6 \mathrm{~mm}$ I.D. The entire test section, including the two-phase mixer, was supported by a rigid steel frame. A survey level was 


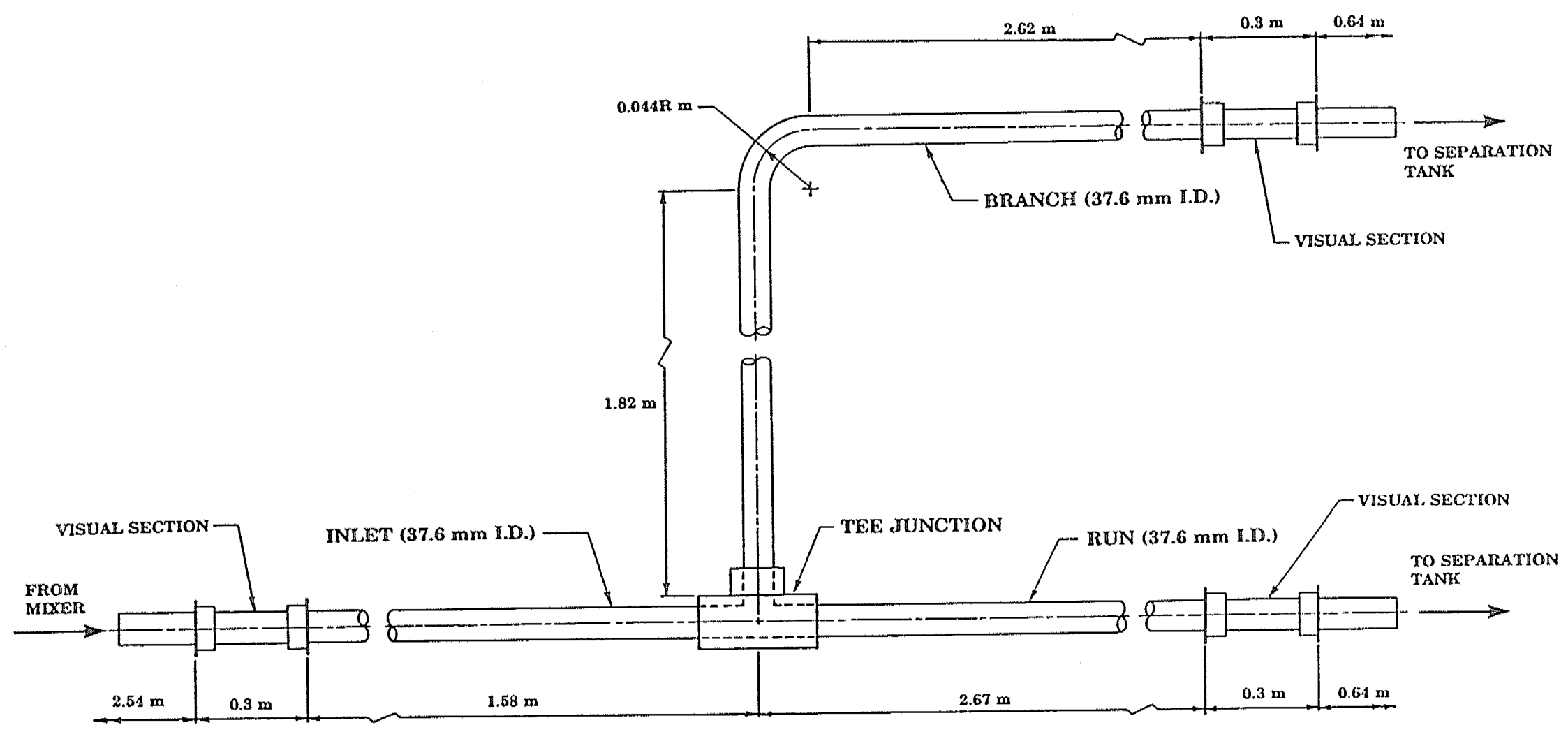

Figure 3.3 Schematic diagram of test section 
used to ensure horizontality of the test section. The following is a brief description of the major components in the test section:

\section{Visual Sections}

The inlet, run, and branch visual sections were identical to those used by Rubel [16, 20]. Each visual section (shown in figure 3.4) consisted of a 254$\mathrm{mm}$ long glass tube supported at both ends by specially machined stuffing boxes. The design of the glass tube and stuffing boxes were such that the inside diameter of the glass tube and stuffing boxes were identical to the inside diameter of the copper tubing entering and exiting each visual section. This eliminated any disturbance to the flow. After assembly, a clear length of about $150 \mathrm{~mm}$ was available in each visual section for flow-regime identification. Since the inside diameter of commercial (off-the-shelf) glass tubing did not match that of the copper tubing, custom-manufactured glass tubing was used. This also allowed for the selection of a thick-wall $(3.45 \mathrm{~mm})$ glass tubing. In assembling each visual section, extreme care was taken to ensure alignment and coaxiality between the copper tubing, stuffing boxes, and the glass tube. The entire assembly was enclosed by a plastic protective shield to guard against injury in case of fracture of the glass tubing. 


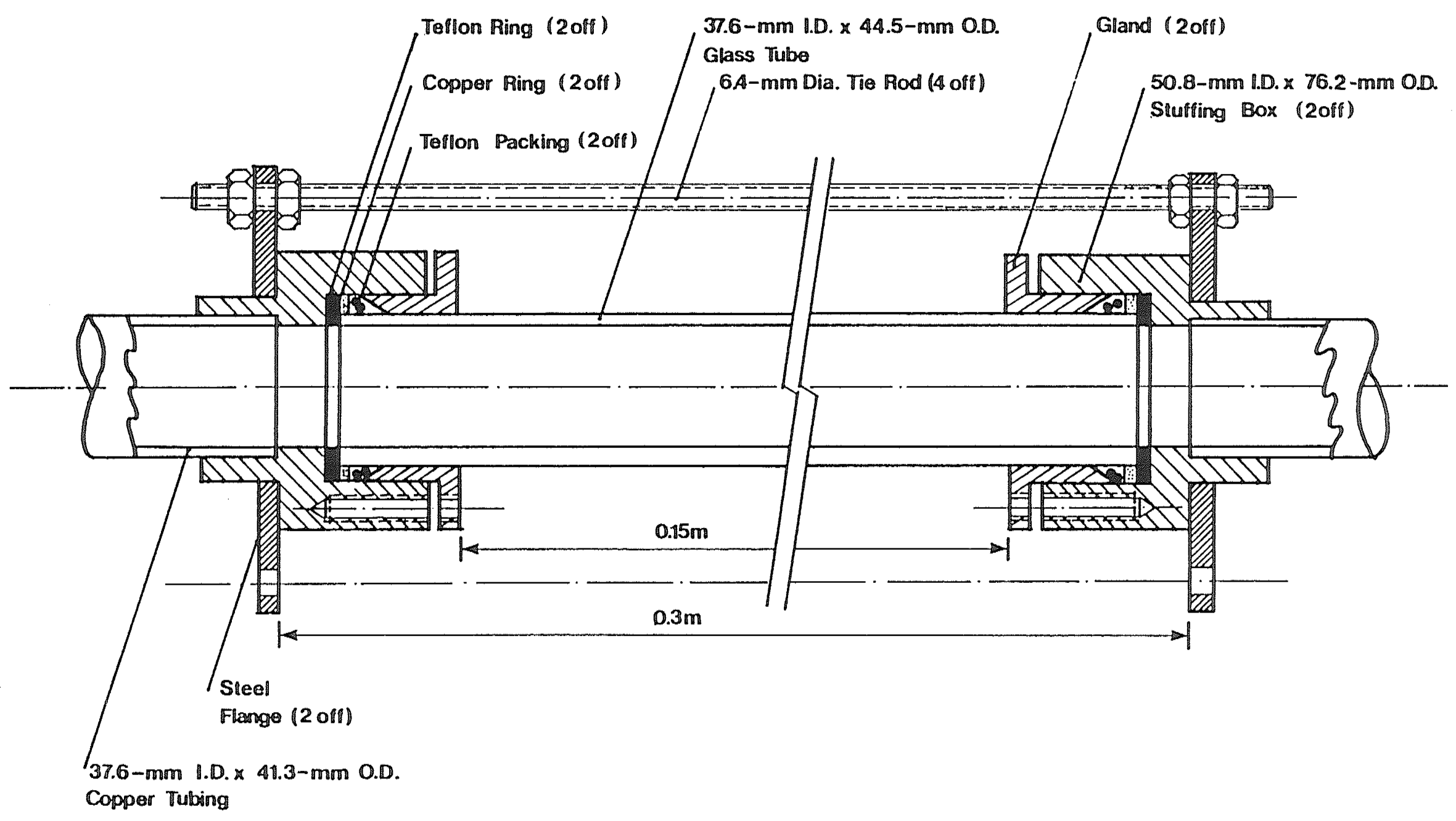

Figure 3.4 Construction details of visual section; reproduced from Rubel [16] 


\section{Tee Junction}

In order to ensure consistency with other research laboratories, a square-edged tee was used. This tee was identical to that used by Rubel [16, 20]. The tee junction, shown in figures 3.5 and 3.6, consisted of two main components: a main body and a branch section. The main body was machined from a $63.5 \mathrm{~mm}$ square brass bar, $126 \mathrm{~mm}$ long. This length was chosen to allow the inlet and run copper tubing to mate with the tee junction for $38 \mathrm{~mm}$, thus maintaining the coaxiality of the assembly. The branch section was machined from a $76-\mathrm{mm}$ diameter brass rod, $44.5 \mathrm{~mm}$ long. On assembly, the branch section fitted into the main body as shown in figure 3.5. Four concentric holes were drilled through the branch section and into the main body, where holes were tapped. An O-ring, placed between the branch and main body sections, eliminated any leaks when four bolts securely tightened the two sections together.

Since the heat required to solder the copper tubing into the tee junction could have resulted in permanent deformation of the tee, a retaining-sealing compound (LOCTITE RC/609) was used to bond the tubes into the brass. Testing of this compound showed excellent sealing of copper tubing with air pressures up to $375 \mathrm{kPa}$. 


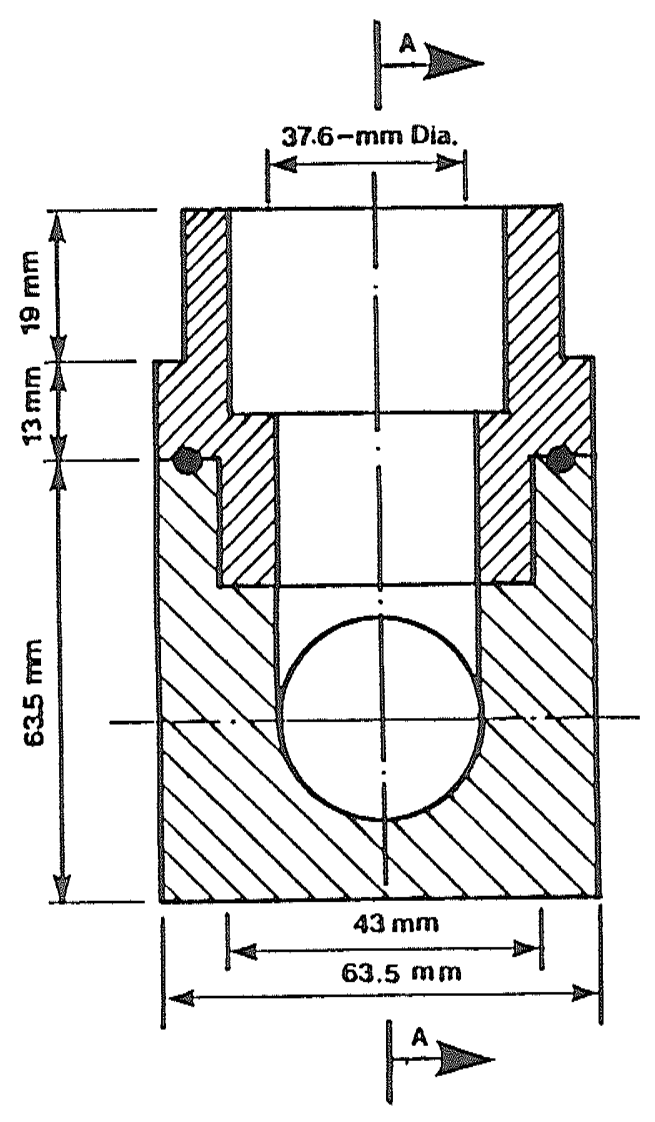

Sectional View $B-B$

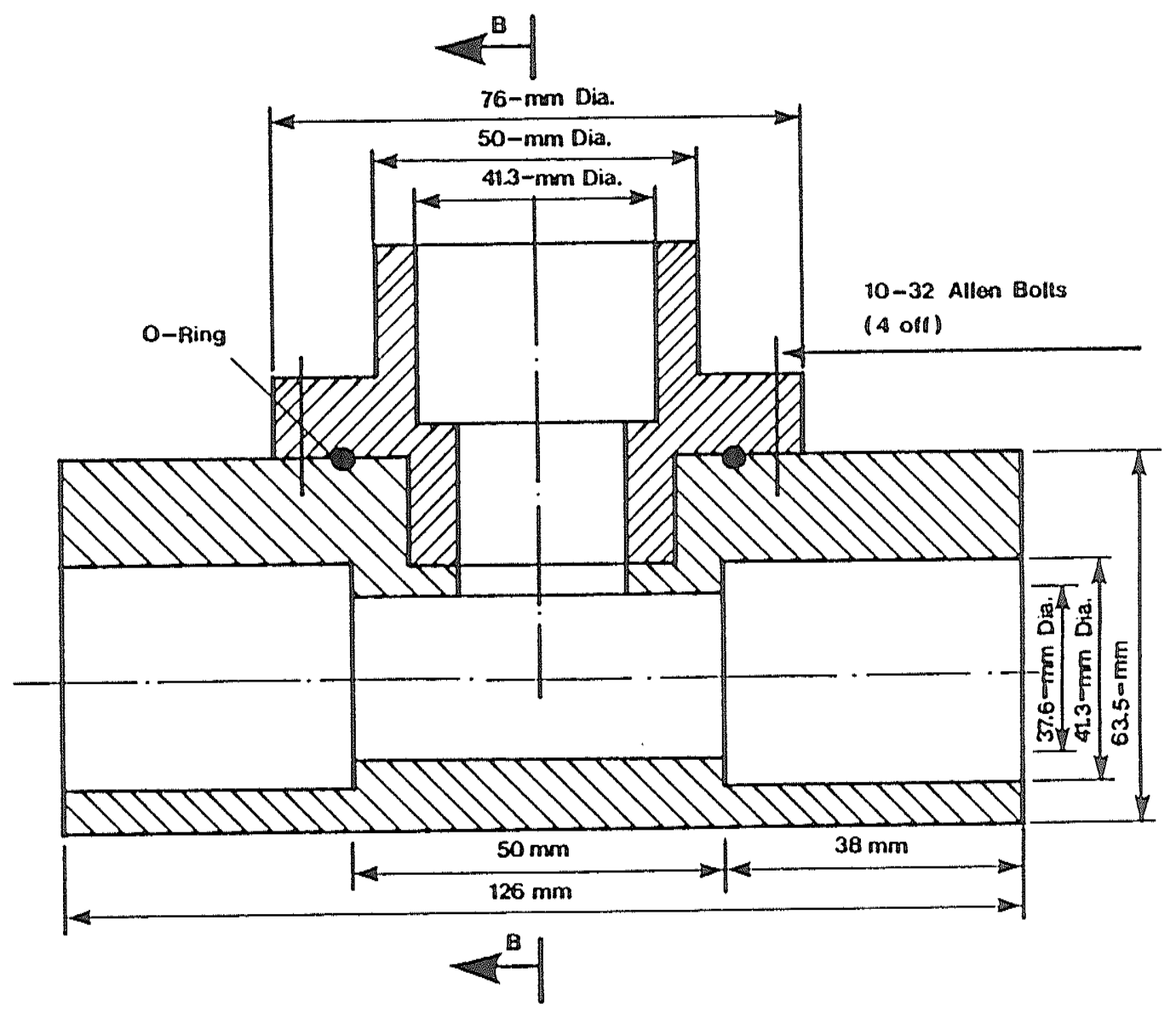

Sectional View A-A

Figure 3.5 Cross-sectional views of the tee junction; reproduced from Rubel [16] 


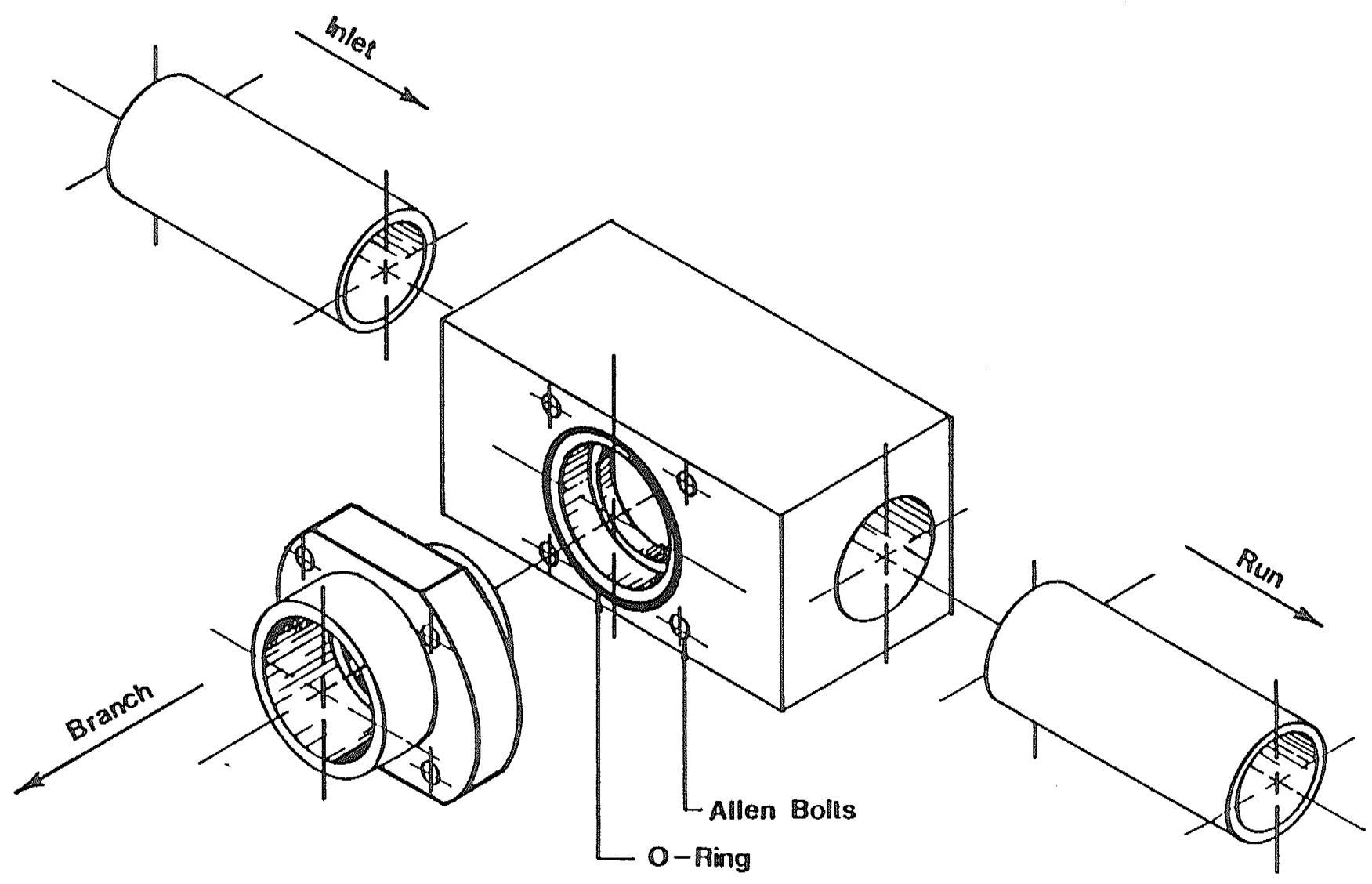

Figure 3.6 Isometric view of the tee junction; reproduced from Rubel [16] 


\section{Pressure Taps}

Forty-one pressure taps were located along the inlet, run, and branch sides of the test section, as shown in figure 3.7. Each pressure tap contained a $1.6-\mathrm{mm}$ hole drilled through the tube wall. After drilling, all taps were filed to ensure that no burrs protruded into the inside of the tube. Hose nipple fittings were soldered onto the outside of the copper tube to facilitate connection of the taps to differential pressure transducers (described in detail in a later section) used to measure the pressure distribution in the test section. Clear plastic tubing (Tygon) was used to connect the pressure taps to the pressure transducers. The pressure taps were located along the bottom side of the test section in order to avoid air entrapment in the plastic tubing pressure lines, which were filled with distilled water.

\subsubsection{Separation Tanks}

The two-phase mixture flowing in both the run and the branch discharged into separation tanks located downstream of the test section. Both the branch and the run tanks, shown in figure 3.8, are identical in design. The two-phase mixture entering from the top of each separation tank was separated using centrifugal action. This was achieved by forcing the flow through two, 25.4-mm nozzles angled to discharge the flow in a downward 


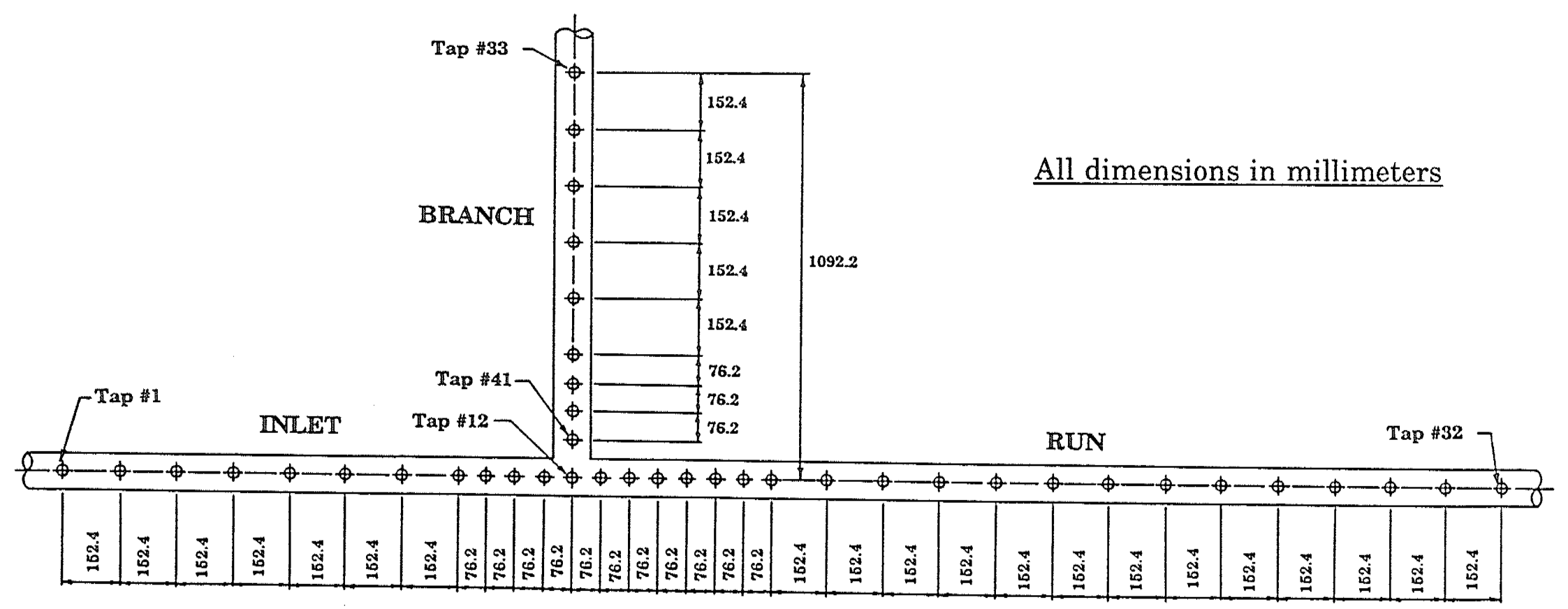

Figure 3.7 Location of pressure taps 


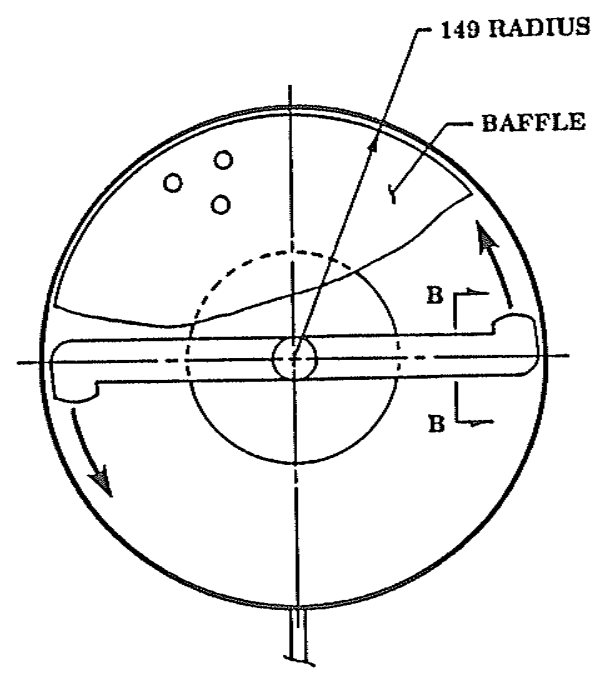

SECTION A-A

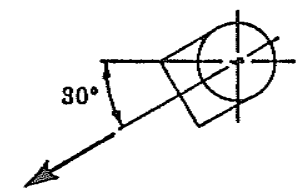

VIEW B-B

All dimensions in millimeters

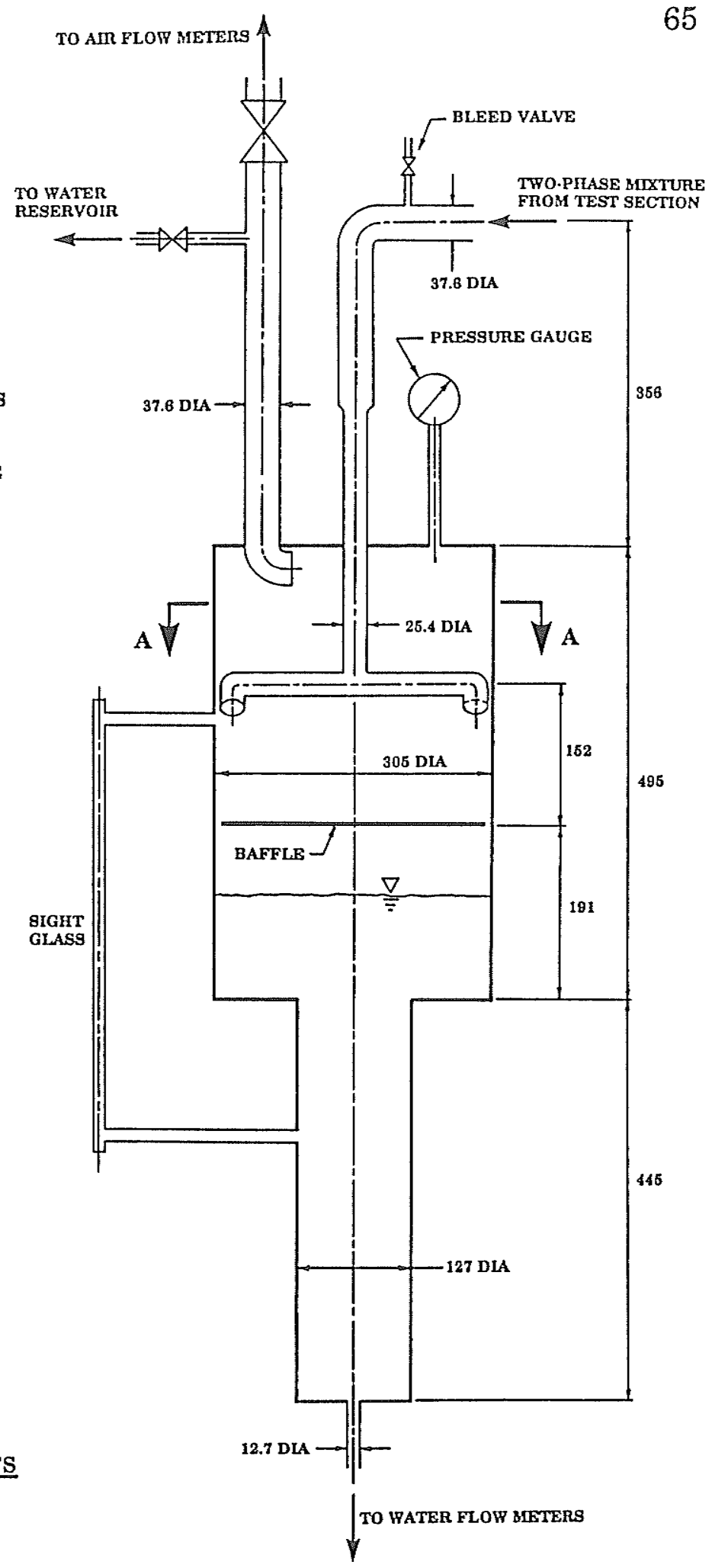

Figure 3.8 Details of one separation tank 
spiralling direction. Water exiting from the nozzles flowed along the tank wall where it drained downward. Air flowed out through the top of each separation tank. A baffle located above the gas-liquid interface isolated the interface from the flow above it. The baffle, a circular disk perforated with many small (4.8 $\mathrm{mm}$ ) holes, had a diameter smaller than that of the inside of the separation tank. This left a gap of $3.2 \mathrm{~mm}$ for the liquid on the tank wall to flow downward through.

The tanks incorporated an abrupt change in cross-sectional area at about mid height. If the liquid flow rate into one particular tank was low, the gas-liquid interface in that tank was maintained in the smaller diameter section. This was the case for all of the test runs, except for the highest liquid flow rate where the interface was maintained in the large diameter section. This procedure decreased the errors in measuring the outlet liquid flow rate resulting from small changes in the height of the interface.

The separation tanks were constructed from steel-pipe sections with flanges welded and bolted to each end. The entire assembly, including the end flanges, was galvanized to prevent corrosion and all fittings connecting the steel tanks to copper tubing were "Dielectric Unions". A 480-mm long sight glass, used to visually observe the liquid level in the tank, was installed vertically with a scale. 


\subsubsection{Temperature Measurement}

Temperature measurements were obtained using iron-constantan (type T) thermocouples at seven locations throughout the flow loop (see figure 3.1 for locations). All thermocouples were connected to a selector switch, which in turn was connected to a Fluke $2170 \mathrm{~A}$ digital thermometer. The digital thermometer was capable of accurate temperature measurement over a range between -99.8 and $400.0^{\circ} \mathrm{C}$. These temperatures were manually typed into a computer system for processing of the data.

The thermocouples and digital thermometer were calibrated as a single unit. This was achieved using a water bath and a precision mercury thermometer. Water bath temperatures of $0^{\circ} \mathrm{C}$ (ice point) and $100^{\circ} \mathrm{C}$ (boiling point), as well as intermediate temperatures measured using a mercury thermometer, were obtained using distilled water. A comparison between the

digital thermometer reading and the water bath temperature indicated a maximum deviation of $\pm 0.3^{\circ} \mathrm{C}$. A correction factor to be added to the digital thermometer reading was obtained. This correction factor was used in the reduction of all data. 


\subsection{Pressure Measurement}

\subsubsection{System Pressure}

For all two-phase test runs the absolute pressure in the test section was maintained near $150 \mathrm{kPa}$. This pressure was measured using a Rosemount differential pressure transducer, model 1151 DP 5A22MB. Figure 3.9 shows the location of this transducer. During this measurement, the high-pressure side of the transducer was connected to pressure tap 11 located on the inlet side of the tee junction (see figure 3.7), while the low-pressure side was open to the atmosphere. Thus, the transducer measured the gauge pressure within the test section. Tap 11 in the inlet was used rather than tap 12 (located at the centre of the junction) since during two-phase flow the pressure fluctuations at tap 11 were smaller than those at tap 12. The pressure transducer gave an output of 4 to $20 \mathrm{~mA}$ over a range of 0 to $187 \mathrm{kPa}$ gauge. The output current was converted into a voltage using a precision resistor installed within the current loop. The voltage drop across the resistor was fed into a channel in the digital acquisition system. The resistance of the resistor was chosen to give a 10 volt drop when the current from the transducer was $20 \mathrm{~mA}$. The transducer was calibrated using a mercury U-tube manometer. The calibration was found to be very linear. 


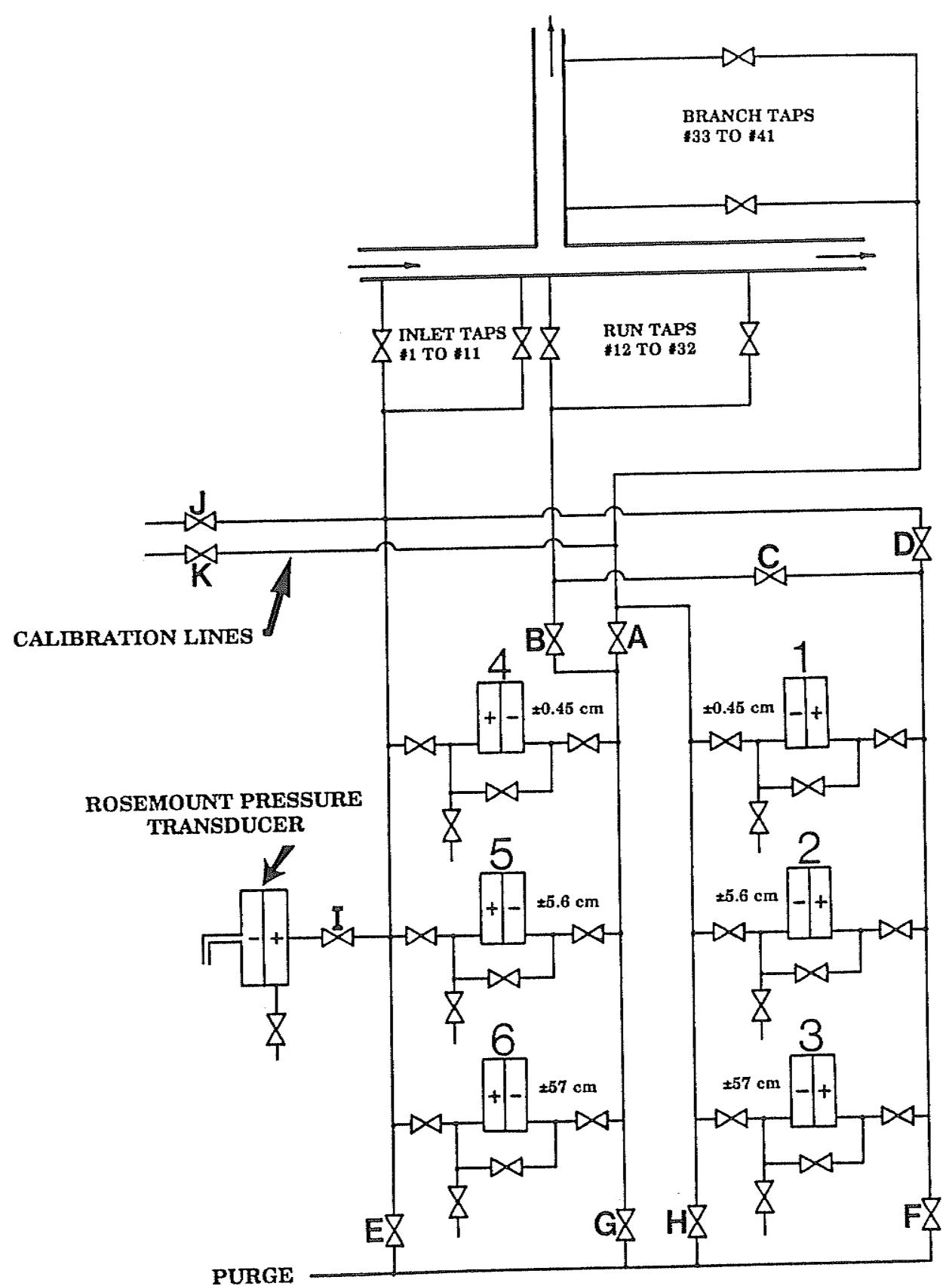

Figure 3.9 Pressure-drop measurement station 


\subsubsection{Pressure Distribution}

Figure 3.9 gives a schematic diagram of the pressure-drop measurement station. The station consisted of two banks of differential pressure transducers with three transducers in each bank. Both banks of transducers were identical. All six transducers were model DP103, manufactured by Validyne Engineering Corp. The DP103 was designed for very low differential pressure measurement. The range of this transducer can be changed by installing different stainless-steel diaphragms to give a maximum range of up to $\pm 880 \mathrm{~cm}$ of water. For this investigation, each bank of three transducers was set up with the following approximate ranges:

$\begin{array}{ll}\text { low-range transducer } & \pm 0.45 \mathrm{~cm} \text { water } \\ \text { medium-range transducer } & \pm 5.6 \mathrm{~cm} \text { water } \\ \text { high-range transducer } & \pm 57 \mathrm{~cm} \text { water. }\end{array}$

Thus, the present set-up was capable of accurate differential pressure measurement over the range $\pm 57 \mathrm{~cm}$ of water. All transducers were calibrated using either a micromanometer or a U-tube oil manometer (specific gravity of 0.826). All calibrations were found to be very linear. Also, calibration of the transducers was repeated several times during testing. This was necessary because it was found that the calibrations of the transducers slowly changed with use.

The outputs from the transducers were processed by a six-channel carrier demodulator; Validyne Engineering Corporation model CD280-6. The 
output from the carrier demodulator was in the form of a \pm 10 volt DC signal. The six channels from the demodulator were fed into separate channels in the digital acquisition system.

The valving layout shown in figure 3.9 allowed the various pressure tap lines to be isolated and connected to the pressure transducers. The highpressure sides of transducers 4,5 , and 6 were connected to the inlet pressure taps, while the low pressure sides were connected to either the run or the branch pressure taps, depending on the settings of valves $\mathbf{A}$ and $\mathbf{B}$. The high pressure sides of transducers 1,2 , and 3 were connected to either the inlet or the run pressure taps, depending on the settings of valves $\mathbf{C}$ and $\mathbf{D}$, while the low pressure sides were connected to the branch pressure taps. Other valves allowed for the purging of the system (to remove air) and also for the calibration of the pressure transducers.

All pressure lines from the pressure taps to the transducers were filled with distilled water. The pressure lines were clear $3.2 \mathrm{~mm}$ Tygon tubing. This allowed for visual inspection to ensure that no air was trapped in the lines.

\subsection{Data-Acquisition System}

Voltage signals from the turbine meters and the pressure transducers were fed into a data acquisition system. The data acquisition system consisted of an 80286-based microcomputer with two plug-in analog-to-digital (A/D) 
boards. Both A/D boards were model DAS-16G1, manufactured by MetraByte Corporation. Each DAS-16G1 was set up with 8 differential analog input channels, giving a total capacity of 16 input channels. The DAS-16G1 was designed for high speed (up to 70000 samples per second) A/D conversion with 12-bit resolution. A computer program was written to control the gathering and reduction of data during experimental runs.

\subsection{System Operation and Data Reduction}

\subsubsection{Two-Phase Flow \\ Start-Up and Steady-State}

Several steps were required to start up the flow loop. The following is a list of steps, in order, which were performed each time the loop was run for a two-phase flow test (reference should be made to figure 3.1, except where noted):

1. The computer system, turbine meter and pressure transducer power supplies, and digital thermometer were switched on.

2. Valve I and tap 11 (see figure 3.9) were opened to connect the Rosemount pressure transducer to the test section inlet.

3. Gas valves at the discharge of the separation tanks (valves $\mathbf{1 1}$ and $\mathbf{1 6}$ ) were checked to ensure that they were open. By-pass valves to inlet, run, and branch air turbine meters (valves 3,13 , and 18) were closed. The by-pass valve to the inlet water turbine meters (valve 6) was closed. 
The inlet water control valves were closed (valves $\mathbf{5 a}$ and $\mathbf{5 b}$ ) and the water by-pass control valve (valve 4) was fully opened.

4. Control valves to the run and branch air turbine meters (valves 14a or $14 b$, and $19 a$ or $19 b$ ) were partially opened. The valves to the desired inlet water turbine meter (valves $\mathbf{7}$ and $\mathbf{8}$, or $\mathbf{9}$ and $\mathbf{1 0}$ ) were opened.

5. The valve to the air compressor (valve 1) was opened. The pressure regulator outlet pressure was adjusted to approximately $140 \mathrm{kPa}$ gauge.

6. The inlet air control valve (valve $\mathbf{2 a}$ or $\mathbf{2 b}$ ) was gradually opened to give approximately the desired air flow rate through the loop.

7. Control valves to the run and branch air turbine meters (valves $\mathbf{1 4 a}$ or $14 b$, and $19 a$ or $19 b$ ) were adjusted simultaneously with the inlet air control valve (valve $\mathbf{2 a}$ or $\mathbf{2 b}$ ) to give the desired air flow rate through the loop at a test section pressure of 1.5 bar abs, and at the proper extraction rate. If the flow rate through either the run or the branch turbine meter was too low (output from the turbine meter below approximately 0.2 volts), then that turbine meter was shut down by closing the control valve (valves $14 \mathbf{a}$ or $14 \mathrm{~b}$, and/or $19 \mathrm{a}$ or $19 \mathrm{~b}$ ) to the turbine meter. The appropriate air rotameters were then activated to measure the air flow rate. This was achieved by opening valve 12 on the run side, and/or valve $\mathbf{1 7}$ on the branch side.

8. The water pump was switched on. 
9. The water bypass control valve (valve 4 ) was slowly closed until the pump outlet pressure reached approximately $140 \mathrm{kPa}$ gauge.

10. The inlet water control valve (valve $\mathbf{5} \mathbf{a}$ or $\mathbf{5 b}$ ) was slowly opened to give the desired water flow rate, while maintaining the pump outlet pressure at $140 \mathrm{kPa}$ gauge using the water bypass control valve (valve 4).

11. When the liquid levels in the separation tanks began to rise the appropriate liquid flowmeters were activated to keep the liquid levels in the tanks steady.

12. The cooling water supply to the water reservoir heat exchanger was turned on, and the cooling water flow rate was set to give a test section temperature near $21.3^{\circ} \mathrm{C}\left(70^{\circ} \mathrm{F}\right)$.

13. If the test section pressure was now too high, then it was restored to 1.5 bar abs by slowly opening the air control valves (valves $14 \mathbf{a}$ or $14 \mathbf{b}$, and 19a or $19 b$ ) to the run and branch turbine meters (or the control valves to the run and/or branch air rotameters, valves $23 \mathbf{a - d}$ and/or $\mathbf{2 4} \mathbf{a - d}$, if they were being used instead). Since this affected the inlet air and water flow rates, the process of having the correct inlet flow rates and the correct test section pressure was an iterative procedure. The liquid level in the separation tanks was kept steady by adjusting the proper liquid flowmeters using valves 15 a-e and 20 a-e.

14. With the correct inlet flow rates and test section pressure now set, and with the liquid level in the separation tanks steady, the extraction rate was checked. If $\mathrm{W}_{3} / \mathrm{W}_{1}$ was different from the desired value, then it was 
adjusted by using the air control valves (valves $14 \mathbf{a}$ or $14 \mathbf{b}$, and $19 \mathrm{a}$ or 19b) to the run and branch turbine meters (or valves 23 a-d and/or 24 a-d to the air rotameters if they were being used instead). Adjustments were done in such a way as to maintain the correct test section pressure of 1.5 bar abs, thus, the inlet flow rates were unchanged by these adjustments. The liquid level in the separation tanks was steadied by adjusting the proper liquid flowmeters using valves 15 a-e and 20 a-e. The extraction rate was checked again, and if it was still incorrect, then it was re-adjusted using the above procedure.

15. The cooling water flow rate to the water reservoir heat exchanger was re-adjusted to maintain the test section temperature near $21.3^{\circ} \mathrm{C}\left(70^{\circ} \mathrm{F}\right)$. Typically, the system required about 1-1/2 hours of continuous adjustment to achieve the desired test conditions. After the desired test conditions were set, it was very important that steady-state was reached before any data were recorded. Data were not taken until the following conditions were steady for at least 15 minutes:

1. The liquid level in the separation tanks

2. The test section temperature

3. All flow rates

4. The test section pressure.

All flow rates, temperatures, pressures, and the liquid level in the separation tanks were continuously monitored while data were being recorded. Fine adjustments were made as needed to ensure that these parameters did 
not drift during the process of data recording. Changes in the flow rates, extraction rate, and test section temperature and pressure were limited during data recording to approximately \pm 2 percent of the initial set values. Usually, the system required an additional three hours of operation to record all phasedistribution and pressure-drop data.

\section{Recording of Phase-Distribution Data}

Once the system achieved steady-state, the phase-distribution data were recorded. These data consisted of the following measurements:

1. The pressure in $\mathrm{kPa}$ gauge and the temperature in ${ }^{\circ} \mathrm{C}$ immediately downstream from the inlet air turbine meter.

2. The average voltage output from the inlet air turbine meter.

3. The temperature in ${ }^{\circ} \mathrm{C}$ at the inlet water turbine meters.

4. The average voltage output from the appropriate inlet water turbine meter.

5. The average voltage from the Rosemount pressure transducer.

6. The temperatures of the water entering the run and branch water rotameters in ${ }^{\circ} \mathrm{C}$.

7. The water flow rate through the run and branch rotameters in height of float in $\mathrm{mm}$. 
8. The temperature in ${ }^{\circ} \mathrm{C}$ and the average voltage from the run air turbine meter if being used; otherwise, the temperature in ${ }^{\circ} \mathrm{C}$ and the air flow rate in height of float in $\mathrm{mm}$ for the run air rotameters.

9. The temperature in ${ }^{\circ} \mathrm{C}$ and the average voltage from the branch air turbine meter if being used; otherwise, the temperature in ${ }^{\circ} \mathrm{C}$ and the air flow rate in height of float in $\mathrm{mm}$ for the branch air rotameters.

10. The atmospheric pressure in the laboratory in $\mathrm{mm} \mathrm{Hg}$.

11. The observed flow regimes at the inlet, run, and branch visual sections based on the descriptions given later in this section.

12. The operating pressure of the air compressor in $\mathrm{kPa}$ gauge.

The average voltages from the turbine meters and the Rosemount pressure transducer were obtained from samples taken over 30 seconds at a rate of 10 samples per second. Preliminary tests indicated that this sampling procedure gave sufficient accuracy. The data were then reduced as outlined later in this section.

\section{Recording of Pressure-Distribution Data}

Once the phase-distribution data were recorded, the pressure distribution in the test section was measured. The following is a description of the procedure that was used to measure the pressure distribution. The layout of the pressure taps is given in figure 3.7 , while the pressure transducers and the 
associated valving are given in figure 3.9. The following description assumes that all valves shown in figure 3.9 were initially closed.

1. The voltage output from each transducer was adjusted to zero with an applied differential pressure of zero. This was accomplished by separately monitoring the instantaneous voltage output from each transducer, with the bypass valve opened and all other valves closed. The voltage outputs from the transducers were adjusted to zero using the appropriate "zero" adjustment on the carrier demodulator.

The run and branch pressure-distribution data were obtained first. The procedure is described in steps 2 through 9 below.

2. Tap $\mathbf{1}$ in the inlet was opened.

3. Valve $\mathbf{B}$ was opened to connect transducers 4,5 , and 6 to the run pressure taps.

4. Valve $\mathbf{D}$ was opened to connect transducers 1,2 , and 3 to the inlet pressure taps.

5. Tap 32 in the run, and tap $\mathbf{3 3}$ in the branch were opened.

6. The pressure signal from the inlet and run pressure taps was directed to pressure transducer 6 , and the instantaneous voltage was monitored. If the voltage reading from the transducer remained within \pm 1 volt, then the pressure signal was then routed to transducer 5 . If the voltage reading from transducer 5 remained within \pm 1 volt, then the pressure signal was routed to transducer 4 . This procedure ensured that the 
transducer with the optimum range for measuring the pressure difference was always used.

7. The pressure signal from the inlet and branch pressure taps was directed to transducer 1,2 , or 3 . The optimum range transducer to read the signal was obtained using a similar procedure to step 6 .

8. Once the optimum-range transducers were found, the average voltages from the two transducers were recorded.

9. Steps 6 and 7 were repeated until all pressure taps in the branch and run were measured with respect to tap $\mathbf{1}$ in the inlet.

The inlet pressure-distribution data were obtained next. The procedure is given in steps 10 through 13 below.

10. Tap 32 in the run, tap 33 in the branch, and tap 1 in the inlet were opened.

11. The pressure signal from the inlet and run pressure taps was directed to the optimum-range transducer (transducer 4,5 , or 6 ) and the pressure signal from the inlet and branch pressure taps was directed to the optimum-range transducer (transducer 1, 2, or 3).

12. The average voltages from the two transducers were recorded.

13. Steps 11 and 12 were repeated until all pressure taps in the inlet were measured with respect to tap $\mathbf{3 2}$ in the run and tap $\mathbf{3 3}$ in the branch.

This completed the measurement of the pressure distribution in the test section. However, before the pressure distribution data were accepted, the 
proper operation of the transducers and the associated valving was verified using the following procedure:

14. Valves $\mathbf{B}$ and $\mathbf{D}$ were closed, and valve $\mathbf{C}$ opened. Valve $\mathbf{1 6}$ in the run, and valve $\mathbf{3 3}$ in the branch, were opened. The average voltage was then read using the optimum range transducer (transducer 1,2, or 3).

15. Step 14 was repeated with valve $\mathbf{1 6}$ in the run, and different valves in the branch opened. This gave data for the branch pressure distribution, independent of the branch pressure-distribution data obtained in steps 2 through 13.

16. The final procedure was to check the agreement between the different transducers used during the test by applying the same differential pressure to both banks of transducers. This was achieved by closing valve $\mathbf{C}$, and opening valves $\mathbf{A}$ and $\mathbf{D}$. A pressure tap in the inlet and a tap in the branch were opened. The average voltages from the different transducers were then recorded.

The average voltages from the transducers were obtained from samples taken over 120 seconds at a rate of 100 samples per second. The average voltages were then converted into average differential pressures using the appropriate calibration equations. The branch pressure-distribution data obtained during steps 14 and 15 were plotted along with the data from steps 2 through 13. If agreement between the two independent sets of data was unacceptable, then all of the pressure-distribution data were rejected. The 
agreement between the different transducers used during the test was checked in step 16. If the agreement between the transducers was within approximately $\pm 2 \%$, then the pressure-distribution data were temporarily accepted, otherwise all data were rejected. Finally, the inlet pressure distribution obtained using transducers 1,2 , and 3 was compared to the inlet pressure distribution obtained using transducers 4,5 , and 6 . Again, if the agreement was good, then the data were accepted, otherwise all data were rejected.

\section{Reduction of Phase-Distribution Data}

The phase-distribution data recorded during each test were reduced using the following procedure:

1. The mass flow rates $\mathrm{W}_{\mathrm{L} 1}, \mathrm{~W}_{\mathrm{G} 1}, \mathrm{~W}_{\mathrm{L} 2}, \mathrm{~W}_{\mathrm{G} 2}, \mathrm{~W}_{\mathrm{L} 3}$, and $\mathrm{W}_{\mathrm{G} 3}$ were calculated using the calibration curve of the appropriate device and the corresponding readings of pressure and/or temperature. The pressures at the run and branch turbine meters and air rotameters were assumed to be atmospheric.

2. The test-section temperature was calculated using an energy balance as outlined in Appendix A.

3. The test-section flow rates $\mathrm{W}_{\mathrm{L} 1}, \mathrm{~W}_{\mathrm{L} 2}, \mathrm{~W}_{\mathrm{L} 3}, \mathrm{~W}_{\mathrm{G} 1}, \mathrm{~W}_{\mathrm{G} 2}$, and $\mathrm{W}_{\mathrm{G} 3}$ were corrected for evaporation using the procedure outlined in Appendix A. This procedure was used to correct flow rates for evaporation of the 
liquid phase in the mixer, test section, and separation tanks. For $J_{G 1}=40$ $\mathrm{m} / \mathrm{s}$ and $J_{L 1} \leq 0.0023 \mathrm{~m} / \mathrm{s}$, these corrections were found to be significant with up to $20 \%$ of the water entering the mixer evaporating. At lower $J_{G 1}$ and higher $\mathrm{J}_{\mathrm{L} 1}$ these corrections were found to be insignificant.

4. The total inlet, run, and branch flow rates were determined by

$$
\begin{aligned}
& W_{1}=W_{G I}+W_{L L}, \\
& W_{2}=W_{G 2}+W_{L 2},
\end{aligned}
$$

and

$$
W_{3}=W_{G 3}+W_{L 3} \text {. }
$$

5. The inlet, run, and branch qualities were computed as

$$
\begin{aligned}
& x_{1}=\frac{W_{G I}}{W_{1}}, \\
& x_{2}=\frac{W_{G 2}}{W_{2}},
\end{aligned}
$$

and

$$
x_{3}=\frac{W_{G 3}}{W_{3}} .
$$

6. Overall mass balances were performed individually on both the air and water. This was achieved by comparing the total mass flow rate of the phase leaving the flow loop with the inlet mass flow rate of the phase.

7. The following parameters were calculated for all tests: 


$$
\begin{gathered}
G_{1}=\frac{W_{1}}{\left(\frac{\pi D_{1}^{2}}{4}\right)}, \\
J_{G 1}=\frac{G_{1} x_{1}}{\rho_{G I}},
\end{gathered}
$$

and

$$
J_{L 1}=\frac{G_{1}\left(1-x_{1}\right)}{\rho_{L 1}} .
$$

8. The fraction of total gas entering the branch and the fraction of total liquid entering the branch were found from

$$
F_{B G}=\frac{W_{G 3}}{W_{G I}},
$$

and

$$
F_{B L}=\frac{W_{L 3}}{W_{L 1}} .
$$

12. The extraction rate $\mathrm{W}_{3} / \mathrm{W}_{1}$ and the ratio of the branch to inlet quality $\mathrm{x}_{3} / \mathrm{x}_{1}$ were computed.

\section{Reduction of Pressure-Distribution Data}

The junction pressure drops were determined by extrapolating the fully developed pressure gradients in the inlet, run, and branch to the centre of the tee junction, as was shown in figure 1.3. Linear equations were fit to the fully 
developed data in the inlet, run, and branch using the method of least-squares analysis. The pressure drops due to the tee junction were defined as

$$
\Delta P_{1 i}=P_{1}-P_{i}
$$

where $i=2$ for the run and $i=3$ for the branch. Details are given in Appendix B.

\section{Flow Regimes}

For horizontal two-phase flow, the two phases will distribute themselves into various flow regimes. Classification of the observed flow regime, especially in the inlet, is extremely important. In this investigation the flow regime type was observed for all three sides of the tee junction. The following is a description of the different flow regimes observed in this investigation. These flow regimes are shown in figure 3.10 .

Stratified : The liquid flows along the bottom of the tube and the gas along the top of the tube with a smooth interface.

Wavy : The two phases are separated with liquid flowing along the bottom of the tube and the gas along the top of the tube. The velocity difference between the gas and the liquid causes the interface to be wavy.

Annular : The liquid flows as a stable film covering the entire tube wall. The gas flows through the core. Part of the liquid phase may be 

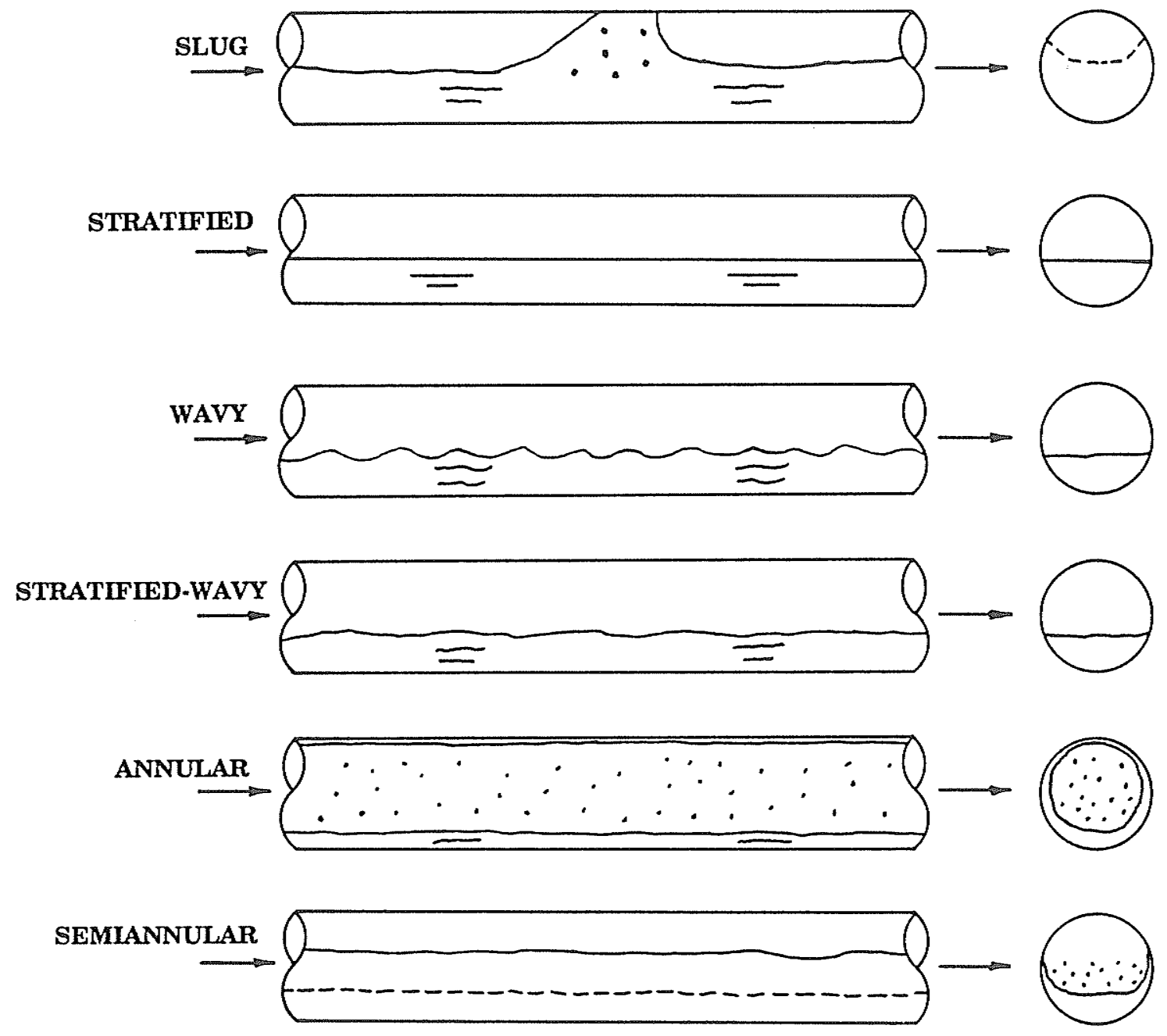

Figure 3.10 Schematic diagrams of observed flow regimes 
entrained as droplets in the gas phase. The liquid film thickness increases around the periphery with a maximum thickness at the bottom of the tube.

Semiannular : A transitional flow regime where the flow is similar in appearance to the annular flow regime, except that the stable film does not cover the entire tube periphery. The liquid film thickness increases to a maximum at the bottom of the tube, while the top of the tube appears dry.

Slug : Similar to wavy flow; however, surface waves frequently grow in size forming slugs that reach the top of the tube. The liquid slugs travel at high velocity and the frequency of their occurrence depends on flow conditions.

Stratified-wavy : A transitional flow regime where the gas-liquid interface is mainly stratified in appearance; however, small surface waves are present intermittently.

In the remaining part of the thesis, the names for the flow regimes are often abbreviated in order to conserve space. These abbreviations are as follows:

$\begin{array}{ll}\text { St } & \text { Stratified } \\ \text { W } & \text { Wavy } \\ \text { SA } & \text { Semiannular } \\ \text { An } & \text { Annular } \\ \text { S } & \text { Slug } \\ \text { St-W } & \text { Stratified-wavy. }\end{array}$




\subsubsection{Single-Phase Flow}

Start-Up and Steady.State

Single-phase-liquid tests were performed in order to obtain pressuredrop data. The single-phase pressure-drop data were used in the calculation of the various loss coefficients appearing in the pressure-drop models given in Chapter 2. The following is a list of the steps performed each time the loop was run for single-phase flow tests (refer to figure 3.1):

1. The computer system, turbine meter and pressure transducer power supplies, and digital thermometer were switched on.

2. Gas valves at the discharge of the separation tanks (valves $\mathbf{1 1}$ and $\mathbf{1 6}$ ) were closed. Gas bleed valves (valves $\mathbf{2 1}$ and $\mathbf{2 2}$ ) from both separation tanks were opened. The by-pass valve to inlet gas turbine meter (valve 3) was closed. The by-pass valve to the inlet water turbine meter (valve 6) was closed. The inlet water control valves were closed (valves $\mathbf{5 a}$ and 5b) and the water by-pass control valve was fully opened (valve 4).

3. The valves to the desired inlet water turbine meter (valves $\mathbf{7}$ and 8 , or 9 and 10) were opened.

4. The water pump was switched on.

5. The water bypass control valve was slowly closed until the pump outlet pressure was approximately $140 \mathrm{kPa}$ gauge. 
6. The inlet water control valve (valve $\mathbf{5 a}$ or $\mathbf{5} \mathbf{b}$ ) was slowly opened to give the desired water flow rate, while maintaining the pump outlet pressure at $140 \mathrm{kPa}$ gauge using the water bypass control valve (valve 4 ).

7. When all of the gas in the test section and both separation tanks was bled out of the system, the gas bleed valves were closed (valves $\mathbf{2 1}$ and 22) and the liquid flowmeters were activated to the desired level.

8. The cooling water supply to the water reservoir heat exchanger was turned on, and the cooling water flow rate was set to give a test section temperature near $21.3^{\circ} \mathrm{C}\left(70^{\circ} \mathrm{F}\right)$.

9. The inlet liquid flow rate and the extraction rate $\mathrm{W}_{3} / \mathrm{W}_{1}$ were checked. If $\mathrm{W}_{3} / \mathrm{W}_{1}$ was incorrect, then it was re-adjusted by using the control valves to the run and branch liquid rotameters (valves $\mathbf{1 5}$ and $\mathbf{2 0}$ ). The inlet liquid flow rate was adjusted using the water control valve (valve 5) and the water bypass control valve (valve 4), while maintaining the pump outlet pressure at $140 \mathrm{kPa}$ gauge.

Pressure-drop data were not taken until the test section temperature steadied at approximately $21.3^{\circ} \mathrm{C}$ and the inlet flow rate and extraction rate steadied at the desired values. All flow rates and temperatures were continually monitored while data were being recorded. Fine adjustments were made as needed to ensure that the flow rates, test section temperature, and extraction rate did not drift during the process of data recording. Changes in 
these parameters were limited during data recording to approximately \pm 2 percent of the desired set values.

\section{Recording and Reduction of Data}

Once the system achieved steady-state with the desired independent flow parameters, all flow rates and temperatures were recorded. This data consisted of the following measurements:

1. The temperature in ${ }^{\circ} \mathrm{C}$ at the inlet water turbine meters.

2. The average voltage output from the appropriate inlet water turbine meter.

3. The temperature of the water entering the run and branch water rotameters in ${ }^{\circ} \mathrm{C}$.

4. The water flow rate in the run and branch rotameters in height of float in $\mathrm{mm}$.

The average voltage from the turbine meter was obtained from samples taken for 30 seconds at a rate of 10 samples per second. Preliminary tests showed that this sampling procedure gave sufficient accuracy.

The mass flow rates $\mathrm{W}_{\mathrm{L} 1}, \mathrm{~W}_{\mathrm{L} 2}$, and $\mathrm{W}_{\mathrm{L} 3}$ were calculated using the calibration curve of the appropriate device and the corresponding readings of temperature. The single-phase pressure-drop data were measured and reduced using the same procedure as for the two-phase test runs, and is outlined in section 3.4.1. 


\section{Chapter 4}

\section{RESULTS AND DISCUSSION}

\subsection{Data Range}

In the present experimental investigation, a total of seven single-phase water and 76 two-phase air-water test runs were performed. Table 4.1 shows the range of operating conditions for the two-phase test runs, and Table 4.2 shows the range of operating conditions for the single-phase test runs. The reduced experimental results for both the single-phase and two-phase test runs are tabulated in Appendix C.

The two-phase test runs comprise a total of 15 groups. Data points within a particular group have the following characteristic operating conditions: fixed $\mathrm{J}_{\mathrm{G} 1}$ and $\mathrm{J}_{\mathrm{L} 1}$, and fixed test section pressure and temperature. As well, the inlet flow regime remained fixed within each group. For all test runs the nominal test section temperature and pressure were $21.3^{\circ} \mathrm{C}\left(70^{\circ} \mathrm{F}\right)$ and 1.5 bar abs, respectively. Thus within each group, the extraction rate was the only parameter which was varied. Actual temperature and pressure for individual test runs were maintained for most test runs within $\pm 2^{\circ} \mathrm{C}$ and \pm 0.1 bar of the nominal value, respectively. Within each group, the actual $J_{G 1}$ and $\mathrm{J}_{\mathrm{L} 1}$ were maintained within $\pm 5 \%$ of the average values for the group for over $95 \%$ of the test runs, with the largest deviation occurring at the lowest $\mathrm{J}_{\mathrm{G} 1}$ or $\mathrm{J}_{\mathrm{L} 1}$ 
Table 4.1

Ranges of Operating Conditions for the Two-Phase Test Runs

\begin{tabular}{|l|c|}
\hline Total number of runs & 76 \\
\hline Inlet flow regimes & $\mathrm{St}$ \\
& $\mathrm{W}$ \\
& $\mathrm{S}$ \\
& $\mathrm{St}-\mathrm{W}$ \\
& $\mathrm{SA}$ \\
& $\mathrm{An}$ \\
\hline Inlet temperature $\mathrm{T}_{1}\left({ }^{\circ} \mathrm{C}\right)$ & 21.3 \\
\hline Inlet pressure $\mathrm{P}_{1}(\mathrm{bar}$ abs $)$ & 1.5 \\
\hline Inlet superficial gas velocity $\mathrm{J}_{\mathrm{G} 1}(\mathrm{~m} / \mathrm{s})$ & $2.7-41$ \\
\hline Inlet superficial liquid velocity $\mathrm{J}_{\mathrm{L} 1}(\mathrm{~m} / \mathrm{s})$ & $0.0021-0.181$ \\
\hline Inlet mass flux $\mathrm{G}_{1}\left(\mathrm{~kg} / \mathrm{m}^{2} \mathrm{~s}\right)$ & $7-259$ \\
\hline Inlet quality $\mathrm{x}_{1}(\%)$ & $2.6-97.6$ \\
\hline Extraction rate $\mathrm{W}_{3} / \mathrm{W}_{1}$ & $0.1-0.9$ \\
\hline \hline
\end{tabular}

Table 4.2

Ranges of Operating Conditions for the Single-Phase Test Runs

\begin{tabular}{||l|c||}
\hline \hline Total number of runs & 7 \\
\hline Inlet liquid velocity $(\mathrm{m} / \mathrm{s})$ & 0.180 \\
\hline Inlet Reynolds number Re & 6450 \\
\hline Inlet mass flux $\mathrm{G}_{1}\left(\mathrm{~kg} / \mathrm{m}^{2} \mathrm{~s}\right)$ & 168 \\
\hline Inlet temperature $\mathrm{T}_{1}\left({ }^{\circ} \mathrm{C}\right)$ & 21.3 \\
\hline Extraction rate $\mathrm{W}_{3} / \mathrm{W}_{1}$ & $0.0-1.0$ \\
\hline
\end{tabular}


The data given in Appendix $\mathrm{C}$ include tabulated values for the mass balance errors. The mass balance error for a particular phase corresponds to the percentage deviation between the inlet flow rate and the sum of the outlet flow rates from both separation tanks, corrected for evaporation. Considering the mass flow rate balance on the air, for all of the two-phase flow test runs the mass balance was maintained within $\pm 9 \%$ ( $\pm 5 \%$ for $82 \%$ of the test runs). For a mass flow rate balance on the water, for all of the two-phase flow test runs the mass balance was maintained within $\pm 7 \%( \pm 5 \%$ for $97 \%$ of the test runs). Mass balance errors were typically largest at the lowest mass flow rates.

All single-phase water test runs were performed at a nominal inlet liquid velocity of $0.180 \mathrm{~m} / \mathrm{s}$. The actual inlet liquid velocity was maintained within $\pm 0.2 \%$ of the nominal value, for all single-phase test runs. The nominal test section temperature was $21.3^{\circ} \mathrm{C}\left(70^{\circ} \mathrm{F}\right)$, with the actual temperature deviating at most $\pm 0.2^{\circ} \mathrm{C}$ from the nominal value. Again, the extraction rate was the only parameter which was varied.

Figure 4.1 shows the nominal $\mathrm{J}_{\mathrm{G} 1}$ and $\mathrm{J}_{\mathrm{L} 1}$ plotted on the Mandhane et al. [30] flow regime map. Very good agreement was found between the visually observed inlet flow regimes (as outlined in section 3.4.1) and the predicted flow regimes. It should be noted again that the transition boundaries given in figure 4.1 were plotted using the coordinates given by Mandhane et al. [30], 


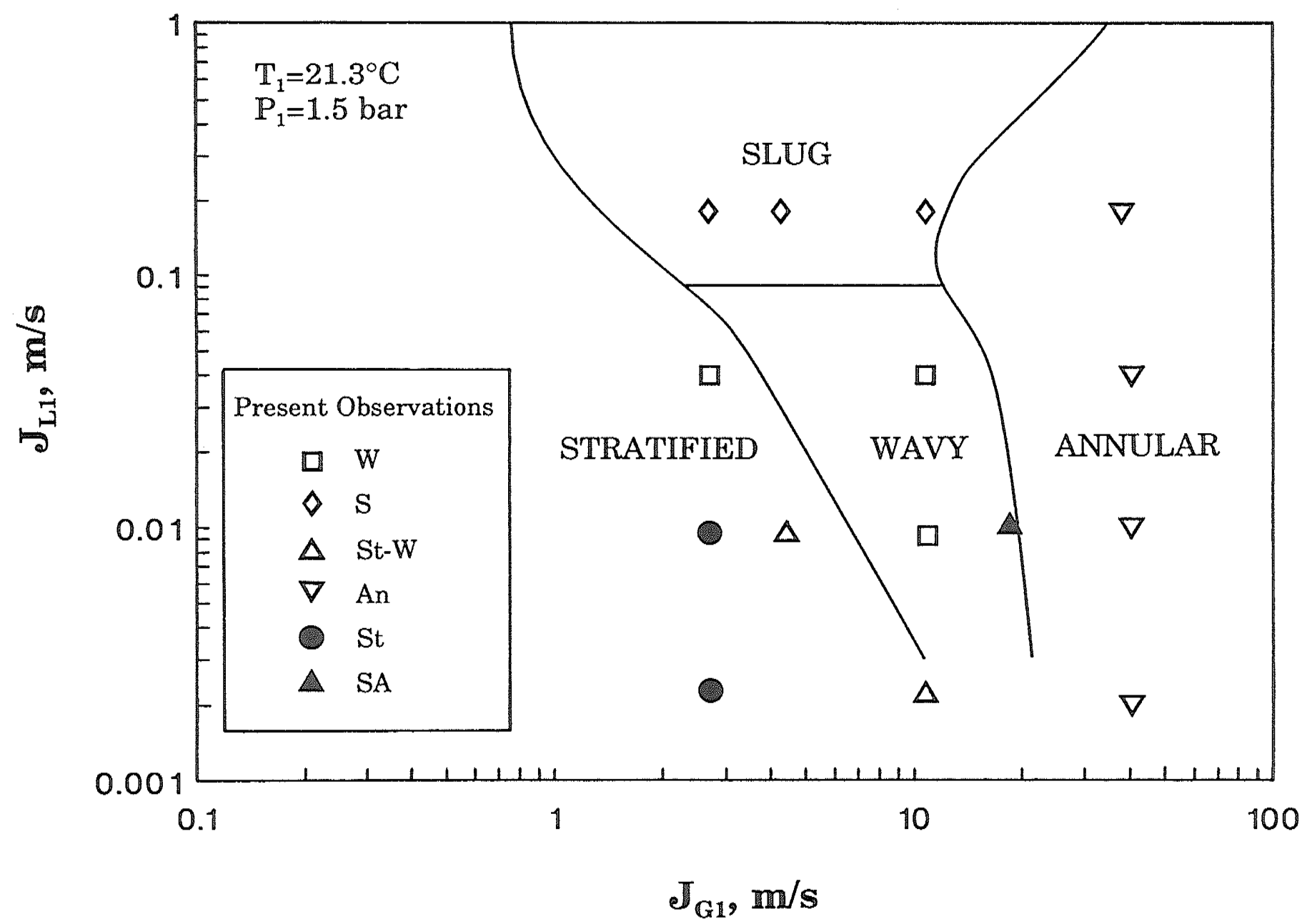

Figure 4.1 The present inlet flow conditons plotted on the Mandhane et al. [30] flow-regime map 
without any physical property corrections. The transition lines shown are typical for low-pressure, air-water flow in small-diameter pipes (less than 51 $\mathrm{mm})$.

\subsection{Presentation of Phase-Distribution Data}

In this section, the phase-distribution data are presented using different methods in an attempt to isolate the individual effects of important independent parameters. The data are plotted graphically using two different

methods: $\mathrm{x}_{3} / \mathrm{x}_{1}$ versus $\mathrm{W}_{3} / \mathrm{W}_{1}$, and $\mathrm{F}_{\mathrm{BG}}$ versus $\mathrm{F}_{\mathrm{BL}}$. Although both types of graphs are obtained from the same data, and the conversion of $x_{3} / x_{1}$ versus $\mathrm{W}_{3} / \mathrm{W}_{1}$ into $\mathrm{F}_{\mathrm{BG}}$ versus $\mathrm{F}_{\mathrm{BL}}$ or vice versa is easily obtained, it will be noted that there can be significant differences in the appearance in which the two graphs display the phase-distribution phenomenon.

\subsubsection{Effect of Inlet Superficial Liquid Velocity}

Figures 4.2 through 4.5 illustrate the effect of varying $\mathrm{J}_{\mathrm{L} 1}$ at fixed $\mathrm{J}_{\mathrm{G} 1}$. Each figure consists of two parts; part (a) is plotted in terms of $x_{3} / x_{1}$ versus $\mathrm{W}_{3} / \mathrm{W}_{1}$ and part $(\mathrm{b})$ is plotted in terms of $\mathrm{F}_{\mathrm{BG}}$ versus $\mathrm{F}_{\mathrm{BL}}$. It should be pointed out that changing $\mathrm{J}_{\mathrm{L} 1}$ while keeping $\mathrm{J}_{\mathrm{G} 1}$ constant can result in changes in the 


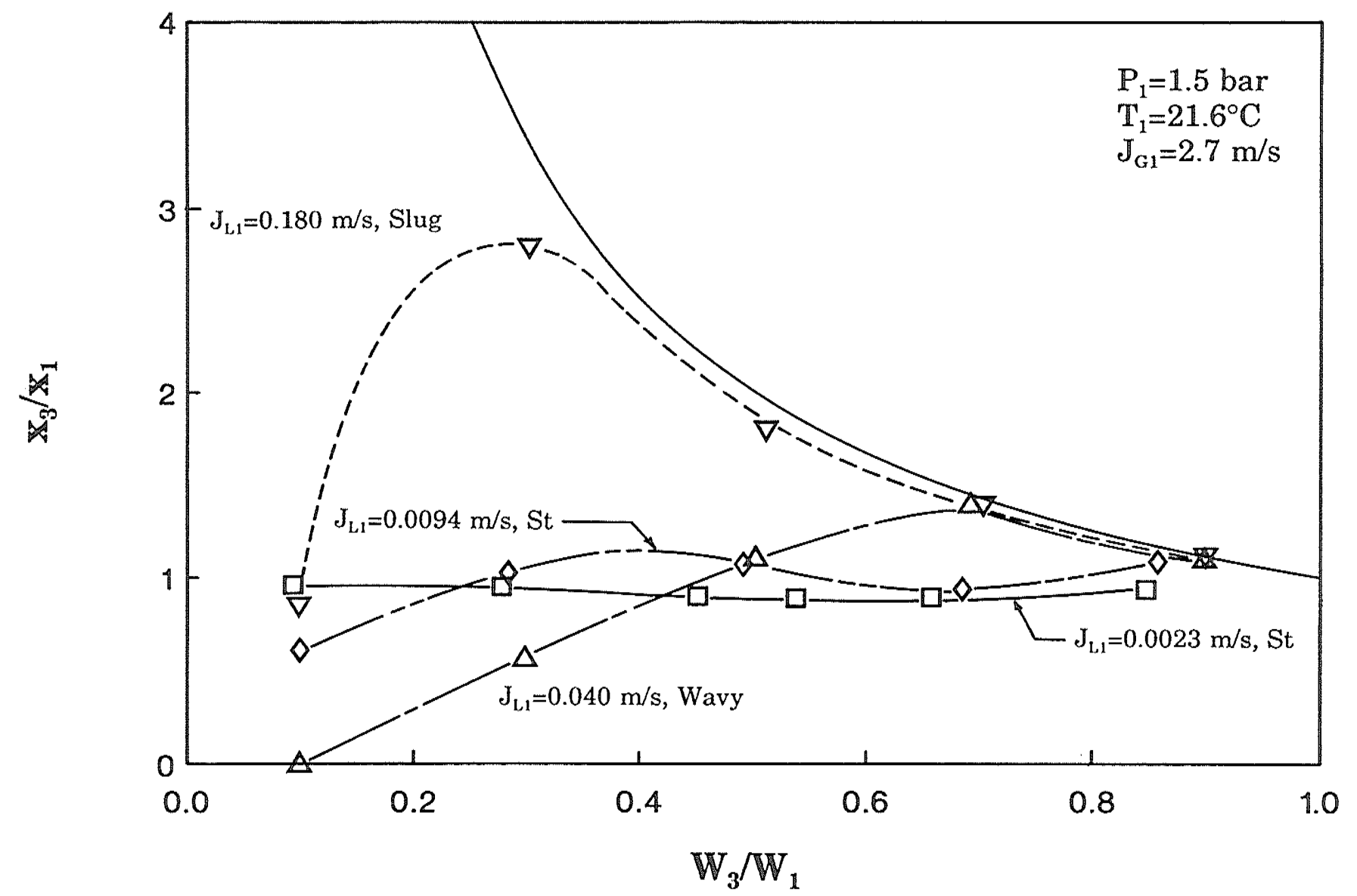

(a)

Figure 4.2 Effect of $J_{L 1}$ on the phase distribution for $J_{\mathrm{G} 1}=2.7 \mathrm{~m} / \mathrm{s}$ 


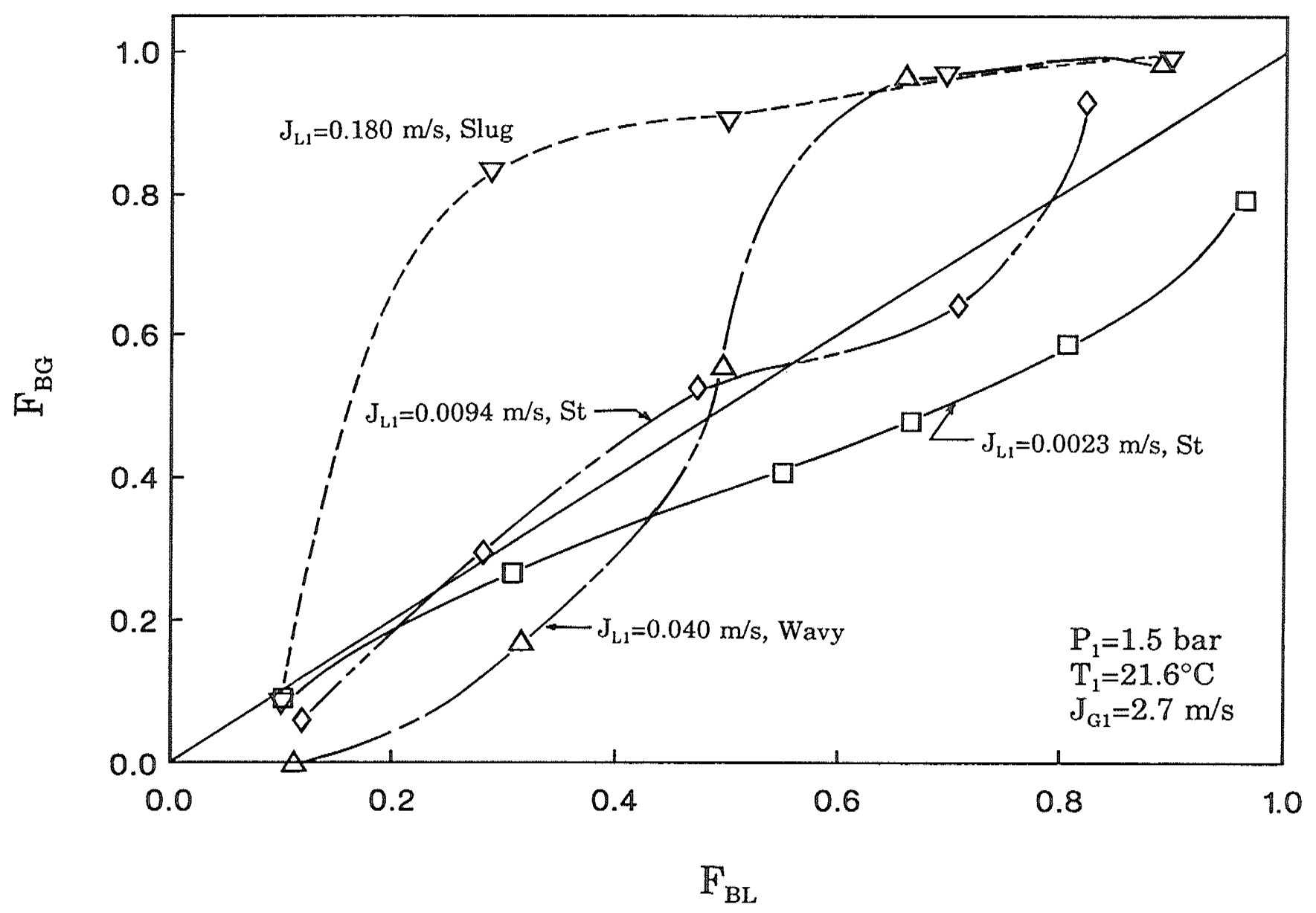

(b)

Figure 4.2 Effect of $J_{L 1}$ on the phase distribution for $\mathrm{J}_{\mathrm{G} 1}=2.7 \mathrm{~m} / \mathrm{s}$ 


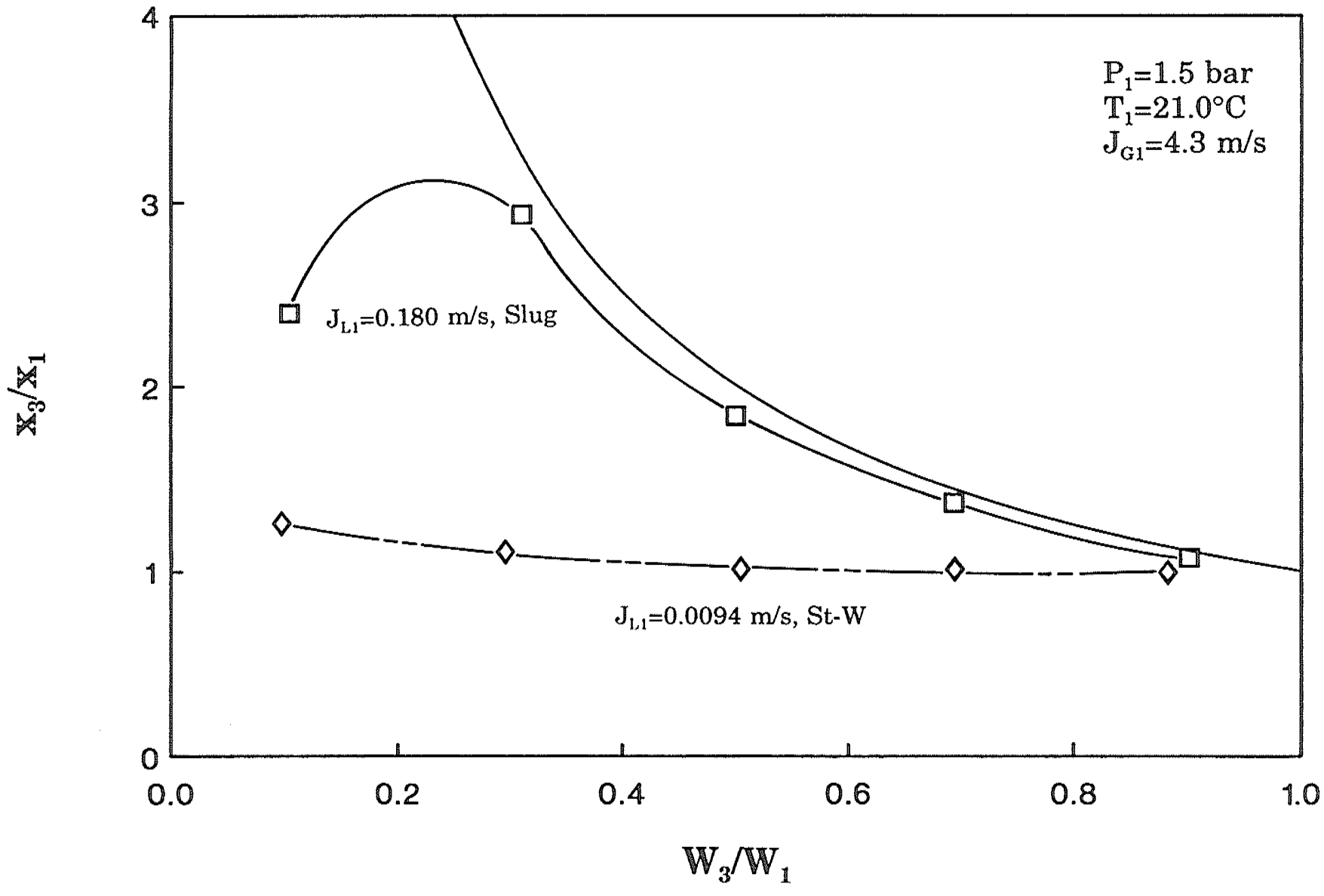

(a)

Figure 4.3 Effect of $J_{L l}$ on the phase distribution for $J_{\mathrm{G} 1}=4.3 \mathrm{~m} / \mathrm{s}$ 


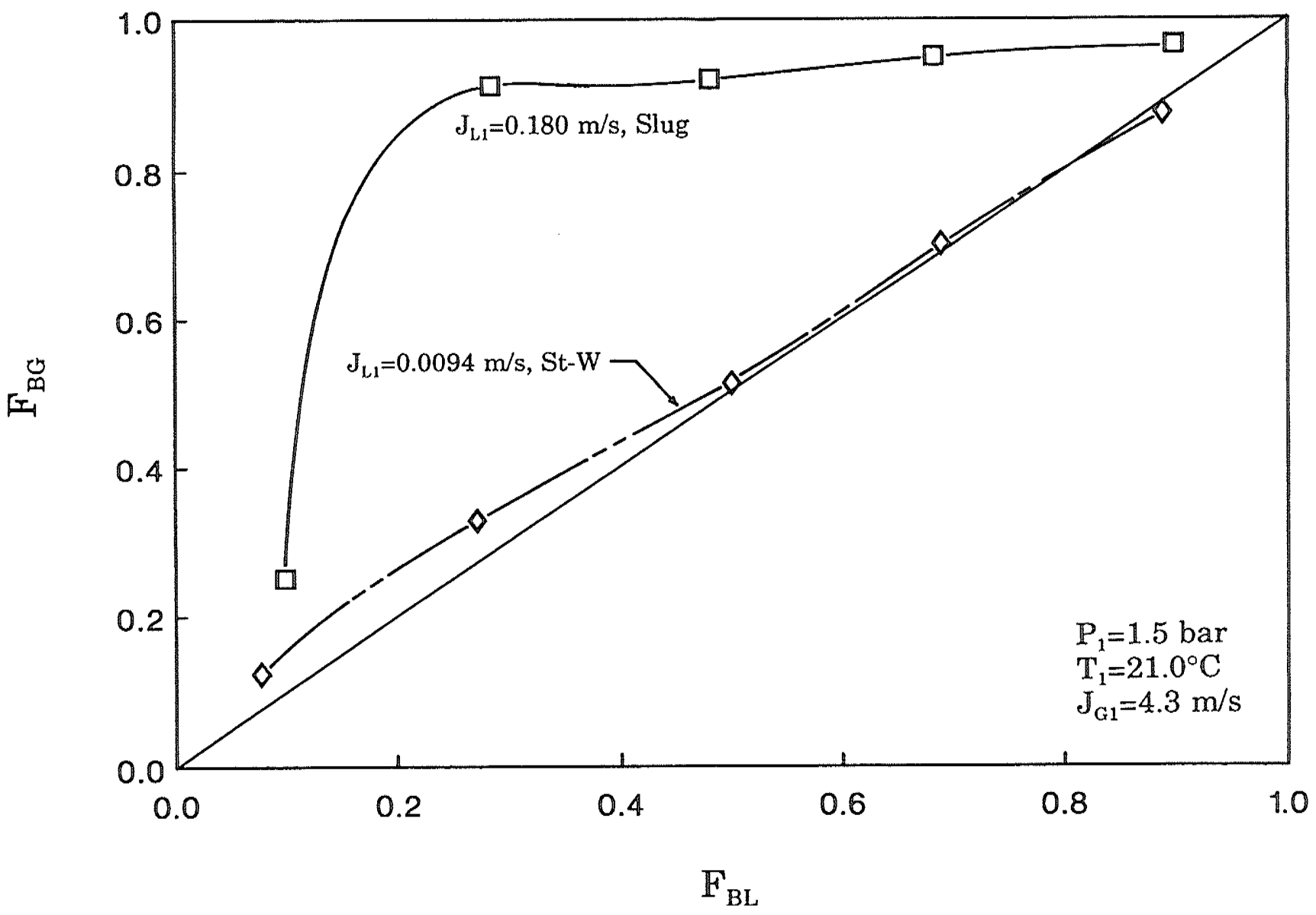

(b)

Figure 4.3 Effect of $J_{L 1}$ on the phase distribution for $J_{G 1}=4.3 \mathrm{~m} / \mathrm{s}$ 


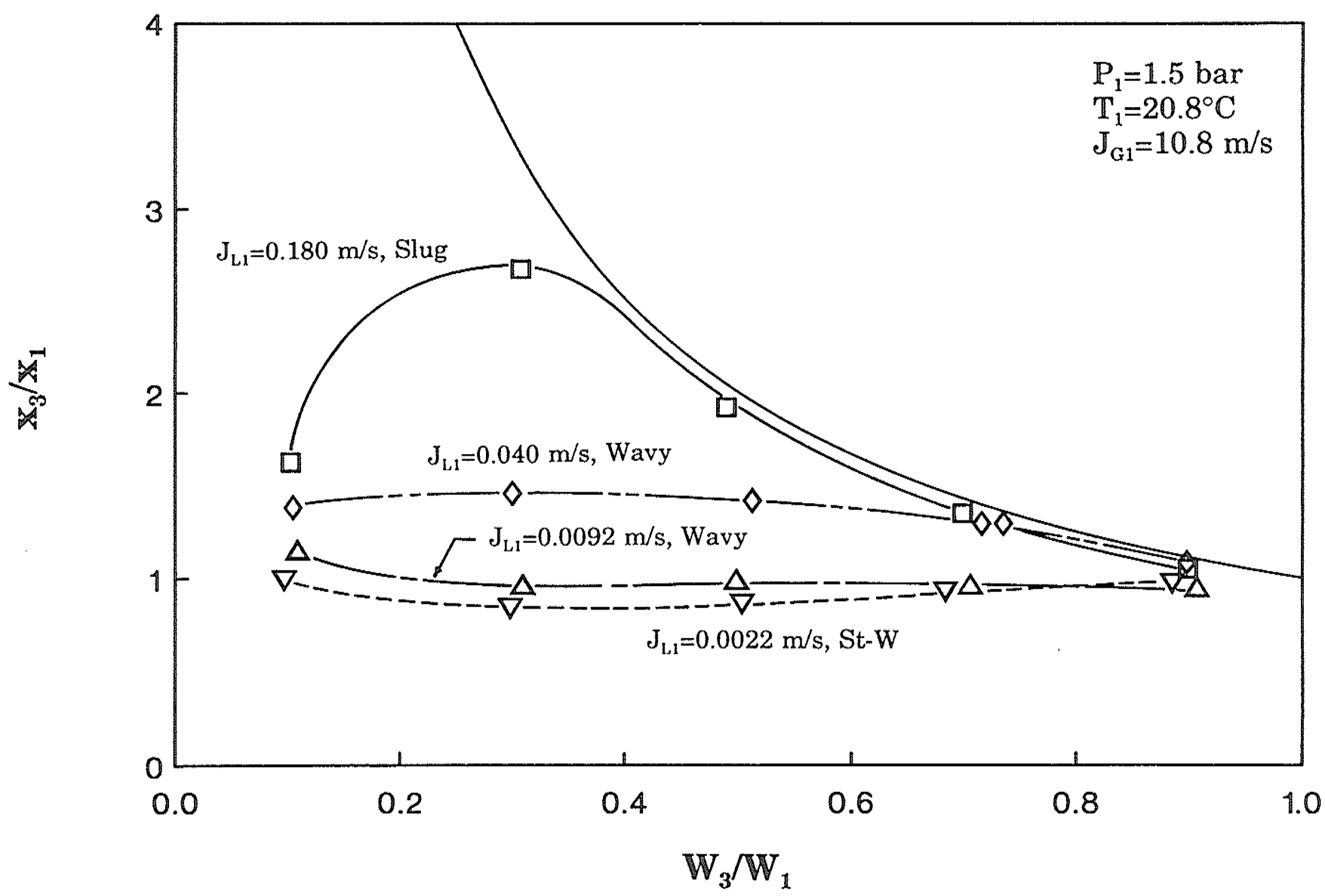

(a)

Figure 4.4 Effect of $J_{L 1}$ on the phase distribution for $\mathrm{J}_{\mathrm{G} 1}=10.8 \mathrm{~m} / \mathrm{s}$ 


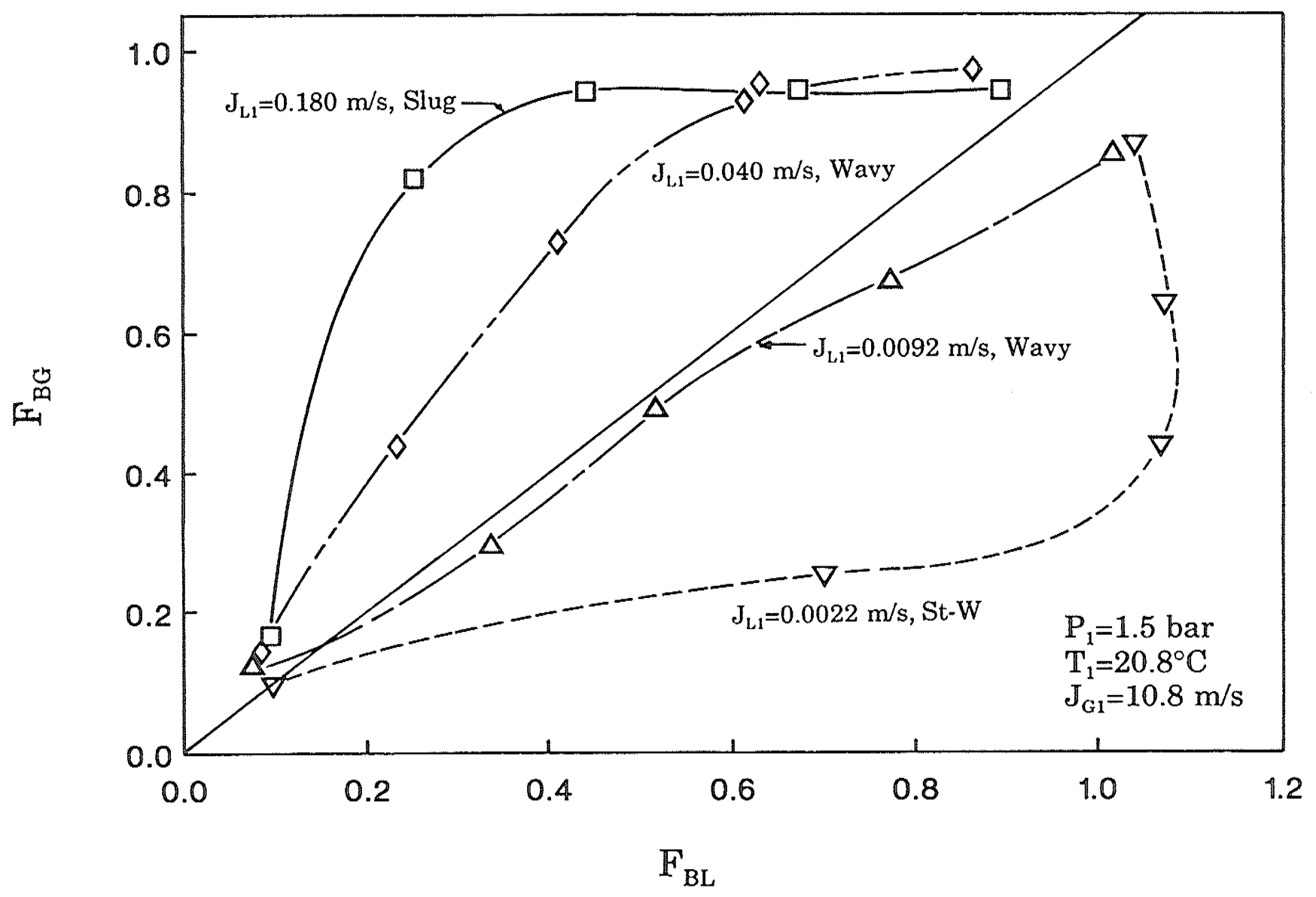

(b)

Figure 4.4 Effect of $\mathrm{J}_{\mathrm{L} 1}$ on the phase distribution for $J_{G 1}=10.8 \mathrm{~m} / \mathrm{s}$ 


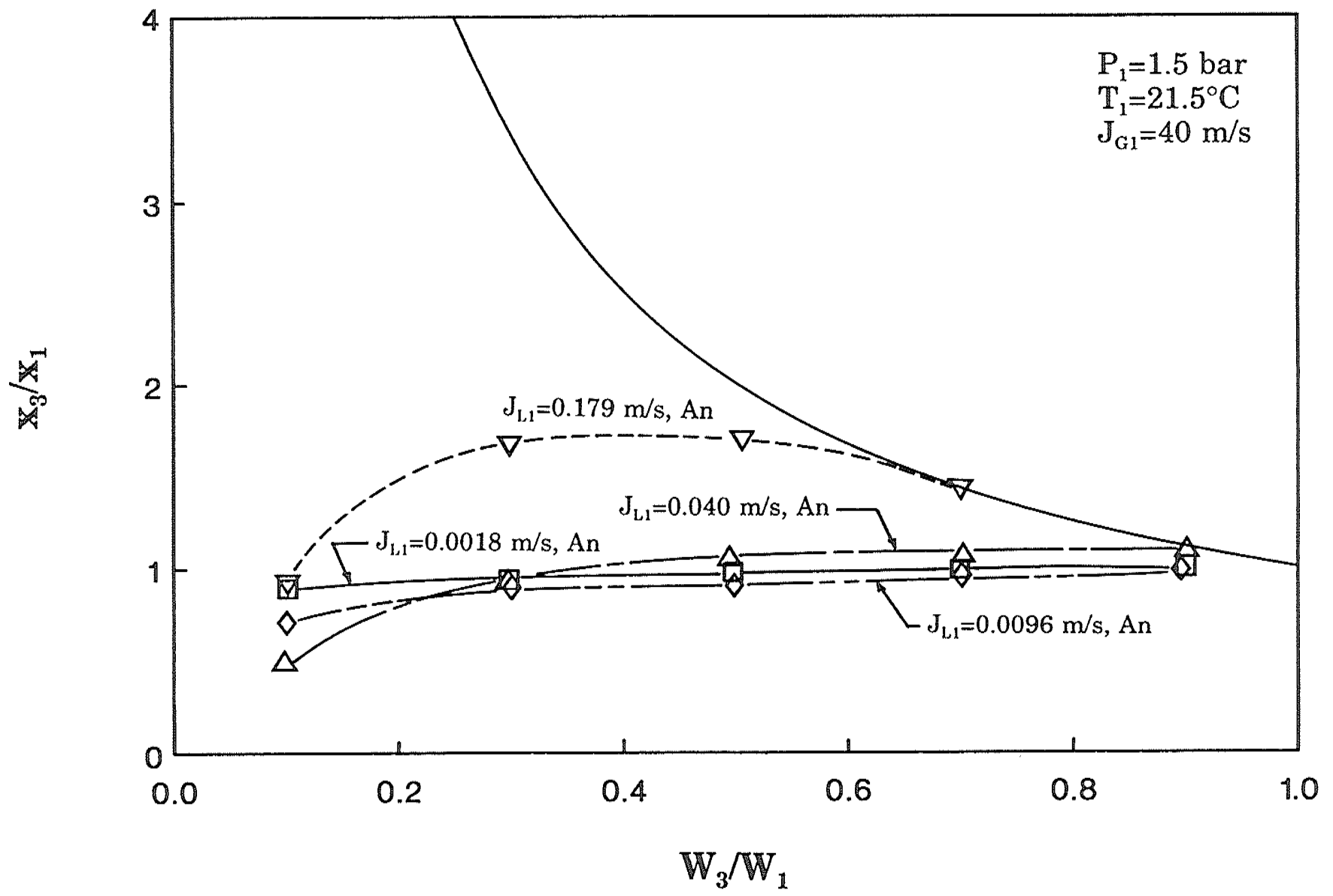

(a)

Figure 4.5 Effect of $J_{\mathrm{L} 1}$ on the phase distribution for $J_{\mathrm{G} 1}=40 \mathrm{~m} / \mathrm{s}$ 


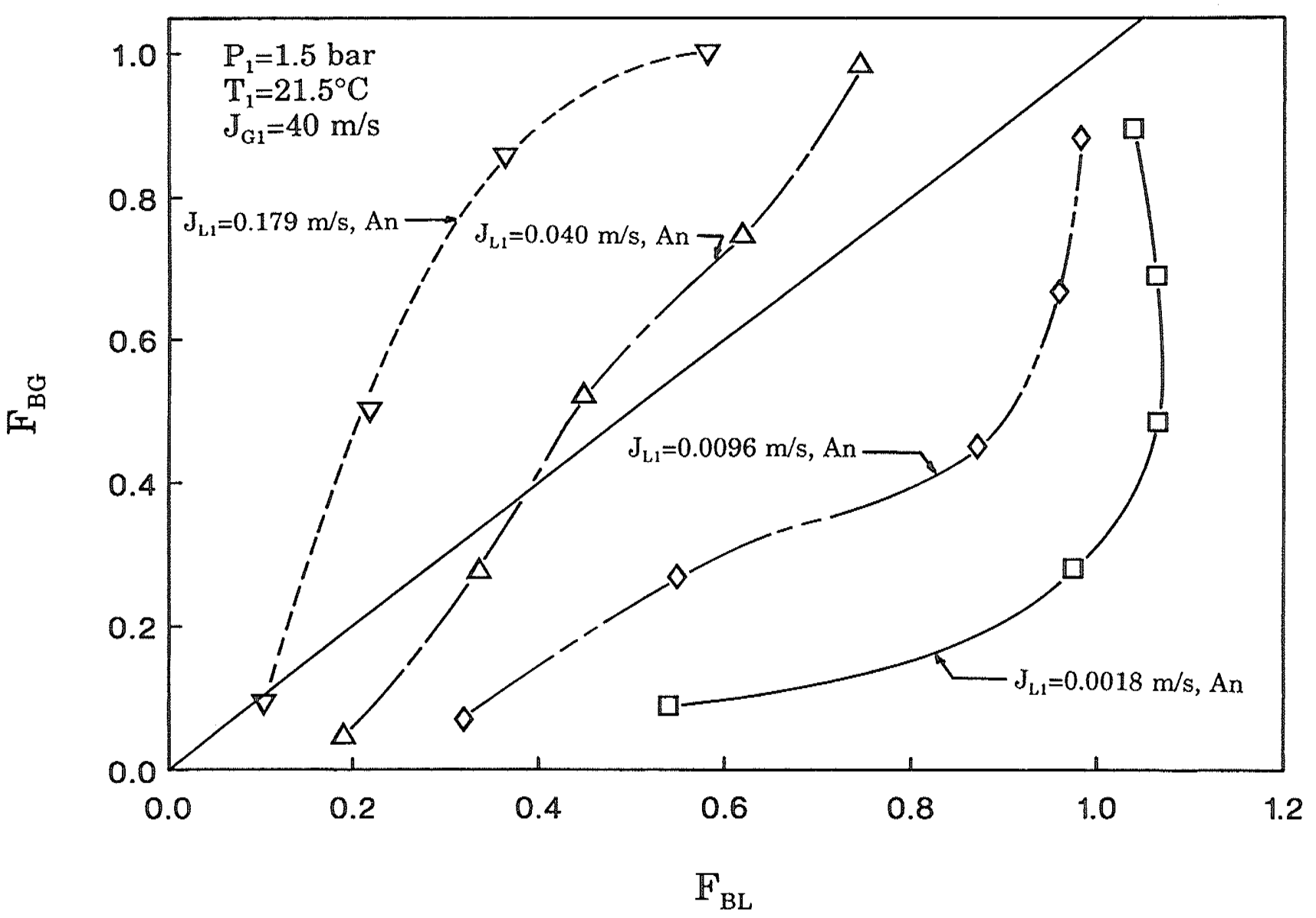

(b)

Figure 4.5 Effect of $J_{L 1}$ on the phase distribution for $\mathrm{J}_{\mathrm{G1}}=40 \mathrm{~m} / \mathrm{s}$ 
inlet flow regime. It will be shown later that the inlet flow regime can have a significant effect on the phase distribution.

For the most part, figures 4.2 to 4.5 illustrate that as $\mathrm{J}_{\mathrm{L} 1}$ increases at a fixed $J_{G 1}$, there is an increasing preference for the gas phase to exit through the branch. The only deviation from this trend can be seen in figure 4.2 at $\mathrm{J}_{\mathrm{L} 1}=0.040 \mathrm{~m} / \mathrm{s}$. The curve corresponding to this condition starts from $\mathrm{x}_{3}=0$ at an extraction rate of 0.1 , and rises steadily to approach the total-phaseseparation curve at $\mathrm{W}_{3} / \mathrm{W}_{1}$ near 0.7 . The test conditions that gave rise to this curve were repeated, with the same results. The behaviour of these particular data could not be explained at this time.

The data shown in figure 4.5 illustrate the significant differences in appearance that can occur between the two different methods of plotting the phase-distribution data. Figure 4.5(b) more clearly shows a significantly increasing preference for the gas phase to exit through the branch as $\mathrm{J}_{\mathrm{L} 1}$ is increased.

Azzopardi et al. [24] suggested that for stratified flow the increase in preference for the gas phase to exit through the branch as $\mathrm{J}_{\mathrm{L} 1}$ is increased can be explained in terms of the effect of $\mathrm{J}_{\mathrm{L} 1}$ variations on the average axial momentum of the liquid. At small values of $\mathrm{J}_{\mathrm{L}}$, the average axial momentum of the liquid is small and liquid is easily diverted into the branch. As $\mathrm{J}_{\mathrm{L} 1}$ increases, the average axial momentum of the liquid increases, although this 
increase can be offset somewhat by a decrease in average inlet void fraction. The increase in average axial momentum of the liquid film results in a decreasing preference for the liquid phase to exit through the branch. For annular flow, Azzopardi et al. [24] suggested that a decrease in the liquid flow rate would decrease the amount of liquid entrainment. This would increase the fraction of liquid in the film, thus increasing $F_{\mathrm{BL}}$.

The same effect of $J_{L 1}$ on the phase distribution was observed by Rubel et al. [20], Shoham et al. [21], and Hong [3].

\subsubsection{Effect of Inlet Superficial Gas Velocity}

The effect of varying $\mathrm{J}_{\mathrm{G} 1}$ at fixed $\mathrm{J}_{\mathrm{L} 1}$ is shown in figures 4.6 to 4.9 . Again, it should be pointed out that changing $J_{G 1}$ with $J_{L 1}$ fixed can result in changes in the inlet flow regime.

All the data shown in figure 4.6(a) appear closely spaced with $x_{3} / x_{1}$ nearly equal to one. However, when these data are plotted in figure 4.6(b), it can be seen that as $\mathrm{J}_{\mathrm{G} 1}$ increases, there is an increasing preference for the liquid phase to exit through the branch. A comment should be made concerning the data in figure 4.6(b) that extends beyond an $\mathrm{F}_{\mathrm{BL}}$ of unity. For this data, visual observations indicated that all, or nearly all, of the liquid was removed through the branch. This corresponds to $\mathrm{F}_{\mathrm{BL}}$ equal to unity. The 


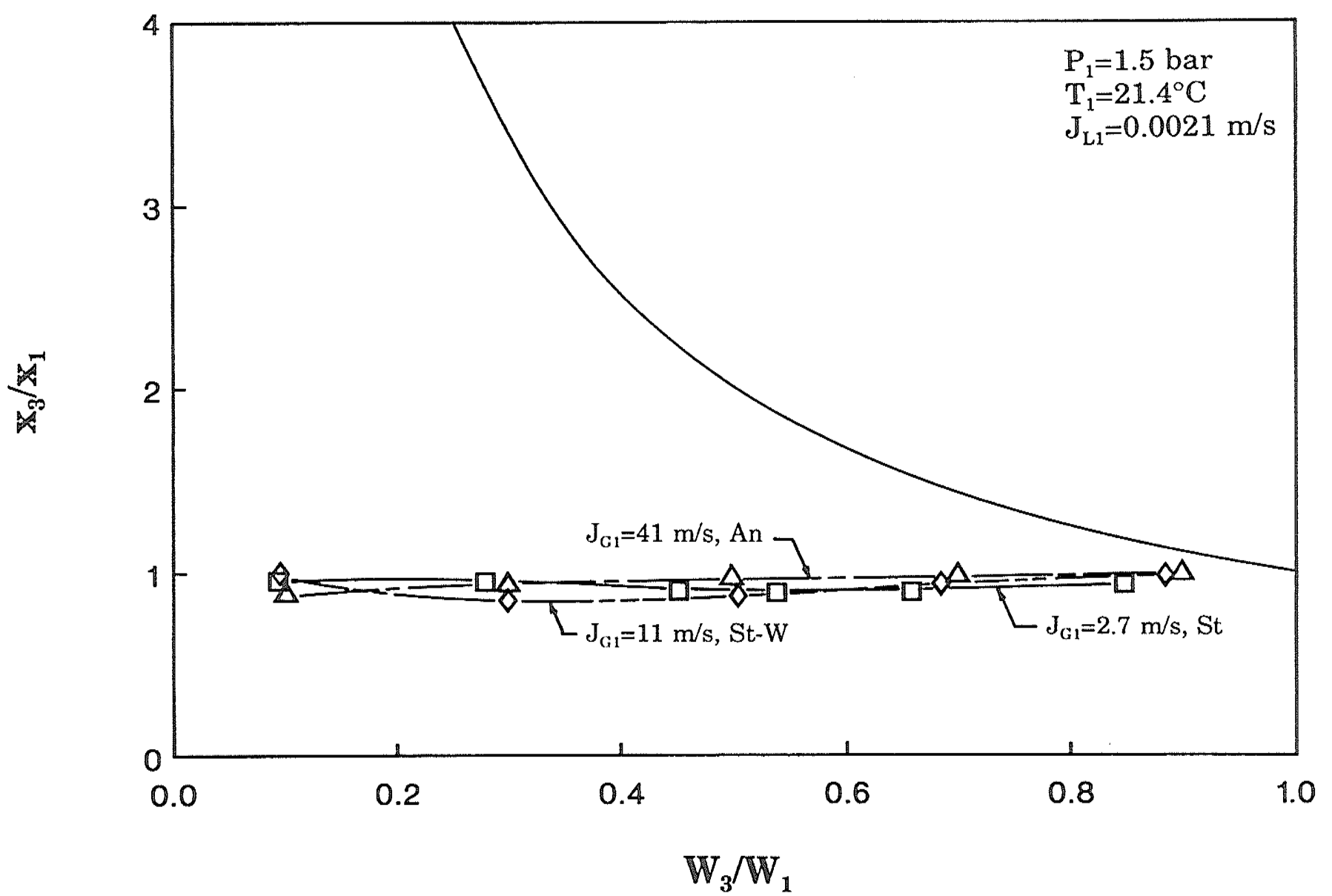

(a)

Figure 4.6 Effect of $J_{\mathrm{G} 1}$ on the phase distribution for $\mathrm{J}_{\mathrm{L} 1}=0.0021 \mathrm{~m} / \mathrm{s}$ 


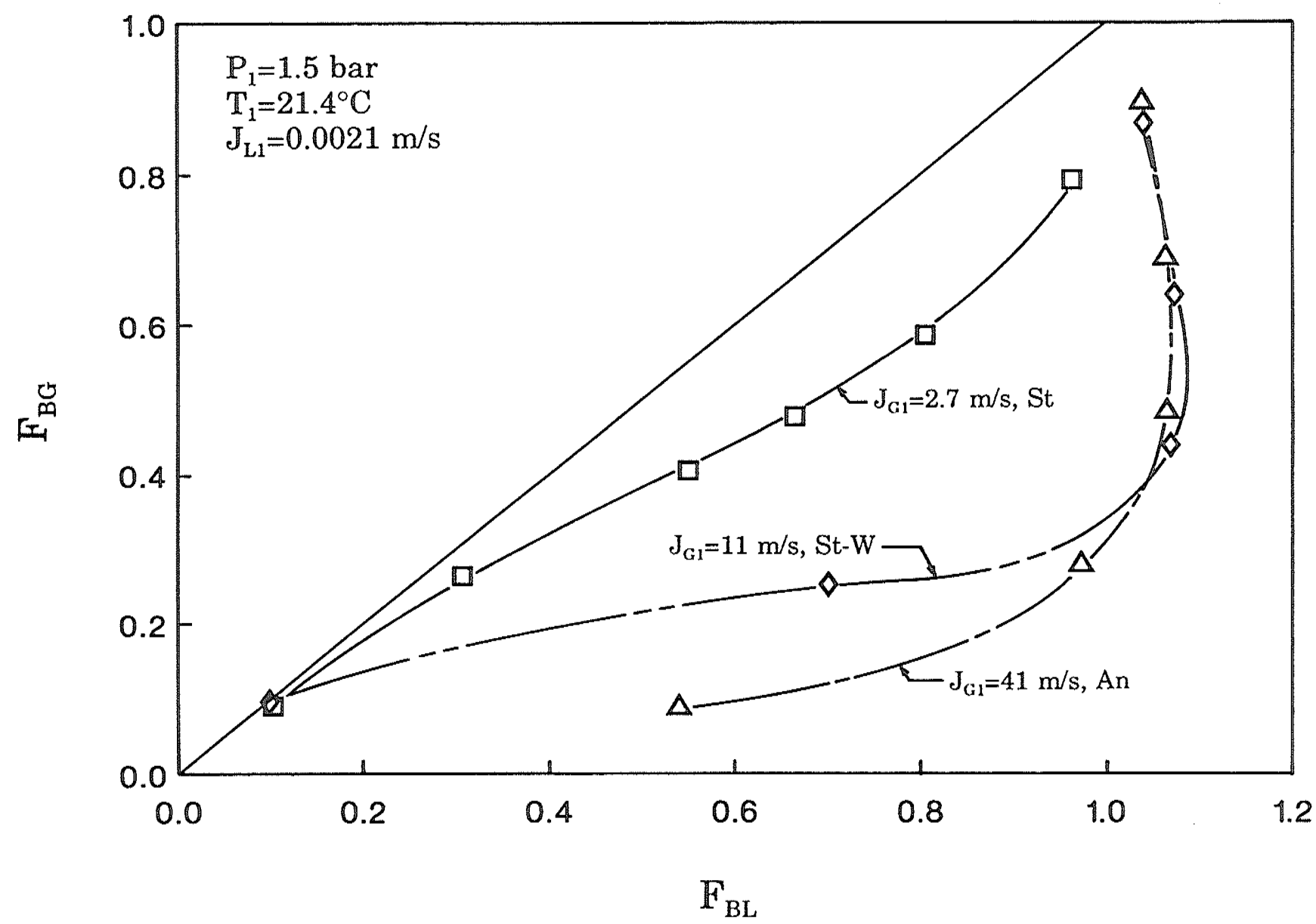

(b)

Figure 4.6 Effect of $J_{G 1}$ on the phase distribution for $\mathrm{J}_{\mathrm{Ll}}=0.0021 \mathrm{~m} / \mathrm{s}$ 


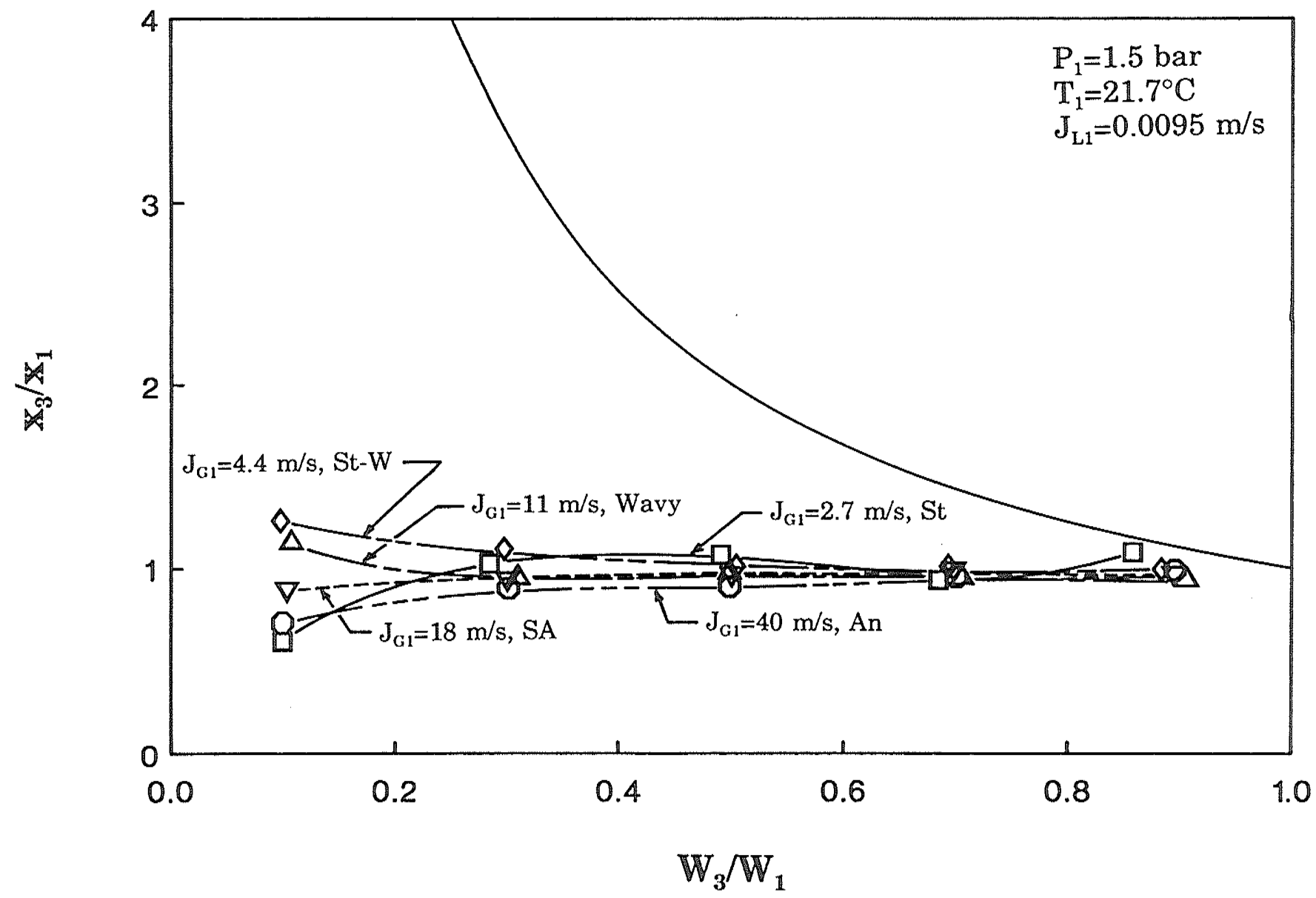

(a)

Figure 4.7 Effect of $J_{G 1}$ on the phase distribution for $\mathrm{J}_{\mathrm{L} 1}=0.0095 \mathrm{~m} / \mathrm{s}$ 


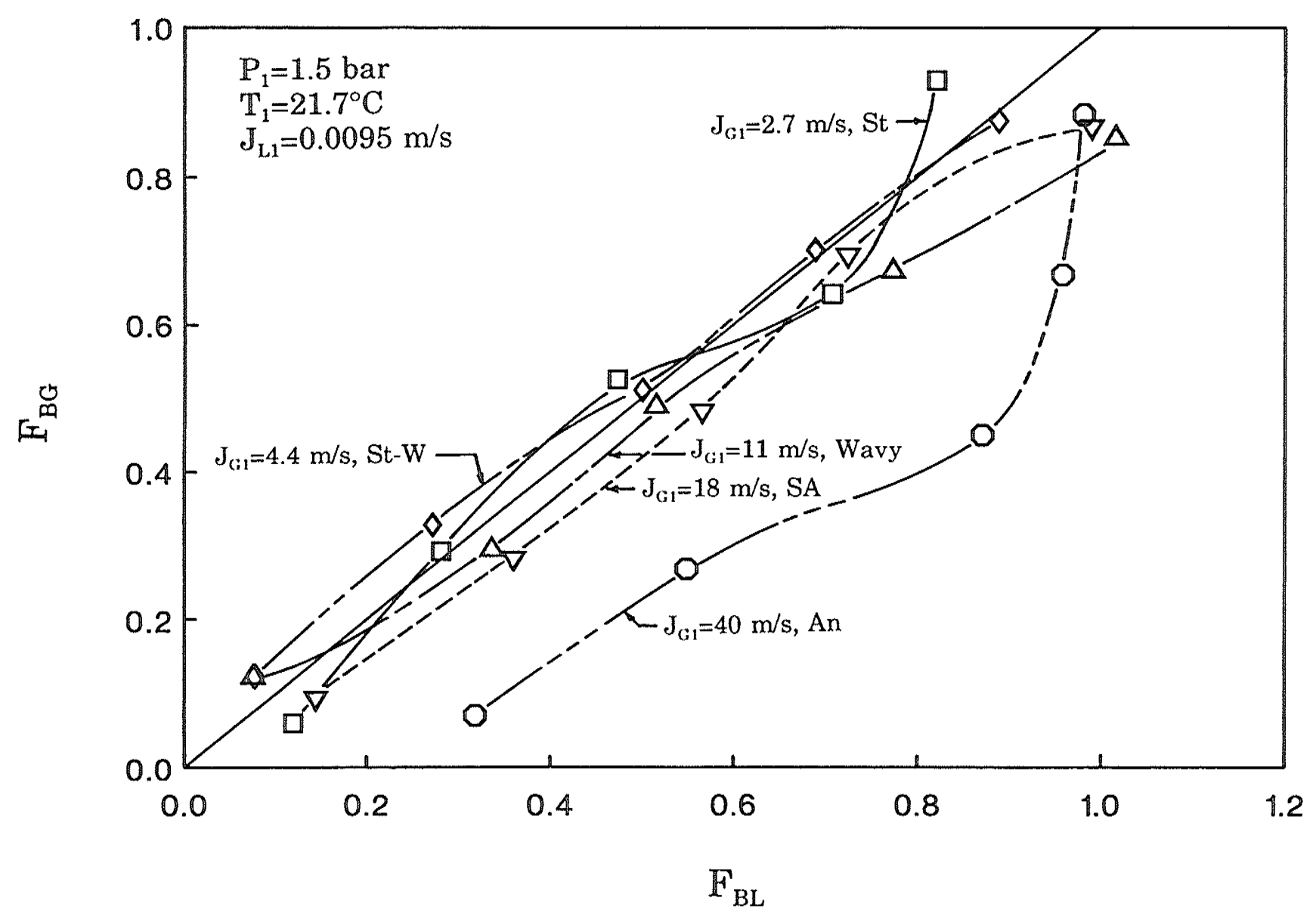

(b)

Figure 4.7 Effect of $J_{\mathrm{G} 1}$ on the phase distribution for $J_{L 1}=0.0095 \mathrm{~m} / \mathrm{s}$ 


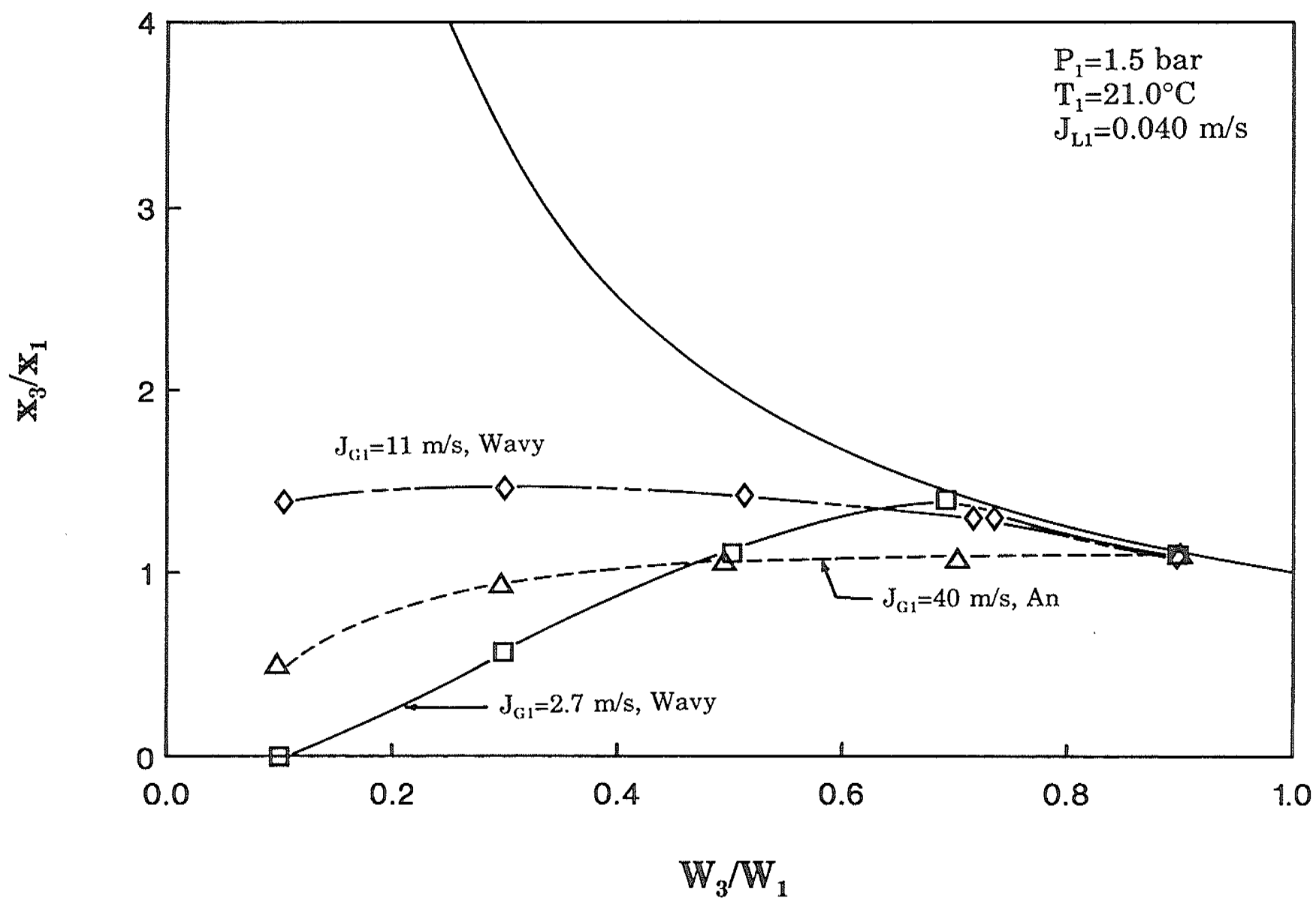

(a)

Figure 4.8 Effect of $J_{\mathrm{G} 1}$ on the phase distribution for $\mathrm{J}_{L 1}=0.040 \mathrm{~m} / \mathrm{s}$ 


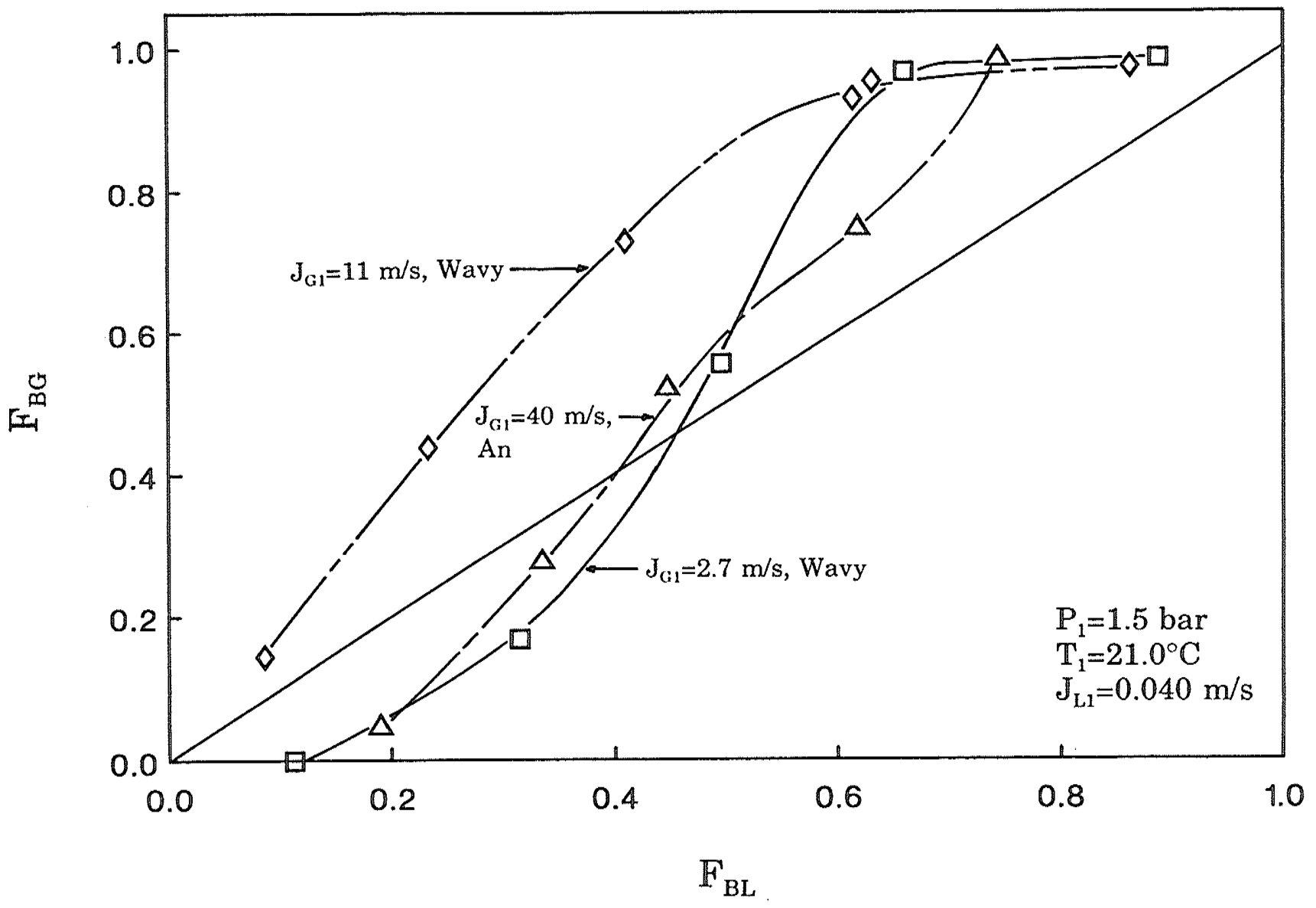

(b)

Figure 4.8 Effect of $J_{G 1}$ on the phase distribution for 


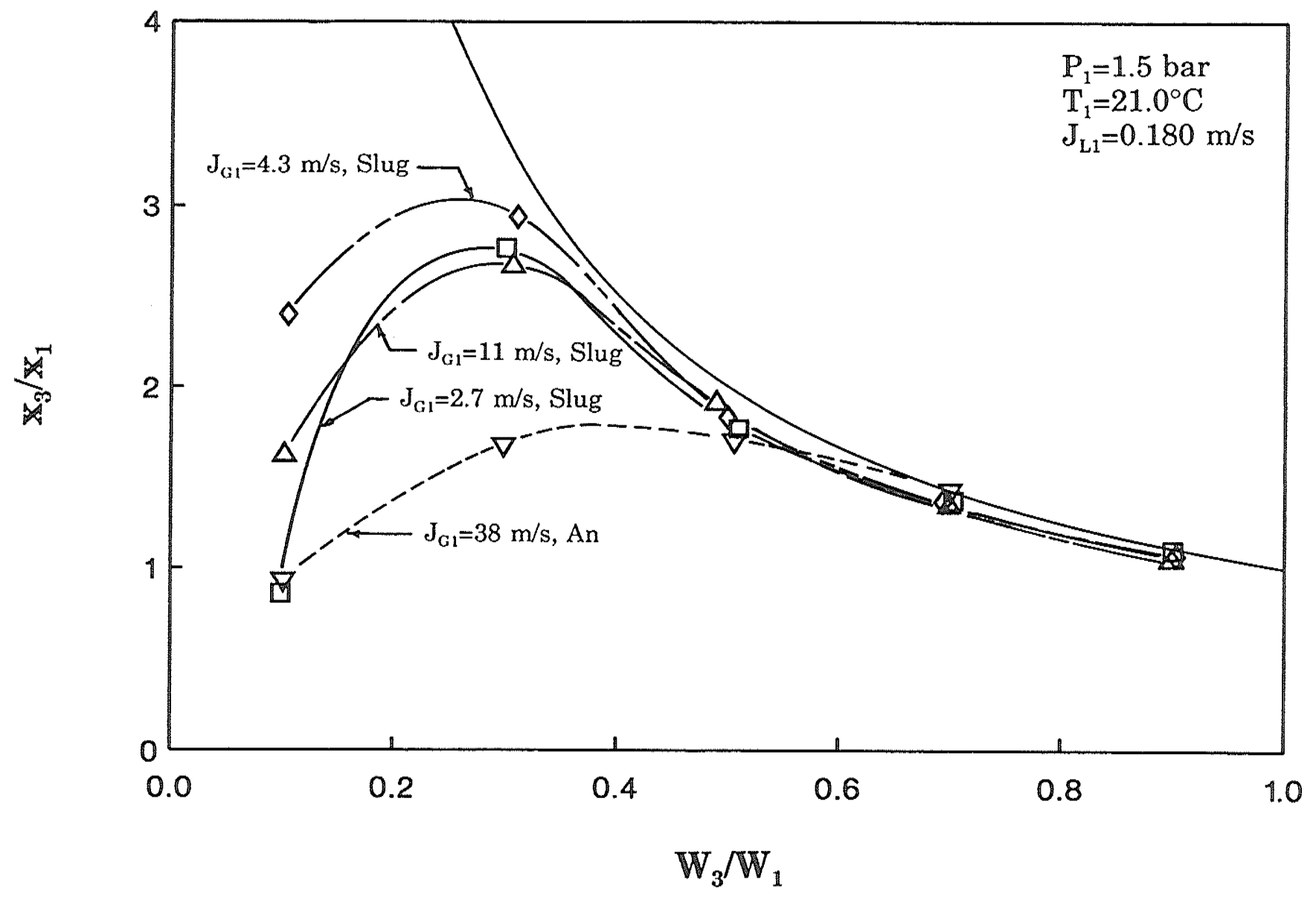

(a)

Figure 4.9 Effect of $J_{G 1}$ on the phase distribution for $J_{L 1}=0.180 \mathrm{~m} / \mathrm{s}$ 


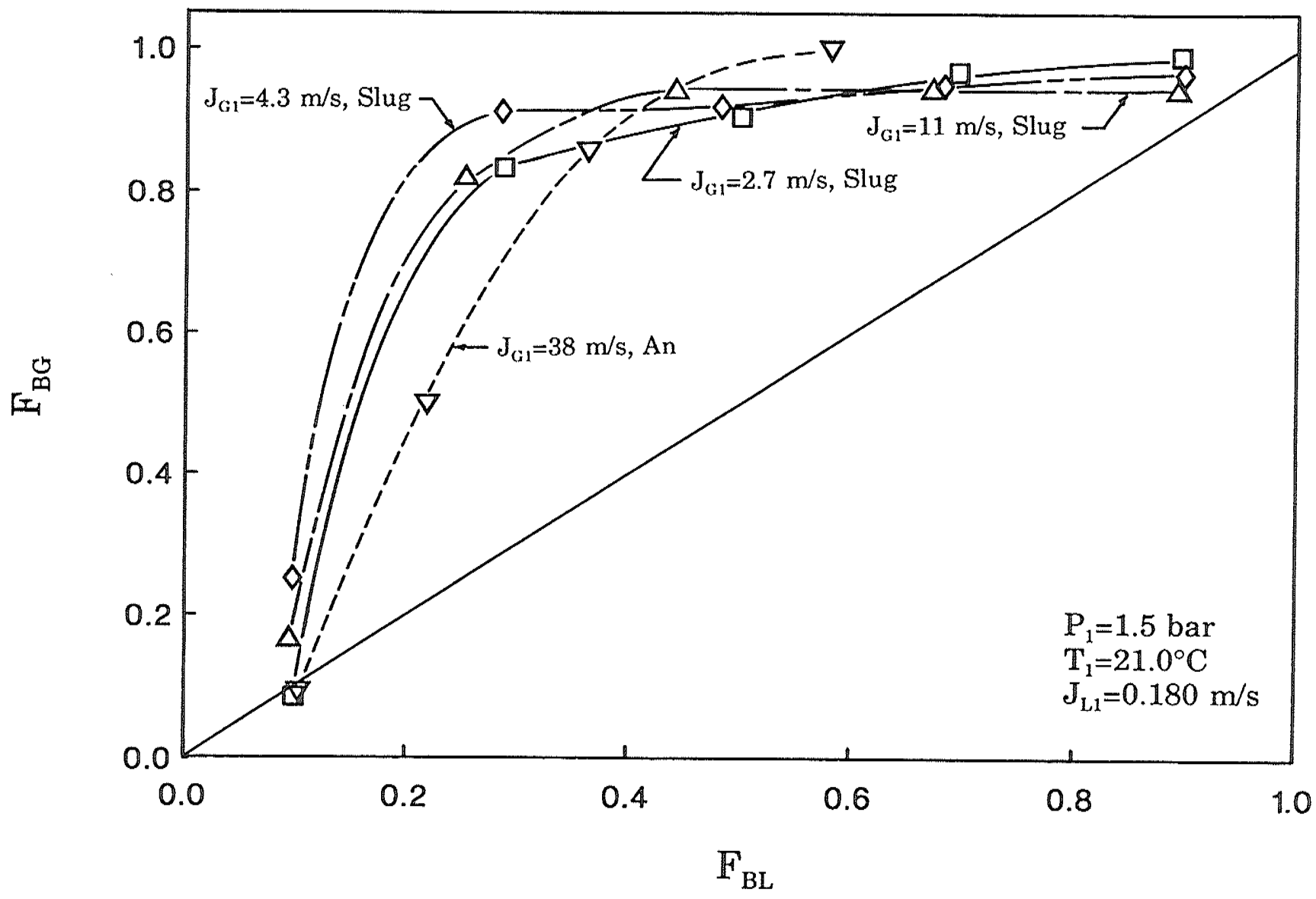

(b)

Figure $4.9 \mathbb{E}$ ffect of $J_{\mathrm{G} 1}$ on the phase distribution for $J_{L 1}=0.180 \mathrm{~m} / \mathrm{s}$ 
calculated values of $\mathrm{F}_{\mathrm{BL}}$ shown in the figure are slightly greater than unity because of the unavoidable errors in measuring the inlet, run, and branch liquid flow rates. Liquid mass balance errors of up to $3 \%$ occurred because of the difficulty in measuring the small liquid flow rates. As well, the associated large air flow rates resulted in significant evaporation of the water within the mixer, test section, and separation tanks, which further increased the difficulty in obtaining accurate measurements. This problem of evaporation of the liquid phase is discussed in more detail in Appendix A.

Most of the data shown in figure 4.7(a) lie close to the line of even phase distribution. When these data are plotted in figure 4.7(b), the curve corresponding to annular flow $\left(J_{G 1}=40 \mathrm{~m} / \mathrm{s}\right)$ clearly displays a preference for the liquid phase to exit through the branch.

In figure 4.8 , there is a decrease in the preference for the gas phase to exit through the branch as $J_{G 1}$ is increased from $11 \mathrm{~m} / \mathrm{s}$ to $40 \mathrm{~m} / \mathrm{s}$. This could be due to the change in inlet flow regime from wavy to annular flow, as will be discussed in a later section. The data for $\mathrm{J}_{\mathrm{G} 1}=2.7 \mathrm{~m} / \mathrm{s}$ were previously discussed in section 4.2.1.

Figure $4.9(\mathrm{a})$ shows the effect of $\mathrm{J}_{\mathrm{G} 1}$ variation at a fixed $\mathrm{J}_{\mathrm{L} 1}$ of $0.180 \mathrm{~m} / \mathrm{s}$. All of the data show a preference for the gas phase to exit through the branch. The slug flow data show a peak value of $x_{3} / x_{1}$ in the range of extraction rate between 0.1 and 0.3 . When the extraction rate is increased beyond 0.3 , all the curves corresponding to slug flow approach the total phase-separation curve. 
The curve corresponding to annular flow $\left(J_{\mathrm{G} 1}=38 \mathrm{~m} / \mathrm{s}\right)$ has a smaller peak value of $\mathrm{x}_{3} / \mathrm{x}_{1}$, and the total phase separation curve is not approached until the extraction rate is increased beyond 0.6. Except for the curve at $J_{\mathrm{G} 1}=2.7 \mathrm{~m} / \mathrm{s}$, an increase in $\mathrm{J}_{\mathrm{G} 1}$ reduces the peak value of $\mathrm{x}_{3} / \mathrm{x}_{1}$ and increases the extraction rate at which the total phase separation curve is approached. This trend was observed by Ballyk et al. [18] for annular steam-water flow in a horizontal tee junction, and by Saba and Lahey [12] for slug air-water flow in a horizontal tee junction.

On the whole, figures 4.6 to 4.9 do not show any consistent trends. Increasing $J_{\mathrm{G} 1}$ at a fixed $\mathrm{J}_{\mathrm{L} 1}$ usually resulted in changes in the inlet flow regime, as shown previously in figure 4.1. Changes in the inlet flow regime can have a large effect on the phase distribution, and therefore could be the most significant factor in the trends exhibited in figures 4.6 to 4.9 .

\subsubsection{Effect of Inlet Mass Flux}

Figures 4.10 to 4.13 investigate the effect of $G_{1}$ on the phase distribution by maintaining a constant $x_{1}$ and allowing $G_{1}$ to vary. At an inlet quality of $89 \%$ the effect of $\mathrm{G}_{1}$ variation is small, as shown in figure 4.13. In general, as the inlet quality is decreased the effect of $\mathrm{G}_{1}$ variation (at fixed $\mathrm{x}_{11}$ ) on the phase distribution appears to become more significant, although this change is not large. However, the change in inlet flow regime as $G_{1}$ varies may be the 


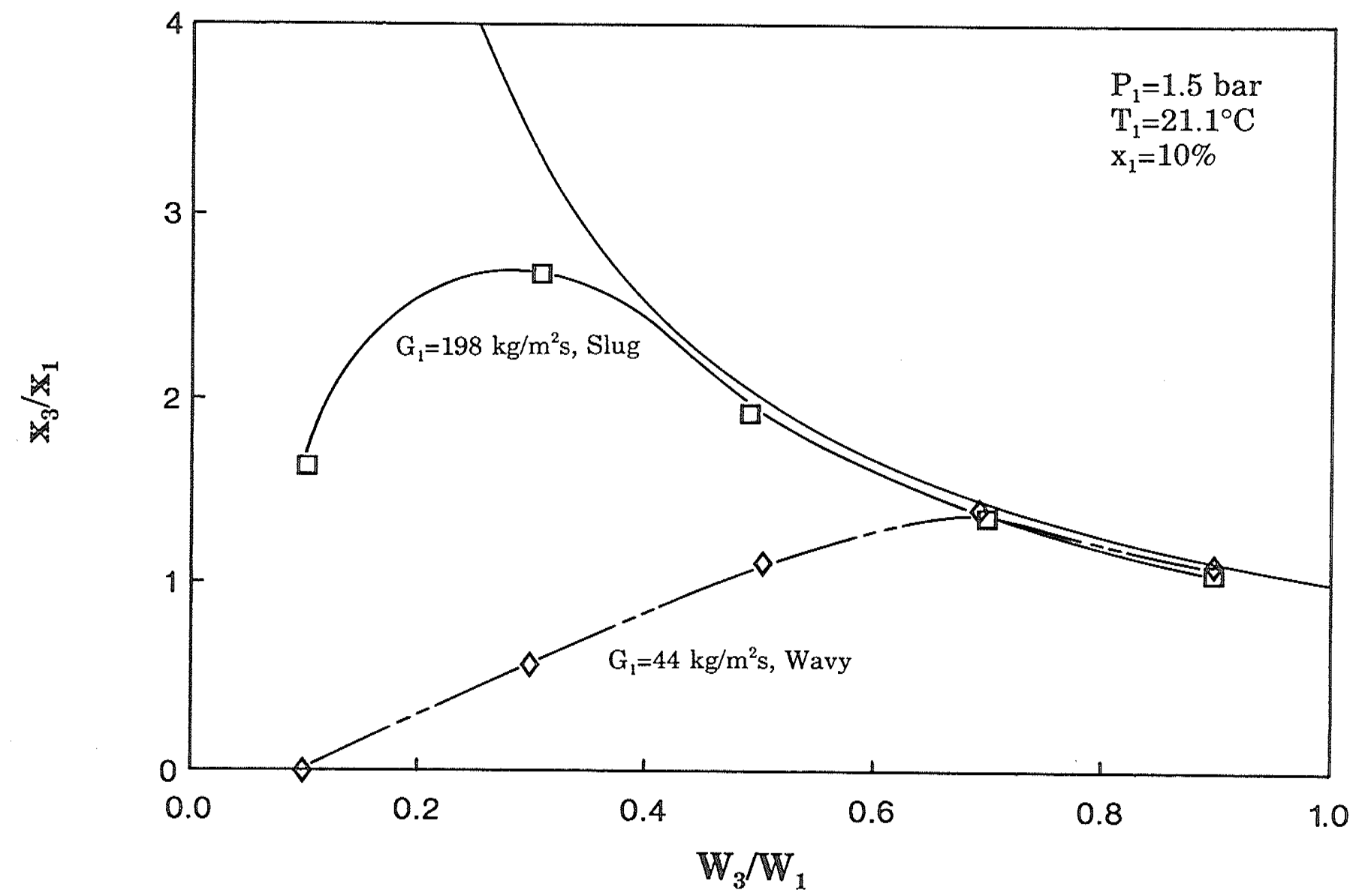

(a)

Figure 4.10 Effect of inlet mass flux on the phase distribution for $\mathrm{x}_{1}=10 \%$ 


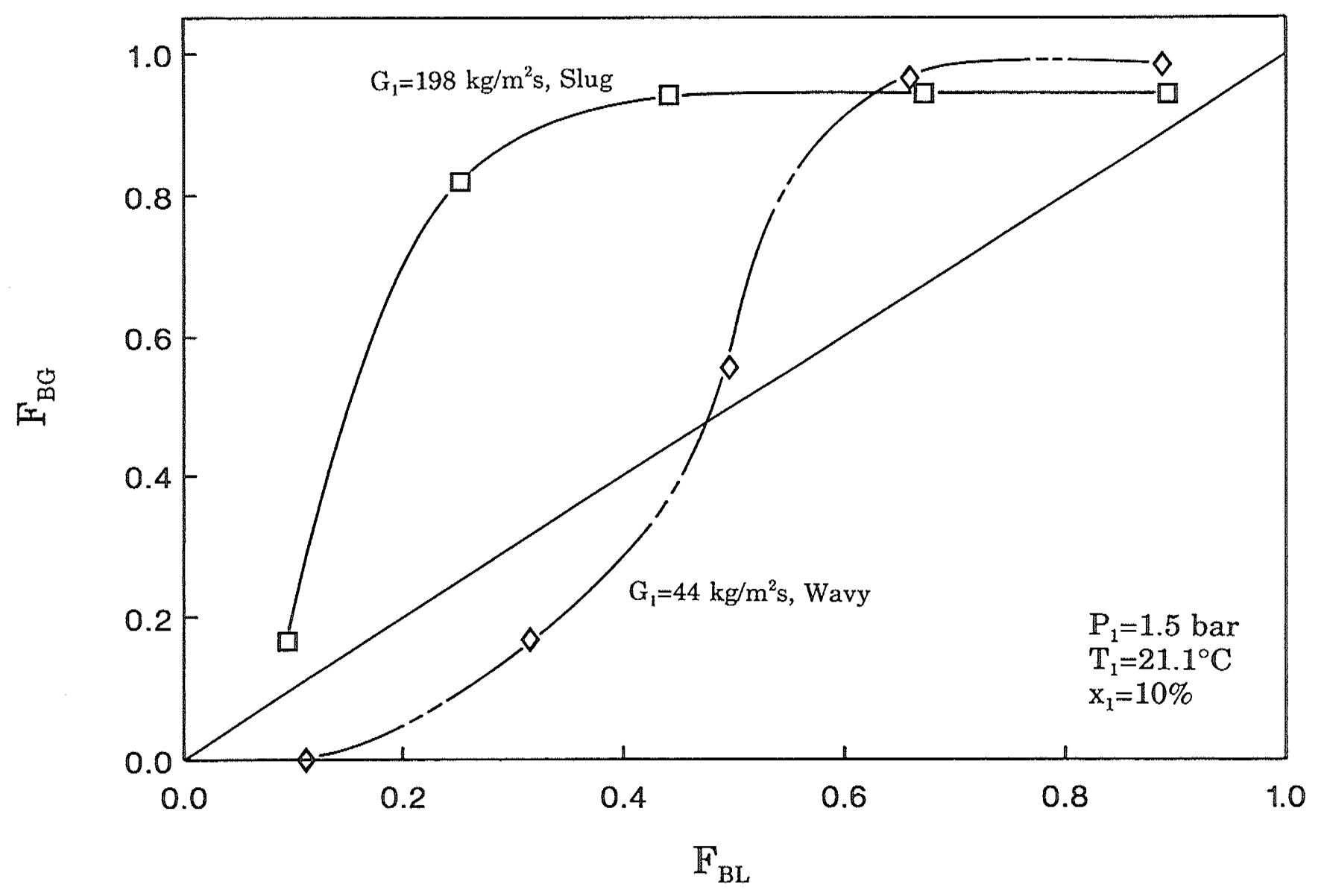

(b)

Figure 4.10 Effect of inlet mass flux on the phase distribution for 


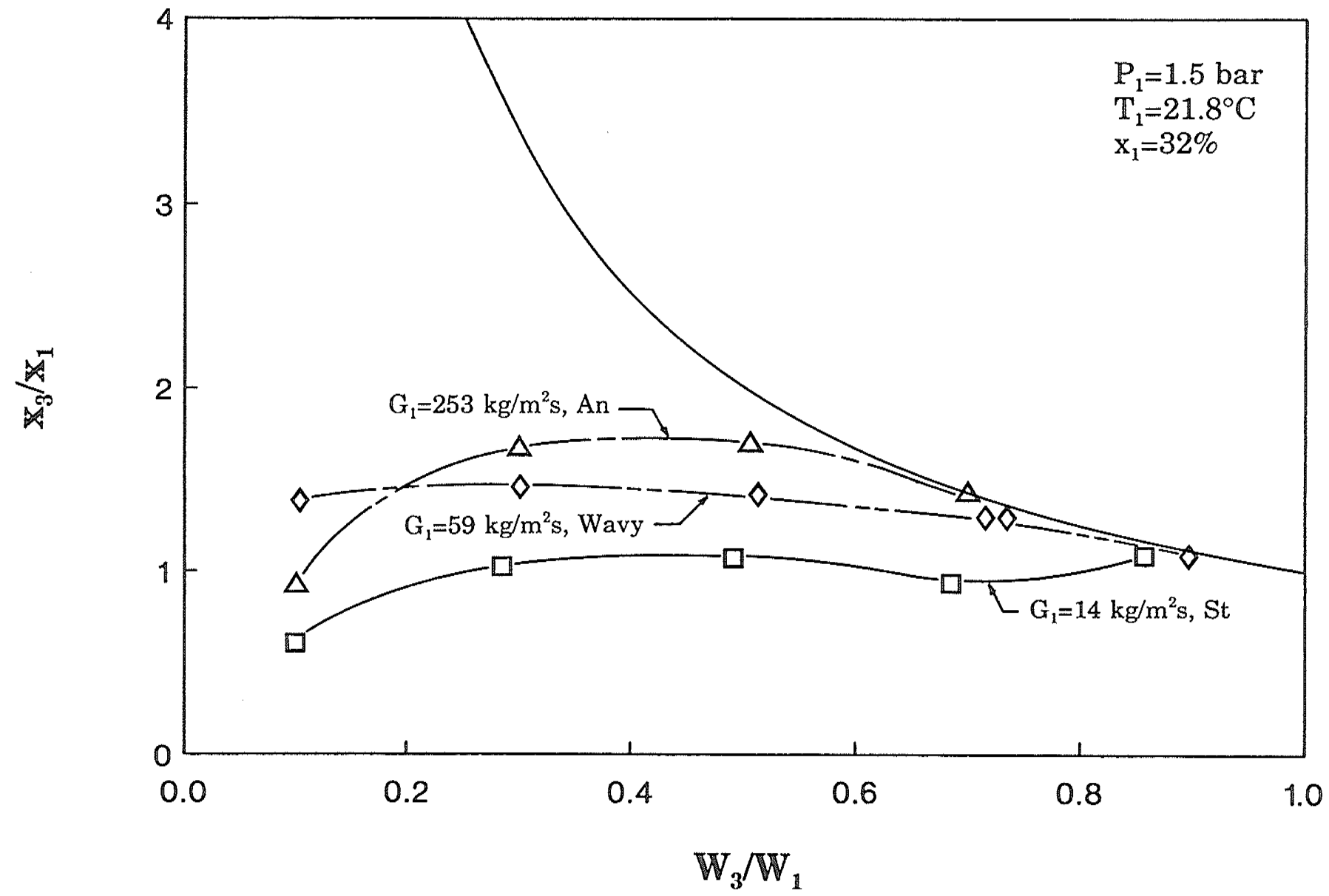

(a)

Figure 4.11 Effect of inlet mass flux on the phase distribution for $\mathrm{x}_{1}=32 \%$ 


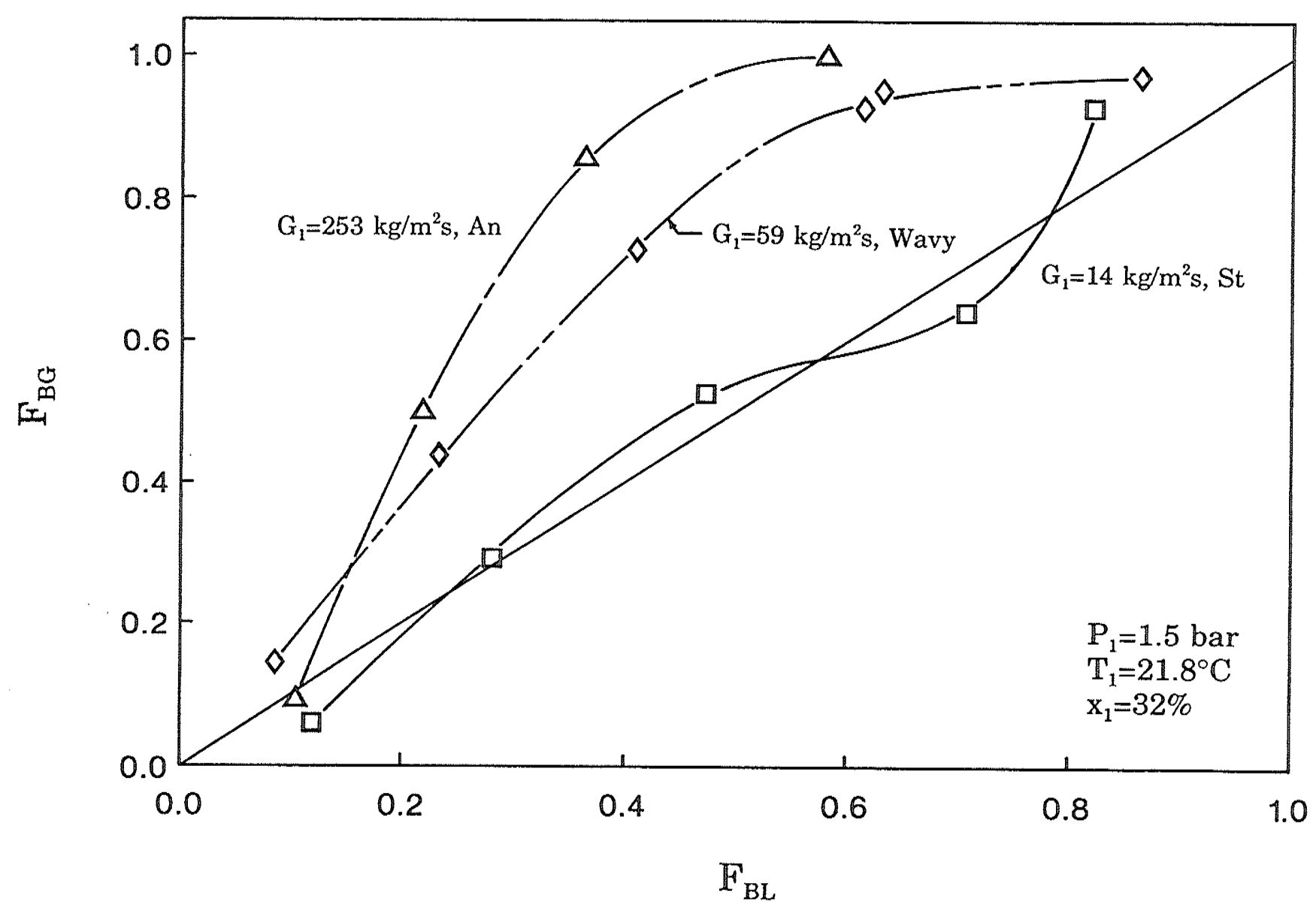

(b)

Figure 4.11 Effect of inlet mass flux on the phase distribution for $\mathrm{x}_{1}=32 \%$ 


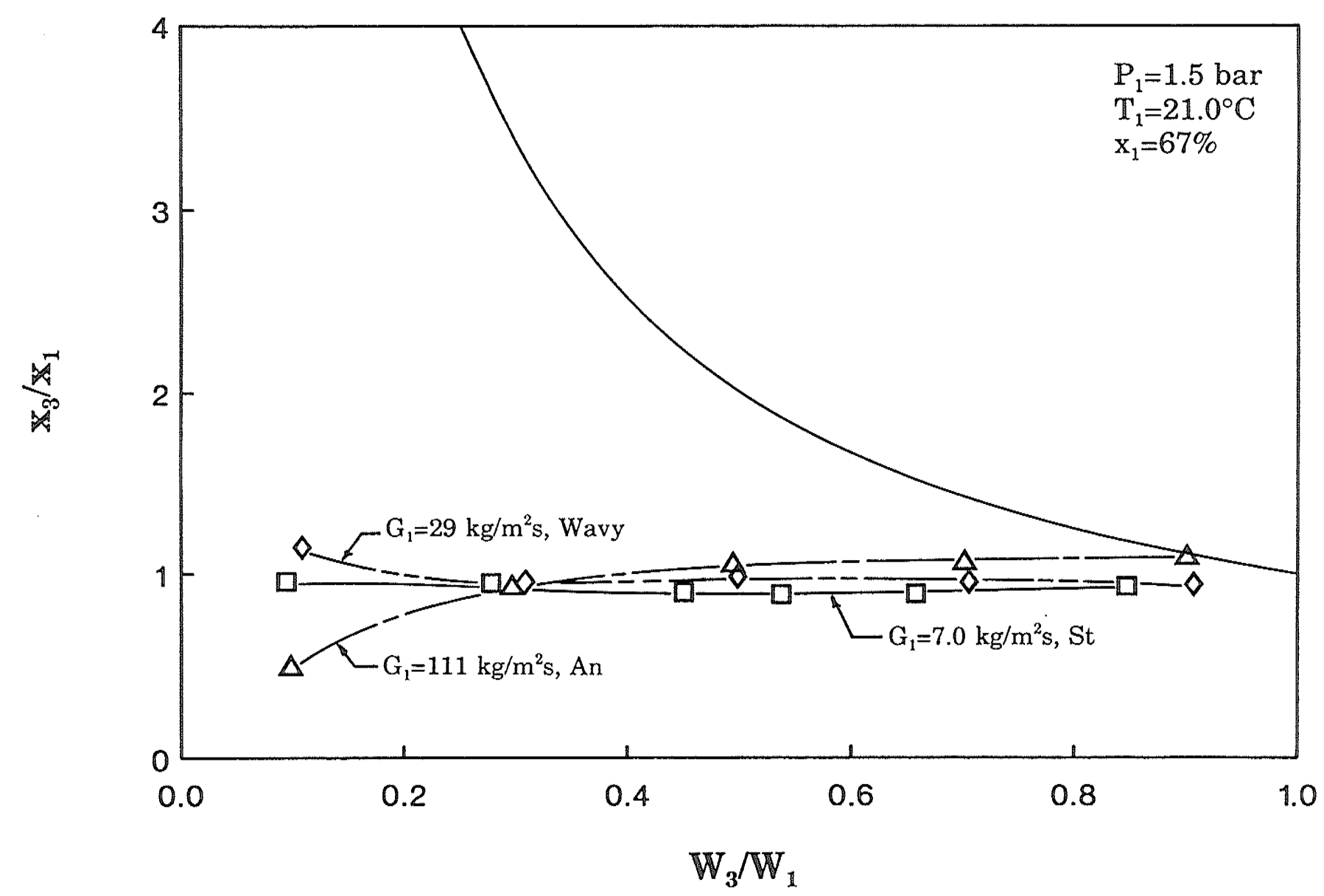

(a)

Figure 4.12 Effect of inlet mass flux on the phase distribution for $\mathrm{x}_{1}=67 \%$ 


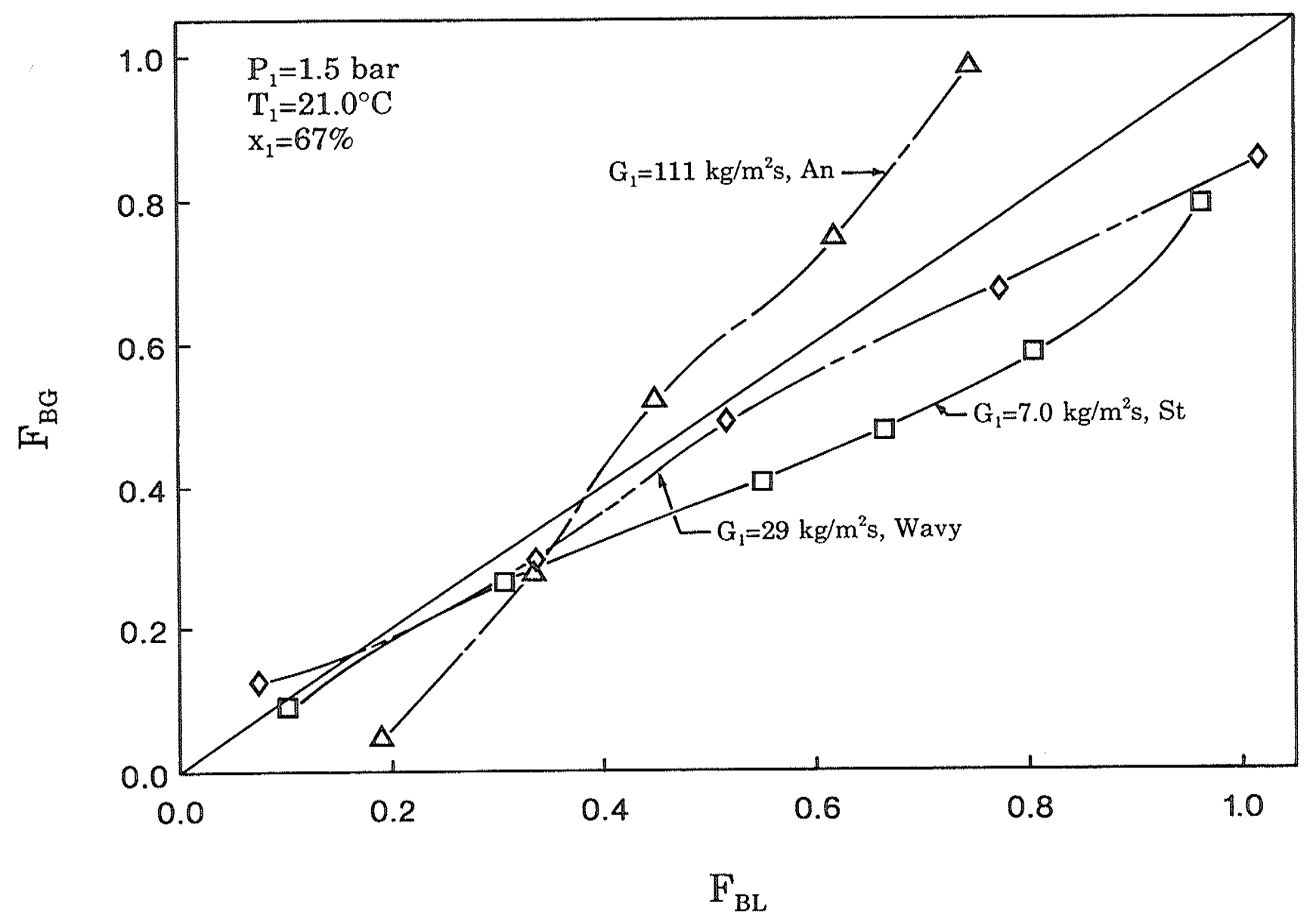

(b)

Figure 4.12 Effect of inlet mass flux on the phase distribution for $\mathrm{x}_{1}=67 \%$ 


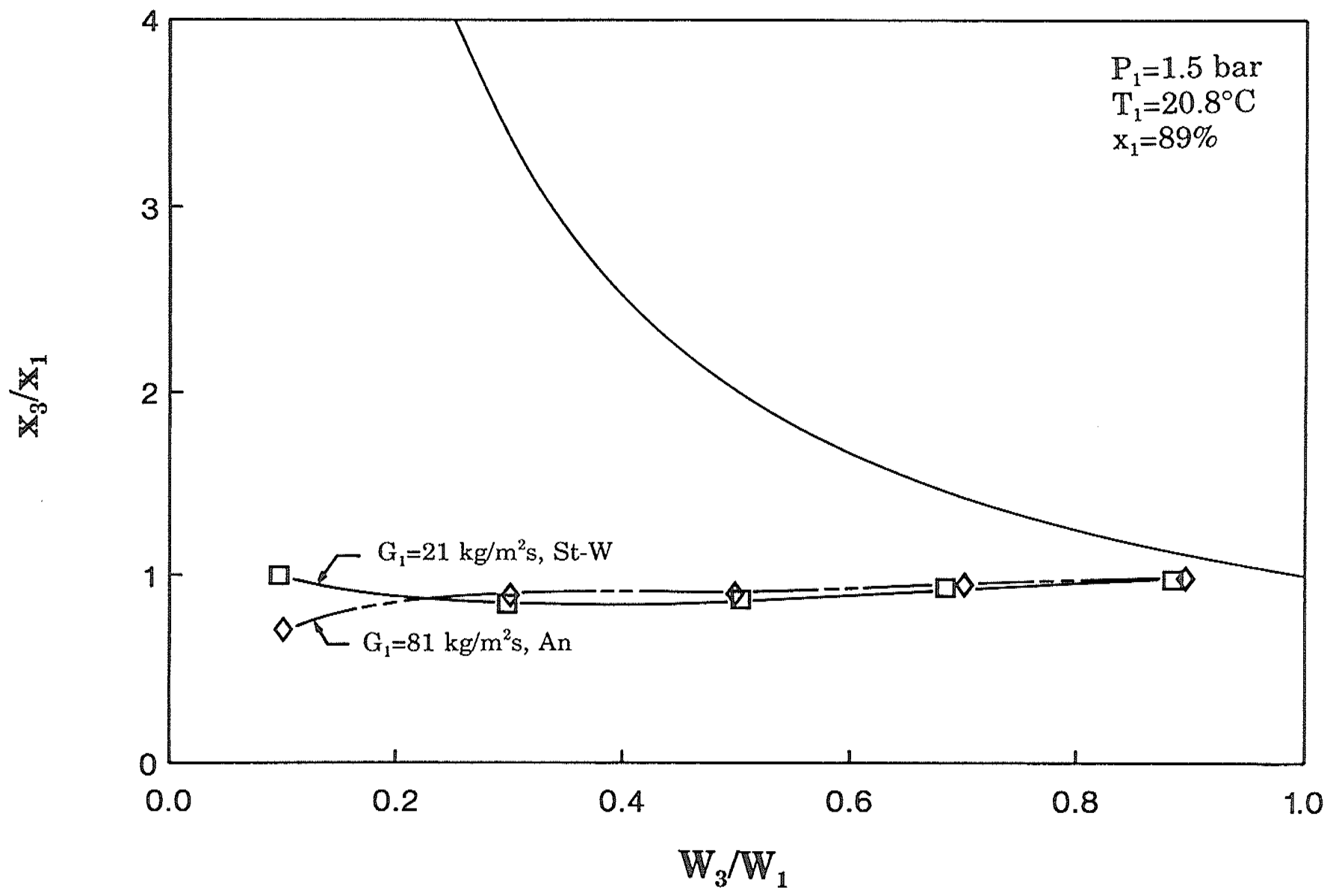

(a)

Figure 4.13 Effect of inlet mass flux on the phase distribution for $\mathrm{x}_{1}=89 \%$ 


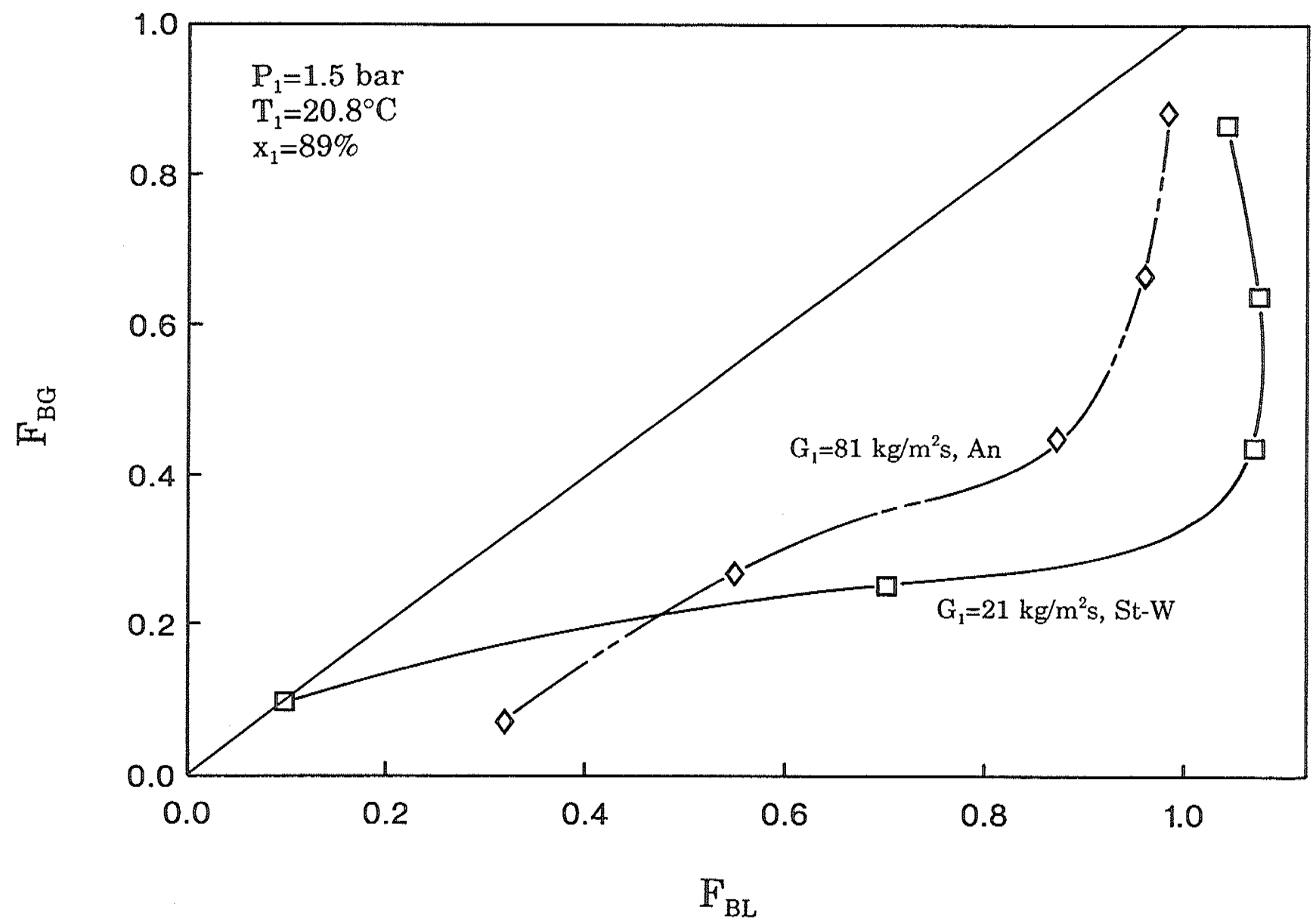

(b)

Figure 4.13 Effect of inlet mass flux on the phase distribution for $\mathrm{x}_{1}=89 \%$ 
dominant influence since none of the data remain within the same inlet flow regime as $G_{1}$ is varied. Rubel et al. [20] also observed that the effect of $G_{1}$ variation at a fixed inlet quality becomes more significant as $\mathrm{x}_{1}$ is decreased. Within a particular inlet flow regime, Rubel et al. [20] observed that the effect of $\mathrm{G}_{1}$ variation on the phase distribution was insignificant; however, it should be noted that the range of $G_{1}$ covered (for the same $x_{1}$ and the same inlet flow regime) was not very wide and this trend may not be valid over a wider range of $\mathrm{G}_{1}$. The data of Saba and Lahey [12] corresponding to an inlet flow regime of slug flow showed very little effect of $G_{1}$ on the phase distribution over the entire range of $x_{1}(0.1-1.0 \%)$ tested. However, the ranges of $G_{1}$ and $x_{1}$ tested were not as wide as the present ranges.

\subsubsection{Effect of Inlet Flow Regime}

In figures 4.2 to 4.13 , the variation of inlet gas and liquid flow rates in many cases resulted in changes in the inlet flow regime. In this section, an attempt is made to isolate the effect of the inlet flow regime on the phase distribution by separately plotting the data corresponding to each inlet flow regime.

Figures 4.14 to 4.16 display the regions occupied by the present annular, semiannular, wavy, stratified-wavy, slug, and stratified flow data. The region of annular flow data, shown in figure 4.14 , occupies a large area that extends 


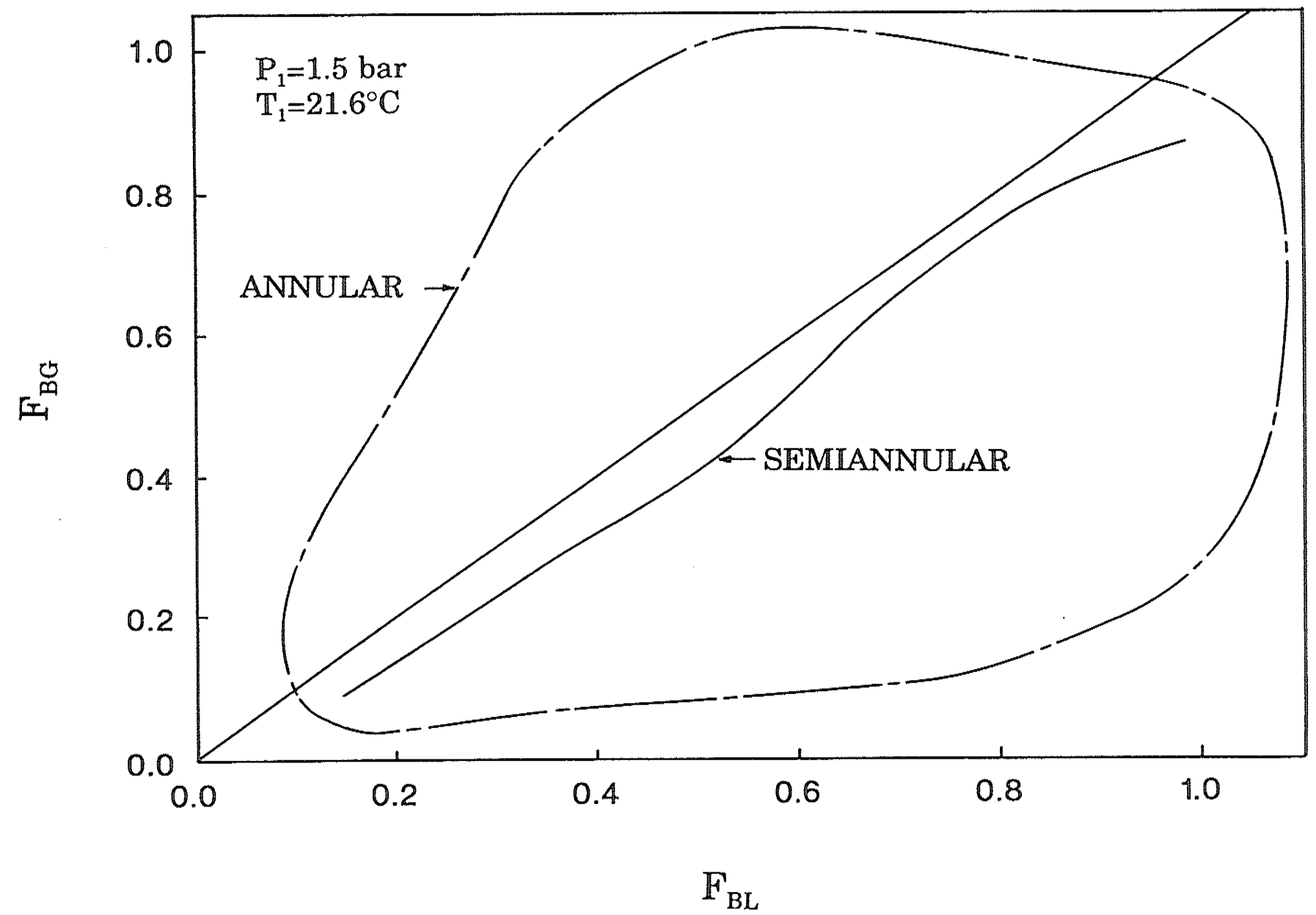

Figure 4.14 Effect of inlet flow regime on the phase distribution for annular and semiannular flow data 


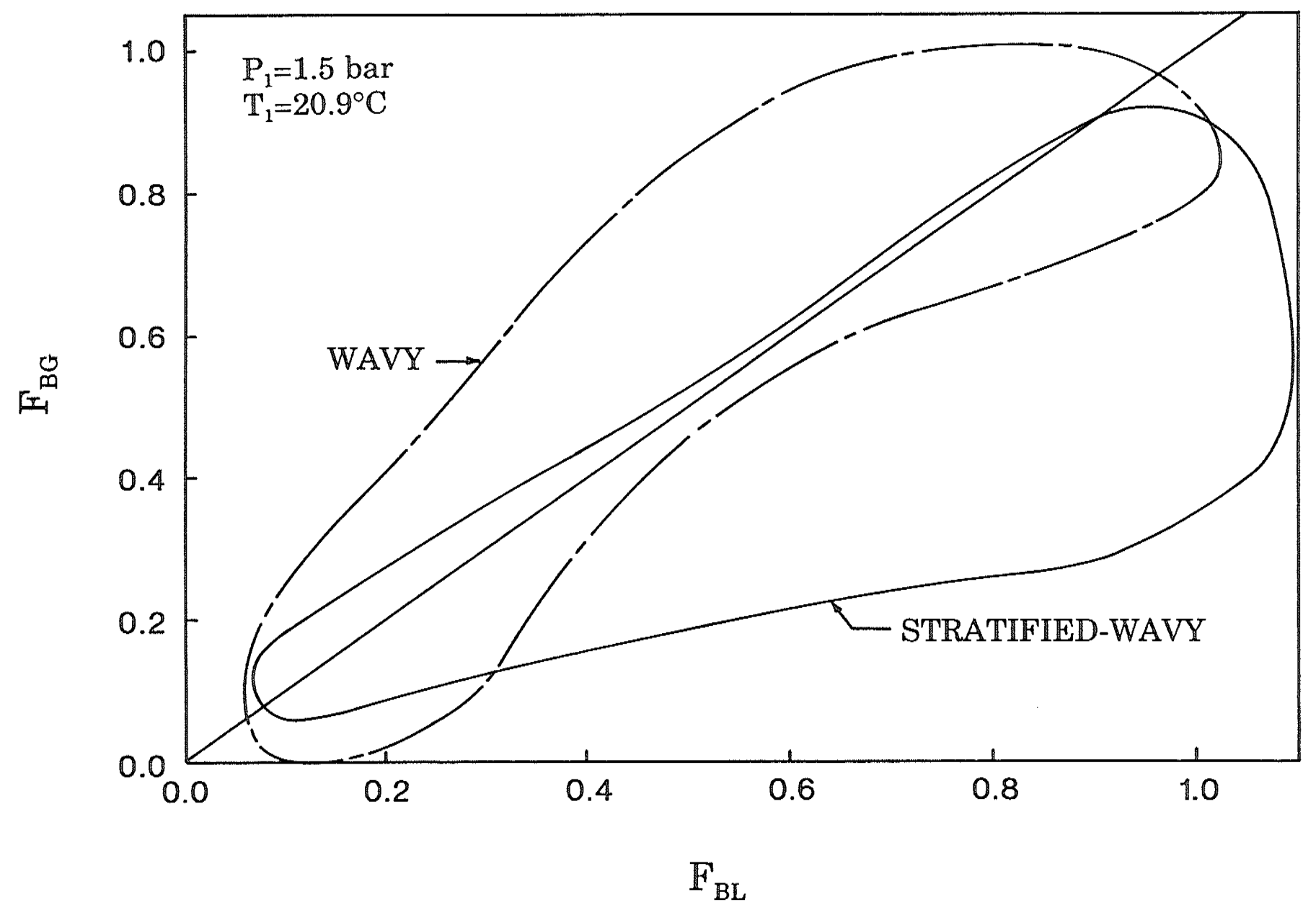

Figure 4.15 Effect of inlet flow regime on the phase distribution for wavy and stratified-wavy flow data 


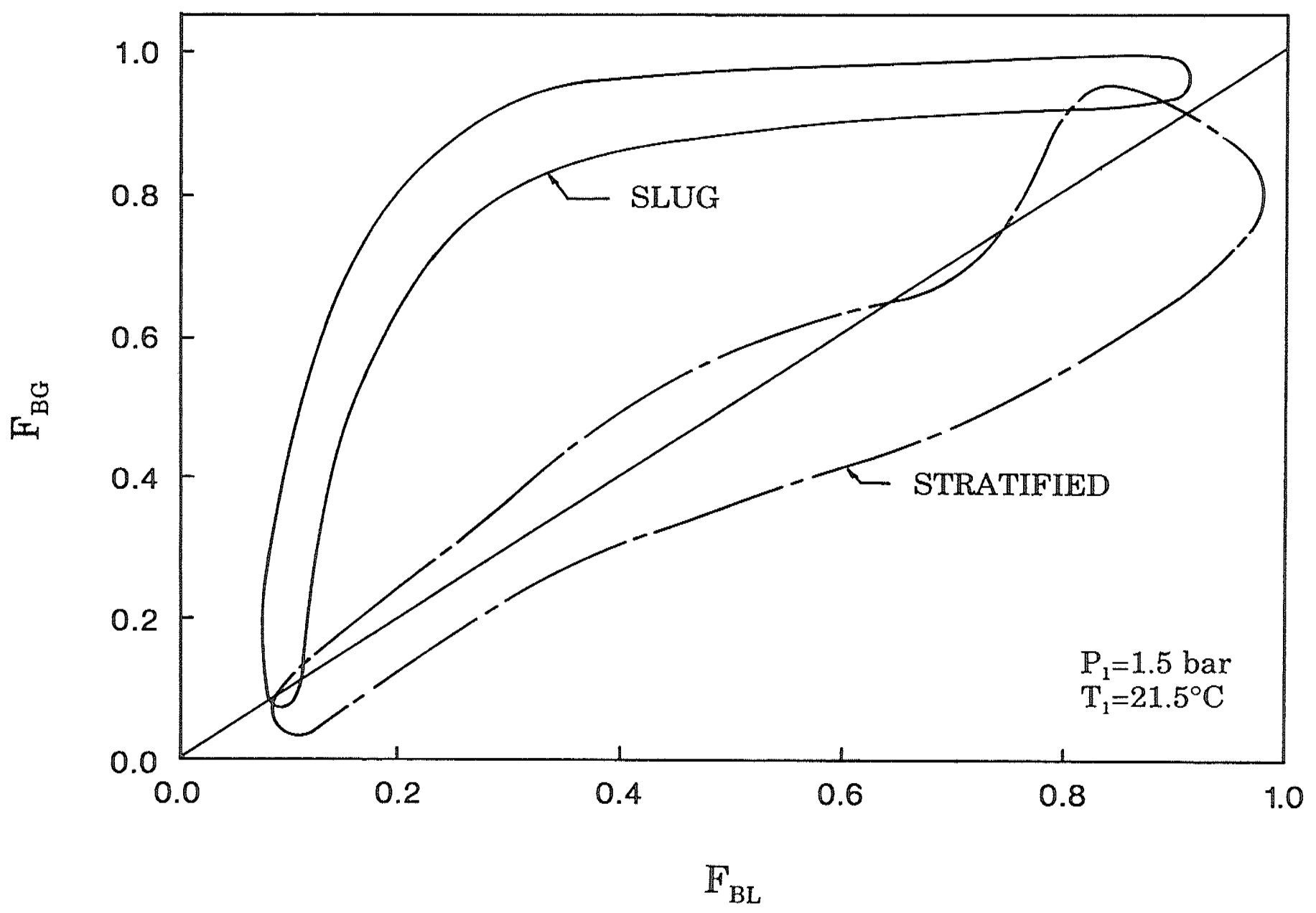

Figure 4.16 Effect of inlet flow regime on the phase distribution for slug and stratified flow data 
well above and below the line of even phase distribution, depending on $J_{\mathrm{L} 1}$ as discussed in section 4.2.1. The semiannular data were only obtained at one set of inlet conditions. Wavy and stratified-wavy data are shown in figure 4.15. The majority of the wavy flow data lie above the line of even phase distribution and nearly all of the stratified-wavy data fall below the line of even phase distribution. The stratified data shown in figure 4.16 lie near the line of even phase distribution, while the slug flow data fall well above the even phase distribution line, indicating a strong preference for the gas to exit through the branch. Saba and Lahey [12] also found that data corresponding to an inlet flow regime of slug flow showed a strong preference for the gas to exit through the branch.

\subsection{Presentation of Pressure-Drop Data}

\subsubsection{Single.Phase Flow}

Single-phase liquid pressure-drop data were obtained under the test conditions described in section 4.1. The operating conditions and corresponding pressure-drop data for single-phase flow are tabulated in Appendix C.

Figures 4.17 and 4.18 show typical pressure distributions obtained during single-phase flow. The ordinate in these figure is $\left(\mathrm{P}-\mathrm{P}_{\mathrm{r}}\right)$, where $\mathrm{P}$ is the absolute pressure at a given location and $P_{r}$ is a reference pressure, selected in this study to be the absolute pressure at tap 1 (see figure 3.7). Values of 


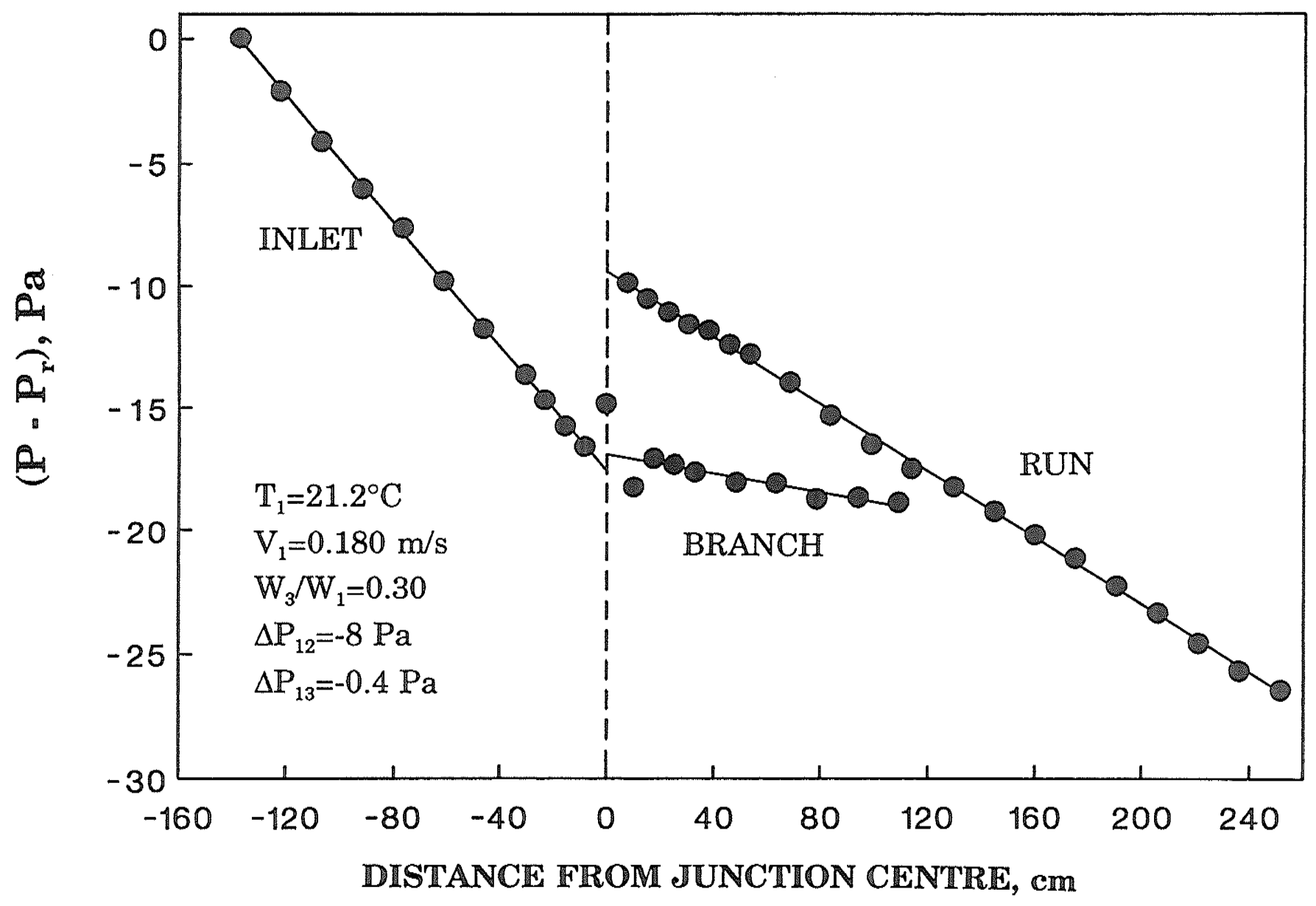

Figure 4.17 Pressure distribution during single-phase flow for $\mathrm{W}_{3} / \mathrm{W}_{1}=0.30$ 


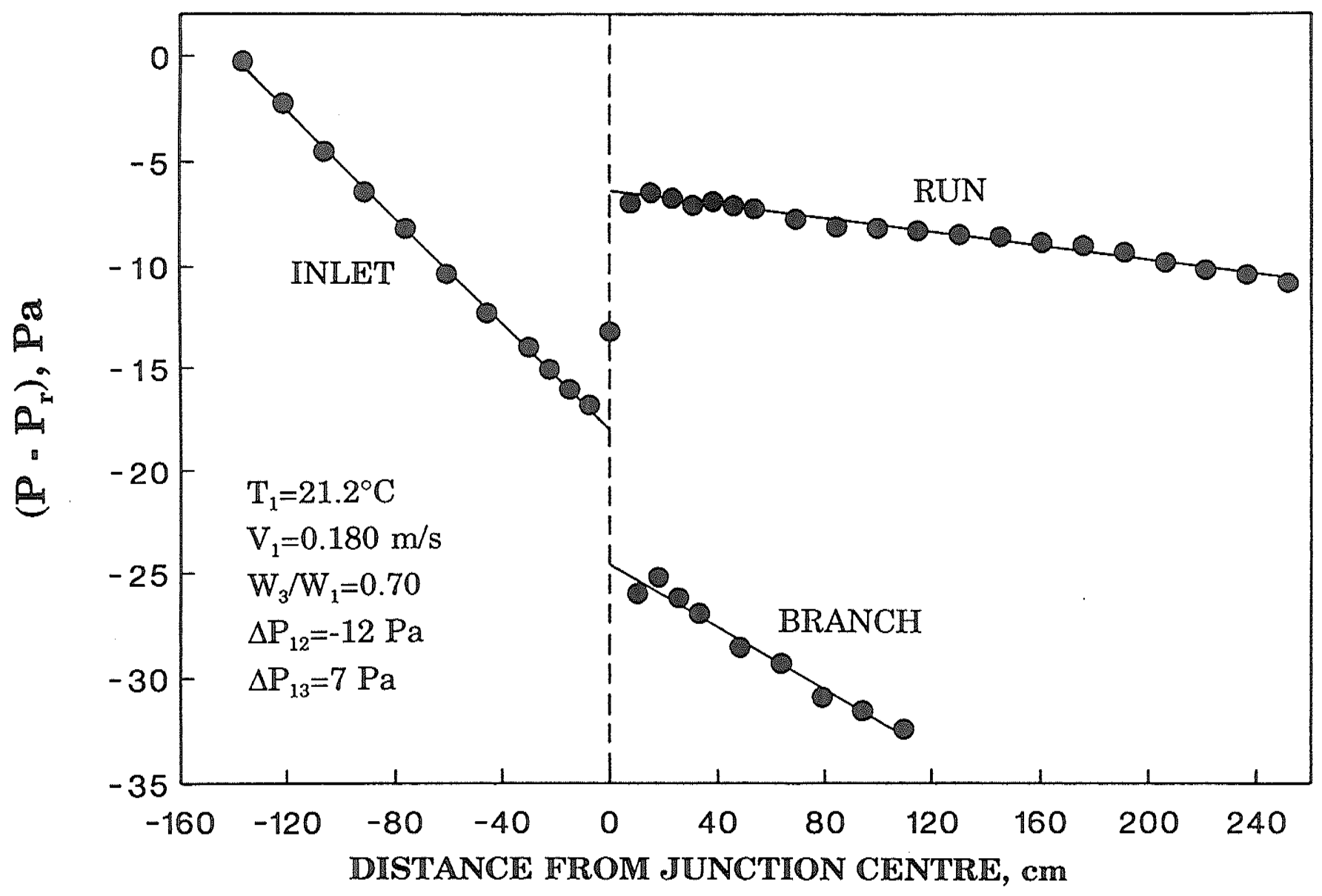

Figure 4.18 Pressure distribution during single-phase flow for $\mathrm{W}_{3} / \mathrm{W}_{1}=0.70$ 
$\Delta \mathrm{P}_{12}$ and $\Delta \mathrm{P}_{13}$ were obtained by extrapolating the fully-developed pressure gradients in the inlet, run, and branch to the junction centre. The linear equations for the inlet, run, and branch were obtained using least-squares analysis as outlined in Appendix B. Figure 4.17 shows the pressure distribution for $\mathrm{W}_{3} / \mathrm{W}_{1}=0.30$, while the pressure distribution shown in figure 4.18 was obtained at $\mathrm{W}_{3} / \mathrm{W}_{1}=0.70$.

Figure 4.19 shows the single-phase loss coefficient $\mathrm{K}_{12}$, and figure 4.20 shows the single-phase loss coefficient $\mathrm{K}_{13}$. The loss coefficients were calculated using equations (2.17), (2.18), and (2.19). Using the method of least squares, the present data were well correlated by

$$
K_{12}=-0.375 \eta+0.959 \eta^{2}-0.310 \eta^{3}
$$

and

$$
K_{13}=1.000-0.982 \eta+1.843 \eta^{2}-0.717 \eta^{3},
$$

where $\eta$ is the extraction rate. The least-squares polynomial for $\mathrm{K}_{12}$ was forced through the origin since, theoretically, $\mathrm{K}_{12}$ should approach zero as the extraction rate approaches zero. Therefore, the datum point at the extraction rate of zero was not used in obtaining the least-squares polynomial. Similarly, the least-squares polynomial for $\mathrm{K}_{13}$ was forced to approach unity at an extraction rate of zero, and the datum point at the extraction rate of zero was not used in obtaining the least-squares polynomial. Agreement between the present $\mathrm{K}_{12}$ and the empirical curves obtained by Reimann and Seeger [26] and Hwang and Lahey [28] is good, considering the much larger inlet mass fluxes 


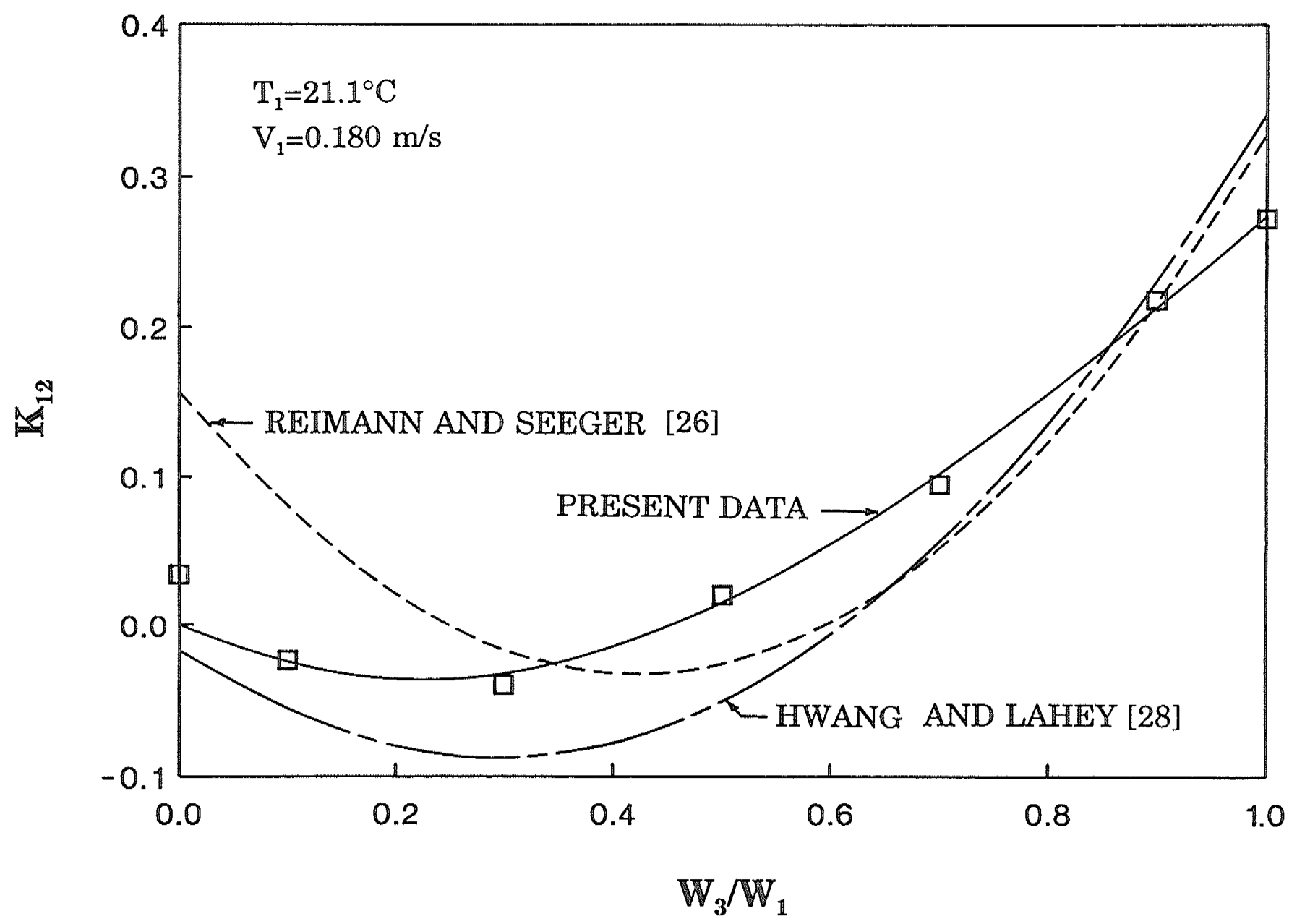

Figure 4.19 Single-phase loss coefficient, $\mathbb{K}_{12}$ 


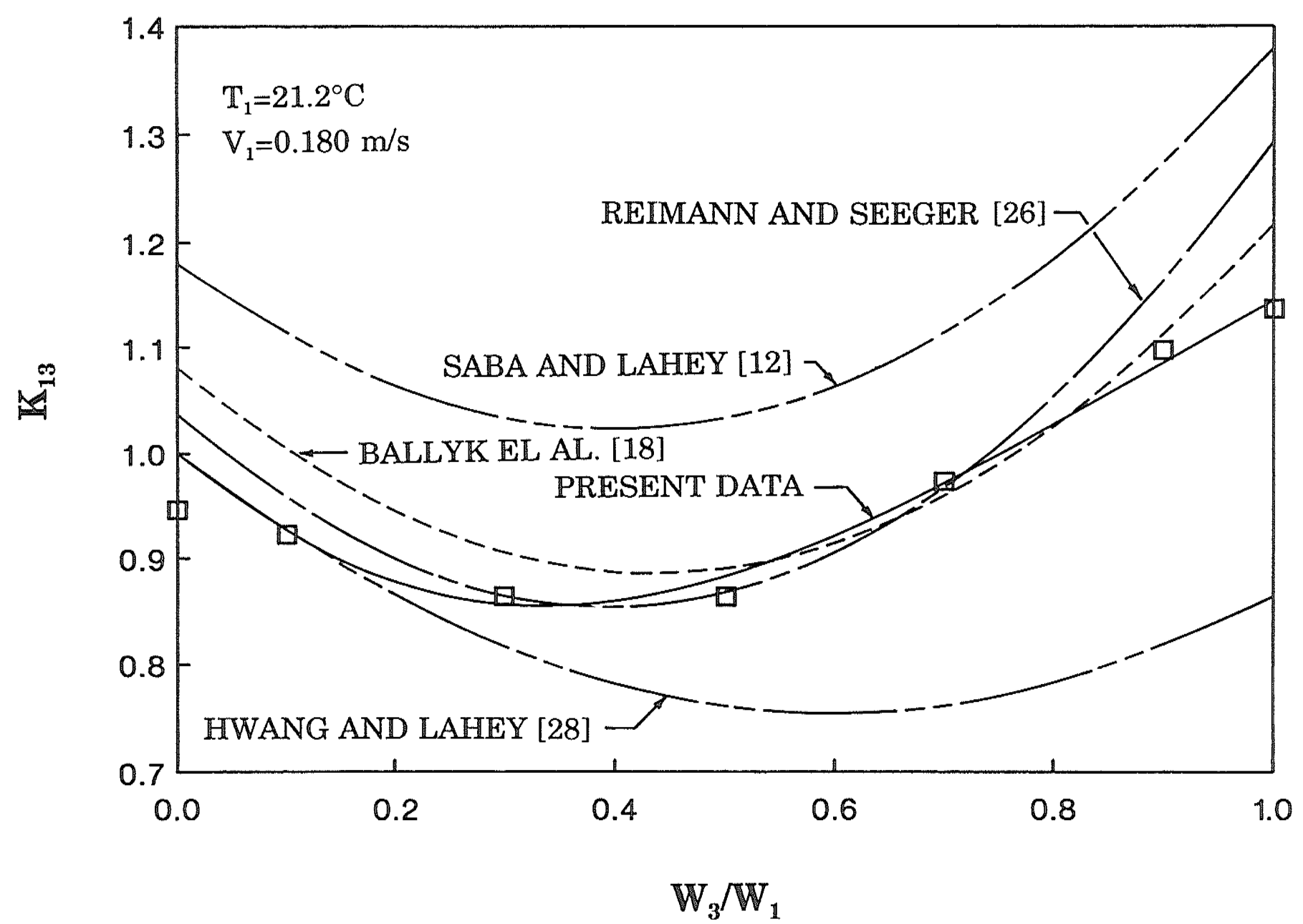

Figure 4.20 Single-phase loss coefficient, $\mathbb{K}_{13}$ 
used in these studies. The present data for $K_{13}$ agree best with the curves published by Ballyk et al. [18] and Reimann and Seeger [26].

Equation (2.16) was used to calculate the single-phase momentum correction factor $\mathrm{K}^{\star}{ }_{12}$ shown in figure 4.21 . Using least squares analysis, the data were well correlated by

$$
K_{12}^{\star}=0.570-0.102 \eta-0.107 \eta^{2},
$$

where $\eta$ is the extraction rate. Equation (4.3) does not apply at $W_{3} / W_{1}=0$ because $K_{12}^{\star}$ is not defined at this point. Agreement with the curves recommended by Ballyk et al. [18] and Hwang and Lahey [28] is very good, particulary at large $\mathrm{W}_{3} / \mathrm{W}_{1}$.

\subsubsection{Two-Phase Flow}

Typical pressure distributions during two-phase flow are shown in figures 4.22 to 4.24 . All two-phase pressure-drop data were obtained at the conditions outlined in table 4.1 , and the extrapolated pressure drops $\Delta \mathrm{P}_{12}$ and $\Delta \mathrm{P}_{13}$ along with the range of inlet operating conditions are given in Appendix C. Figure 4.22 gives a typical pressure distribution corresponding to an inlet flow regime of wavy flow with $\mathrm{W}_{3} / \mathrm{W}_{1}=0.31$. For this particular test run, there is a net pressure rise from the inlet to both the run and branch. This was typical for small extraction rates $\left(\mathrm{W}_{3} / \mathrm{W}_{1} \leq 0.3\right)$. For large extraction rates, the net pressure drop from the inlet to the branch became positive, as shown in 


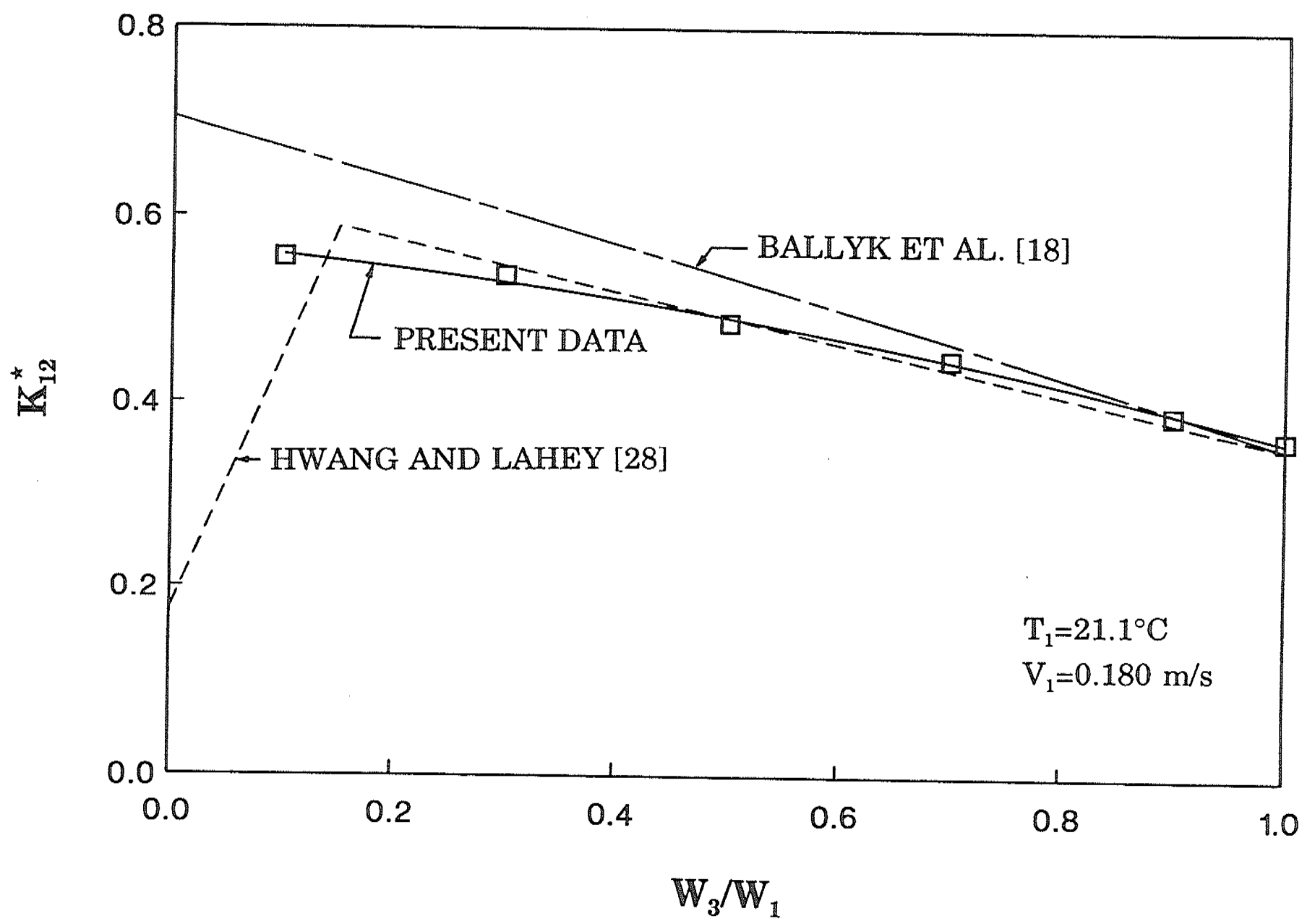

Figure 4.21 Single-phase momentum correction factor, $\mathbb{K}^{\star}{ }_{12}$ 


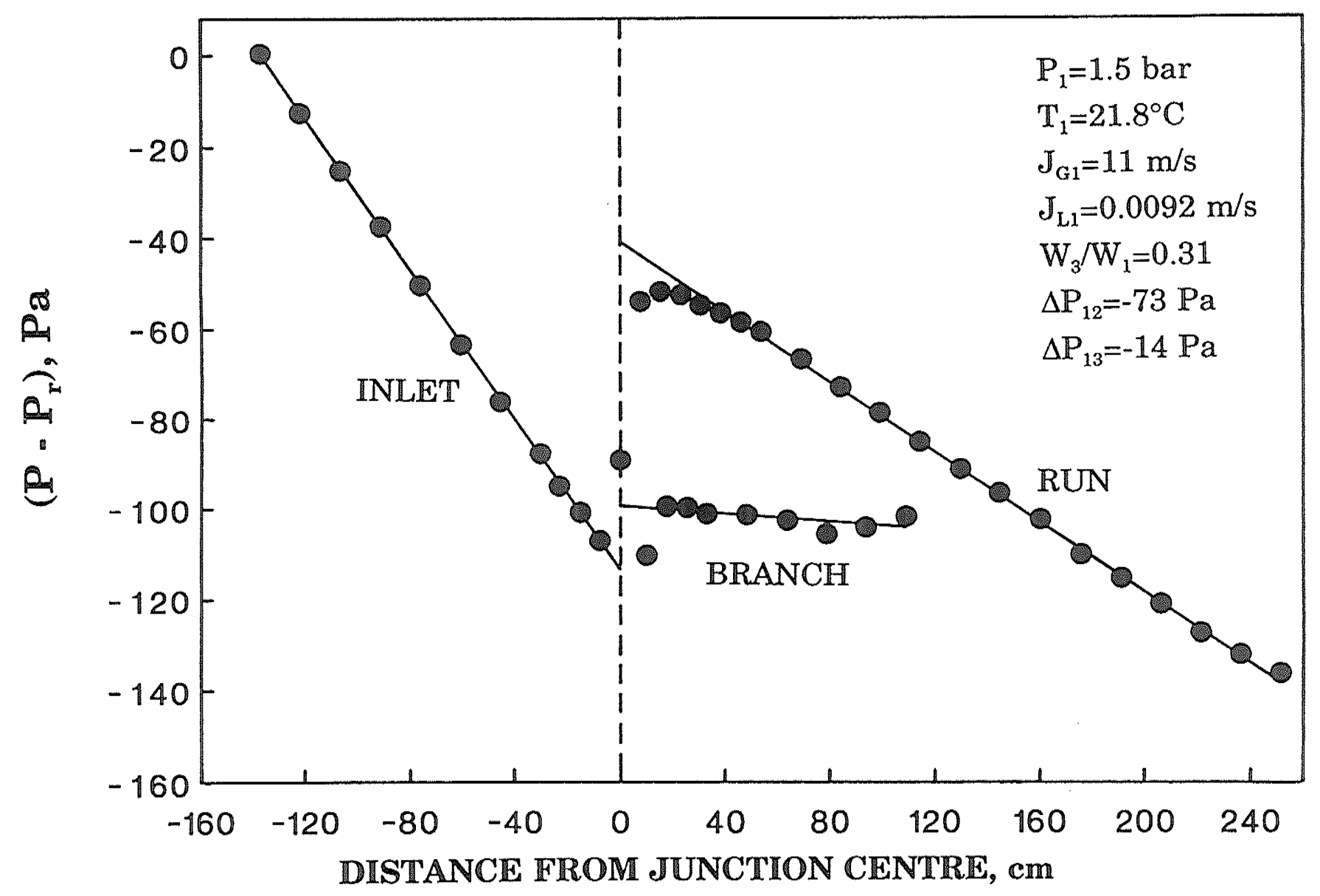

Figure 4.22 Pressure distribution during two-phase flow, test 2-2 


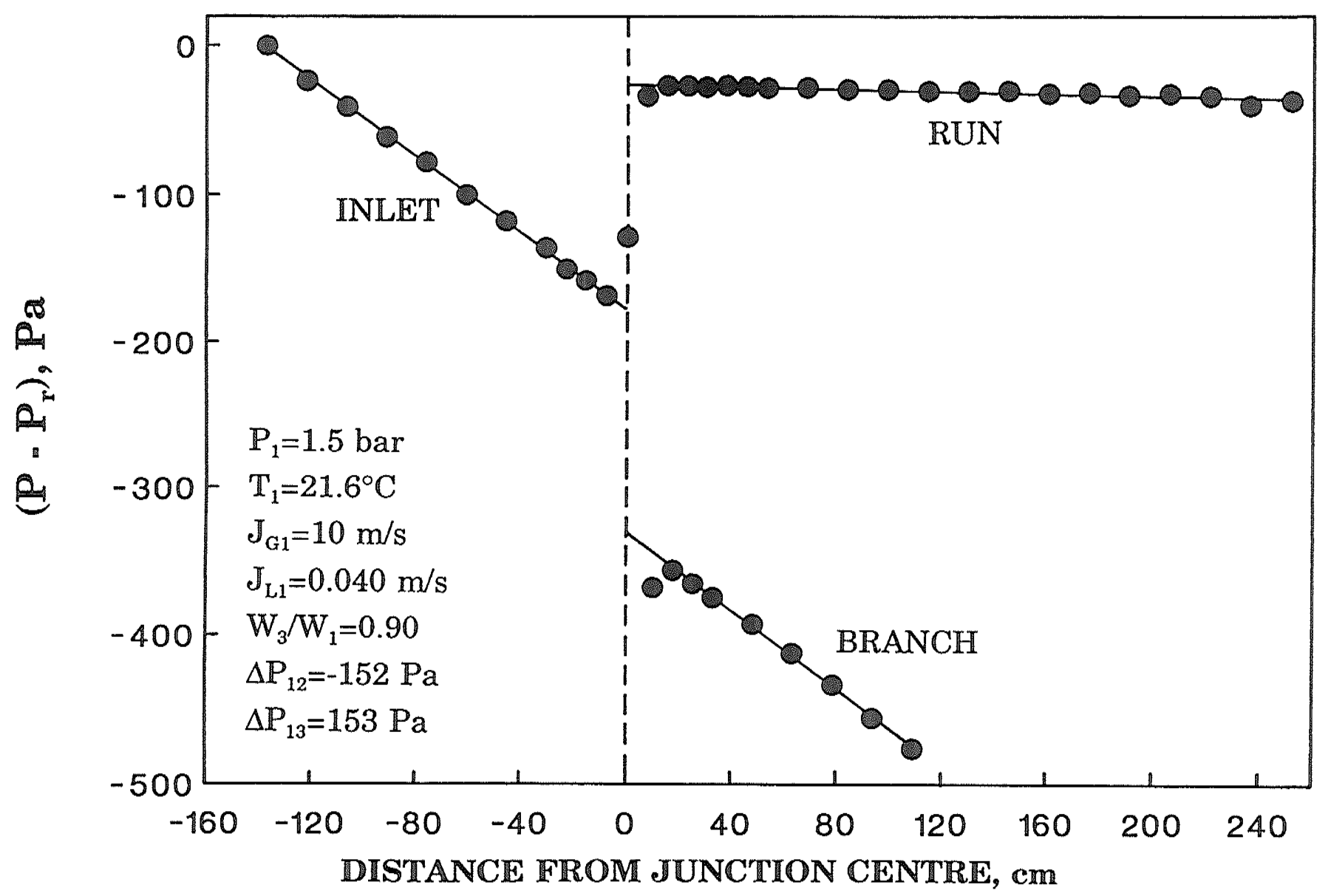

Figure 4.23 Pressure distribution during two-phase flow, test 1-6 


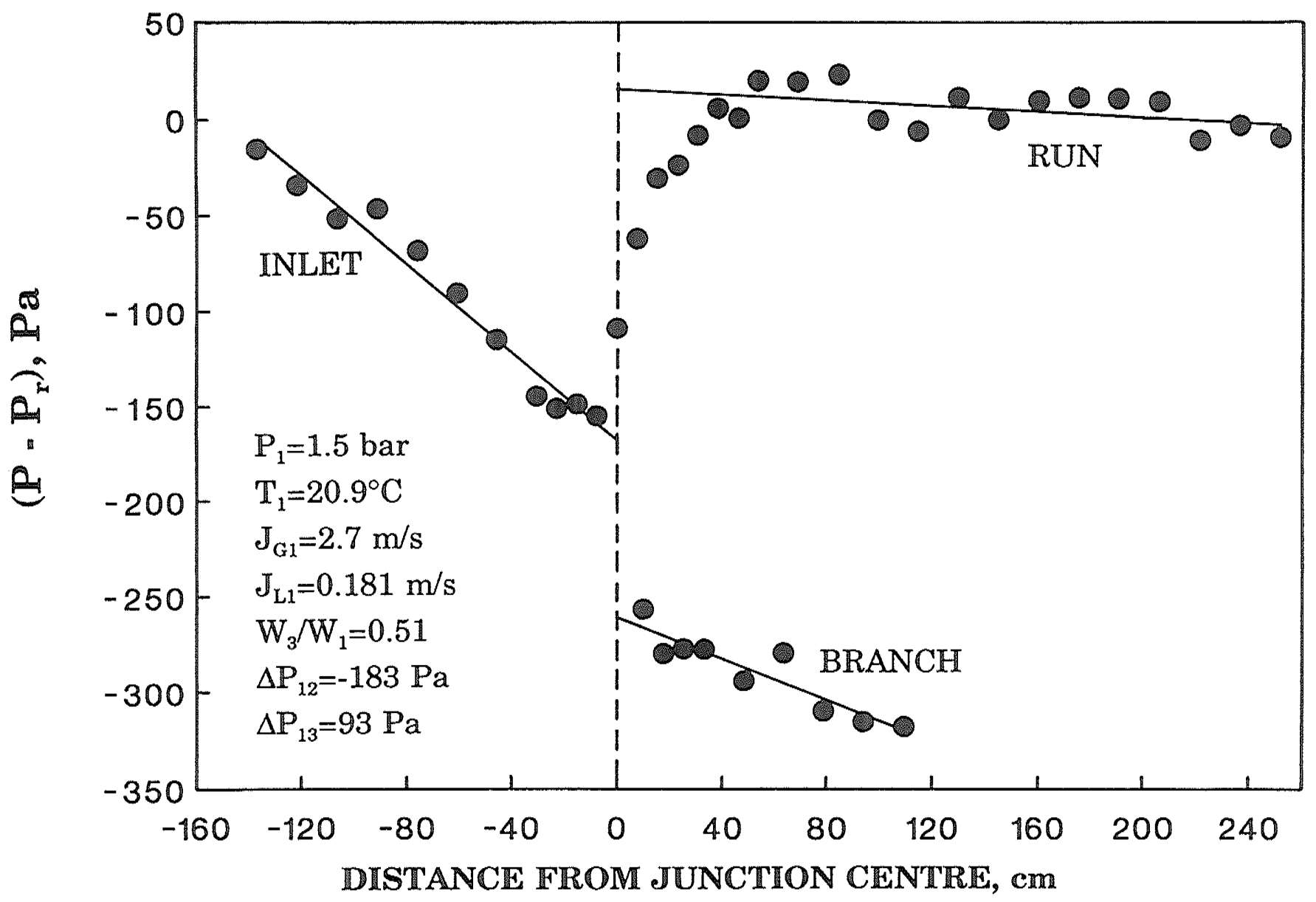

Figure 4.24 Pressure distribution during two-phase flow, test 6-3 
figure 4.23 , due to an increase in the irreversible pressure drop. Figure 4.24 shows a typical pressure distribution corresponding to an inlet flow regime of slug flow. The data show more scatter around the "best fit" equations in the inlet, run, and branch. This was caused by the pressure fluctuations that are typical of slug flow. This scatter, which is still within acceptable bounds, would undoubtedly increase the uncertainty in the values of $\Delta \mathrm{P}_{12}$ and $\Delta \mathrm{P}_{13}$.

A careful study of the pressure-drop data in Appendix $\mathrm{C}$ reveals that values of $\Delta \mathrm{P}_{12}$ and $\Delta \mathrm{P}_{13}$ are not given for all test runs. Although an attempt was made to obtain pressure-drop data for each test run, accurate values of the pressure drops could not be measured for all test runs due to a number of different reasons. For example, no pressure-drop data were obtained during stratified and some stratified-wavy flow test runs since, at the very small inlet flow rates typical of these flow regimes, the pressure gradients and junction pressure drops were too small to be measured accurately. At some other test conditions, $\Delta \mathrm{P}_{12}$ could not be obtained because the flow in the run appeared not to be fully developed. Problems encountered in measuring the pressure distributions are discussed in more detail in Appendix D.

Figures 4.25 and 4.26 illustrate the effect of $\mathrm{J}_{\mathrm{L} 1}$ variation at a fixed $\mathrm{J}_{\mathrm{G} 1}$ on the pressure drops $\Delta \mathrm{P}_{12}$ and $\Delta \mathrm{P}_{13}$. Analysis of the graphs reveals that the absolute value of $\Delta \mathrm{P}_{12}$ increased as $\mathrm{J}_{\mathrm{L} 1}$ increased. In general, $\Delta \mathrm{P}_{13}$ also increased as $\mathrm{J}_{\mathrm{L} 1}$ was increased, due to an increase in the irreversible pressure losses. 


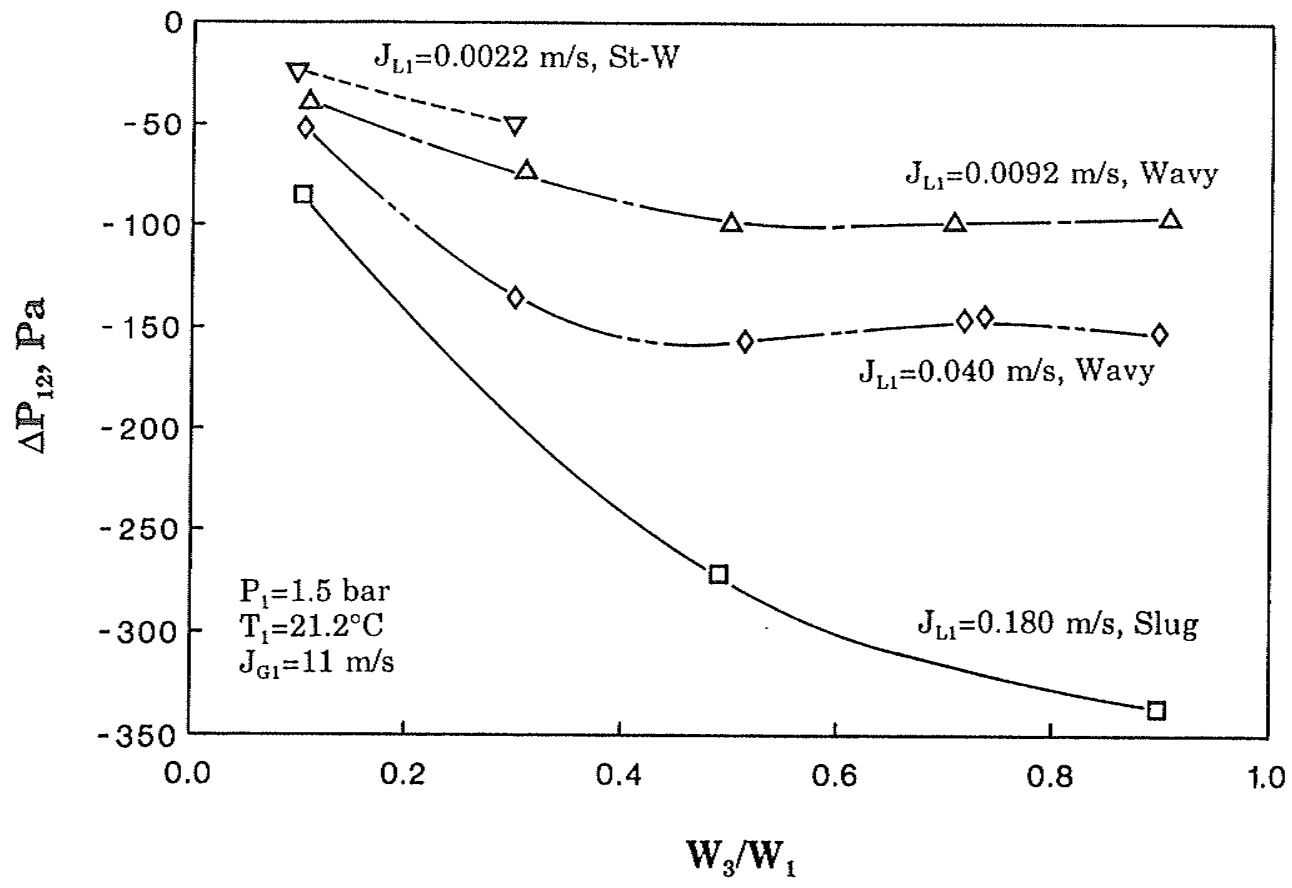

(a)

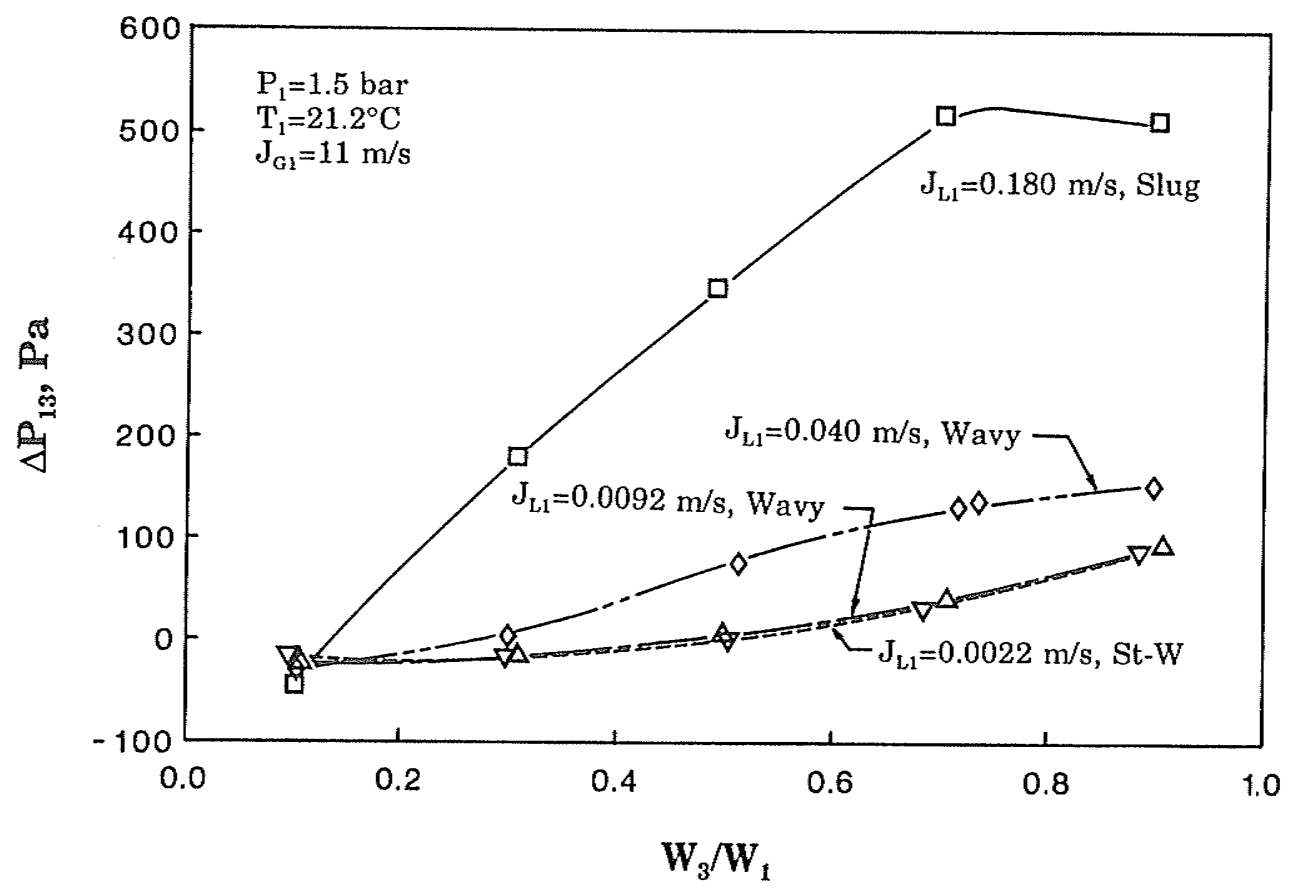

(b)

Figure 4.25 Effect of $J_{L 1}$ on the pressure drops for $J_{G 1}=11 \mathrm{~m} / \mathrm{s}$ 


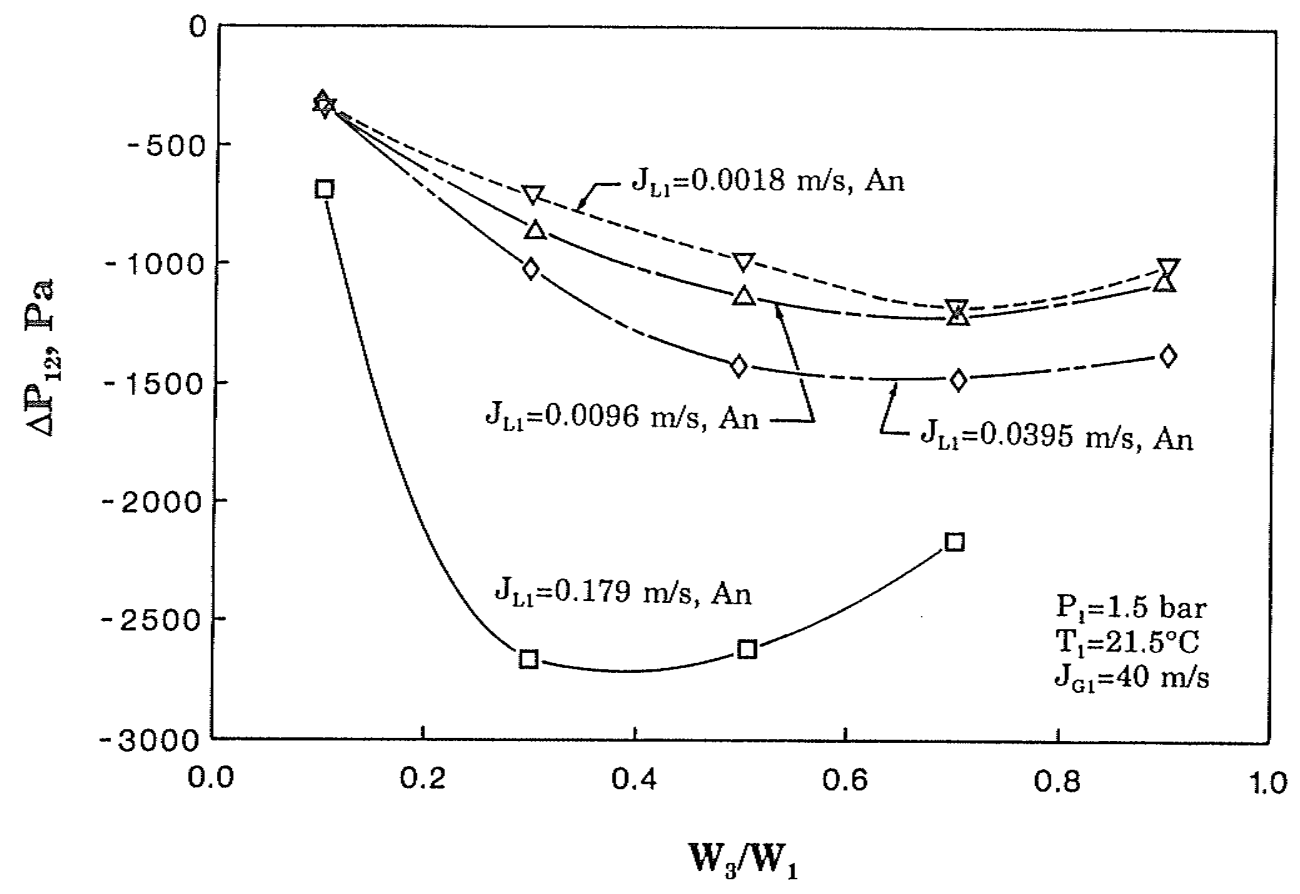

(a)

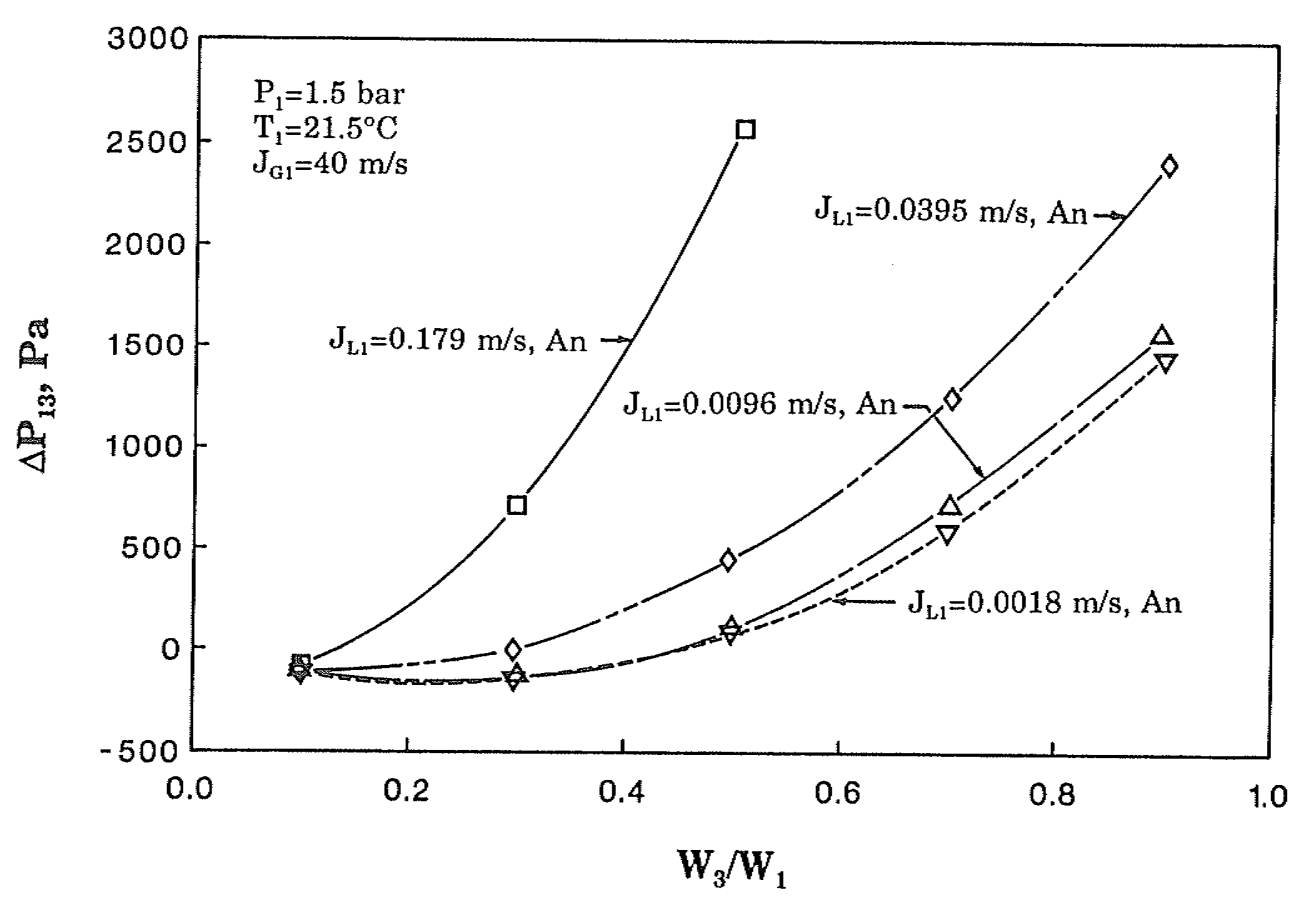

(b)

Figure 4.26 Effect of $J_{\mathrm{L} 1}$ on the pressure drops for $\mathrm{J}_{\mathrm{G} 1}=40 \mathrm{~m} / \mathrm{s}$ 
The effect of $\mathrm{J}_{\mathrm{G} 1}$ variation at a fixed $\mathrm{J}_{\mathrm{L} 1}$ on the pressure drops $\Delta \mathrm{P}_{12}$ and $\Delta \mathrm{P}_{13}$ is shown in figures 4.27 and 4.28. In general, the absolute value of $\Delta \mathrm{P}_{12}$ and $\Delta \mathrm{P}_{13}$ increased (at a fixed $\mathrm{W}_{3} / \mathrm{W}_{1}$ ) as $\mathrm{J}_{\mathrm{G} 1}$ was increased. Both figures show that $\Delta \mathrm{P}_{12}$ and $\Delta \mathrm{P}_{13}$ change significantly as the inlet flow regime changes to annular flow. Also shown in figure 4.28 are the single-phase pressure-drop data.

\subsection{Experimental Uncertainty}

An error analysis was undertaken for both the phase-distribution and pressure-drop data. The procedure and the results of this analysis are given in Appendix E. A summary of the error analysis is provided here.

The experimental uncertainty in the values of $\mathrm{J}_{\mathrm{G} 1}, \mathrm{~J}_{\mathrm{L} 1}, \mathrm{G}_{1}$, and $\mathrm{x}_{1}$ was found to be within $\pm 5 \%$. For $\mathrm{W}_{3} / \mathrm{W}_{1}, \mathrm{x}_{3} / \mathrm{x}_{1}$, and $\mathrm{F}_{\mathrm{BG}}$, the uncertainty was within approximately $\pm 15 \%$, although typical values were near $\pm 6 \%$. The uncertainty in $\mathrm{F}_{\mathrm{BL}}$ ranged between \pm 4 and $\pm 25 \%$, although values were typically closer to $\pm 10 \%$. The estimate of the rate of variation of the height of the gas-liquid interface in the branch separation tank was found to be the dominant parameter for the errors in $\mathrm{F}_{\mathrm{BL}}$. Finally, the errors in the test section inlet pressure and temperature were found to be within $\pm 1.3 \%$ and $\pm 0.3^{\circ} \mathrm{C}$, respectively.

For the two-phase $\Delta \mathrm{P}_{12}$ data, $94 \%$ of the data had relative uncertainties less than $\pm 17 \%$. For the two-phase $\Delta \mathrm{P}_{13}$ data, $76 \%$ of the data had relative 


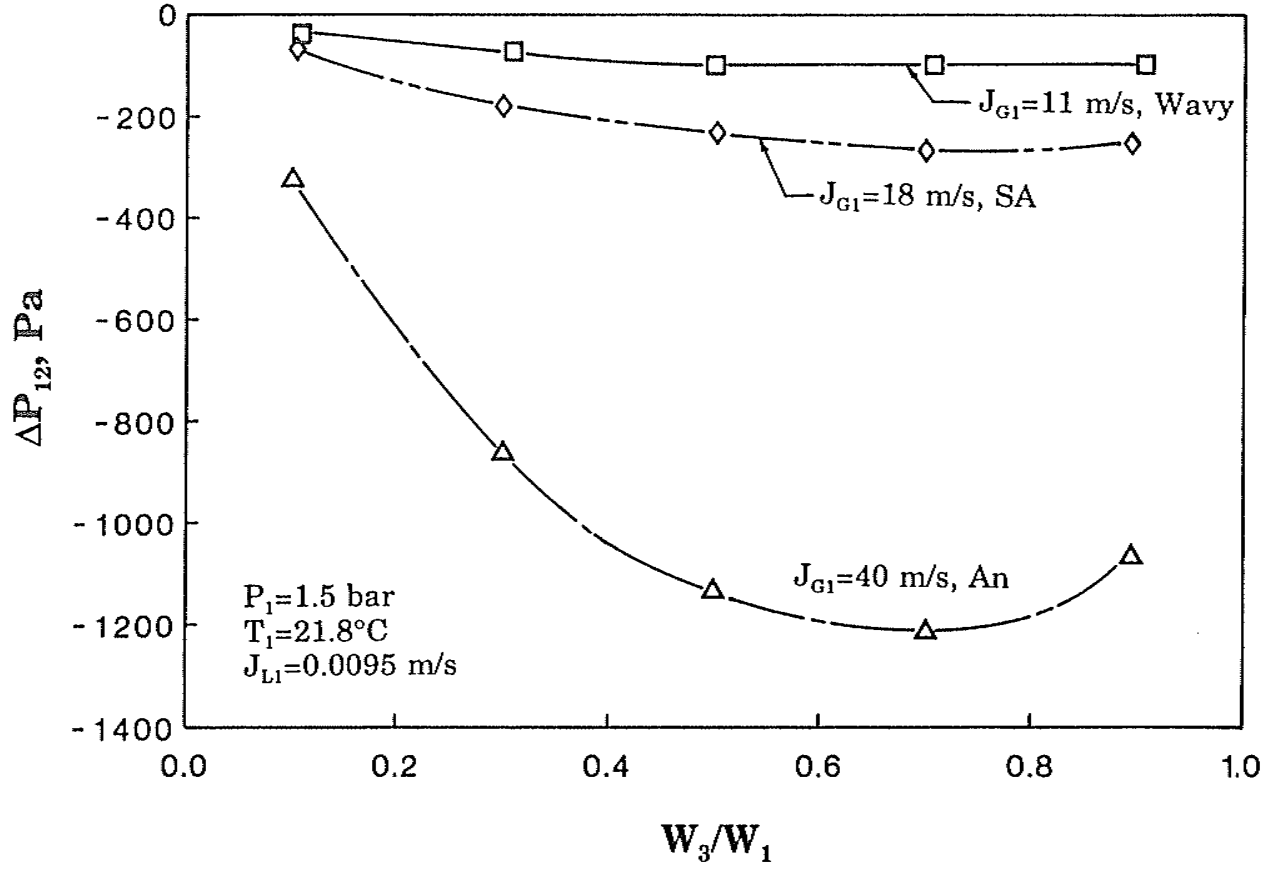

(a)

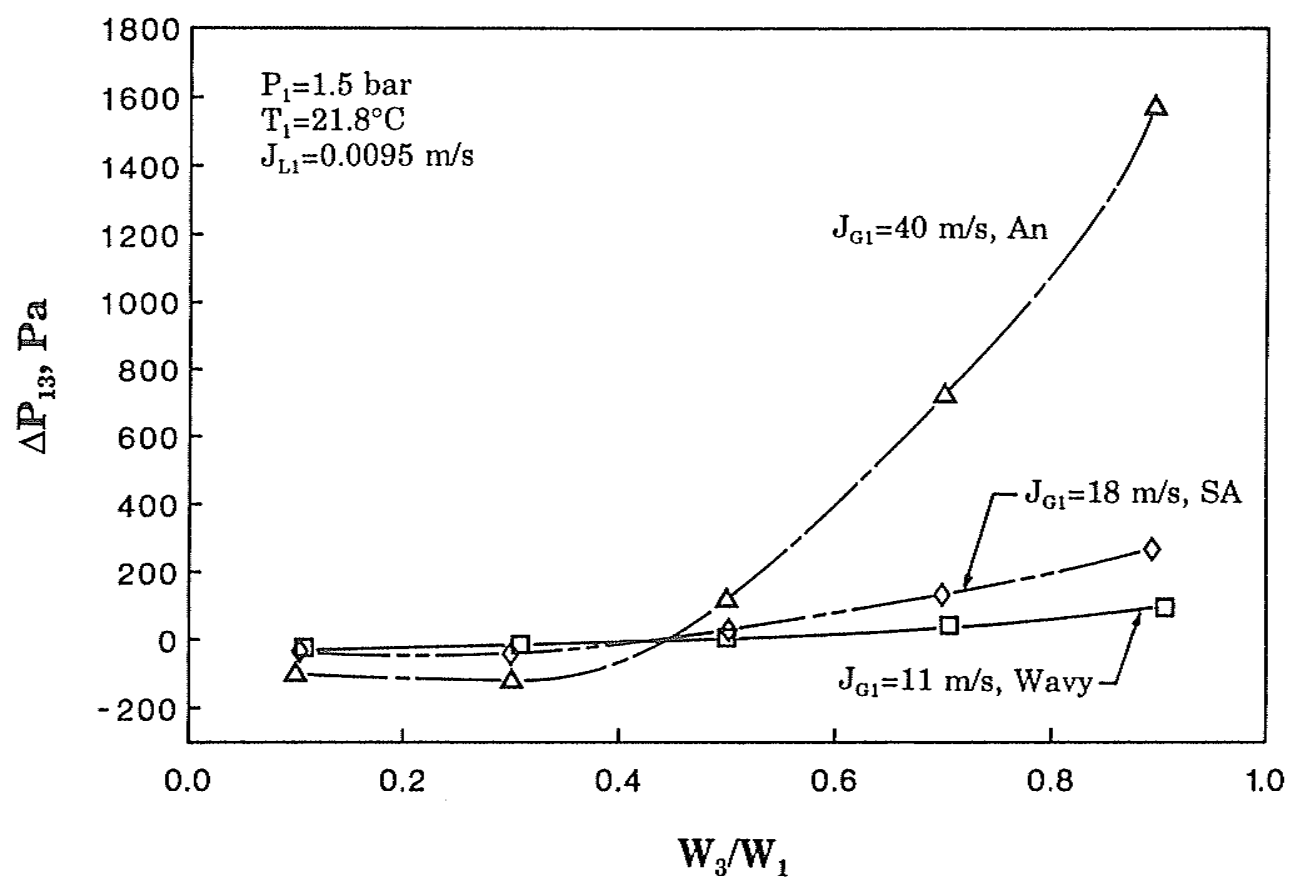

(b)

Figure 4.27 Effect of $\mathrm{J}_{\mathrm{G} 1}$ on the pressure drops for $\mathrm{J}_{\mathrm{L} 1}=0.0095 \mathrm{~m} / \mathrm{s}$ 


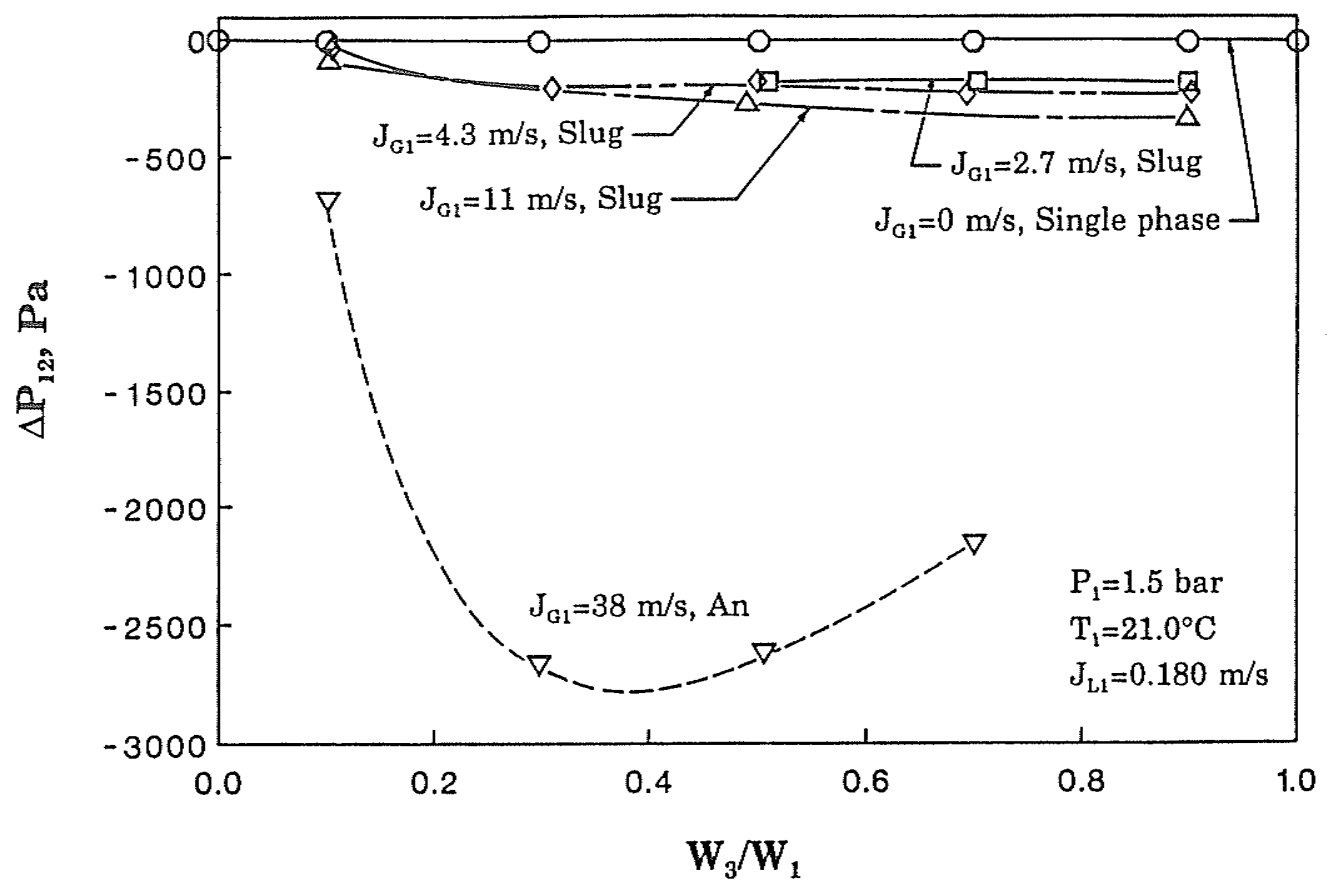

(a)

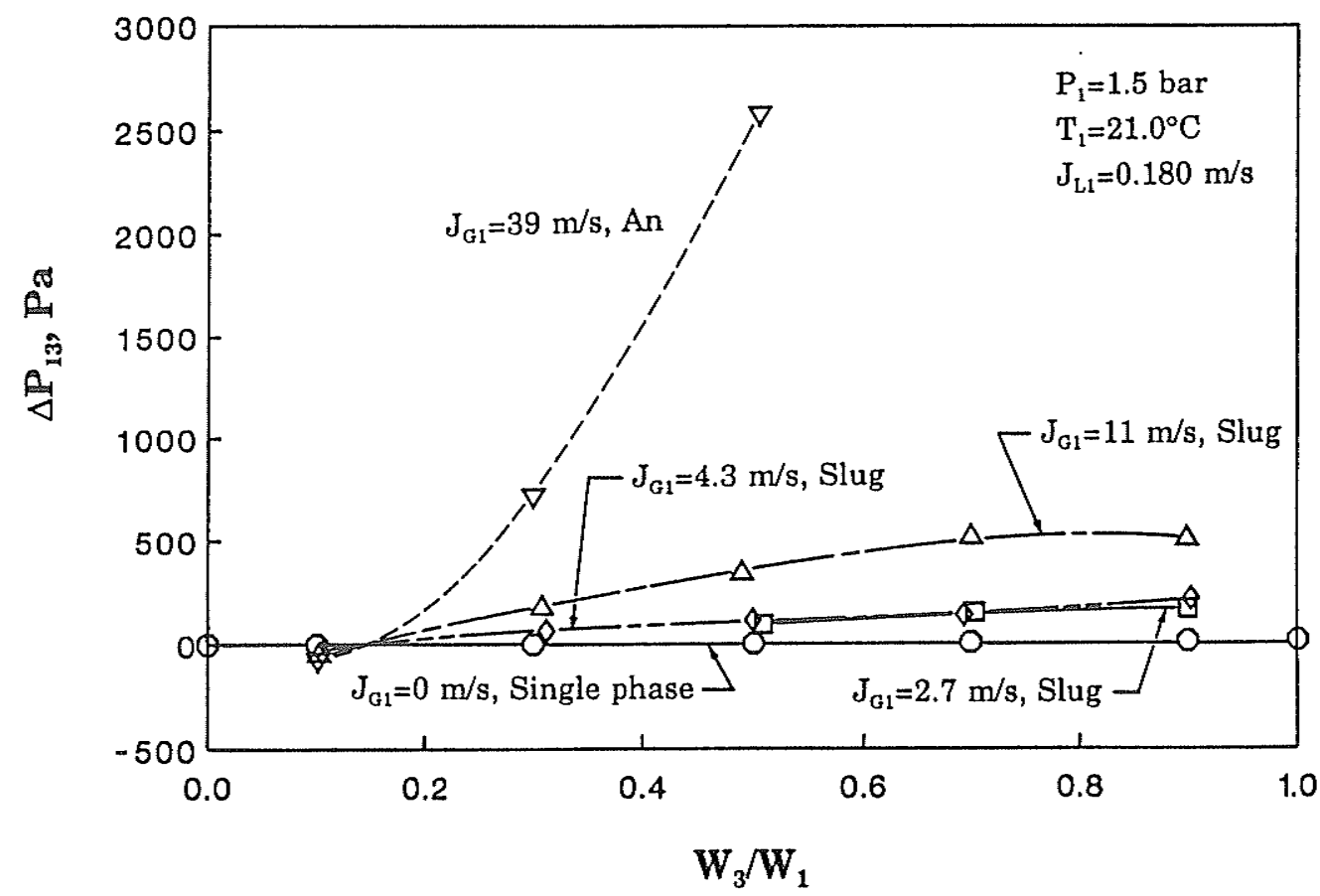

(b)

Figure 4.28 Effect of $J_{G 1}$ on the pressure drops for $\mathrm{J}_{\mathrm{L} 1}=0.180 \mathrm{~m} / \mathrm{s}$ 
uncertainties less than $\pm 30 \%$; these figures do not include three data points where $\Delta \mathrm{P}_{13}$ had an absolute value less than or equal to $1 \mathrm{~Pa}$ (at these extremely small $\Delta \mathrm{P}_{13}$ 's the relative error would be expected to be very large). More detail is given in Appendix $\mathrm{E}$ where values of the relative uncertainty in $\Delta \mathrm{P}_{12}$ and $\Delta \mathrm{P}_{13}$ are tabulated.

\subsection{Comparisons Between the Present Data and Existing Models}

\subsubsection{Phase-Distribution Data}

In this section, existing phase-distribution models are compared to the present experimental data. Results of these comparisons are presented in several succeeding figures. In these figures, the ordinate is $\mathrm{x}_{3} / \mathrm{x}_{1}$ predicted by the model divided by the measured value of $x_{3} / x_{1}$ at the same conditions, and the abscissa is the extraction rate.

\section{Azzopardi and Whalley Model [6]}

The model presented by Azzopardi and Whalley [6] is a geometricallybased model for annular flow in an equal-sided tee junction. The model tested herein is given by equation (2.1) with $\theta$ given by equation (2.2). This model was used to predict $\mathrm{x}_{3} / \mathrm{x}_{1}$ for the present experimental values of $\mathrm{W}_{1}, \mathrm{~W}_{3} / \mathrm{W}_{1}, \mathrm{~F}_{\mathrm{BL}}$,

$\rho_{\mathrm{L} 1}$, and $\rho_{\mathrm{G} 1}$. The entrainment rate $\mathrm{E}_{1}$ was calculated using the correlation developed by Kataoka and Ishii [31]. 
The results of this comparison are shown in figure 4.29 for inlet flow regimes of annular and semiannular flow. The model's prediction is quite good with $83 \%$ of the data predicted within $\pm 30 \%$, and $79 \%$ of the data predicted within $\pm 20 \%$. The prediction of the model became better as the extraction rate was increased. At extraction rates less than 0.3 , the model underpredicted the semiannular data and overpredicted the annular data. The underprediction of the semiannular data may have occurred because the model applies to annular flow with a uniform film thickness, while for semiannular flow much of the liquid is contained within a thick stratum at the bottom of the tube.

\section{Azzopardi Model [25]}

Another phase-distribution model tested was the model presented by Azzopardi [25]. This model is given by equation (2.1) with equations (2.12) through (2.15). As recommended by Azzopardi [25], $\mathrm{E}_{1}$ was calculated using the correlation developed by Dallman et al. [32] and the liquid film thickness was calculated using the correlation published by Laurinat et al. [33]. This model was used to predict values of $x_{3} / x_{1}$, for present experimental values of $\mathrm{W}_{1}, \mathrm{x}_{1}, \mathrm{D}_{1}, \rho_{\mathrm{L} 1}, \rho_{\mathrm{G} 1}$, and $\mathrm{F}_{\mathrm{BL}}$.

The comparison between this model and the experimental data for annular and semiannular flow is given in figure 4.30. This model performed similar to the Azzopardi and Whalley model [6], with $83 \%$ of the data predicted 


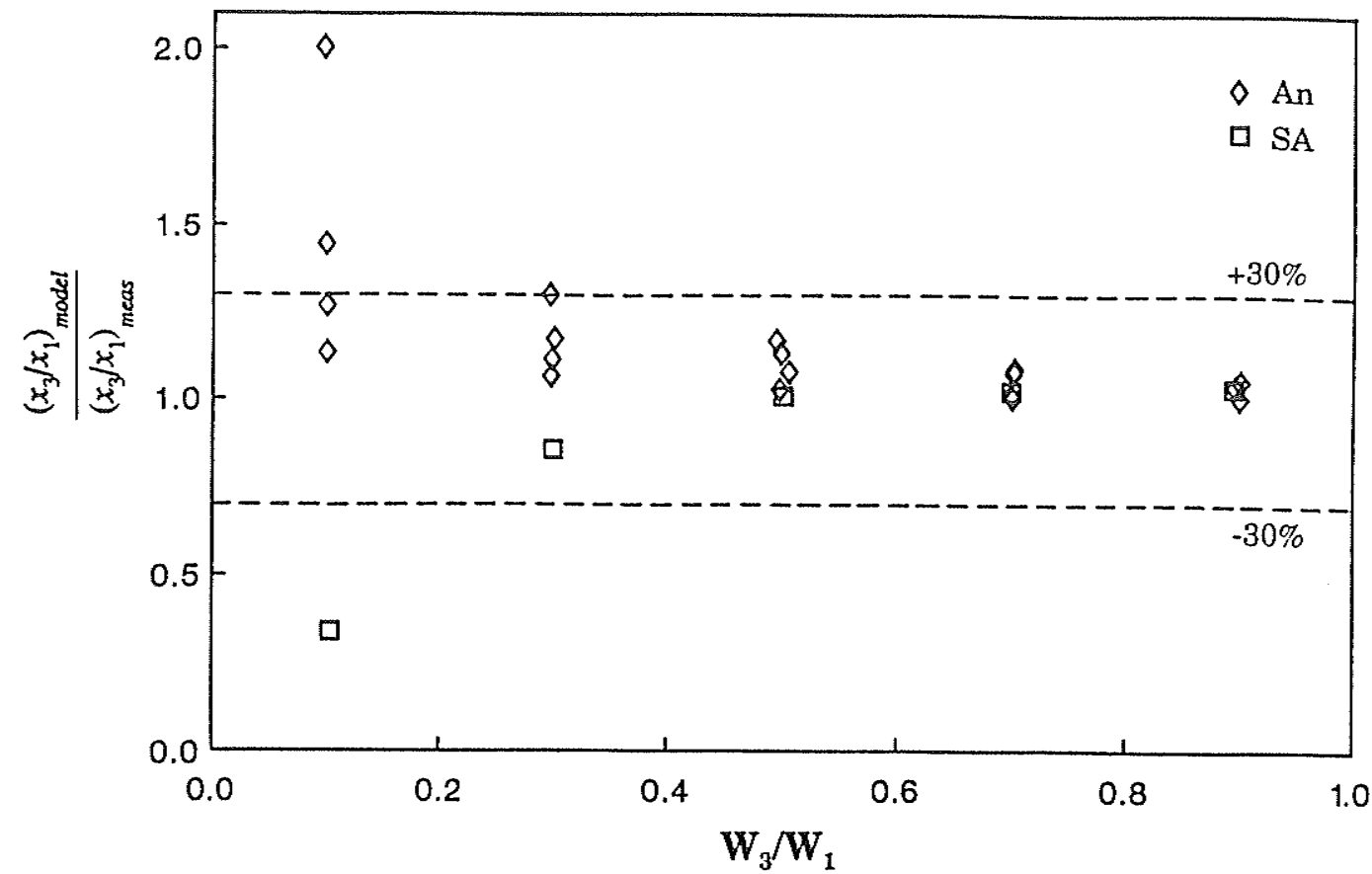

Figure 4.29 Comparison between the Azzopardi and Whalley model [6] and the present annular and semiannular data

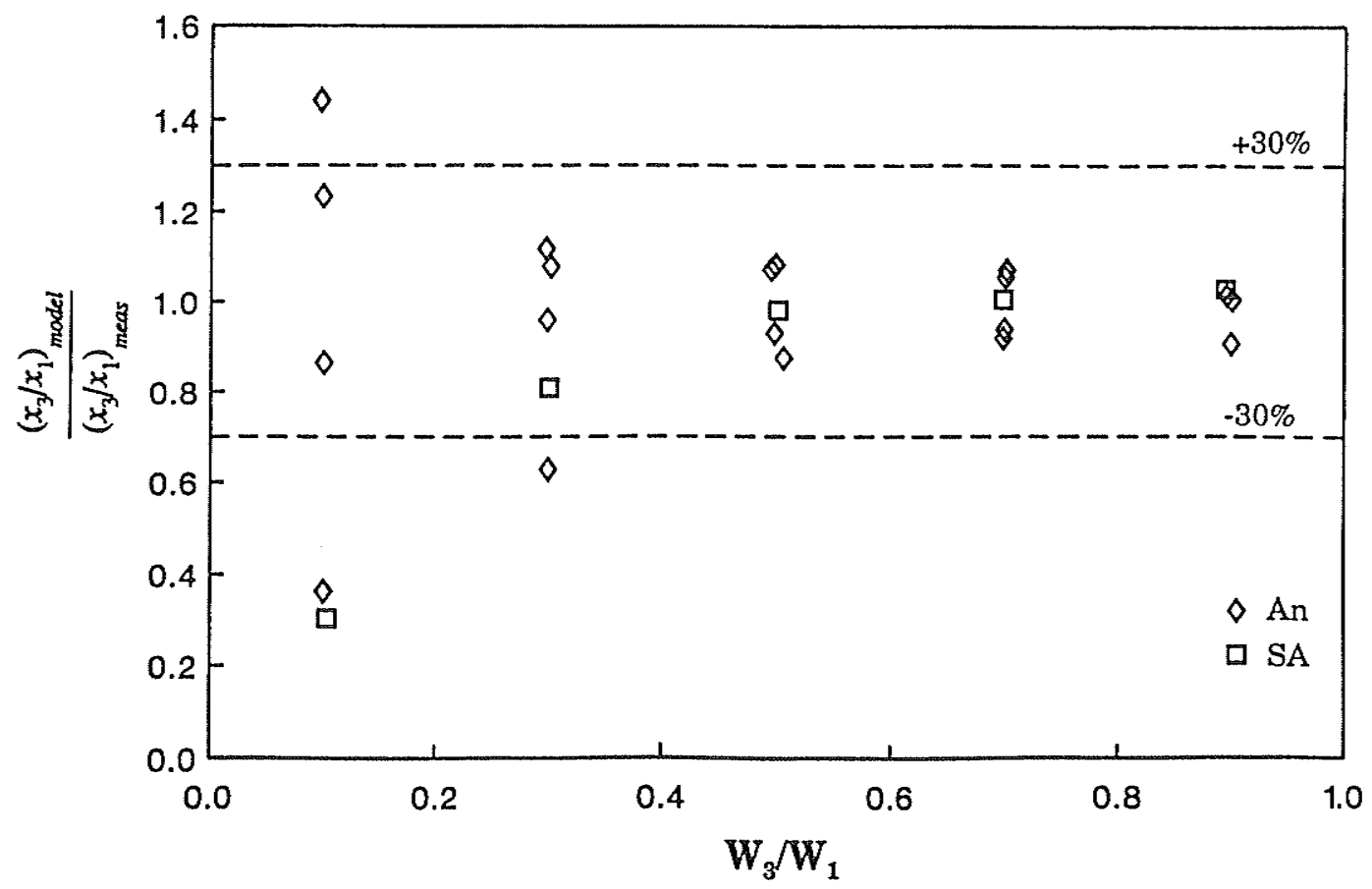

Figure 4.30 Comparison between the Azzopardi model [25] and the present annular and semiannular data 
within $\pm 30 \%$ ( $79 \%$ predicted within $\pm 20 \%$ ). Again, the prediction of the model became better as the extraction rate was increased.

\section{Hwang et al. Model [19]}

The third model tested was the model developed by Hwang et al. [19]. For separated flow (stratified, wavy, or annular), the model simplifies to a balance between centrifugal forces, and is given by equations (2.9), (2.10), and (2.11). The mean velocities given in equation (2.9) were calculated using the following equations:

$$
V_{G 1}=\frac{x_{1} G_{1}}{\rho_{G 1} \alpha_{1}},
$$

and

$$
V_{L I}=\frac{\left(1-x_{1}\right) G_{1}}{\rho_{L I}\left(1-\alpha_{1}\right)} .
$$

Equations (2.9), (2.10), (4.4), and (4.5) can be combined to give the following result:

$$
\frac{\left(\delta_{L} D D_{1}\right)^{n_{L}}}{\left(\delta_{G} D_{1}\right)^{n_{G}}}=\left[\frac{1-\alpha_{1}}{\alpha_{1}}\right]^{2}\left[\frac{x_{1}}{1-x_{1}}\right]^{2} \frac{\rho_{L I}}{\rho_{G 1}}
$$

This model was used to predict values of $\mathrm{x}_{3} / \mathrm{x}_{1}$ for present experimental values of $\mathrm{W}_{1}, \mathrm{x}_{1}, \rho_{\mathrm{L} 1}, \rho_{\mathrm{G} 1}$, and $\mathrm{F}_{\mathrm{BL}}$. A comparison between this model and the present data was made assuming the inlet flow regime to be stratified for a segment 
of the data, and annular for the remaining data. The modeling procedure for these two cases will be discussed below.

The procedure used to predict $x_{3} / x_{1}$ under the assumption of stratified flow in the inlet is similar to the one reported by Hwang et al. [19]. Figure 4.31 shows a schematic of the inlet flow geometry at a cross-section just upstream of the junction, for an inlet flow regime of stratified flow. The parameters $\delta_{\mathrm{G}}$ and $\delta_{\mathrm{L}}$ are the depths of the gas and liquid zones of influence, respectively, as was shown in figure 2.2. With this flow geometry, the gas contained in $\mathrm{A}_{\mathrm{G} 3}$ and the liquid contained in $\mathrm{A}_{\mathrm{L} 3}$ flow into the branch, while the gas contained in $\mathrm{A}_{\mathrm{G} 2}$ and the liquid contained in $\mathrm{A}_{\mathrm{L} 2}$ flow into the run. The computation procedure is as follows:

1. From the input data, values of $\alpha_{1}$ and $h_{L} / D_{1}$ were calculated using the model of Taitel and Dukler [34].

2. Assuming a uniform velocity within the liquid phase in the inlet, $\mathrm{F}_{\mathrm{BL}}$ can be expressed as

$$
F_{B L}=\frac{A_{L 3}}{A_{L 2}+A_{L 3}} .
$$

Thus, $\delta_{\mathrm{L}} / \mathrm{D}_{1}$ was calculated from geometrical considerations.

3. The corresponding value of $\delta_{\mathrm{G}} / \mathrm{D}_{1}$ was calculated by solving equations (2.11) and (4.6) iteratively. The areas $\mathrm{A}_{\mathrm{G} 2}$ and $\mathrm{A}_{\mathrm{G} 3}$ were then calculated from geometrical considerations.

4. Under the assumption of uniform gas velocity within the gas phase in the inlet, $\mathrm{F}_{\mathrm{BG}}$ was determined using the following relation: 


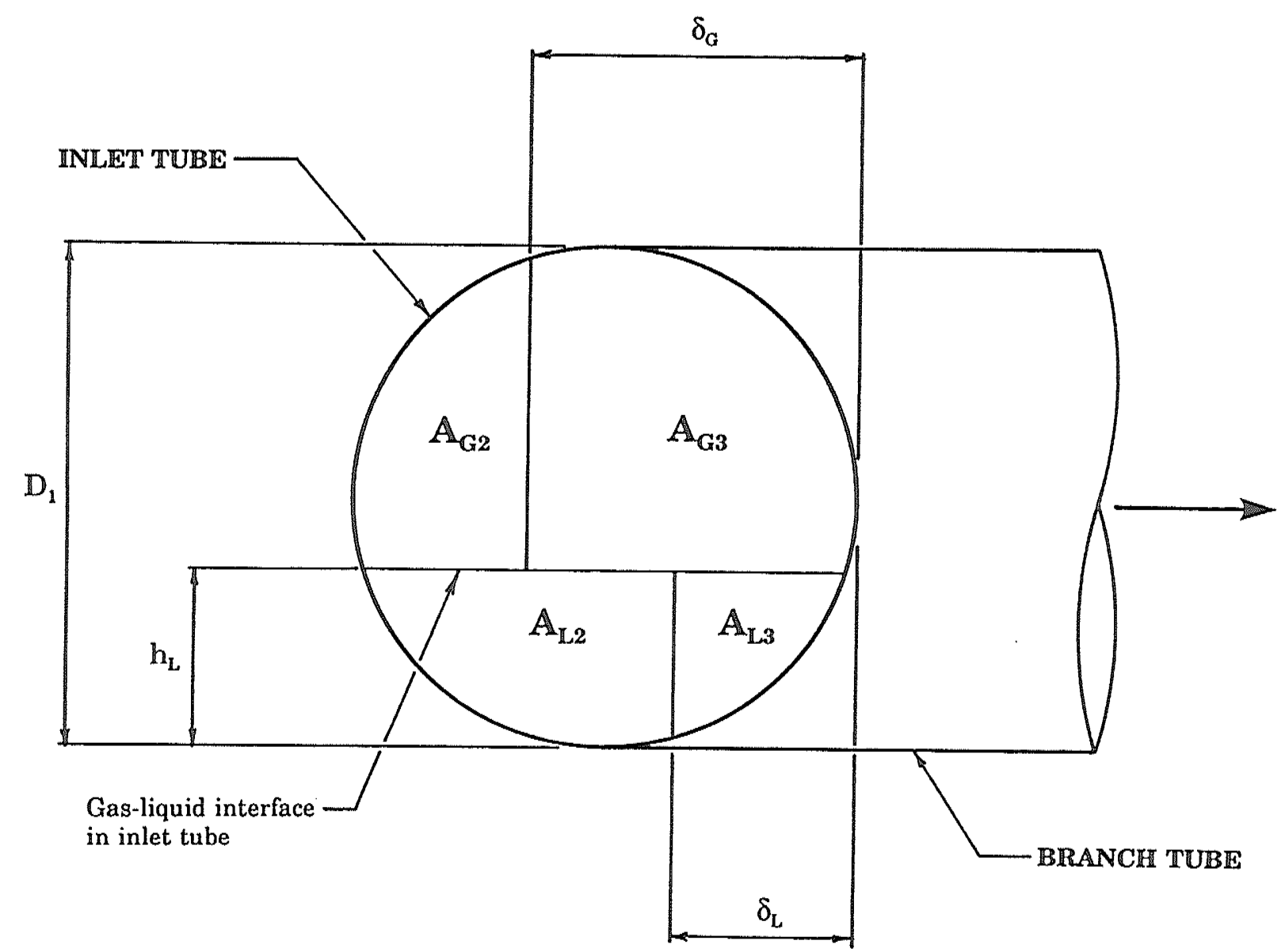

Figure 4.31 Inlet flow geometry for stratified flow 


$$
F_{B G}=\frac{A_{G 3}}{A_{G 2}+A_{G 3}} .
$$

5. Finally, $\mathrm{x}_{3} / \mathrm{x}_{1}$ was calculated using the predicted value of $\mathrm{F}_{\mathrm{BG}}$, and the present experimental value of $\mathrm{W}_{3} / \mathrm{W}_{1}$.

Hwang et al. [19] used the Zuber-Findlay model [29] with $\mathrm{C}_{0}$ given by equation (2.42) in order to calculate the inlet void fraction, whereas, in the present analysis, $\alpha_{1}$ was calculated using the model of Taitel and Dukler [34].

For the case of an inlet flow regime of annular flow, a procedure similar to that used by Hwang et al. [19] was incorporated. Figure 4.32 shows a schematic diagram of the inlet flow geometry at a cross section just upstream of the junction, for an inlet flow regime of annular flow. Again, the gas and liquid velocity profiles were assumed uniform. As well, the liquid film thickness was assumed uniform around the inlet tube periphery. Finally, any liquid existing as entrained droplets was assumed to by-pass the branch and flow into the run. The procedure used to predict $x_{3} / x_{1}$ is as follows:

1. The inlet slip ratio $S_{1}$ was calculated using equations (2.42) and (2.43). The inlet void fraction was then found using

$$
\alpha_{i}=\left[1+S_{i} \frac{\rho_{G i}}{\rho_{L}} \frac{\left(1-x_{i}\right)}{x_{i}}\right]^{-1},
$$

where $\mathrm{i}=1$ for the inlet. The liquid film thickness was calculated under the assumption of uniform film thickness. The liquid entrainment was calculated using the correlation developed by Kataoka and Ishii [31]. 


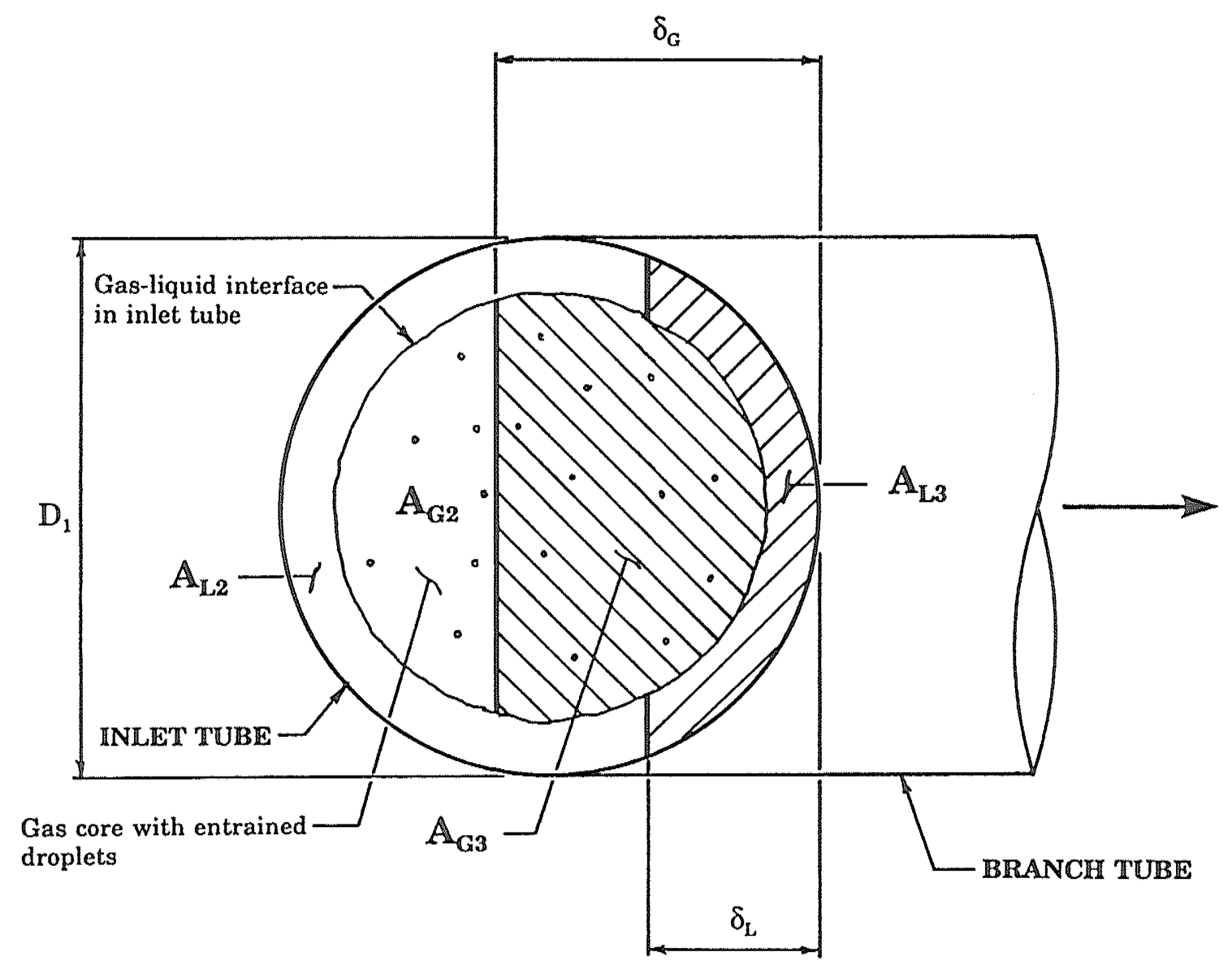

Figure 4.32 Inlet flow geometry for annular flow 
2. With the assumption of a uniform velocity profile in the liquid film, $\mathrm{F}_{\mathrm{BL}}$ can be expressed as

$$
F_{B L}=\left[\frac{A_{L 3}}{A_{L 2}+A_{L 3}}\right]\left[1-E_{1}\right] .
$$

The ratio $\delta_{\mathrm{L}} / \mathrm{D}_{1}$ was then calculated from geometric considerations.

3. The corresponding value of $\delta_{G} / D_{1}$ was calculated by solving equations (2.11) and (4.6) iteratively.

4. The value of $\mathrm{F}_{\mathrm{BG}}$ was found from geometric considerations using equation (4.8).

5. Finally, $\mathrm{x}_{3} / \mathrm{x}_{1}$ was calculated using the predicted value of $\mathrm{F}_{\mathrm{BG}}$ and the present experimental value of $\mathrm{W}_{3} / \mathrm{W}_{1}$.

Figure 4.33 shows the comparison between the model of Hwang et al. [19] for stratified flow and the present stratified, stratified-wavy, wavy, and slug data. Eighty percent of these data were predicted within $\pm 30 \%$. Data corresponding to slug flow were predicted poorly, with only $47 \%$ of the slug data predicted within $\pm 30 \%$. The model tended to underpredict $x_{3} / x_{1}$ for the slug flow data at low extraction rates $\left(\mathrm{W}_{3} / \mathrm{W}_{1} \leq 0.5\right)$. The model predicted $94 \%$ of the present stratified, stratified-wavy, and wavy data within $\pm 30 \%$.

A comparison between the model of Hwang et al. [19] for annular flow and the present annular and semiannular data is given in figure 4.34. In this case, the model predicted $88 \%$ of the data within $\pm 30 \%$ ( $79 \%$ within $\pm 20 \%$ ).

Rubel et al. [20] also compared their data for stratified, wavy, and semiannular flow in a horizontal tee junction to the model of Hwang et al. [19] 


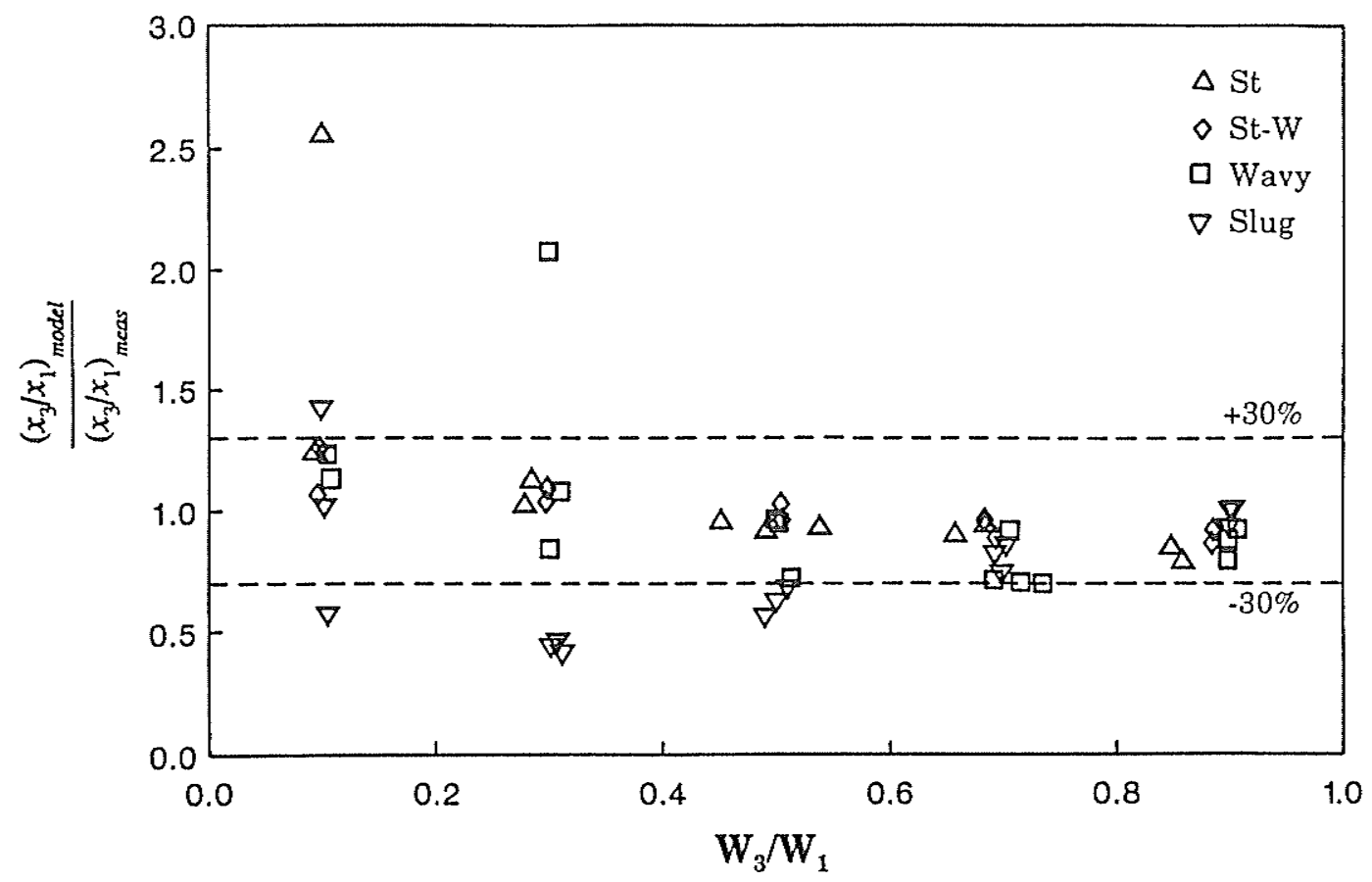

Figure 4.33 Comparison between the Hwang et al. model [19] for stratified flow and the present stratified, stratified-wavy, wavy, and slug data

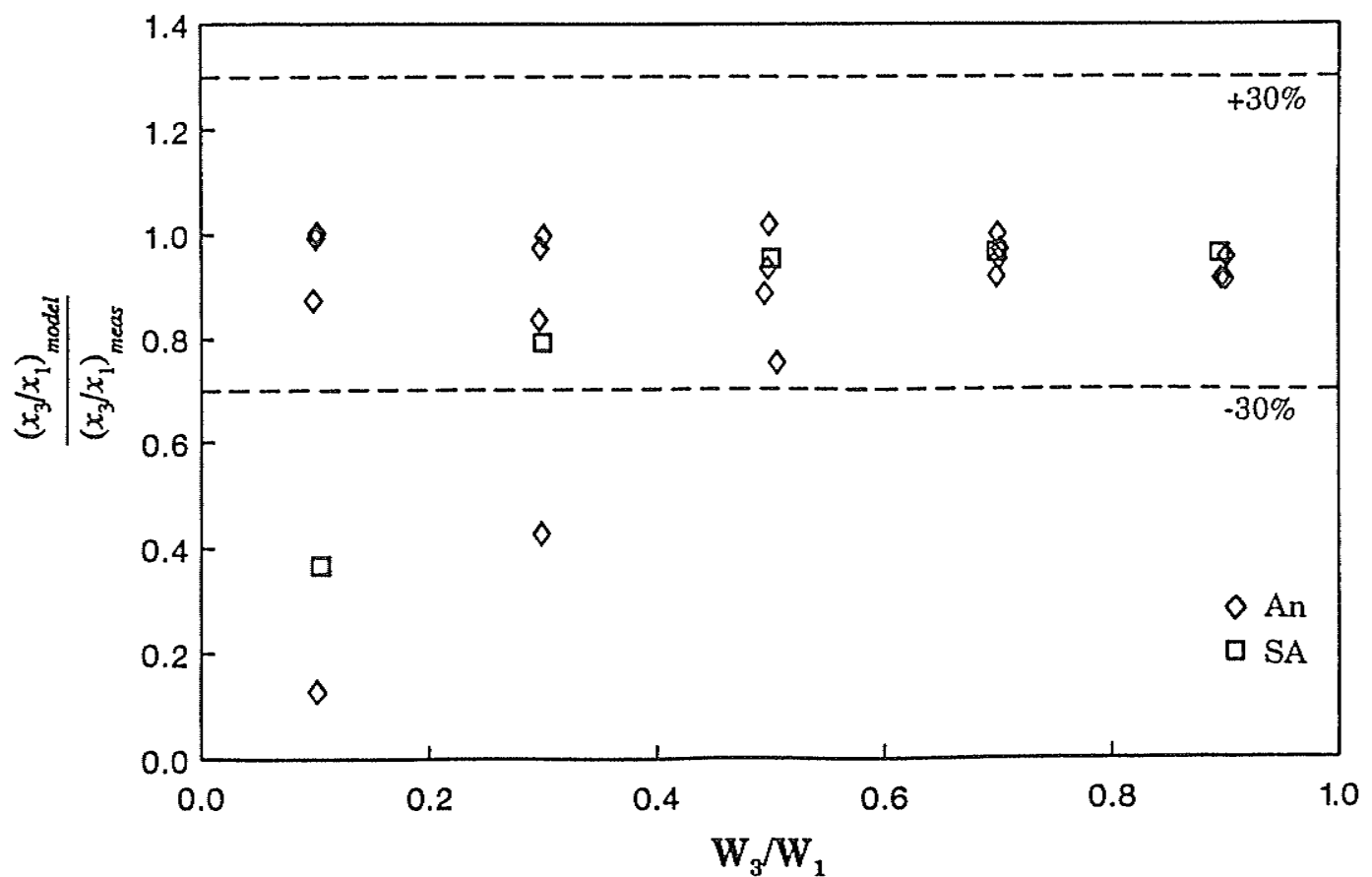

Figure 4.34 Comparison between the Hwang et al. model [19] for annular flow and the present annular and semiannular data 
under the assumption of stratified flow in the inlet. Nearly all of the data were predicted within $\pm 30 \%$.

\section{Seeger et al. Model [14]}

The final phase-distribution model tested was the empirical correlation published by Seeger et al. [14]. This model is given by equation (2.4), with the coefficient ' $a$ ' given by equation (2.5). The slip ratio in the inlet was calculated using the correlation developed by Rouhani [15] and is given by equations (2.6), (2.7), and (2.8). For the present comparison, the term (1- $\left.\mathrm{x}_{1}\right)$ in equation (2.8) was retained.

The results of this comparison are shown in figure 4.35. In this figure, all of the present phase-distribution data were compared to the predictions of the Seeger et al. model [14]. Overall, $67 \%$ of the data were predicted within $\pm 30 \%$. The model generally underpredicted the data for $\mathrm{W}_{3} / \mathrm{W}_{1}<0.5$; however, at higher extraction rates the model performed very well, with nearly all of the data predicted within $\pm 30 \%$.

As noted earlier, Seeger et al. [14] omitted the (1- $\left.x_{1}\right)$ term in equation (2.8). A comparison between the Seeger et al. model [14] with the (1- $\left.\mathrm{x}_{1}\right)$ term omitted in equation (2.8) and the present data made little difference to the model's prediction. With the $\left(1-\mathrm{x}_{1}\right)$ term omitted, the Seeger et al. model [14] also predicted $67 \%$ of the data within $\pm 30 \%$. A comparison of the magnitude 


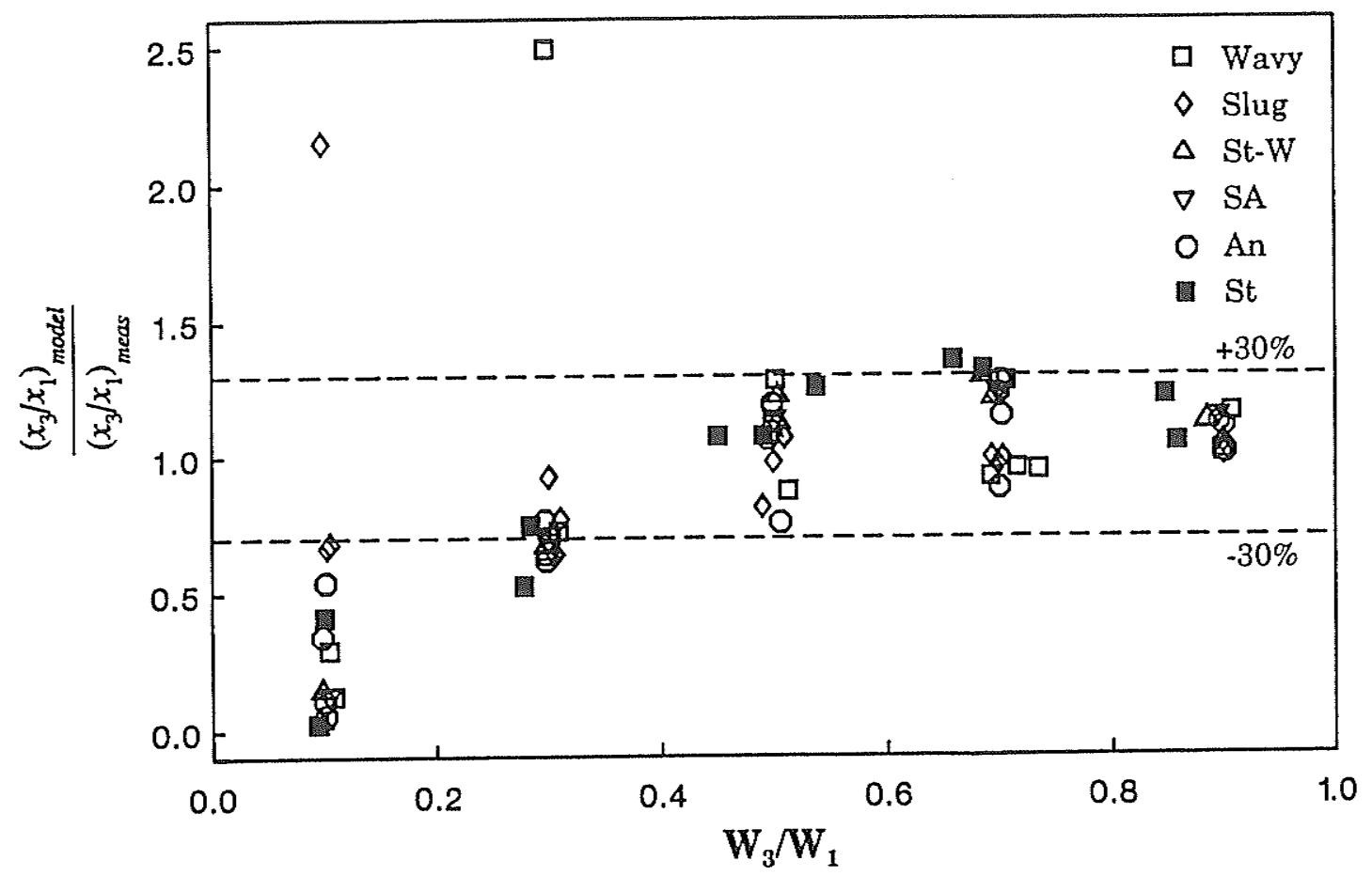

Figure 4.35 Comparison between the Seeger et al. model [14] and the present data 
of the various terms in equation (2.6) indicated that for the present data the term $V_{\mathrm{REL}} / \mathrm{G}_{1}$ was much less significant than the other terms. This would account for the unimportance of the $\left(1-\mathrm{x}_{1}\right)$ term in equation (2.8) for the present data.

\subsubsection{Pressure-Drop Data}

In this section, the present pressure-drop data are compared to the predictions of various pressure-drop models given in the literature. These comparisons are shown in several succeeding figures. In these figures, the ordinate is $\Delta \mathrm{P}_{1 \mathrm{i}}$ predicted by the model divided by the measured value of $\Delta \mathrm{P}_{1 \mathrm{i}}$ ( $i=2$ for the run, and $i=3$ for the branch), and the abscissa is the extraction rate.

\section{Data of $\Delta \mathbf{P}_{12}$}

Comparisons were made between the present data for $\Delta \mathrm{P}_{12}$ and the predictions of various $\Delta \mathrm{P}_{12}$ models. The various models tested were as follows:

1. The homogeneous flow model (HFM) given by equation (2.27) with $\left(\mathrm{K}^{\star}{ }_{12}\right)_{\mathrm{H}}$ calculated using equation (4.3).

2. The separated flow model (SFM) given by equation (2.25) with $\alpha_{1}$ and $\alpha_{2}$ calculated using the correlation by Rouhani [15], and $\left(\mathrm{K}^{{ }^{*}}{ }_{12}\right)_{\mathrm{S}}$ calculated 
using equation (4.3). The Rouhani correlation [15], given by equations (2.6), (2.7), and (2.8), gave the slip ratios $S_{1}$ and $S_{2}$. The void fractions were then found using equation (4.9) where $i=1$ for the inlet and $i=2$ for the run.

3. The separated flow model (BM) given by equation (2.25) with $\alpha_{1}$ and $\alpha_{2}$ calculated using the correlation by Rouhani [15], and $\left(\mathrm{K}^{\mathrm{*}}{ }_{12}\right)_{\mathrm{S}}=1.0$. This model was recommended by Ballyk et al. [18].

4. The Reimann and Seeger model [26] (RSM) given by equations (2.35) through (2.38), with $\mathrm{i}=2$ and $\mathrm{S}_{\mathrm{C} 2}=1.0$. The value of $\mathrm{K}_{12}$ was calculated using equation (4.1), while $S_{1}$ and $S_{2}$ were found using the correlation developed by Rouhani [15].

5. The model recommended by Hwang and Lahey [28]. This model is given by equation (2.25) with $\rho_{\mathrm{M} 2}=\rho_{\mathrm{H} 2}$. Replacing $\rho_{\mathrm{M} 2}$ with $\rho_{\mathrm{H} 2}$ and $\left(\mathrm{K}^{*}{ }_{12}\right)_{\mathrm{S}}$ with the single-phase momentum correction factor $\mathrm{K}^{\star}{ }_{12}$ gives

$$
\Delta P_{12}=K_{12}^{\star}\left(\frac{G_{2}^{2}}{\rho_{H 2}}-\frac{G_{1}^{2}}{\rho_{M I}}\right) .
$$

The value of $\mathrm{K}^{\star}{ }_{12}$ was found using equation (4.3), while $\alpha_{1}$ was calculated using two different procedures: from the Zuber-Findlay model [29] as recommended by Hwang and Lahey [28] (HLM1), which is given by equation (4.9) along with equations (2.42) and (2.43); and from equation (4.9) with $\mathrm{S}_{1}$ found using the Rouhani correlation [15] (HLM2). 
Table 4.3 summarizes the performance of the various $\Delta \mathrm{P}_{12}$ models. It must be recalled that data could not be obtained for stratified flow. A careful examination of Table 4.3 and figures 4.36 to 4.41 reveals that the separated flow model (SFM) given by equation (2.25) performed best with $71 \%$ of the pressure-drop data predicted within $\pm 30 \%$. However, figure 4.37 shows that this model underpredicted most of the data corresponding to an inlet flow regime of slug flow. In general, the separated flow model tended to underpredict the experimental data. For slug flow data, the models recommended by Ballyk et al. [18] (BM) and Hwang and Lahey [28] (HLM1) performed best, both with $64 \%$ of the slug data predicted within $\pm 30 \%$. Figures 4.40 and 4.41 give the predictions of the model recommended by Hwang and Lahey [28]. In figure $4.40 \alpha_{1}$ was calculated using the Rouhani correlation [15] and in figure $4.41 \alpha_{1}$ was calculated using the Zuber-Findlay model [29]. The correlation for $\alpha_{1}$ was found to have little effect on the predictive capability of the model. At extraction rates near 0.1, the Hwang and Lahey model [28] underpredicted most of the data, however, at larger $\mathrm{W}_{3} / \mathrm{W}_{1}$ the model performed well.

Based on the above discussion, for the prediction of the present $\Delta \mathrm{P}_{12}$ data the separated flow model (SFM) is recommended for all data except slug flow. For slug flow, the model presented by Hwang and Lahey (HLM1) is 
Table 4.3

Summary of the Performance of $\Delta \mathrm{P}_{12}$ Models

\begin{tabular}{|c|c|c|c|c|c|}
\cline { 3 - 5 } \multicolumn{2}{c|}{} & \multicolumn{4}{c|}{$\%$ of data predicted correctly } \\
\cline { 3 - 6 } \multicolumn{2}{c|}{} & \multicolumn{3}{c|}{ Inlet flow regime } & \multirow{2}{*}{ Overall } \\
Model $^{(1)}$ & $\begin{array}{c}\text { Interval } \\
\%\end{array}$ & W & S & SA & \\
\hline \multirow{2}{*}{ HFM } & \pm 50 & 50 & 36 & 83 & 63 \\
& \pm 30 & 50 & 18 & 79 & 57 \\
& \pm 20 & 36 & 9 & 46 & 35 \\
\hline \multirow{2}{*}{ SFM } & \pm 50 & 100 & 55 & 100 & 90 \\
& \pm 30 & 79 & 27 & 88 & 71 \\
& \pm 20 & 50 & 27 & 79 & 59 \\
\hline \multirow{2}{*}{ BM } & \pm 50 & 43 & 73 & 25 & 41 \\
& \pm 30 & 14 & 64 & 13 & 24 \\
& \pm 20 & 7 & 55 & 4 & 16 \\
\hline RSM & \pm 50 & 64 & 36 & 88 & 69 \\
& \pm 30 & 57 & 27 & 88 & 65 \\
& \pm 20 & 50 & 27 & 79 & 59 \\
\hline \multirow{2}{*}{ HLM2 } & \pm 50 & 71 & 27 & 75 & 63 \\
& \pm 30 & 50 & 9 & 63 & 50 \\
& \pm 20 & 29 & 9 & 58 & 39 \\
\hline \multirow{2}{*}{ HLM1 } & \pm 50 & 64 & 73 & 75 & 71 \\
& \pm 30 & 43 & 64 & 67 & 59 \\
& \pm 20 & 21 & 55 & 50 & 43 \\
\hline
\end{tabular}

(1) HFM = homogeneous flow model, $\mathrm{SFM}=$ separated flow model, $\mathrm{BM}=$ Ballyk et al. model [18], RSM = Reimann and Seeger model [26], HLM1 = Hwang and Lahey model [28] with $\alpha_{1}$ calculated using the Zuber-Findlay model [29], HLM2 = Hwang and Lahey model [28] with $\alpha_{1}$ calculated using the Rouhani correlation [15] 


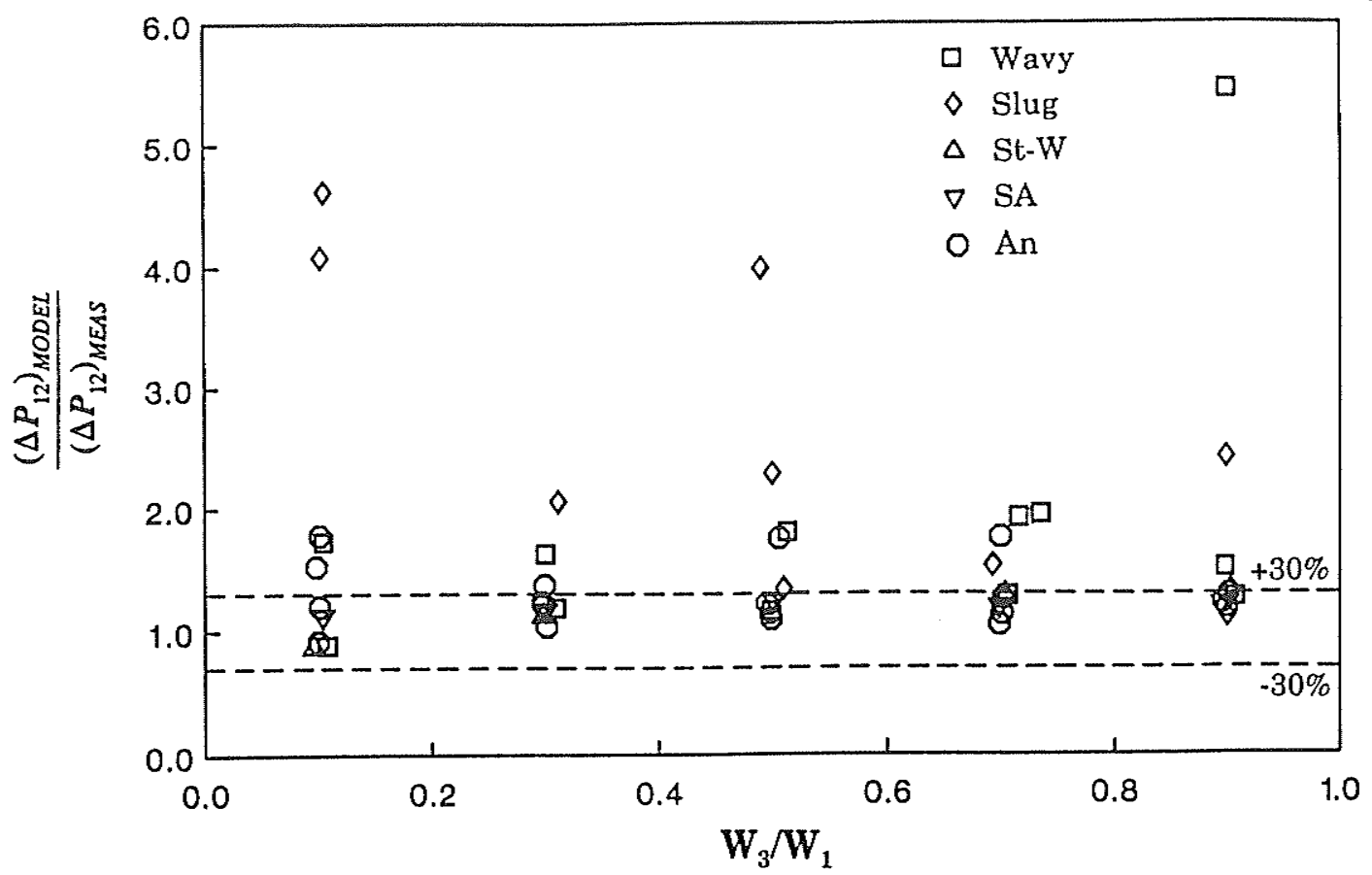

Figure 4.36 Homogeneous flow model (HFM) for $\Delta \mathrm{P}_{12}, \mathrm{~K}^{\star}{ }_{12}$ present value

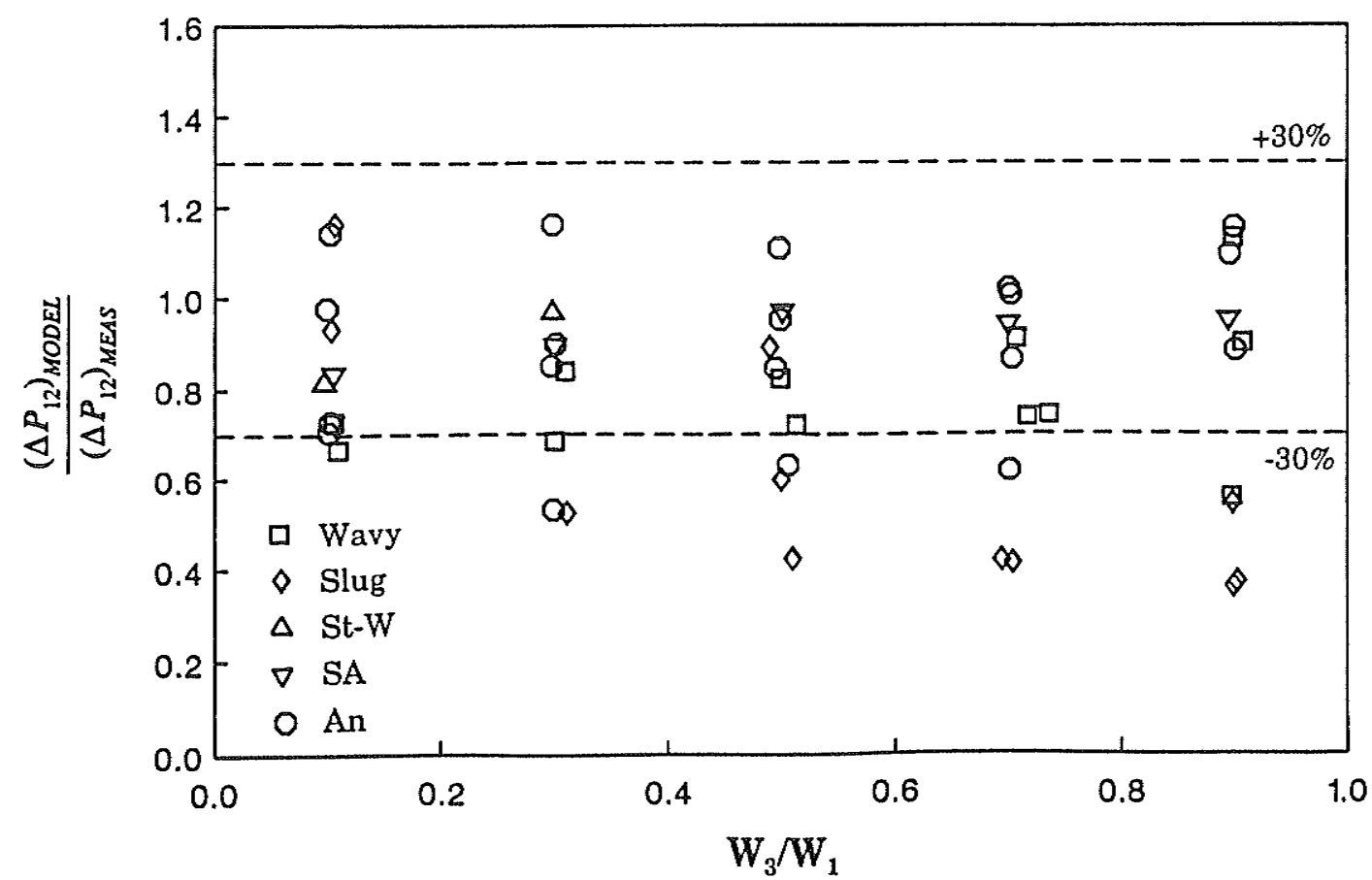

Figure 4.37 Separated flow model (SFM) for $\Delta \mathrm{P}_{12}, \mathrm{~K}^{\star}{ }_{12}$ present value, $\alpha$ using Rouhani correlation [15] 


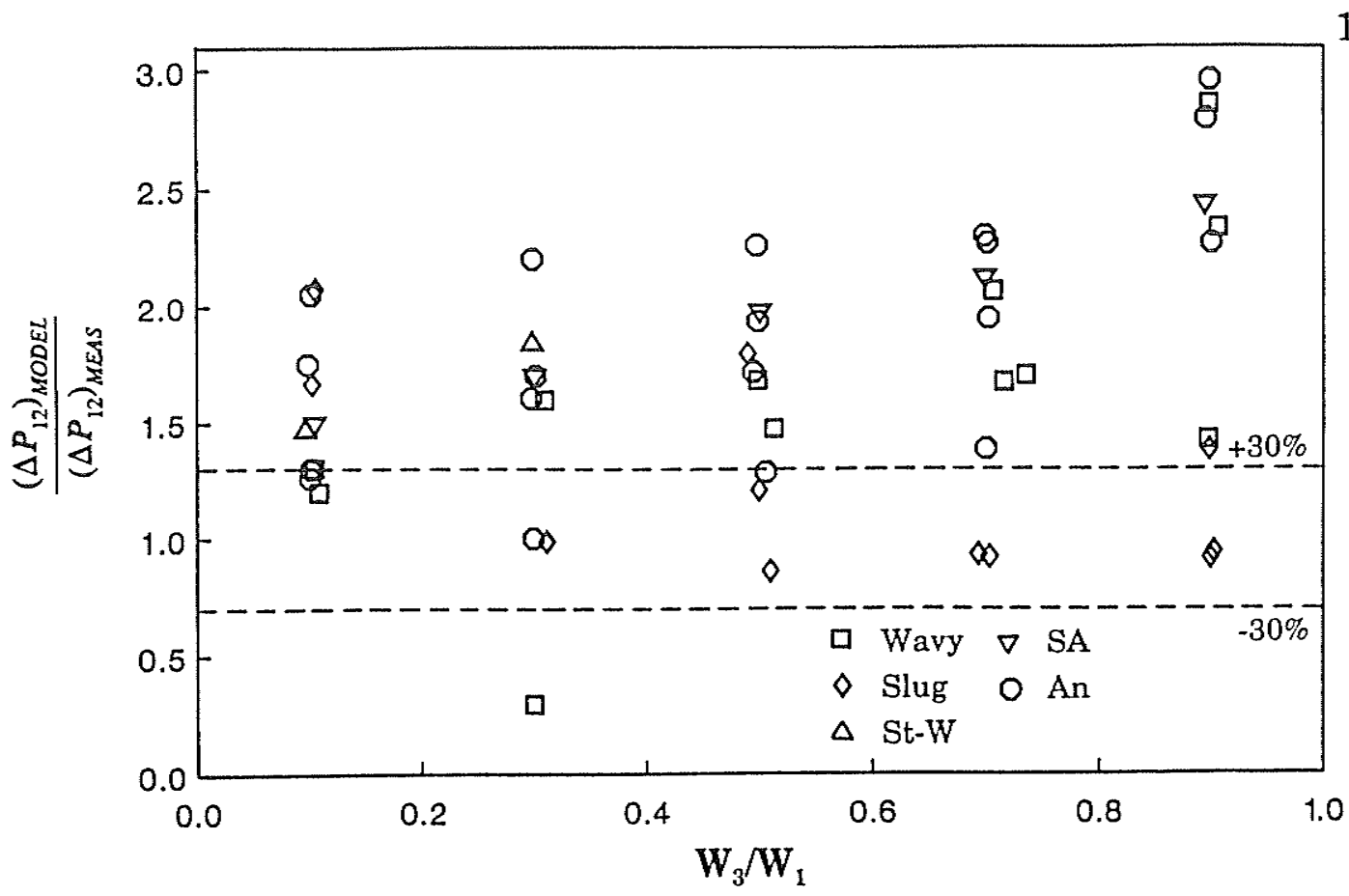

161

Figure 4.38 Separated flow model (BM) for $\Delta \mathrm{P}_{12}, \mathrm{~K}^{*}{ }_{12}=1.0$, $\alpha$ using Rouhani correlation [15]

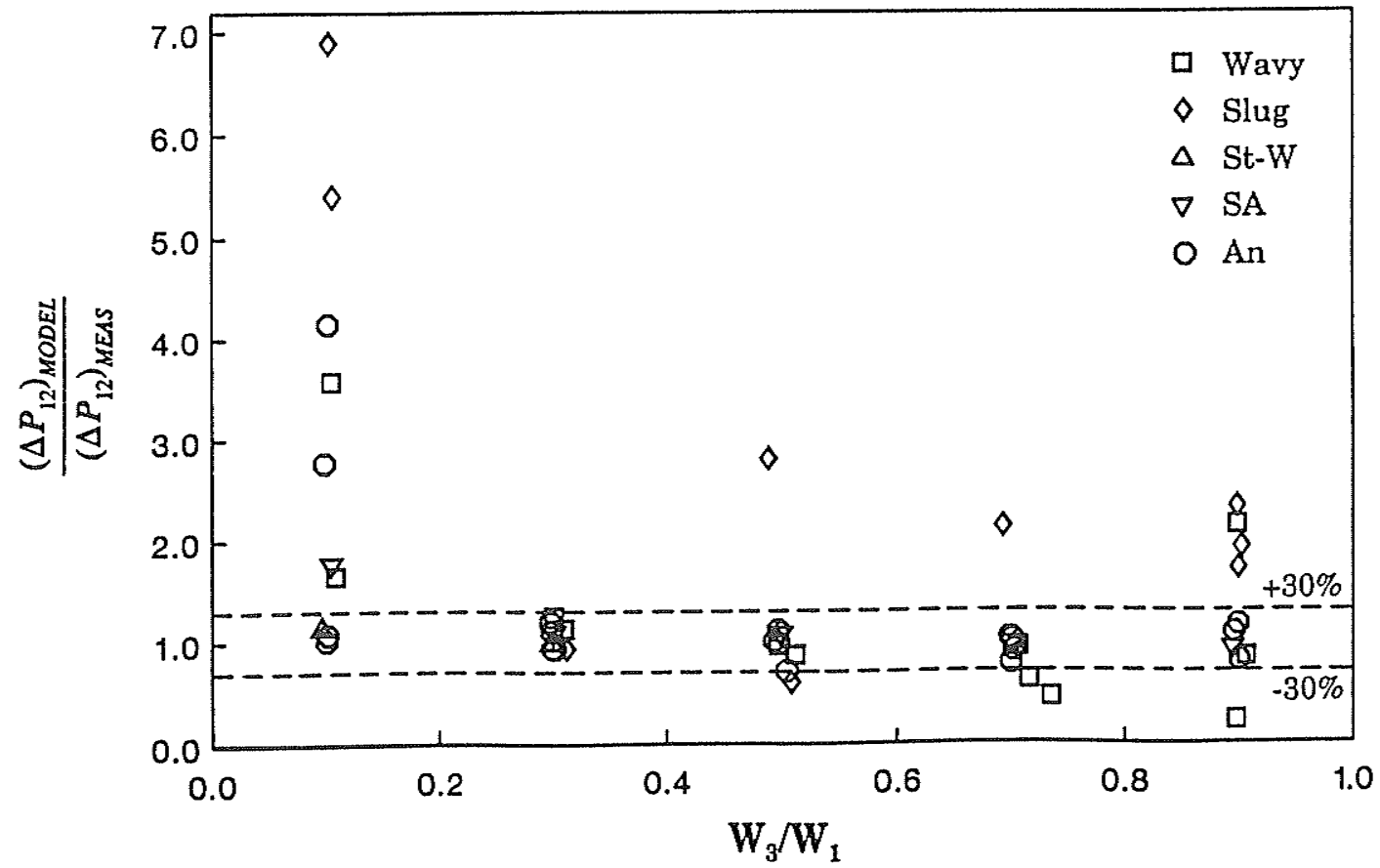

Figure 4.39 Reimann and Seeger model [26] (RSM) for $\Delta P_{12}, K_{12}$ present value, $\alpha$ using Rouhani correlation [15] 


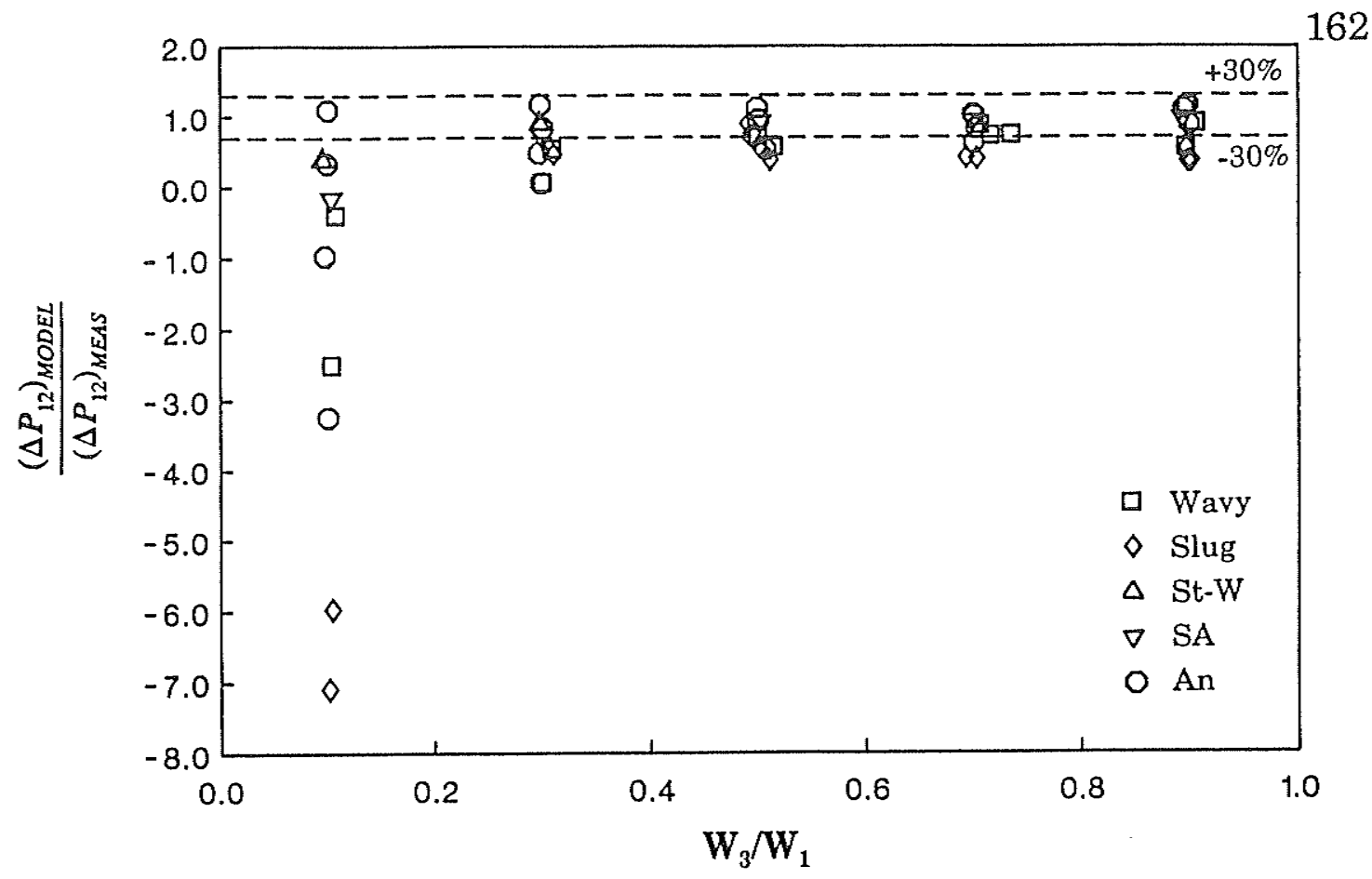

Figure 4.40 Hwang and Lahey model [28] (HLM2) for $\Delta \mathrm{P}_{12}, \mathrm{~K}^{\star}{ }_{12}$ present value, $\alpha_{1}$ using Rouhani correlation [15]

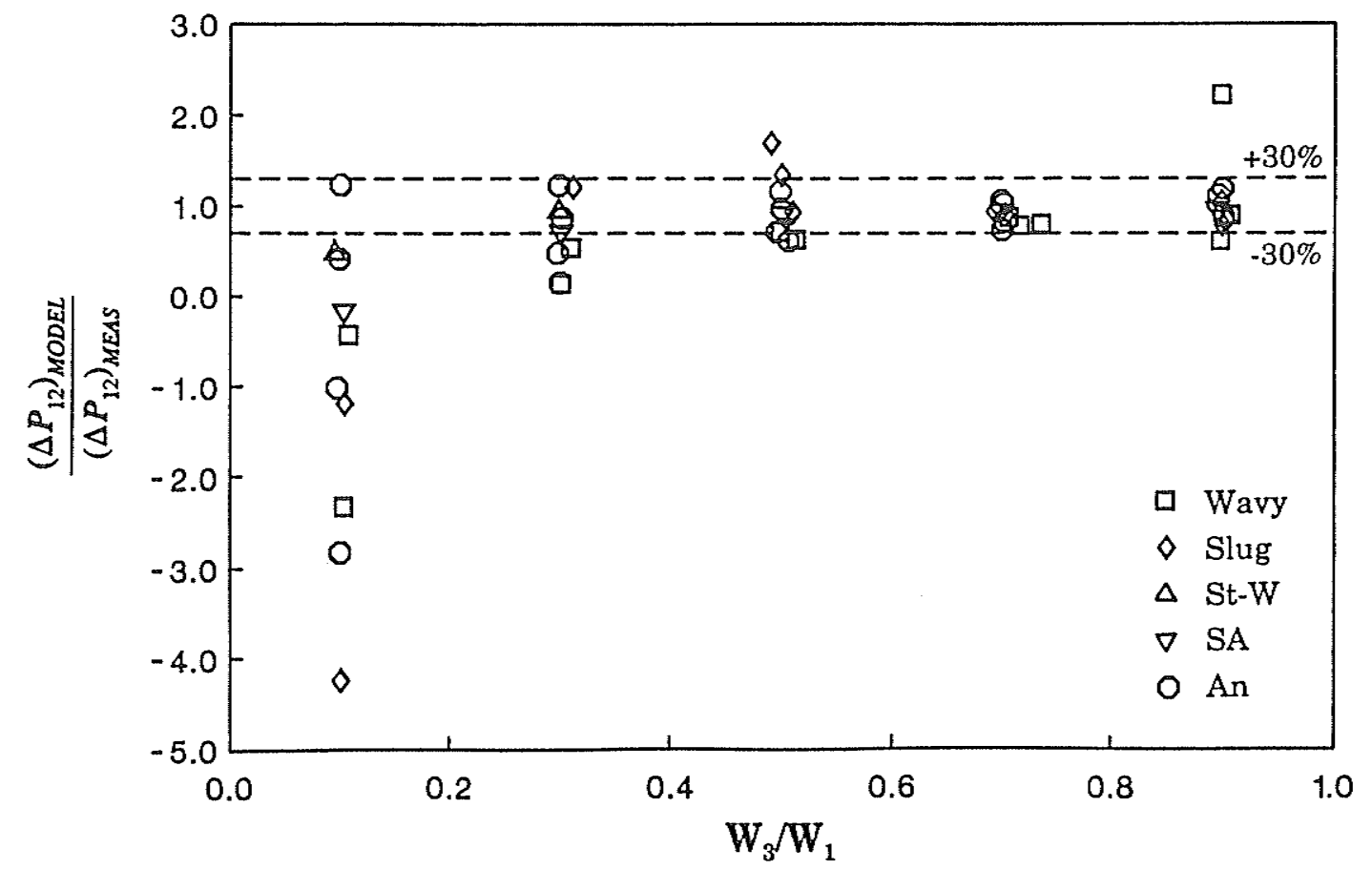

Figure 4.41 Hwang and Lahey model [28] (HLM1) for $\Delta \mathrm{P}_{12}, \mathrm{~K}^{\star}{ }_{12}$ present value, $\alpha_{1}$ using Zuber-Findlay model [29] 
recommended for $\mathrm{W}_{3} / \mathrm{W}_{1}>0.1$; however, for $\mathrm{W}_{3} / \mathrm{W}_{1} \leq 0.1$ the separated flow model (SFM) is recommended.

The void fractions used in the above models were determined from correlations rather than experimental data. Therefore, for the models in which the void fraction was required, some disagreement between the model's prediction and experimental data may be attributed to the correlation used to obtain the void fraction.

Present values of $\mathrm{K}^{*}{ }_{12}$ and $\mathrm{K}_{12}$ were used in the above models. The comparisons between the $\Delta \mathrm{P}_{12}$ models and the present data were repeated with values of $\mathrm{K}_{12}^{*}$ and $\mathrm{K}_{12}$ recommended by various authors $[12,26,28]$. In general, this made little difference to the predictive capability of the various models; in fact, present values of $\mathrm{K}^{\star}{ }_{12}$ and $\mathrm{K}_{12}$ usually resulted in better prediction of the present data.

\section{Data of $\Delta \mathbf{P}_{13}$}

Comparisons were made between the present data for $\Delta \mathrm{P}_{13}$ and the predictions of various $\Delta \mathrm{P}_{13}$ models presented in the literature. The various models tested were as follows:

1. The homogeneous flow model (HFM) given by equation (2.33) with the two-phase multiplier recommended by Saba and Lahey [12], given by $\varphi_{\mathrm{H}}=\rho_{\mathrm{L} 1} / \rho_{\mathrm{H} 1}$, and $K_{13}$ given by equation (4.2). 
2. The separated flow model (SFM) recommended by Saba and Lahey [12] and given by equations (2.30) and (2.32) with $\mathrm{K}_{13}$ given by equation (4.2). The void fractions were found using equation (4.9) with the slip ratios estimated using the correlation developed by Rouhani [15], given by equations (2.6), (2.7), and (2.8).

3. The Reimann and Seeger model [26] given by equations (2.33) and (2.40) with $\mathrm{K}_{13}$ calculated from equation (4.2). The correction factor $\mathrm{K}$ given in equation (2.41) was used, as suggested by Reimann and Seeger [26]. This model was tested with $\mathrm{K}=1.0$ (RSM1) and $\mathrm{K}=1.34$ (RSM2).

4. The model presented by Ballyk et al. [18] (BM). This model is given by equations (2.44) through (2.48). The void fractions were found using equation (4.9) with the slip ratios estimated using the correlation developed by Rouhani [15], and $\mathrm{K}_{13}$ calculated using equation (4.2).

5. The model recommended by Hwang and Lahey [28] (HLM). This model is given by equation (2.30) with $\varphi_{\mathrm{S}}$ calculated using equation (2.40) and $\rho_{\mathrm{E} 3}=\rho_{\mathrm{H} 3}$. Therefore, the final form of this model is

$$
\Delta P_{13}=\frac{\rho_{H 3}}{2}\left[\frac{G_{3}^{2}}{\rho_{H 3}^{2}}-\frac{G_{1}^{2}}{\rho_{E I}^{2}}\right]+K_{13} \frac{G_{1}^{2}}{2} \frac{\rho_{H 3}}{\rho_{H 1}^{2}} .
$$

The value of $K_{13}$ was found using equation (4.2).

Table 4.4 gives a summary of the performance of the various $\Delta \mathrm{P}_{13}$ models and the results are shown in figures 4.42 through 4.47 . In general, none of the models for $\Delta \mathrm{P}_{13}$ performed satisfactorily for all flow conditions. Significant 
Table 4.4

Summary of the Performance of $\Delta \mathrm{P}_{13}$ Models

\begin{tabular}{|c|c|c|c|c|c|}
\hline \multirow[b]{3}{*}{ Model $^{(1)}$} & \multirow[b]{3}{*}{$\begin{array}{c}\text { Interval } \\
\%\end{array}$} & \multicolumn{4}{|c|}{$\%$ of data predicted correctly } \\
\hline & & \multicolumn{3}{|c|}{ Inlet flow regime } & \multirow{2}{*}{ Overall } \\
\hline & & $\begin{array}{c}W \\
\text { St-W }\end{array}$ & $\mathbf{s}$ & $\begin{array}{l}\text { SA } \\
\text { An }\end{array}$ & \\
\hline \multirow[t]{3}{*}{ HFM } & \pm 50 & 30 & 0 & 59 & 35 \\
\hline & \pm 30 & 15 & 0 & 55 & 27 \\
\hline & \pm 20 & 10 & 0 & 41 & 20 \\
\hline \multirow[t]{3}{*}{ SFM } & \pm 50 & 70 & 62 & 68 & 67 \\
\hline & \pm 30 & 60 & 31 & 41 & 46 \\
\hline & \pm 20 & 45 & 8 & 27 & 29 \\
\hline \multirow[t]{3}{*}{ RSM1 } & \pm 50 & 35 & 62 & 73 & 56 \\
\hline & \pm 30 & 10 & 39 & 64 & 38 \\
\hline & \pm 20 & 5 & 31 & 41 & 26 \\
\hline \multirow[t]{3}{*}{ RSM2 } & \pm 50 & 0 & 0 & 23 & 9 \\
\hline & \pm 30 & 0 & 0 & 9 & 4 \\
\hline & \pm 20 & 0 & 0 & 5 & 2 \\
\hline \multirow[t]{3}{*}{$\mathrm{BM}$} & \pm 50 & 11 & 39 & 0 & 13 \\
\hline & \pm 30 & 0 & 15 & 0 & 4 \\
\hline & \pm 20 & 0 & 8 & 0 & 0 \\
\hline \multirow[t]{3}{*}{ HLM } & \pm 50 & 5 & 0 & 41 & 18 \\
\hline & \pm 30 & 5 & 0 & 27 & 13 \\
\hline & \pm 20 & 5 & 0 & 18 & 7 \\
\hline
\end{tabular}

(1) HFM = homogeneous flow model, SFM = separated flow model, RSM1 = Reimann and Seeger model [26] with $K=1.0$, RSM2 = Reimann and Seeger model [26] with $K=1.34, \mathrm{BM}$ $=$ Ballyk et al. model [18], HLM = Hwang and Lahey model [28] 


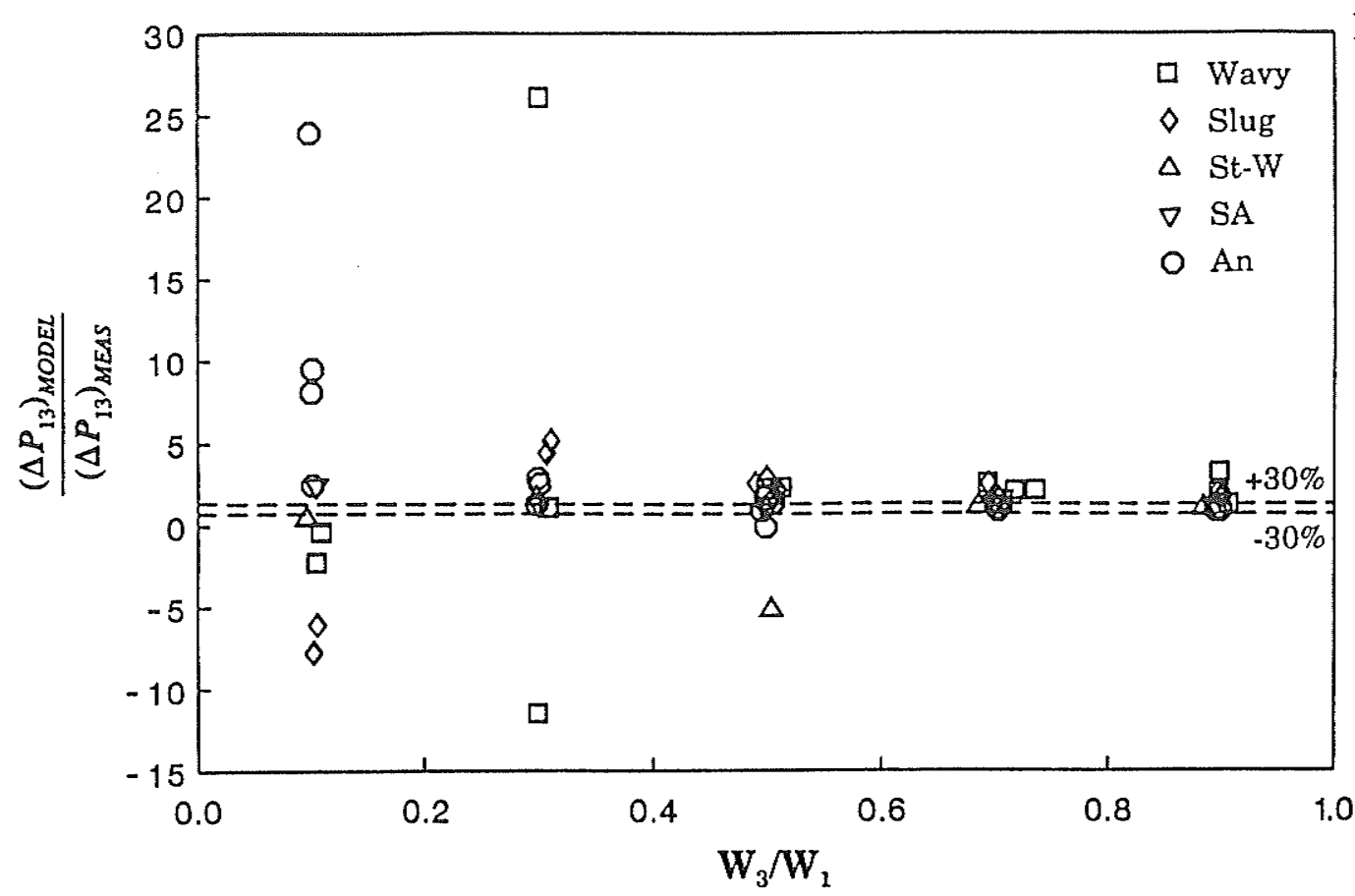

Figure 4.42 Homogeneous flow model (HFM) for $\Delta \mathrm{P}_{13}, \mathrm{~K}_{13}$ present value

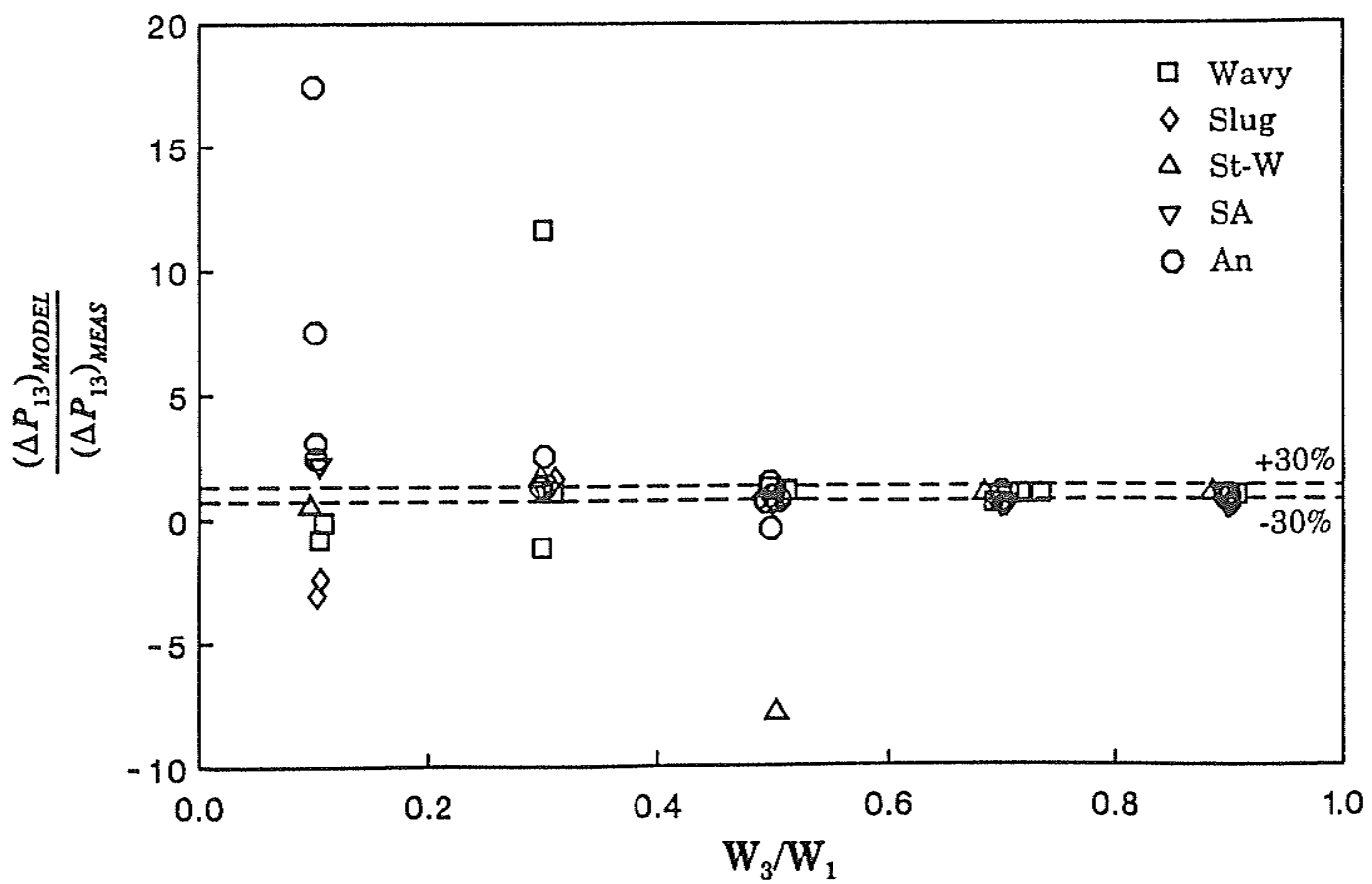

Figure 4.43 Separated flow model (SFM) recommended by Saba and Lahey [12] for $\Delta \mathrm{P}_{13}, \mathrm{~K}_{13}$ present value, $\alpha$ using Rouhani correlation [15] 


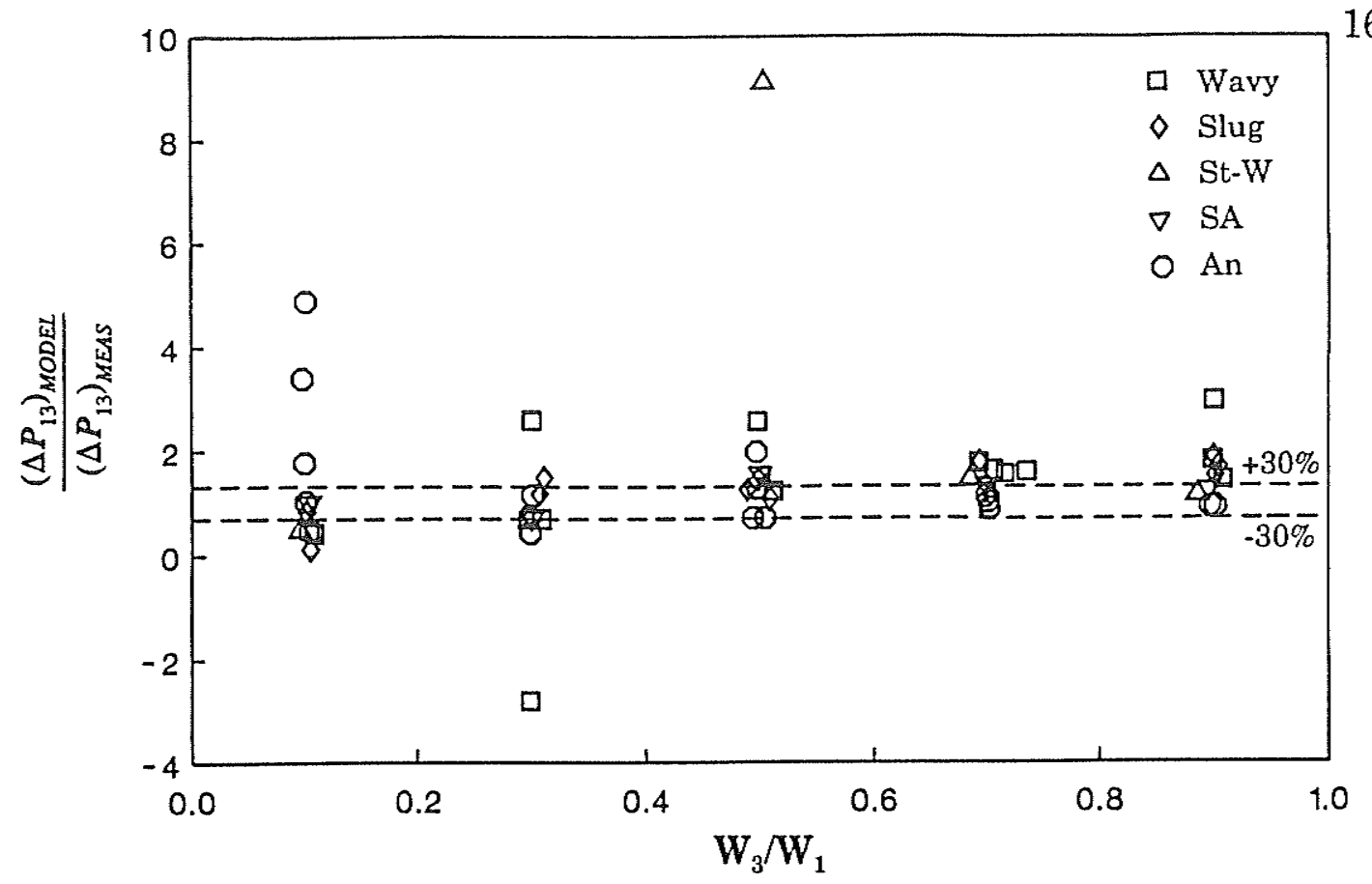

Figure 4.44 Reimann and Seeger model [26] (RSM1) for $\Delta \mathrm{P}_{13}, \mathrm{~K}_{13}$ present value, $\alpha_{1}$ using Rouhani correlation [15], $\mathrm{K}=1.0$

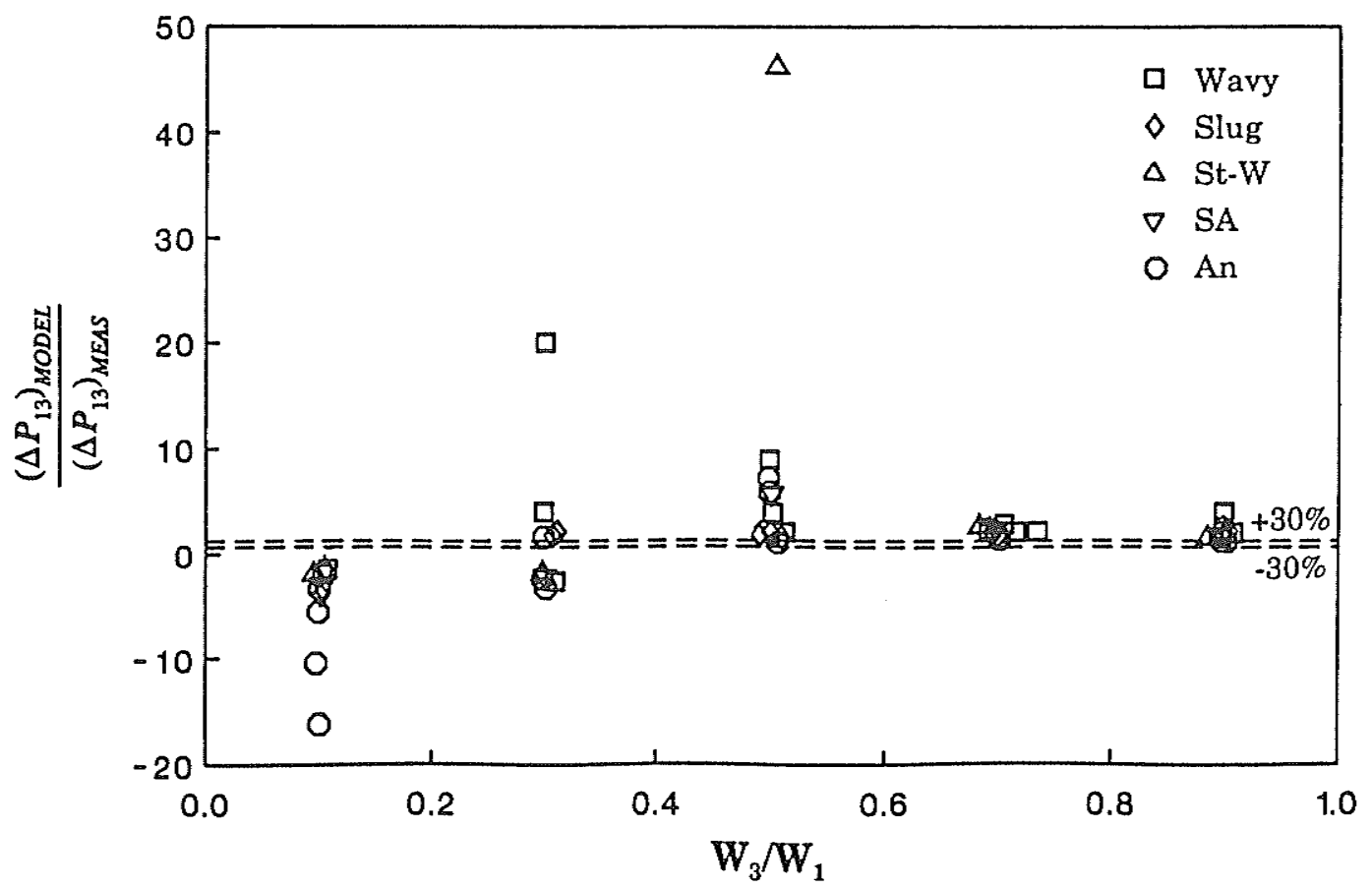

Figure 4.45 Reimann and Seeger model [26] (RSM2) for $\Delta \mathrm{P}_{13}, \mathrm{~K}_{13}$ present value, $\alpha_{1}$ using Rouhani correlation [15], $\mathrm{K}=1.34$ 


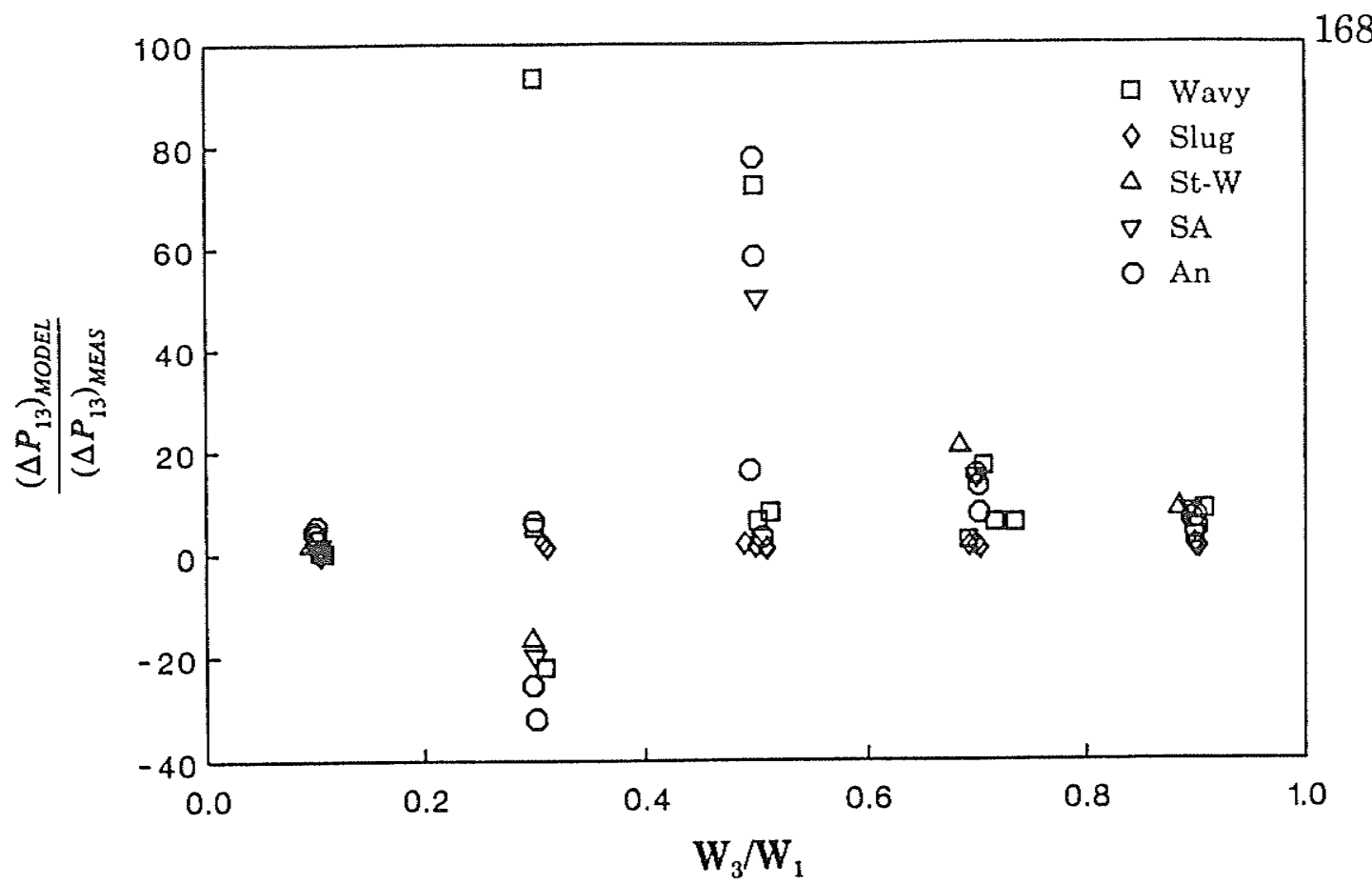

Figure 4.46 Ballyk et al. model [18] (BM) for $\Delta \mathrm{P}_{13}, \mathrm{~K}_{13}$ present value, $\alpha$ using Rouhani correlation [15]

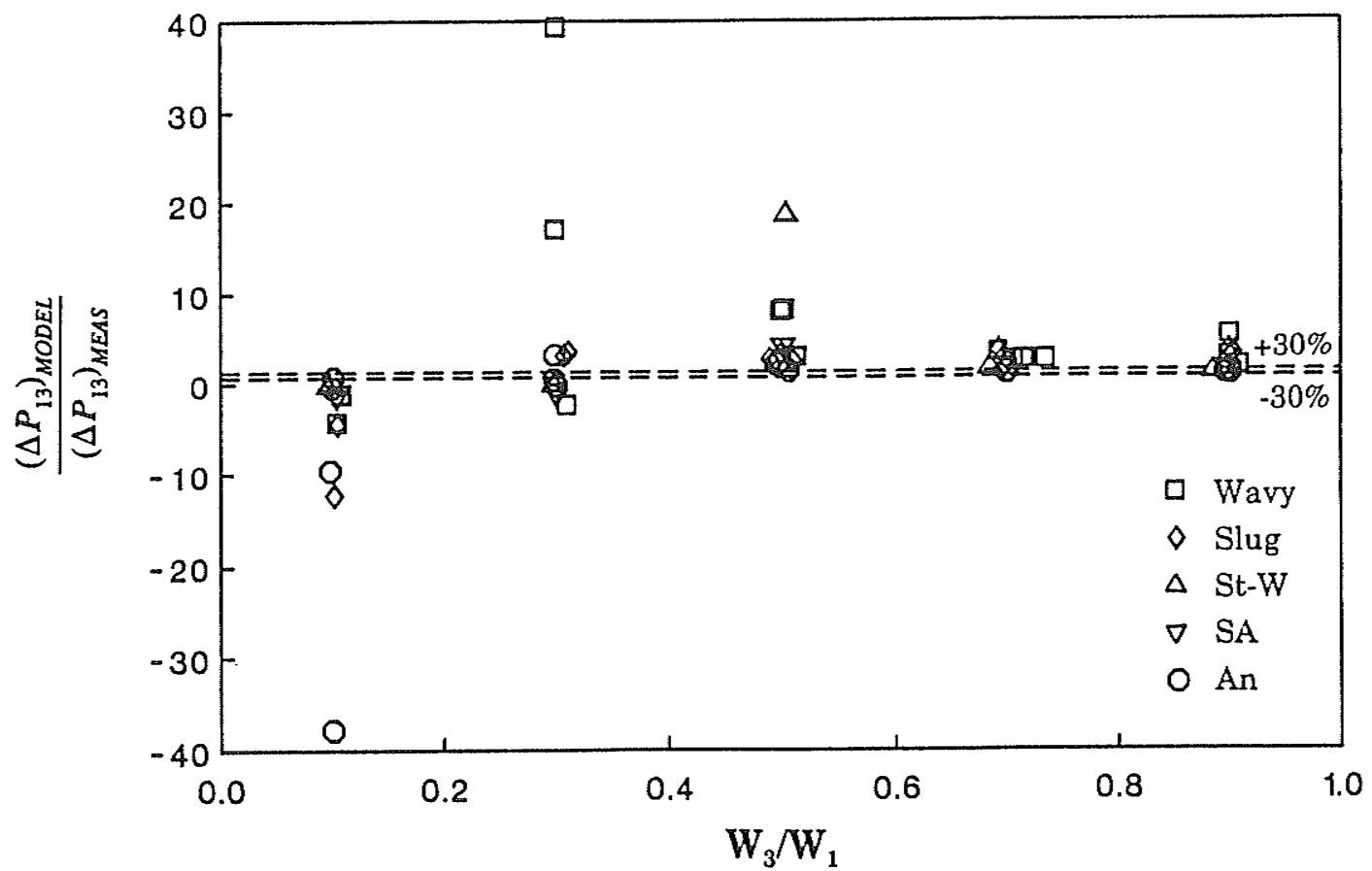

Figure 4.47 Hwang and Lahey model [28] (HLM) for $\Delta \mathrm{P}_{13}, \mathrm{~K}_{13}$ present value, $\alpha_{1}$ using Rouhani correlation [15] 
scatter can be seen in all of the figures. The separated flow model recommended by Saba and Lahey [12] (SFM) gave the best overall agreement with the experimental data with $46 \%$ of the data predicted within $\pm 30 \%$ (67\% predicted within $\pm 50 \%$ ); however, for $\mathrm{W}_{3} / \mathrm{W}_{1} \geq 0.3$ this model predicted $63 \%$ of the data within $\pm 30 \%$ ( $89 \%$ within $\pm 50 \%$ ). The model presented by Reimann and Seeger [26] (RSM1) predicted $38 \%$ of the data within $\pm 30 \%$ (56\% within $\pm 50 \%$ ) with the correction factor $\mathrm{K}$ in equation (2.41) equal to unity; however, with $K=1.34$ the model (RSM2) gave very poor predictions. For $W_{3} / W_{1}<0.3$, the Reimann and Seeger model [26] (RSM1) gave the best predictions of the present data with $32 \%$ of the data for $\mathrm{W}_{3} / \mathrm{W}_{1}<0.3$ predicted within $\pm 30 \%$ ( $58 \%$ within $\pm 50 \%$ ).

Based on the above discussion, the separated flow model (SFM) is recommended for the prediction of the present $\Delta \mathrm{P}_{13}$ data for $\mathrm{W}_{3} / \mathrm{W}_{1} \geq 0.3$. For $\mathrm{W}_{3} / \mathrm{W}_{1}<0.3$, the Reimann and Seeger model [26] (RSM1) is recommended.

Again, because the void fractions used in the above models were determined from correlations rather than experimental data, some disagreement between the models' predictions and experimental data may be attributed to the correlation used to obtain the void fraction. However, the large scatter seen in figures 4.42 to 4.47 indicates that none of the models tested is completely satisfactory; that is, for the present $\Delta \mathrm{P}_{13}$ data none of the models correctly describe the pressure-distribution phenomenon occurring at the tee 
junction. It should be noted that all of the models for $\Delta \mathrm{P}_{13}$ were developed using experimental data obtained at higher $\mathrm{J}_{\mathrm{L} 1}$ than the present study. This can be clearly seen in figure 2.5 .

Present values of $\mathrm{K}_{13}$ were used in the above $\Delta \mathrm{P}_{13}$ models. The comparisons between the $\Delta \mathrm{P}_{13}$ models and the present data were repeated with values of $\mathrm{K}_{13}$ recommended by various authors $[12,18,26,28]$. Similar to the $\Delta \mathrm{P}_{12}$ models, this made little difference to the predictive capability of the various models.

\subsection{Comparison of the Present Phase-Distribution Data With Data From Other Authors}

A comparison between figures 2.4 and 4.1 reveals that other authors have obtained phase-distribution data under similar inlet conditions to the present study. In this section, an attempt will be made to compare the present data with the data from some of these authors.

Shoham et al. [21] obtained phase-distribution data at a number of fixed values of $J_{G 1}$, as shown in figure 2.4. These data were obtained under conditions very similar to the present study. Shoham et al. used a horizontal, equal-sided tee junction (51 mm I.D.) with two-phase mixtures of air and water. A full range of extraction rates was tested. The data for inlet flow 
regimes of stratified, wavy, and annular flow are reproduced in figures 4.48 to 4.50 .

Agreement between the present stratified data, shown earlier in figure 4.2, and the stratified data of Shoham et al. [21] is poor. In the present study, all stratified data lie near the line of even phase distribution; while all of the stratified data of Shoham et al. [21] indicate a strong preference for the gas phase to exit through the branch. It should be noted that the data of Shoham et al. [21] were obtained at a nominal pressure near $300 \mathrm{kPa}$, which is significantly higher than the value used in the present study. However, this would probably not account for the disagreement between the two sets of data.

The phase-distribution data of Shoham et al. [21] corresponding to an inlet flow regime of wavy flow are given in figure 4.49. For simplicity of comparison, this data are re-plotted in figure 4.51 as a composite region. Also shown in figure 4.51 is the region of the present wavy and stratified-wavy data corresponding to $\mathrm{J}_{\mathrm{G} 1}=4.4$ and $11 \mathrm{~m} / \mathrm{s}$. Agreement between the two regions is very good. Figure 4.52 gives a comparison between the present wavy and stratified-wavy data and the wavy data of Shoham et al. [21], all at $\mathrm{J}_{\mathrm{L} 1}$ near $0.0093 \mathrm{~m} / \mathrm{s}$. Again, agreement between the two data sets is very good.

The present annular data are shown in figure 4.5 , and the phasedistribution data of Shoham et al. [21] corresponding to an inlet flow regime of annular flow are given in figure 4.50. A direct comparison between the two sets of data is difficult since the present annular data were obtained at a 


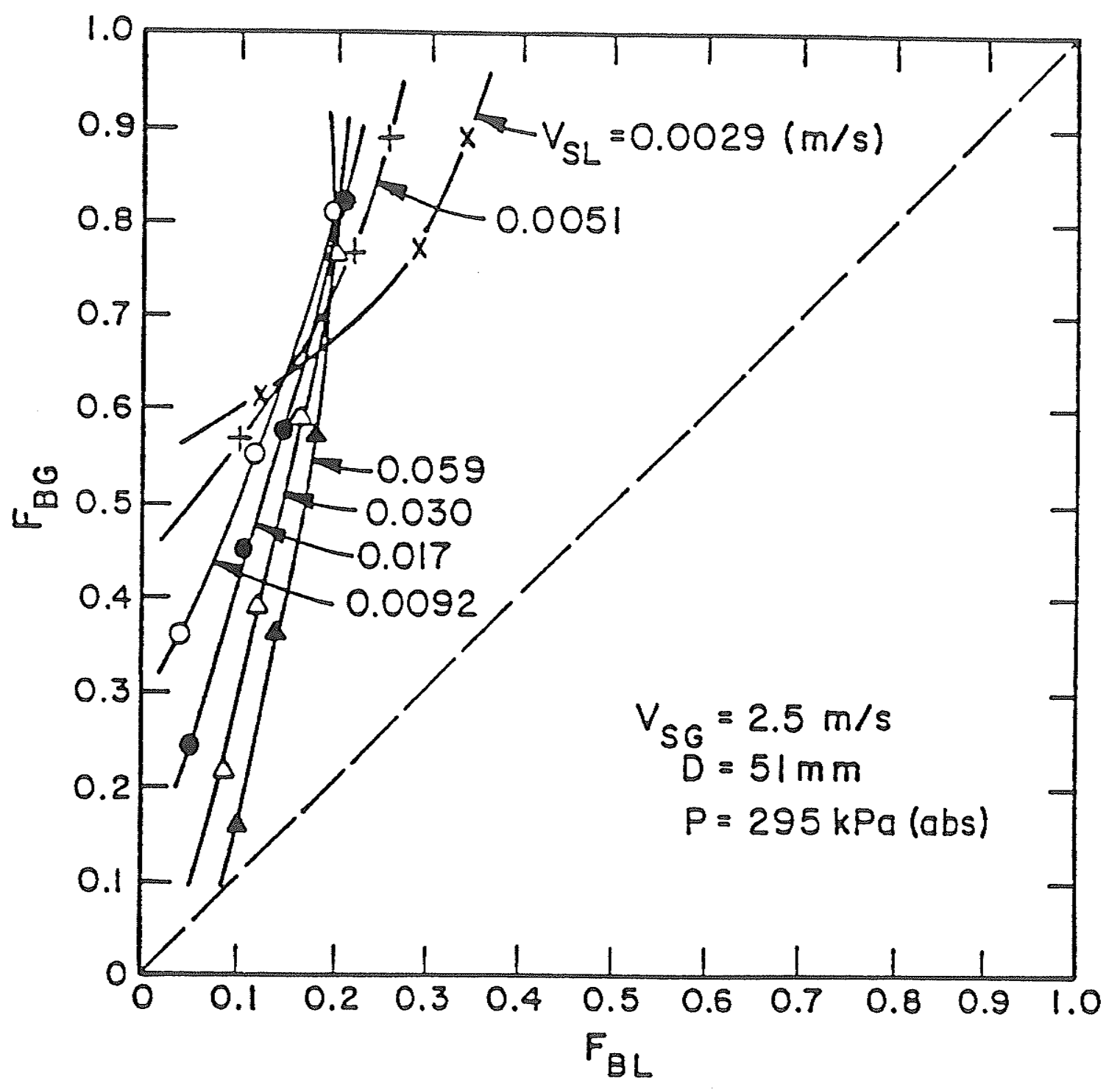

Figure 4.48 Phase-distribution data of Shoham et al. [21] for stratified flow; reproduced from Shoham et al. [21] 


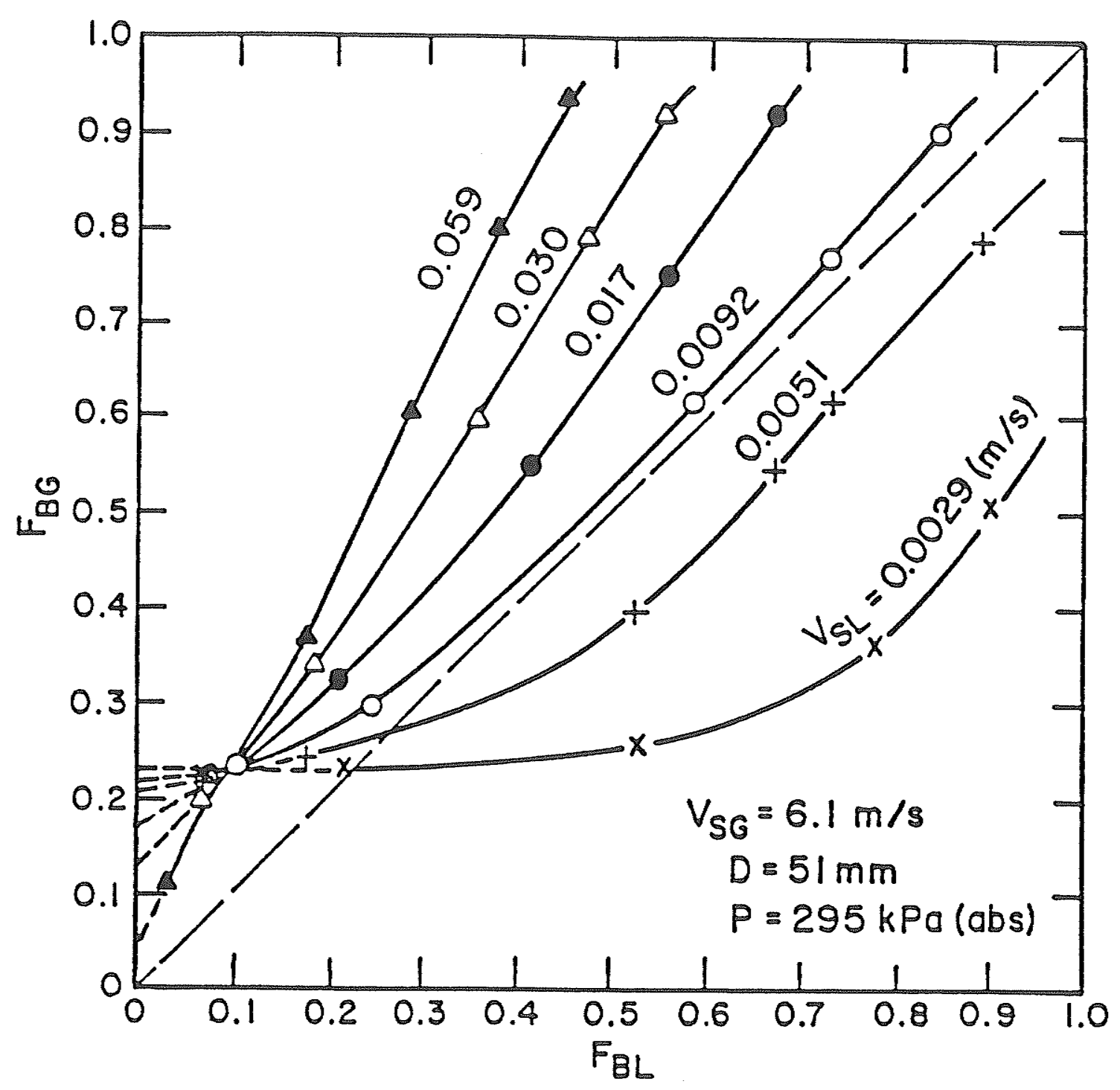

Figure 4.49 Phase-distribution data of Shoham et al. [21] for wavy flow; reproduced from Shoham et al. [21] 


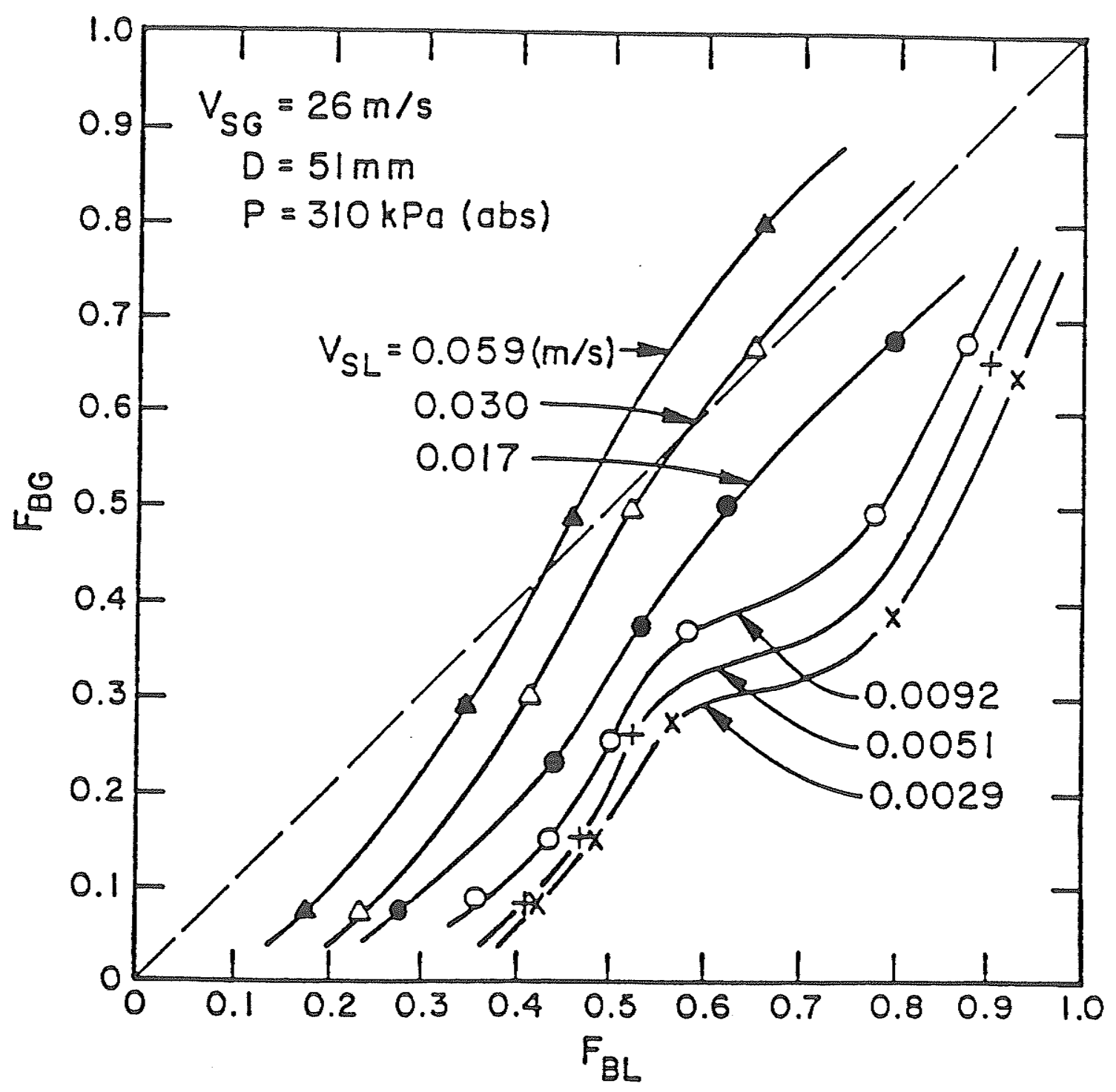

Figure 4.50 Phase-distribution data of Shoham et al. [21] for annular flow; reproduced from Shoham et al. [21] 


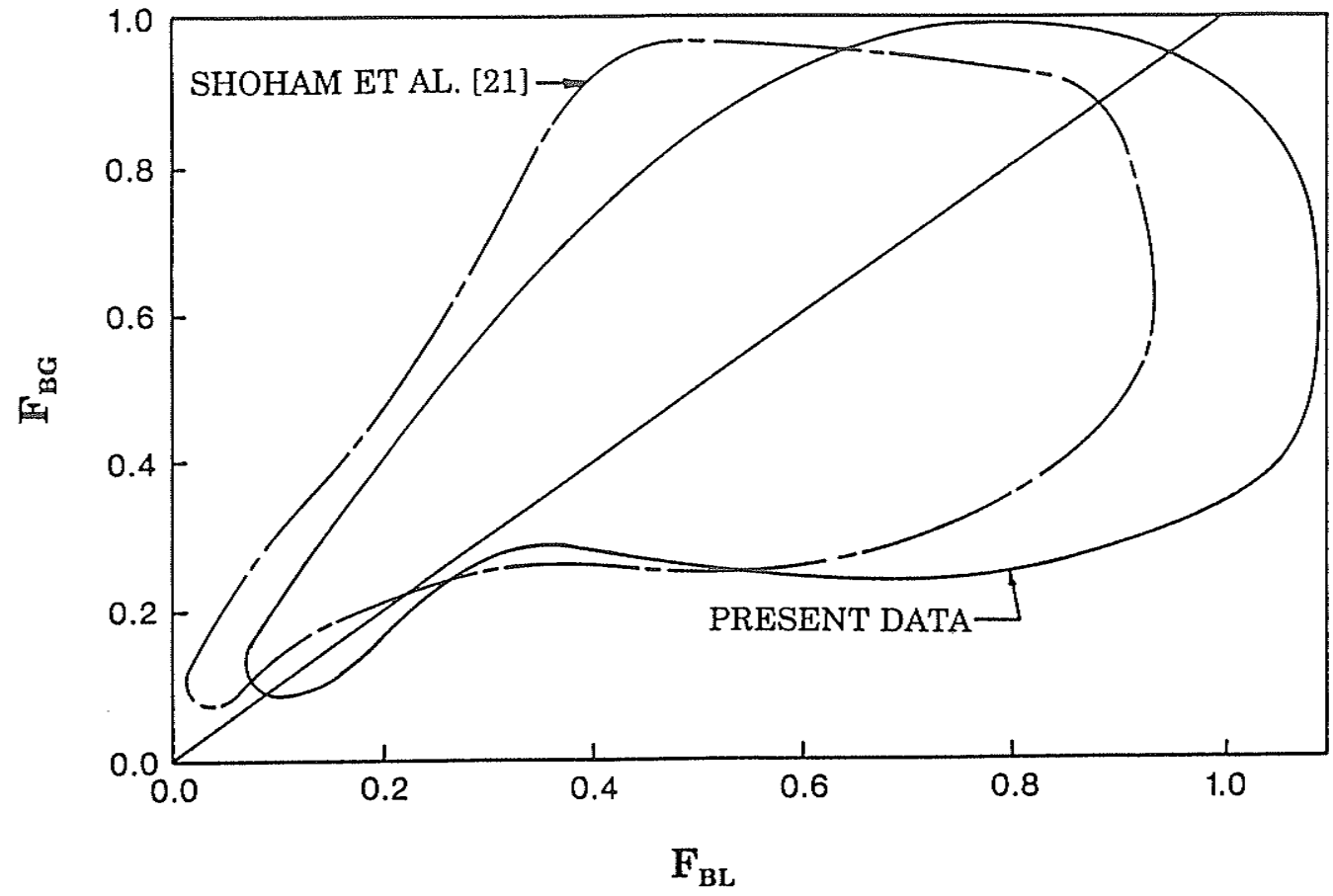

Figure 4.51 Composite drawing of present wavy and stratified-wavy data, $\mathrm{J}_{\mathrm{G} 1}=4.4$ and $11 \mathrm{~m} / \mathrm{s}$, and the data of Shoham et al. [21], $\mathrm{J}_{\mathrm{G} 1}=6.1 \mathrm{~m} / \mathrm{s}$

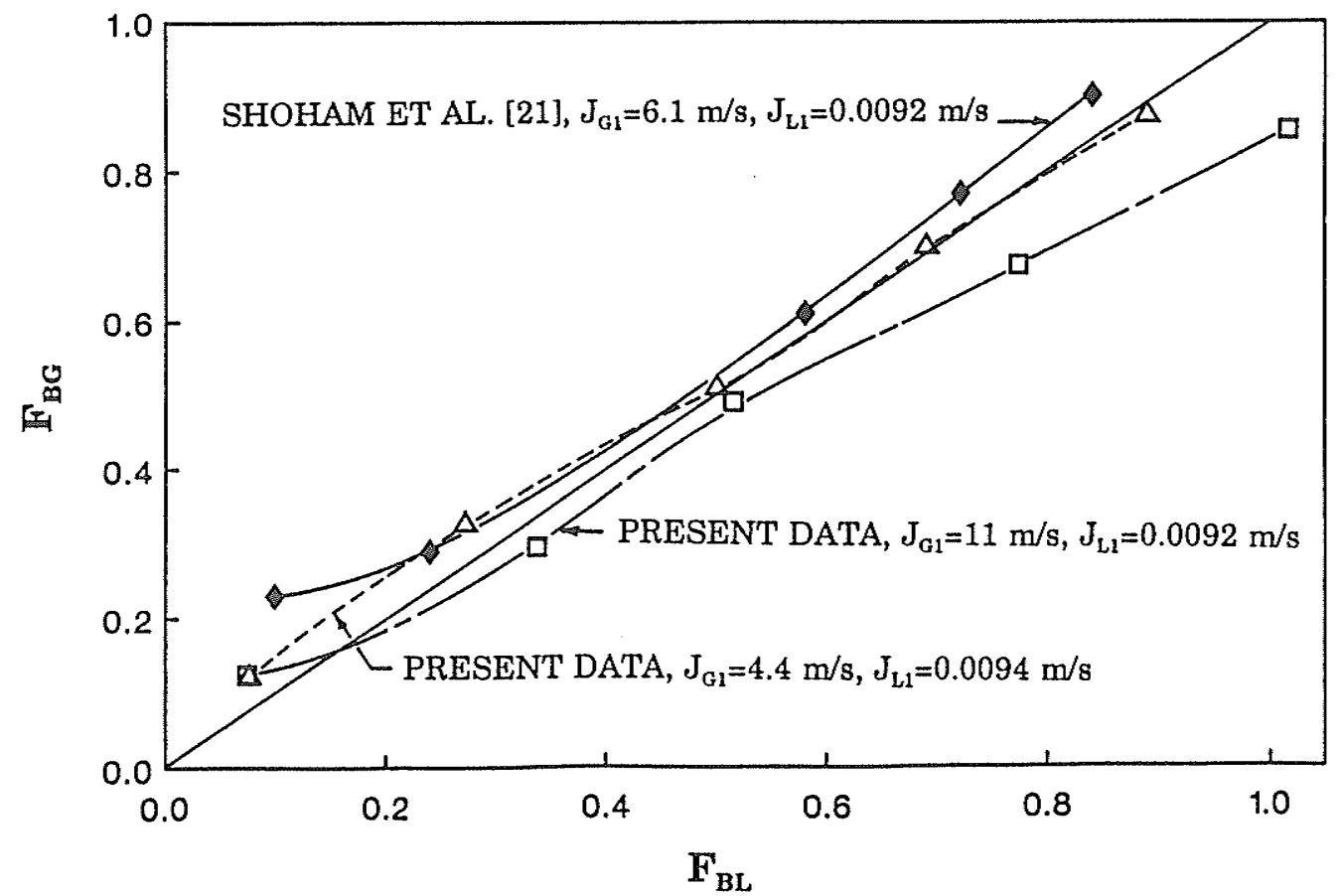

Figure 4.52 Comparison between the present wavy and stratifiedwavy data and the wavy data of Shoham et al. [21] for $\mathrm{J}_{\mathrm{L1}}=0.0093 \mathrm{~m} / \mathrm{s}$ 
higher $\mathrm{J}_{\mathrm{G} 1}$ and a wider range of $\mathrm{J}_{\mathrm{L} 1}$. However, it is clear that similar trends can be observed between the two sets of data, as was discussed is section 4.2.1.

Finally, the data of Shoham et al. [21] were compared to the predictions of the Hwang et al. model [19] using the procedure outlined in section 4.5.1. Results of this comparison are given in figure 4.53. The Hwang et al. model [19] was used because it gave good predictions of the present stratified, wavy, and annular data. The stratified and wavy data of Shoham et al. [21] were compared to the Hwang et al. model [19] with the assumption of an inlet flow regime of stratified flow. For the annular data, the Hwang et al. model [19] was used with the assumption of annular flow in the inlet. The model predicted the annular and wavy data very well. However, the model underpredicted the stratified data. This is consistent with the comparison between the present stratified data and the stratified data of Shoham et al. [21].

Rubel et al. [20] obtained phase-distribution data for steam-water flow through a horizontal tee junction with equal diameter sides $(37.6 \mathrm{~mm})$. Inlet flow regimes of stratified, wavy, and semiannular flow were observed. Figure 4.54 gives a comparison between the present data and the data of Rubel et al. [20] for $\mathrm{J}_{\mathrm{L} 1}$ near $0.0094 \mathrm{~m} / \mathrm{s}$. The data of Rubel et al. [20] lie slightly above the present data; however, the difference is quite small. A comparison between the present data for $J_{G 1}=11 \mathrm{~m} / \mathrm{s}$ and $J_{\mathrm{L} 1}=0.0092 \mathrm{~m} / \mathrm{s}$ and the data of Rubel et al. [20] is given in figure 4.55. Present data for $\mathrm{J}_{\mathrm{L} 1}=0.040 \mathrm{~m} / \mathrm{s}$ and $\mathrm{J}_{\mathrm{L} 1}=0.0022 \mathrm{~m} / \mathrm{s}$ are also shown in this figure. The present data for $J_{L 1}=0.0092 \mathrm{~m} / \mathrm{s}$ agree well 


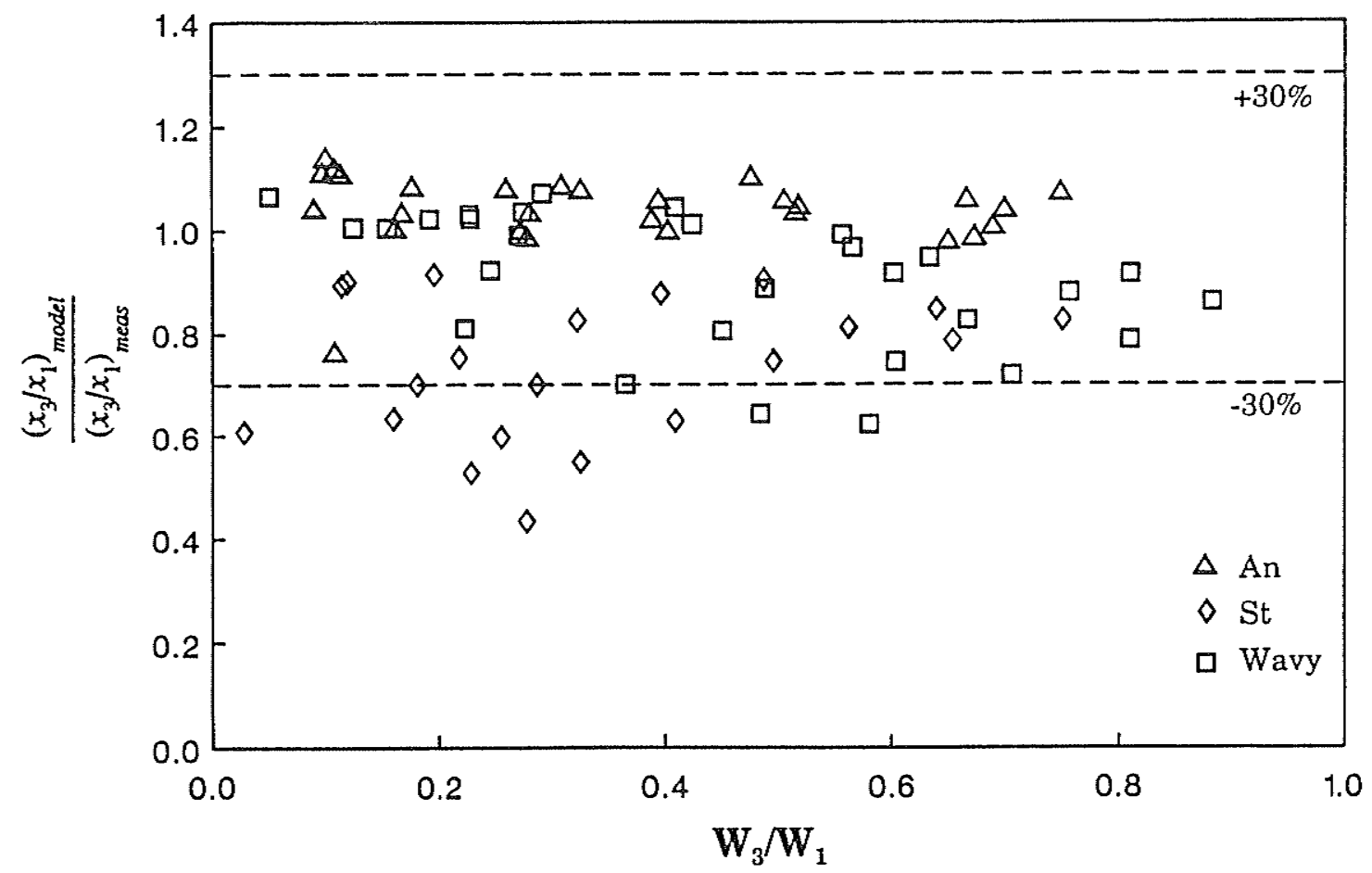

Figure 4.53 Comparison between the Hwang et al. model [19] and the data of Shoham et al. [21] 


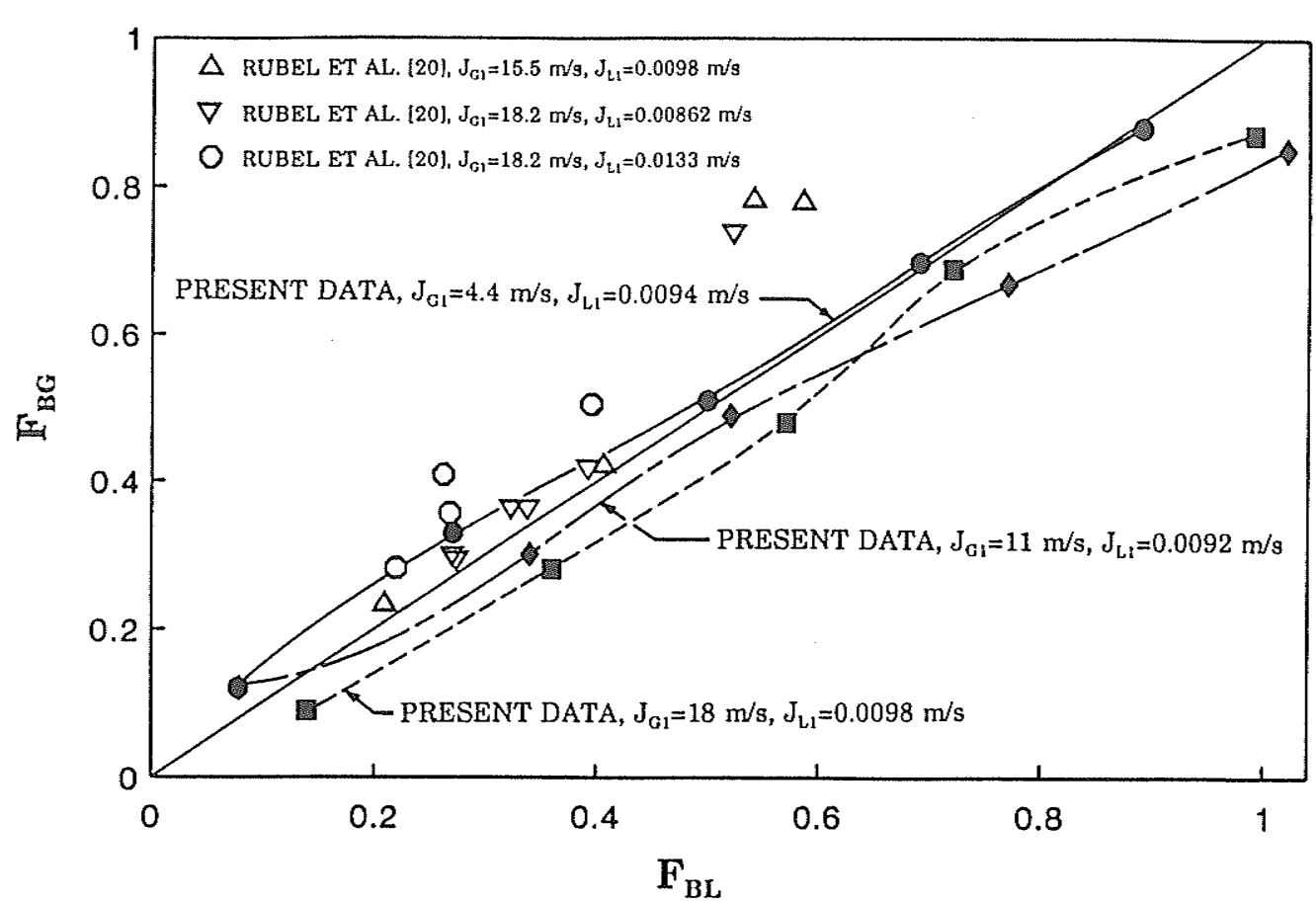

178

Figure 4.54 Comparison between the present data for $\mathrm{J}_{\mathrm{L} 1}=0.0094 \mathrm{~m} / \mathrm{s}$ and the data of Rubel et al. [20]

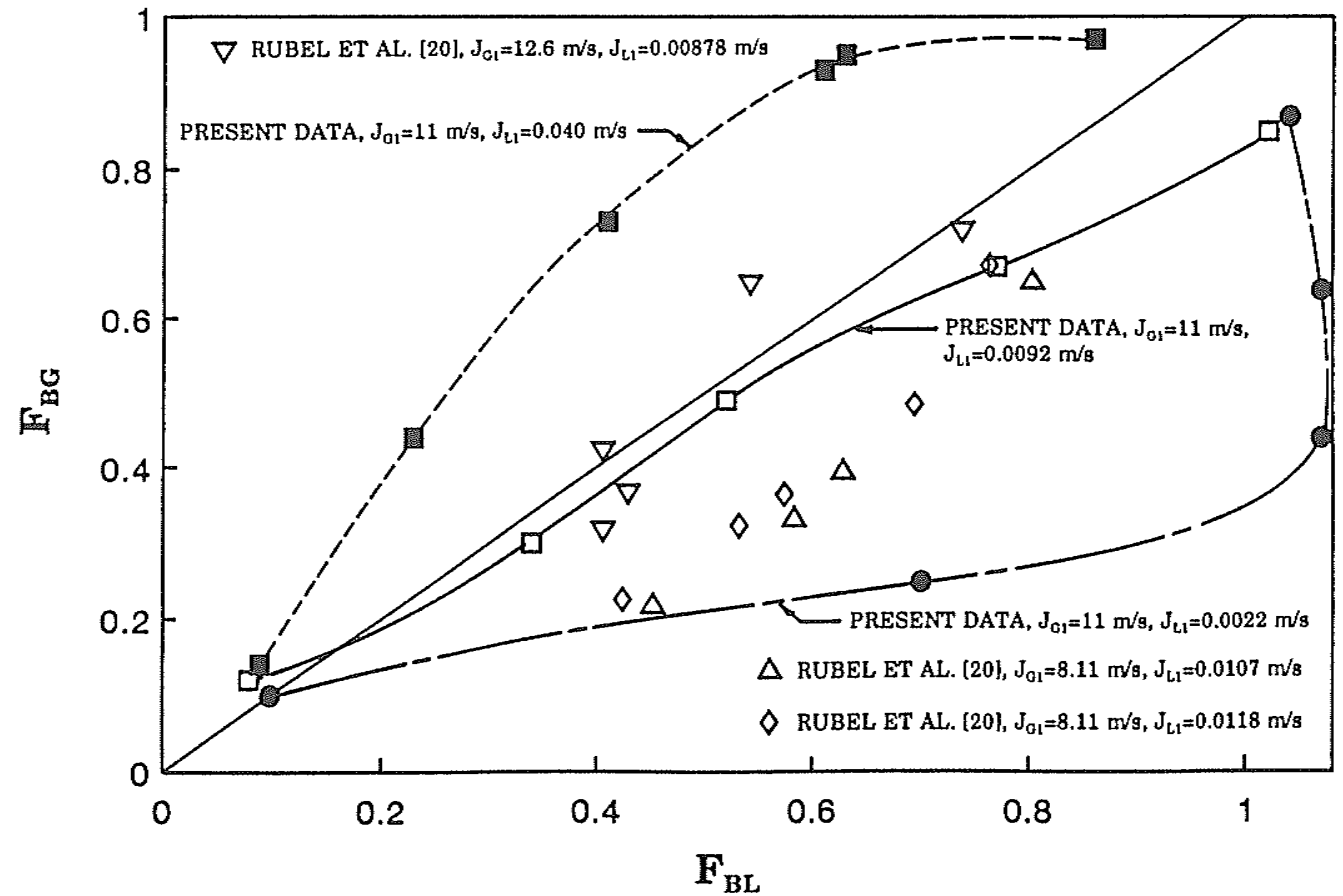

Figure 4.55 Comparison between the present data for $\mathrm{J}_{\mathrm{G} 1}=11 \mathrm{~m} / \mathrm{s}$ and $\mathrm{J}_{\mathrm{L} 1}=0.0092 \mathrm{~m} / \mathrm{s}$ and the data of Rubel et al. [20] 
with the data of Rubel et al. [20] for $J_{\mathrm{G} 1}=12.6 \mathrm{~m} / \mathrm{s}$ and $J_{\mathrm{L} 1}=0.00878 \mathrm{~m} / \mathrm{s}$; however, the data of Rubel et al. [20] for $J_{G 1}=8.11 \mathrm{~m} / \mathrm{s}$ and $J_{\mathrm{L} 1}=0.0107 \mathrm{~m} / \mathrm{s}$ and $0.0118 \mathrm{~m} / \mathrm{s}$ lie slightly below the present data for $J_{\mathrm{L} 1}=0.0092 \mathrm{~m} / \mathrm{s}$. Other direct comparisons between the present data and the data of Rubel et al. [20] could not be made. However, many of the same trends were observed between the two sets of data, as was discussed in previous sections.

A segment of the phase-distribution data of Hong [3] can be compared with the present study. Hong [3] used an equal sided (9.5 mm I.D.) tee junction with a horizontal inlet and branch orientations of vertical upwards, horizontal, and vertical downwards. Comparisons between the present data and the data of Hong [3] for a horizontal branch are given in figures 4.56 and 4.57.

The two parts of figure 4.56 show the comparison between the present data and the data of Hong [3] at $J_{G 1}$ near $40 \mathrm{~m} / \mathrm{s}$. The present data for $\mathrm{J}_{\mathrm{L} 1}=0.0395 \mathrm{~m} / \mathrm{s}$ all lie above the data of Hong [3], as shown in figure 4.56(a). In figure $4.56(\mathrm{~b})$, the present data for $\mathrm{J}_{\mathrm{L} 1}=0.0096 \mathrm{~m} / \mathrm{s}$ lie slightly above the data of Hong [3] for $\mathrm{J}_{\mathrm{L} 1}=0.0117 \mathrm{~m} / \mathrm{s}$; however, the difference is small. The present data for $J_{L 1}$ of $0.0018 \mathrm{~m} / \mathrm{s}$ also lie close to the data of Hong for $J_{L 1}=0.00234 \mathrm{~m} / \mathrm{s}$. Comparisons between the present data and the data of Hong [3] for $\mathrm{J}_{\mathrm{G} 1}$ near $10 \mathrm{~m} / \mathrm{s}$ are given in the two parts of figure 4.57 . In figure 4.57(a), the present data for $\mathrm{J}_{\mathrm{L} 1}=0.040 \mathrm{~m} / \mathrm{s}$ lie fairly close to the data of Hong [3] for $\mathrm{J}_{\mathrm{L} 1}=0.0468$ $\mathrm{m} / \mathrm{s}$, but with a slightly greater preference for the gas phase to exit through the 


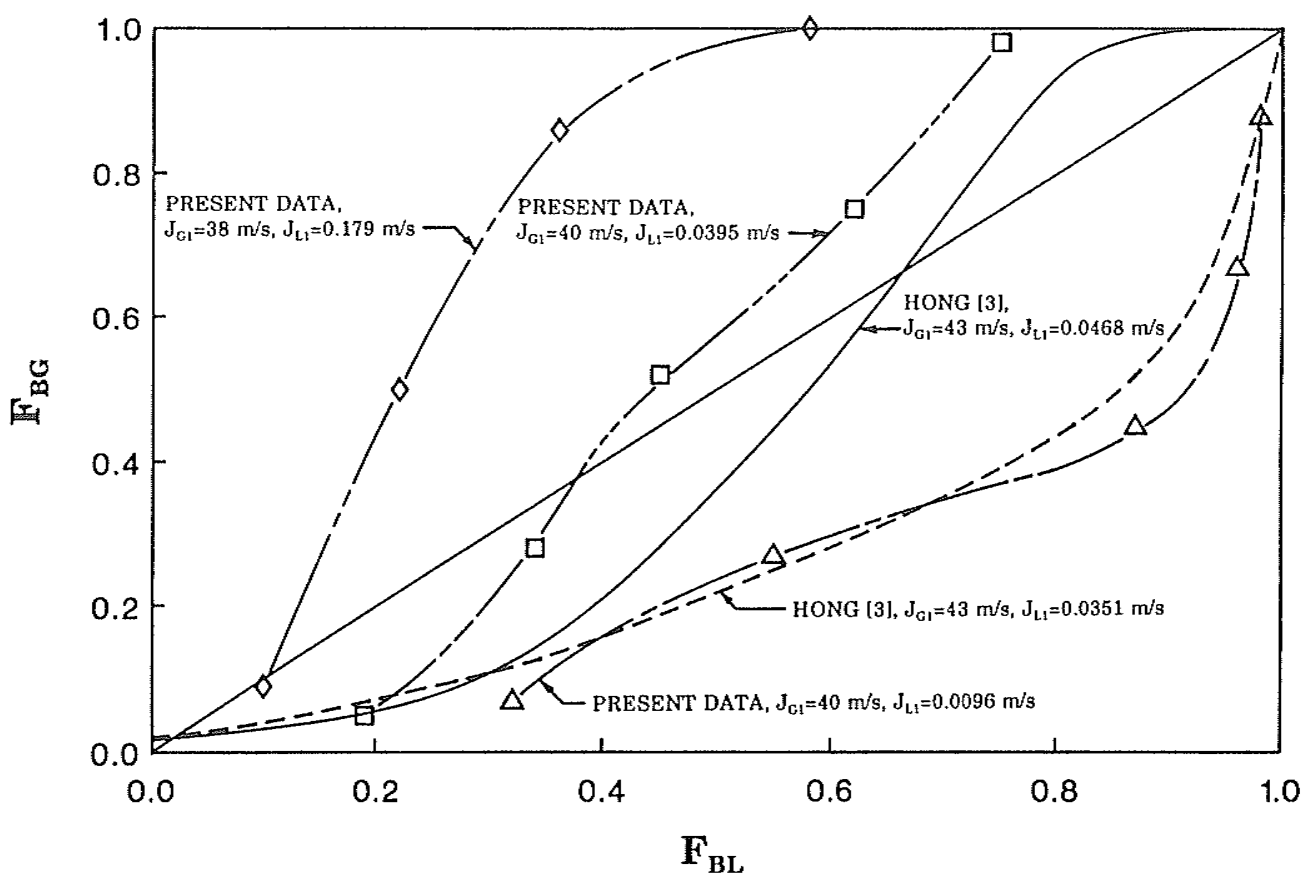

(a)

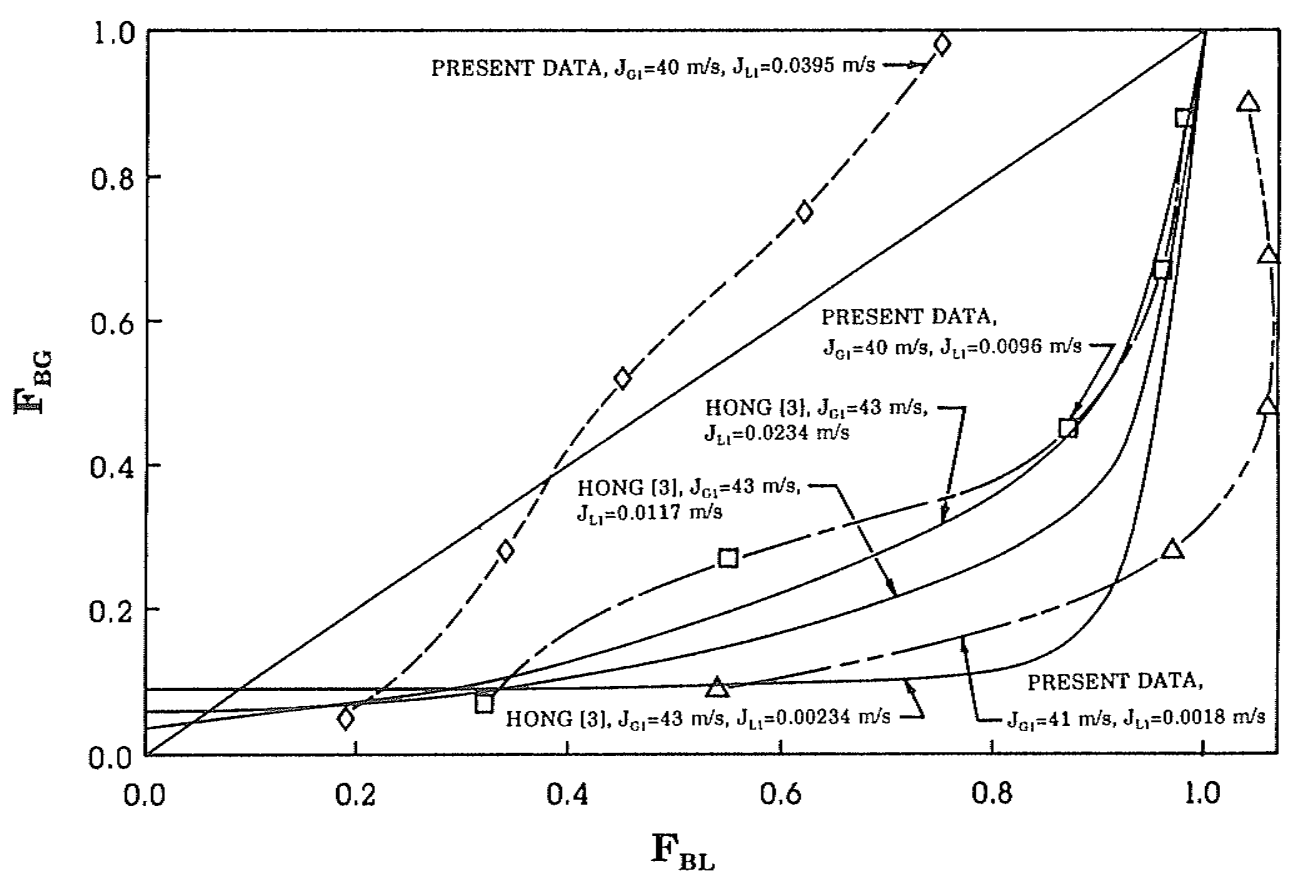

(b)

Figure 4.56 Comparison between the present data and the data of Hong [3] for $J_{G 1}=40 \mathrm{~m} / \mathrm{s}$ 


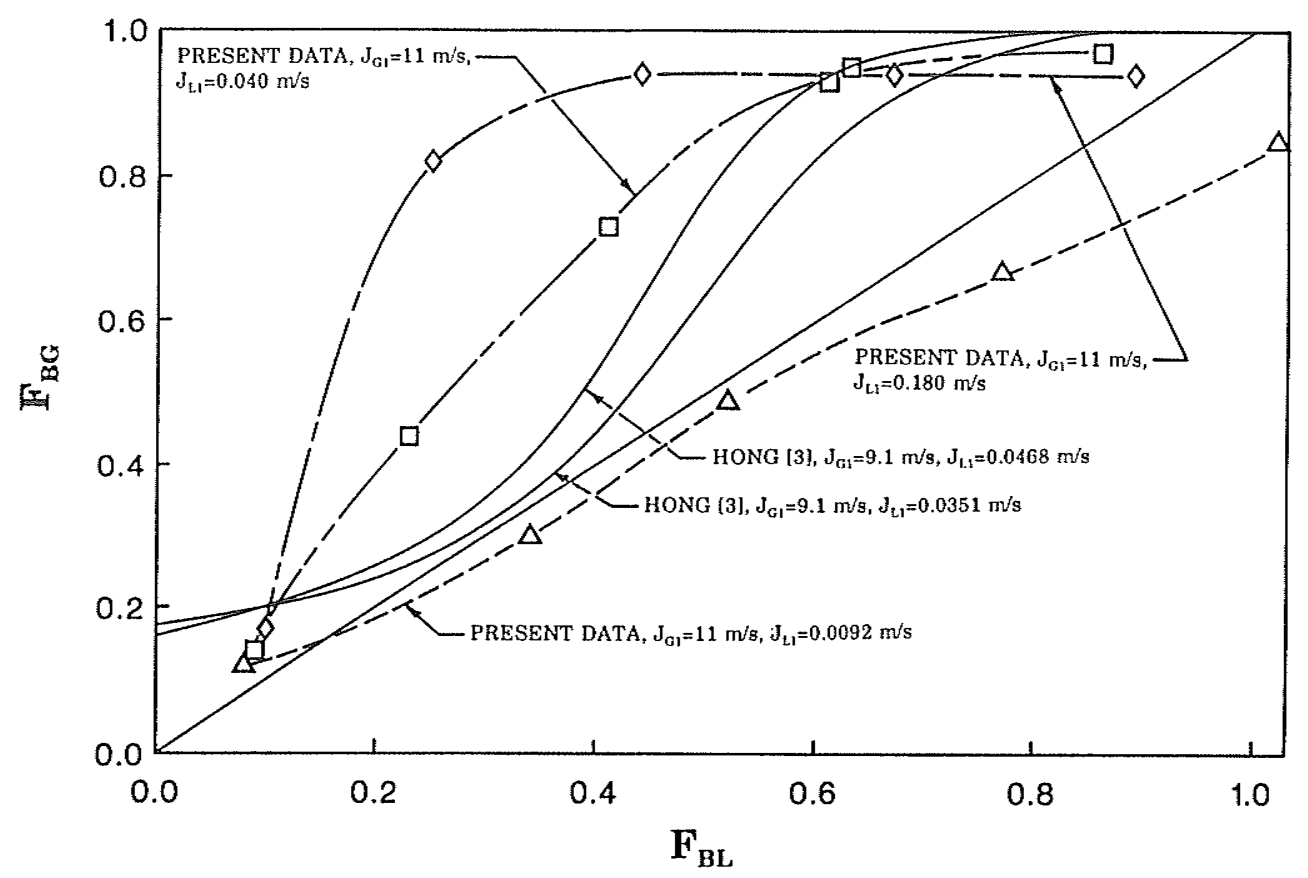

(a)

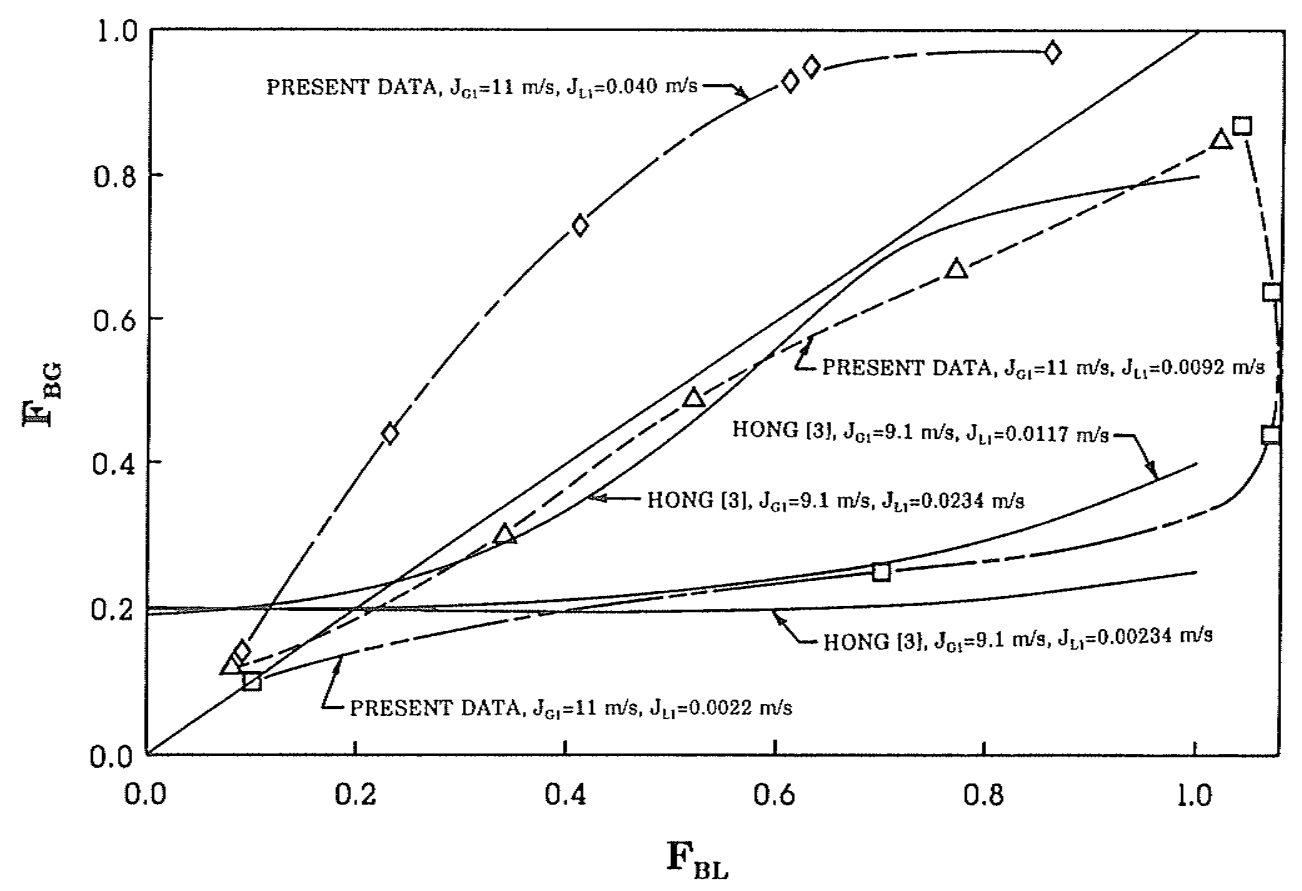

(b)

Figure 4.57 Comparison between the present data and the data of Hong [3] for $\mathrm{J}_{\mathrm{G} 1}=10 \mathrm{~m} / \mathrm{s}$ 
branch. In figure $4.57(\mathrm{~b})$, for $J_{\mathrm{L} 1}$ near $0.0092 \mathrm{~m} / \mathrm{s}$ the present data generally lie well above the data of Hong [3]. For $\mathrm{J}_{\mathrm{L} 1}$ near $0.0022 \mathrm{~m} / \mathrm{s}$, the present data and the data of Hong [3] agree quite well.

In general, at lower $\mathrm{J}_{\mathrm{L} 1}$ the data of Hong [3] and the present data agree well. At higher $J_{L 1}$, the present data indicated a greater preference for the gas phase to exit through the branch. It is noted that Hong [3] used a small diameter tee junction (9.5 mm I.D.). For this small diameter, under some conditions, surface tension could possibly have a significant effect on the phase distribution. 


\section{Chapter 5}

\section{CONCLUSIONS AND RECOMMENDATIONS}

\subsection{Conclusions}

In the present investigation, extensive data for air-water flow in a horizontal tee junction with equal diameter sides were obtained. These data consist of both the phase distribution and pressure drops at different extraction rates, and correspond to a wide range of inlet conditions, as shown in figure 4.1. A comparison between the present operating conditions and the previously tested conditions, shown in figures 2.4 and 2.5, reveals that a limited amount of phase-distribution data were previously obtained under operating conditions similar to the present study. However, the present pressure-drop data are unique. The present data were compared to existing correlations for predicting the phase distribution and pressure drops. In addition, the present phasedistribution data were compared to data from previous investigations.

Based on the present results and comparisons, the following conclusions can be drawn:

1. In general, the phases did not distribute themselves evenly through the tee junction.

2. All data corresponding to inlet flow regimes of stratified and wavy flow occupied a narrow strip surrounding the line of even phase distribution, 
with the wavy flow data showing a slightly greater preference for the gas phase to exit through the branch. Stratified-wavy flow data showed a slight preference for the liquid to exit through the branch. All slug data displayed a strong preference for the gas to exit through the branch and for $\mathrm{W}_{3} / \mathrm{W}_{1}>0.3, \mathrm{~F}_{\mathrm{BG}}$ was near unity. Annular data showed large variations in the distribution of the phases, depending on $\mathrm{J}_{\mathrm{L} 1}$. Semiannular data were only obtained at one particular inlet condition, and showed near-even phase distribution.

3. As $\mathrm{J}_{\mathrm{L} 1}$ was increased at a fixed $\mathrm{J}_{\mathrm{G} 1}$, there was an increased preference for the gas phase to exit through the branch, irrespective of the inlet flow regime.

4. The effect of $J_{G 1}$ on the phase distribution did not result in consistent trends, possibly due to the associated flow regime transitions.

5. The effect of $\mathrm{G}_{1}$ on the phase distribution (at a fixed $\mathrm{x}_{1}$ ) appeared to be small at large values of $x_{1}$ but became more significant as $x_{1}$ was decreased.

6. The pressure drops $\Delta \mathrm{P}_{12}$ and $\Delta \mathrm{P}_{13}$ depended greatly on $\mathrm{W}_{3} / \mathrm{W}_{1}, \mathrm{~J}_{\mathrm{G} 1}$, and $\mathrm{J}_{\mathrm{L} 1}$. In general, the absolute value of $\Delta \mathrm{P}_{12}$ and $\Delta \mathrm{P}_{13}$ increased as $\mathrm{G}_{1}$ or $\mathrm{W}_{3} / \mathrm{W}_{1}$ was increased.

7. The phase-distribution model developed by Hwang et al. [19] gave the best overall predictions of the present data. Ninety-four percent of the present stratified, stratified-wavy, and wavy flow data and $88 \%$ of the 
present annular and semiannular flow data were predicted within $\pm 30 \%$. The model underpredicted the present slug flow data. The models developed by Azzopardi and Whalley [6] and Azzopardi [25] performed well in predicting the present annular and semiannular flow data. The Seeger et al. model [14] underpredicted the present data for $\mathrm{W}_{3} / \mathrm{W}_{1}<0.5$; however, at higher $\mathrm{W}_{3} / \mathrm{W}_{1}$ the model performed well.

8. For all inlet flow regimes other than slug, $\Delta \mathrm{P}_{12}$ was predicted best by the separated flow model (SFM) presented by Fouda and Rhodes [27], with $\left(\mathrm{K}^{*}{ }_{12}\right)_{\mathrm{S}}$ equal to the single-phase momentum correction factor $\mathrm{K}^{*}{ }_{12}$. For slug flow, the model presented by Hwang and Lahey [28] (HLM1) gave the best predictions for $\mathrm{W}_{3} / \mathrm{W}_{1}>0.1$; however, for $\mathrm{W}_{3} / \mathrm{W}_{1} \leq 0.1$ the separated flow model (SFM) gave the best predictions.

9. In general, $\Delta \mathrm{P}_{13}$ was poorly predicted by existing correlations. For $\mathrm{W}_{3} / \mathrm{W}_{1}$ $\geq 0.3$, the separated flow model (SFM) recommended by Saba and Lahey [12] gave the best predictions of the present data. For $\mathrm{W}_{3} / \mathrm{W}_{1}<0.3$, the Reimann and Seeger model [26] (RSM1) gave the best predictions.

10. Most of the present phase-distribution data compared well with data from previous investigations. The major exception to this good agreement occurred when comparing the stratified-flow data of this investigation with similar data reported by Shoham et al. [21]. However, this segment of the present data was found to be consistent with other data by Rubel [16] and model predictions by Hwang et al. [19]. 


\subsection{Recommendations for Future Work}

Although extensive pressure-drop and phase-distribution data have been obtained in the present study, more work is clearly needed. The present study only focused on one particular junction geometry. Previous studies have also been restricted to a limited number of different junction geometries. As well, all of the present data were obtained using an air-water mixture near ambient temperature and pressure. Therefore, to aid in the development of generalized mathematical models, more experimental investigations are required at previously untested operating conditions and junction geometries. Future studies should include the measurement of both the phase distribution and pressure drops. Several suggestions for future experimental work are as follows:

1. More low pressure air-water data should be taken using tee junctions of different geometries. The influence of $D_{1}, D_{3}$, and $D_{3} / D_{1}$, as well as junction orientation, should be studied over a wide range of operating conditions.

2. The present data should be extended to higher pressures in order to study the effect of $\rho_{G 1}$ on the phase distribution and pressure drops.

3. More steam-water flow data are required. 


\section{REFERENCES}

1. Tsuyama, M., and Taga, M., "On the Flow of the Air-Water Mixture in the Branch Pipe - 1. Experiment on the Horizontal Branch Which is Equal to the Main One in Diameter", Bull. JSME, Vol. 2, pp. 151-156, 1959.

2. Collier, J.G., "Single-Phase and Two-Phase Flow Behaviour in Primary Circuit Components", Proceedings of NATO Advanced Study Institute on Two-Phase Flow and Heat Transfer, Istanbul, Turkey, 1976.

3. Hong, K.C., "Two-Phase Flow Splitting at a Pipe Tee", Journal of Petroleum Technology, Vol. 30, pp. 290-296, 1978.

4. Johansen, S.E., "Experimental Study of Gas-Liquid Flow in a Pipe Tee", M.Sc. Thesis, University of Tulsa, 1979.

5. Henry, J.A.R., "Dividing Annular Flow in a Horizontal Tee", Int. J. Multiphase Flow, Vol. 7, pp. 343-355, 1981.

6. Azzopardi, B.J., and Whalley, P.B., "The Effect of Flow Patterns on TwoPhase Flow in a T Junction", Int. J. Multiphase Flow, Vol. 8, pp. 491507, 1982.

7. Whalley, P.B., and Azzopardi, B.J., "Two-Phase Flow in a 'T" Junction", UKAEA Report AERE-R 9699, 1980.

8. Whalley, P.B., and Fells, N.S., "Two-Phase Flow in a ' $\mathrm{T}$ ' Junction: Further Experimental Results", UKAEA Report AERE-M 3149, 1981.

9. Azzopardi, B.J., and Baker, S.R., "Two-Phase Flow in a 'T' Junction: The Effect of Flow Pattern in Vertical Upflow", UKAEA Report AERE-R 10174, 1981.

10. Azzopardi, B.J., and Freeman-Bell, G., "The Effect of the Side Arm Diameter on the Two-Phase Flow Split at a "T" Junction", UKAEA Report AERE-M 3290, 1983.

11. Azzopardi, B.J., "The Effect of the Side Arm Diameter on the Two-Phase Flow Split at a "T" Junction", Int. J. Multiphase Flow, Vol. 10, pp. 509$512,1984$. 
12. Saba, N., and Lahey, R.T., "The Analysis of Phase Separation Phenomena in Branching Conduits", Int. J. Multiphase Flow, Vol. 10, pp. 1-20, 1984.

13. Lahey, R.T., "Current Understanding of Phase Separation Mechanisms in Branching Conduits", Nuclear Engineering and Design, Vol. 95, pp. 145-161, 1986.

14. Seeger, W., Reimann, J., and Muller, U., "Two-Phase Flow in a TJunction With a Horizontal Inlet - Part I: Phase Separation", Int. J. Multiphase Flow, Vol. 12, pp. 575-585, 1986.

15. Rouhani, Z., "Modified Correlations for Void and Two-Phase Pressure Drop", AB Atomenergi Sweden, Report AE-RTV-841, 1969.

16. Rubel, M.T., "Experimental Investigation of Phase Distribution in a Horizontal Tee Junction", M.Sc. Thesis, University of Manitoba, 1986.

17. Ballyk, J.D., and Shoukri, M., "Steam-Water Annular Flow in Horizontal Dividing Tee-Junctions", Thermo-fluids Research Report No. ME/87/TF/RI, McMaster University, 1987.

18. Ballyk, J.D., Shoukri, M., and Chan, A.M.C., "Steam-Water Annular Flow in a Horizontal Dividing T-Junction", Int. J. Multiphase Flow, Vol. 14, pp. 265-285, 1988.

19. Hwang, S.T., Soliman, H.M., and Lahey, R.T.,"Phase Separation in Dividing Two-Phase Flows", Int. J. Multiphase Flow, Vol. 14, pp. 439$458,1988$.

20. Rubel, M.T., Soliman, H.M., and Sims, G.E., "Phase Distribution During Steam-Water Flow in a Horizontal Tee Junction", Int. J. Multiphase Flow, Vol. 14, pp. 425-438, 1988.

21. Shoham, O., Brill, J.P., and Taitel, Y., "Two-Phase Flow Splitting in a Tee Junction - Experiment and Modeling", Chemical Engineering Science, Vol. 42, pp. 2667-2676, 1987.

22. Reimann, J., Brinkmann, H.J., and Domanski, R., "Gas-Liquid Flow in Dividing Tee-Junctions With a Horizontal Inlet and Different Branch Orientations and Diameters", Report KfK 4399, 1988. 
23. Azzopardi, B.J., "Measurements and Observations of the Split of Annular Flow at a Vertical T-Junction", Int. J. Multiphase Flow, Vol. 14, pp. 701-710, 1988.

24. Azzopardi, B.J., Wagstaff, D., Patrick, L., Memory, S.B., and Dowling, J., "The Split of Two-Phase Flow at a Horizontal T - Annular and Stratified Flow", UKAEA Report AERE-R 13059, 1988.

25. Azzopardi, B.J., "An Additional Mechanism in the Flow Split of High Quality Gas-Liquid Flows At a T Junction", UKAEA Report AERE-R 13058, 1988.

26. Reimann, J., and Seeger, W., "Two-Phase Flow in a T-Junction With a Horizontal Inlet - Part II: Pressure Differences", Int. J. Multiphase Flow, Vol. 12, pp. 587-608, 1986.

27. Fouda, A.E., and Rhodes, E., "Two-Phase Annular Flow Stream Division in a Simple Tee", Trans. Instn Chem. Engrs., Vol. 52, pp. 354-360, 1974.

28. Hwang, S.T., and Lahey, R.T., "A Study on Single- and Two-Phase Pressure Drop in Branching Conduits", Experimental Thermal and Fluid Science, Vol. 1, pp. 111-125, 1988.

29. Zuber, N., and Findlay, J.A., "Average Volumetric Concentration in TwoPhase Flow Systems", J. Heat Transfer, pp. 453-468, November, 1965.

30. Mandhane, J.M., Gregory, G.A., and Aziz, K., "A Flow Pattern Map for Gas-Liquid Flow in Horizontal Pipes", Int. J. Multiphase Flow, Vol. 1, pp. 537-553, 1974.

31. Kataoka, I., and Ishii, M., "Entrainment and Deposition Rates of Droplets in Annular Two-Phase Flow", Proceedings of ASME/JSME Thermal Engineering Joint Conference, Vol. 1, pp. 69-80, Honolulu, Hawaii, March 20-24, 1983.

32. Dallman, J.C., Laurinat, J.E., and Hanratty, T.J., "Entrainment For Horizontal Annular Gas-Liquid Flow", Int. J. Multiphase Flow, Vol. 10, pp. $677-690,1984$.

33. Laurinat, J.E., Hanratty, T.J., and Dallman, J.C., "Pressure Drop and Film Height Measurements For Annular Gas-Liquid Flow", Int. J. Multiphase Flow, Vol. 10, pp. 341-356, 1984. 
34. Taitel, Y., and Dukler, A.E., "A Model for Predicting Flow Regime Transitions in Horizontal and Near Horizontal Gas-Liquid Flow", AIChE J., Vol. 22, pp. 47-55, 1976. 


\section{Appendix A}

\section{CORRECTION FOR EVAPORATION}

In the main body of the thesis it was mentioned that the inlet, run, and branch flow rates were corrected for evaporation within the mixer, test section, and separation tanks. In this appendix, the procedure used to account for evaporation of the liquid phase within the flow loop is discussed.

The procedure outlined in this appendix is based on a simplified model for the mixture of gases and a vapor. The model used here was presented in [A.1], and can be found in most textbooks on thermodynamics. The gaseous mixture of air and water vapor is treated as a mixture of ideal gases. As well, when equilibrium exists between the gaseous mixture and the condensed phase (water), the partial pressure of the vapor is assumed to be equal to the saturation pressure corresponding to the temperature of the mixture.

The following discussion is split into three sections as follows:

A.1 Calculation of Flow Conditions at the Mixer Outlet

A.2 Calculation of Inlet Flow Conditions

A.3 Calculation of Run and Branch Flow Conditions. 


\section{A.1 Calculation of Flow Conditions at the Mixer Outlet}

Figure A.1 presents all of the relevant parameters for the calculation of the mixer outlet conditions. The air compressor shown in figure A.1 was set for an outlet pressure $\left(\mathrm{P}_{\mathrm{COMP}}\right)$ of $790 \mathrm{kPa}$ abs. The compressed air leaving the compressor flowed into an air dryer whose purpose was to remove moisture from the air. The air exiting the air dryer was assumed to be saturated with water vapor. Thus, the vapor content (kg vapor/kg dry air) at the air dryer outlet, $\omega_{\text {GIN }}$, can be found using

$$
\omega_{G N}=0.622 \frac{P_{V}}{P_{A}},
$$

where $P_{V}$ is the partial pressure of the vapor, $P_{A}$ is the partial pressure of the air, and 0.622 is the ratio of the vapor molecular weight to the air molecular weight. The total pressure is given by

$$
P_{T}=P_{V}+P_{A} .
$$

Substituting equation (A.2) into (A.1) gives

$$
\omega_{G N}=0.622 \frac{P_{V}}{P_{T}-P_{V}} .
$$

Since the air was assumed to be saturated, then $P_{V}=P_{S A T}$, where $P_{S A T}$ is the saturation pressure of the water vapor at the mixture temperature. The total pressure $\mathrm{P}_{\mathrm{T}}$ was assumed to be equal to the air compressor pressure $(790 \mathrm{kPa}$ abs), while the temperature of the mixture was assumed to be equal to the measured temperature at the inlet air turbine meter $\mathrm{T}_{\mathrm{A} 1 \mathrm{M}}$. Thus, 


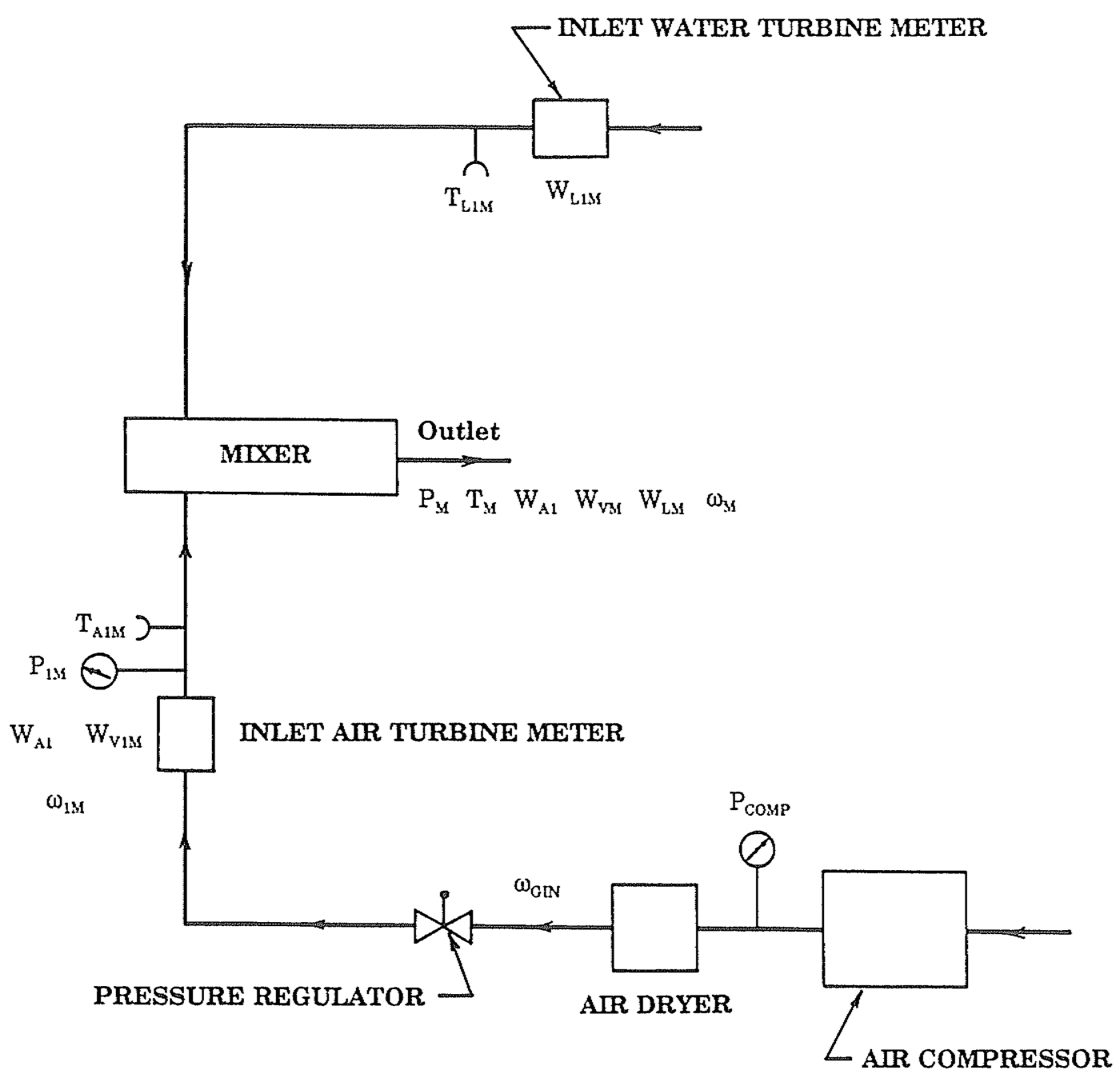

Figure A.1 Relevant parameters for the calculation of flow conditions at the mixer outlet 


$$
\omega_{G N}=0.622 \frac{P_{S A T}}{P_{C O M P}-P_{S A T}},
$$

where $P_{S A T}$ is evaluated at $T_{A 1 M}$, and $P_{\text {COMP }}$ is the compressor pressure.

Since no condensation of water vapor occurred between the air dryer outlet and the inlet air turbine meter, the humidity ratio at the inlet air turbine meter $\omega_{1 \mathrm{M}}$ is given by equation (A.4).

The total gas flow rate through the inlet air turbine meter $\mathrm{W}_{\mathrm{G} 1 \mathrm{M}}$, the sum of $\mathrm{W}_{\mathrm{A} 1}$ and $\mathrm{W}_{\mathrm{V} 1 \mathrm{M}}$, was found from the calibration curve for the turbine meter. This required the air-vapor mixture density at the turbine meter to be calculated. Under the assumption of ideal gases, the mixture density at the turbine meter $\rho_{\mathrm{G} 1 \mathrm{M}}$ can be shown to be the sum of the densities of the air and water vapor, each at its partial pressure. Therefore,

$$
\rho_{G I M}=\frac{P_{1 M}}{\mathbb{R} T_{A I M}}\left[\frac{P_{A I M}}{P_{1 M}} M_{A}+\frac{P_{V I M}}{P_{1 M}} M_{W H}\right]
$$

where: $\mathbb{R}$ is the universal gas constant $(8.3143 \mathrm{~kJ} / \mathrm{kmol} \cdot \mathrm{K})$,

$\mathrm{P}_{1 \mathrm{M}}$ is the measured pressure at the inlet air turbine meter,

$\mathrm{T}_{\mathrm{A} 1 \mathrm{M}}$ is the measured temperature at the inlet air turbine meter,

$\mathrm{P}_{\mathrm{A} 1 \mathrm{M}}$ is the air partial pressure at the inlet air turbine meter,

$\mathrm{P}_{\mathrm{V} 1 \mathrm{M}}$ is the vapor partial pressure at the inlet air turbine meter,

$\mathrm{M}_{\mathrm{A}}$ is the molecular weight of air $(28.97 \mathrm{~kg} / \mathrm{kmol})$,

$\mathrm{M}_{\mathrm{W}}$ is the molecular weight of water $(18.015 \mathrm{~kg} / \mathrm{kmol})$.

Using equations (A.1) and (A.2), the parameter $\mathrm{P}_{\mathrm{AlM}} / \mathrm{P}_{1 \mathrm{M}}$ can be shown to be given by 


$$
\frac{P_{A I M}}{P_{1 M}}=\left[1+\frac{M_{A}}{M_{V}} \omega_{1 M}\right]^{-1},
$$

and the parameter $\mathrm{P}_{\mathrm{V}_{1} \mathrm{M}} / \mathrm{P}_{1 \mathrm{M}}$ by

$$
\frac{P_{V I M}}{P_{1 M}}=\frac{\omega_{1 M}}{\left[\frac{M_{V}}{M_{A}}+\omega_{1 M}\right]} .
$$

The following equation was then used to find the mass flow rate of dry air $\mathrm{W}_{\mathrm{A} 1}$ :

$$
W_{A l}=\frac{W_{G I M}}{1+\omega_{1 M}},
$$

while the vapor flow rate through the turbine meter is given by

$$
W_{V I M}=\omega_{1 M} W_{A I} .
$$

The two-phase mixture leaving the mixer was also assumed to be saturated with water vapor. Therefore, the humidity ratio at the mixer outlet $\omega_{\mathrm{M}}$ is given by

$$
\omega_{M}=0.622 \frac{P_{S A T}}{P_{M}-P_{S A T}},
$$

where $\mathrm{P}_{M}$ is the pressure at the outlet of the mixer, and $\mathrm{P}_{\mathrm{SAT}}$ is evaluated at the mixer outlet temperature $\mathrm{T}_{\mathrm{M}}$.

An energy balance neglecting kinetic and potential energy terms yields (refer to figure A.1)

$$
Q_{M}+W_{A I} h_{A I M}+W_{V I M} h_{V I M}+W_{L I M} h_{L I M}=W_{A I} h_{A M}+W_{V M} h_{V M}+W_{L M} h_{L M},
$$

where: $\quad W$ is the mass flow rate,

$\mathbf{Q}_{\mathrm{M}}$ is the heat transfer rate to the mixer,

$\mathrm{h}$ is the enthalpy, 


\section{subscripts}

L liquid,

V vapor,

A air,

$1 \mathrm{M}$ measured value at inlet water and gas turbine meters, M mixer outlet.

Assuming $\mathbf{Q}_{\mathrm{M}}=0$, dividing equation (A.11) by $\mathrm{W}_{\mathrm{A} 1}$, and re-arranging gives

$$
\left(h_{A I M}-h_{A M}\right)+\omega_{1 M} h_{V I M}+\frac{W_{L I M}}{W_{A I}} h_{L I M}=\omega_{M} h_{V M}+\frac{W_{L M}}{W_{A I}} h_{L M} .
$$

A mass balance for water (vapor and liquid) gives

$$
W_{L I M}+W_{V I M}=W_{V M}+W_{L M} \text {. }
$$

Also, $\left(h_{A 1 M}-h_{A M}\right)$ can be expressed as

$$
\left(h_{A I M}-h_{A M}\right)=C_{P}\left(T_{A I M}-T_{M}\right),
$$

where $C_{P}$ is the specific heat of air at constant pressure $\left(C_{P}=1.0035 \mathrm{~kJ} / \mathrm{kg} \cdot \mathrm{K}\right)$. Substituting equation (A.13) and (A.14) into (A.12) yields

$$
C_{P}\left(T_{A I M}-T_{M}\right)+\frac{W_{L I M}}{W_{A I}}\left(h_{L I M}-h_{L M}\right)+\omega_{1 M}\left(h_{V I M}-h_{L M}\right)+\omega_{M}\left(h_{L M}-h_{V M}\right)=0
$$

Equations (A.10) and (A.15) were solved to give $\mathrm{T}_{\mathrm{M}}$ and $\omega_{\mathrm{M}}$. This required the pressure at the mixer outlet $P_{M}$, which was found by extrapolating the measured pressure gradient in the tee junction inlet to the mixer outlet. 


\section{A.2 Calculation of Flow Conditions At the Inlet to the Tee Junction}

An energy balance between the inlets to the mixer and the tee junction was required in order to calculate conditions at the later. The relevant parameters are shown in figure A.2. The air-vapor-water mixture was assumed to be at equilibrium at the junction inlet, therefore, the humidity ratio at the junction inlet is given by

$$
\omega_{1}=0.622 \frac{P_{S A T}}{P_{S Y S}-P_{S A T}},
$$

where $P_{\text {SYS }}$ is the inlet pressure measured by the Rosemount pressure transducer, and $\mathrm{P}_{\mathrm{SAT}}$ is evaluated at the mixture temperature at the inlet of the tee junction $\mathrm{T}_{1}$. An energy balance (neglecting kinetic and potential energy terms) along with a mass balance on the water gives

$$
\frac{Q_{1}}{W_{A I}}+C_{P}\left(T_{A I M}-T_{1}\right)+\frac{W_{L I M}}{W_{A I}}\left(h_{L I M}-h_{L I}\right)+\omega_{1 M}\left(h_{V I M}-h_{L I}\right)+\omega_{1}\left(h_{L l}-h_{V I}\right)=0,
$$

where $\mathbf{Q}_{1}$ is the net heat transfer rate to the air-vapor-water mixture, and the subscript 1 refers to the tee junction inlet. Equations (A.16) and (A.17) along with an equation for $Q_{1}$ (see details later) were solved to give $T_{1}$ and $\omega_{1}$.

The water vapor flow rate at the tee inlet $\mathrm{W}_{\mathrm{v} 1}$ is given by

$$
W_{V 1}=\omega_{1} W_{A 1} \text {. }
$$

The liquid flow rate entering the tee can be found from a mass balance. The final result is

$$
W_{L I}=W_{L I M}+W_{A I}\left(\omega_{1 M}-\omega_{1}\right)
$$

This can also be expressed as 
INLET WATER TURBINE MEETER

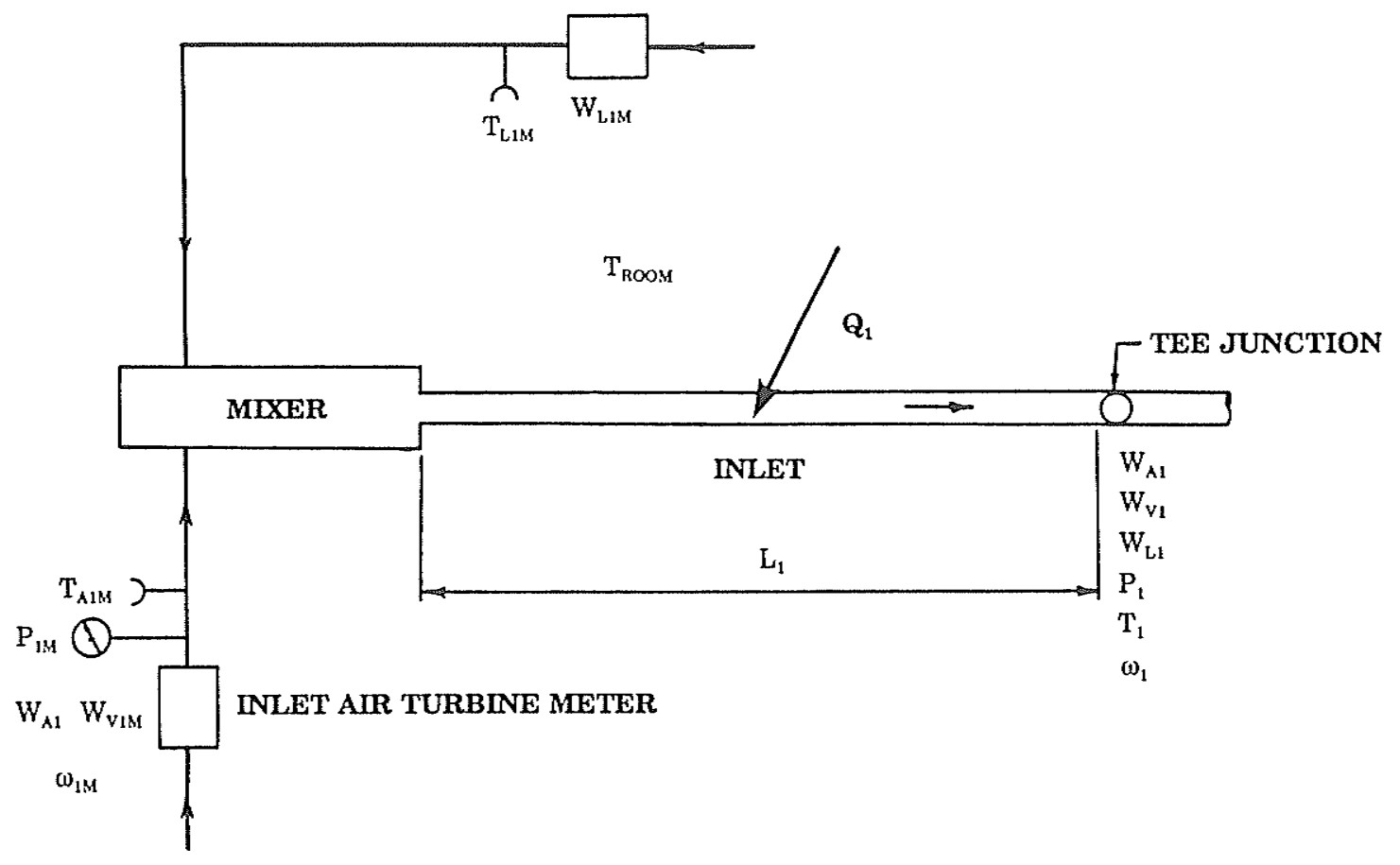

Figure A.2 Relevant parameters for the calculation of flow conditions at the tee-junction inlet 


$$
W_{L I}=W_{L I M}+\operatorname{CORR}_{L I} \text {, }
$$

where $\mathrm{CORR}_{\mathrm{L} 1}$ is the correction factor (always negative) to be added to the measured inlet water flow rate $\mathrm{W}_{\mathrm{L} 1 \mathrm{M}}$. The gas flow rate at the tee inlet is given by

$$
W_{G I}=W_{A I}+W_{V I},
$$

where $W_{v 1}$ is found using equation (A.18). The above equation can also be expressed as

$$
W_{G l}=\operatorname{CORR}_{G I} \times W_{G I M},
$$

where $\mathrm{W}_{\mathrm{G} 1 \mathrm{M}}$ is the measured gas flow rate at the inlet air turbine meter, and the correction factor $\mathrm{CORR}_{\mathrm{G} 1}$ can be shown to be

$$
\operatorname{CORR}_{G I}=\left[\frac{1+\omega_{1}}{1+\omega_{1 M}}\right] .
$$

For completeness, the heat transfer rate $\mathbf{Q}_{1}$ was estimated using an empirical correlation. Figure A.3 shows all of the relevant parameters required in order to calculate the heat transfer rate to a horizontal tube.

Both the thermal resistance of the tube wall and the thermal resistance for convection inside the tube were assumed negligible compared to the free convection thermal resistance on the outside of the tube. Therefore, the temperature of the tube surface $\mathrm{T}_{\mathrm{TUBE}}$ was assumed to be equal to the temperature of the mixture flowing in the tube $\mathrm{T}_{\mathrm{MIX}}$ (the mean of inlet and outlet temperatures), and $\mathbf{Q}$ can be found using

$$
Q=\left(T_{\text {ROOM }}-T_{M X X}\right) \pi D_{0} L h_{0},
$$

where: $\quad \mathrm{T}_{\mathrm{ROOM}}$ is the laboratory room temperature, 


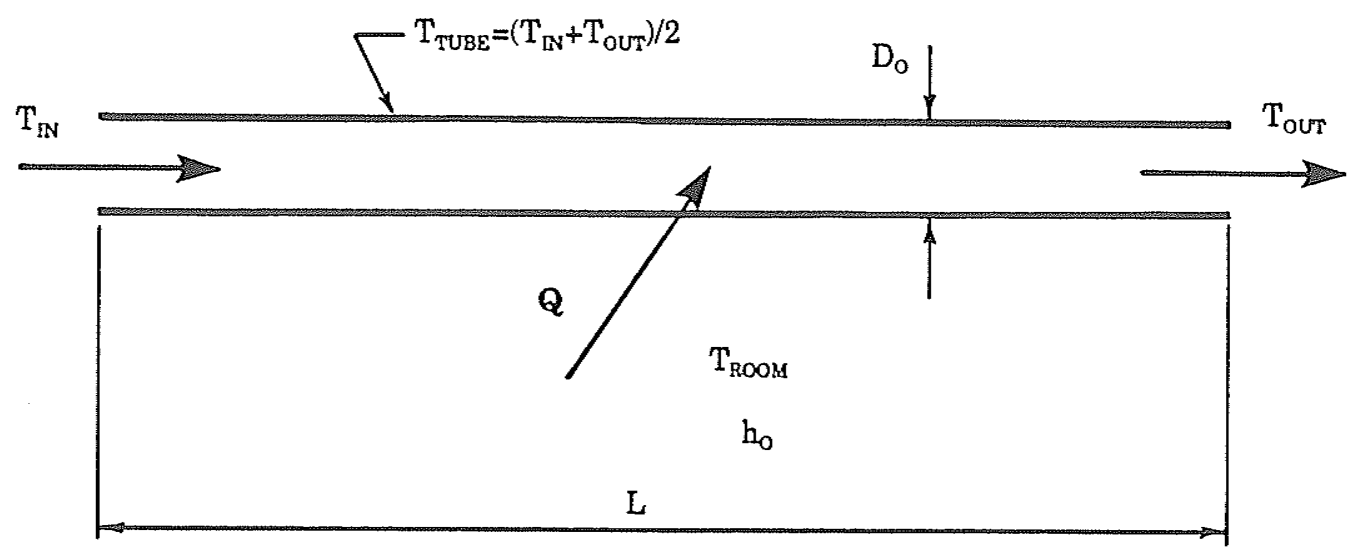

Figure A.3 Relevant parameters for the calculation of heat transfer to a horizontal tube 
$\mathrm{T}_{\mathrm{MIX}}$ is the average temperature of the mixture flowing in the tube,

$\mathrm{D}_{0} \quad$ is the outside diameter of the tube,

$h_{0} \quad$ is the average free convection coefficient over length $L$,

$\mathrm{L} \quad$ is the length of the tube.

For average Nusselt numbers $\mathrm{Nu}$ on isothermal horizontal cylinders, Kuehn and Goldstein [A.2] recommended

$$
N u=0.518\left[1+\left(\frac{0.599}{P r}\right)^{3 / 5}\right]^{-5 / 12}\left(G r_{D} P r\right)^{1 / 4}
$$

for $\mathrm{Gr}_{\mathrm{D}} \operatorname{Pr}<10^{9}$, where all properties are evaluated at the average film temperature given by

$$
T_{f}=\frac{\left(T_{M I X}+T_{R O O M}\right)}{2}
$$

In equation (A.25), Pr is the Prandlt number for air and $\mathrm{Gr}_{\mathrm{D}}$ is the Grashof number given by

$$
G r_{D}=\frac{g \beta D_{0}^{3}}{v^{2}}\left(T_{R O O M}-T_{M I X}\right)
$$

where: $\quad \mathrm{g}$ is the acceleration due to gravity $\left(9.81 \mathrm{~m} / \mathrm{s}^{2}\right)$,

$\beta$ is the volumetric coefficient of thermal expansion for air $\left(\mathrm{K}^{-1}\right)$,

$v \quad$ is the kinematic viscosity of air $\left(\mathrm{m}^{2} / \mathrm{s}\right)$.

A correction was given for equation (A.25) as follows:

$$
N u_{\text {CORR }}=\frac{2}{\ln \left(1+\frac{2}{N u}\right)},
$$

where $\mathrm{Nu}_{\mathrm{CORR}}$ is the corrected Nusselt number. The average heat-transfer coefficient $h_{0}$ can then be calculated from $\mathrm{Nu}_{\text {CORR }}$. 
The value of $\mathbf{Q}_{1}$ was calculated using equations (A.24) through (A.28), and was found to be insignificant for all test runs. The temperature $\mathrm{T}_{\mathrm{MIX}}$ was assumed to be the average of $T_{M}$ and $T_{1}$.

The procedure for calculating the inlet conditions can be summarized as follows:

1. Calculate $\omega_{\text {GIN }}$ using equation (A.4) with $P_{\text {SAT }}$ evaluated at $T_{A 1 M}$ and $\mathrm{P}_{\mathrm{COMP}}=790 \mathrm{kPa}$ abs.

2. Calculate $\rho_{\mathrm{G} 1 \mathrm{M}}$ using equations (A.5), (A.6), and (A.7).

3. Calculate $\mathrm{W}_{\mathrm{GIM}}$ using the calibration curve for the inlet air turbine meter.

4. Calculate $\mathrm{W}_{\mathrm{A} 1}$ using equation (A.8).

5. Calculate $\mathrm{W}_{\mathrm{V} 1 \mathrm{M}}$ using equation (A.9) with $\omega_{1 \mathrm{M}}=\omega_{\mathrm{GIN}}$.

6. Calculate $\mathrm{P}_{\mathrm{M}}$ by extrapolating the measured pressure gradient in the inlet back to the outlet from the mixer.

7. Solve equations (A.10) and (A.15) iteratively to give $\mathrm{T}_{\mathrm{M}}$ and $\omega_{\mathrm{M}}$.

8. Solve equations (A.16), (A.17), and (A.24) iteratively with $\mathrm{T}_{\mathrm{MIX}}=\left(\mathrm{T}_{\mathrm{M}}+\mathrm{T}_{1}\right) / 2$ to give $\mathrm{T}_{1}$ and $\omega_{1}$.

9. Calculate $\mathrm{W}_{\mathrm{L} 1}$ using equation (A.19) and $\mathrm{W}_{\mathrm{G} 1}$ using equations (A.21) and (A.18) for $W_{\mathrm{V} 1}$.

\section{A.3 Calculation of Flow Conditions At the Run and Branch Outlets From the Tee Junction}

Due to evaporation within the test section, as well as in both separation 
tanks, the measured values of the run and branch flow rates differed from the flow rates at the outlets of the tee junction. Therefore, correction factors were also required in order to calculate $\mathrm{W}_{\mathrm{L} 2}, \mathrm{~W}_{\mathrm{L} 3}, \mathrm{~W}_{\mathrm{G} 2}$, and $\mathrm{W}_{\mathrm{G} 3}$. The correction factors for the branch were calculated using the same procedure as for the run; therefore, the procedure is only shown for the run.

Figure A.4 shows all of the relevant parameters required for the calculation of the flow conditions in the run. The air within the separation tank was assumed to be saturated with water vapor; therefore,

$$
\omega_{2 T}=0.622 \frac{P_{S A T}}{P_{2 T}-P_{S A T}},
$$

where $P_{2 T}$ is the pressure inside the separation tank and $P_{S A T}$ is evaluated at the mixture temperature within the separation tank $\mathrm{T}_{2 \mathrm{~T}}$.

The total gas flow rate $\mathrm{W}_{\mathrm{G} 2 \mathrm{M}}$ was measured by either a turbine meter or by a bank of rotameters. The mixture density $\rho_{\mathrm{G} 2 \mathrm{M}}$ of the air-vapor mixture flowing through the turbine meter or rotameters was calculated using the same method as for the inlet air turbine meter. Thus,

$$
\rho_{G 2 M}=\frac{P_{A T M}}{R T_{A 2 M}}\left[\frac{P_{A 2 M}}{P_{A T M}} M_{A}+\frac{P_{V 2 M}}{P_{A T M}} M_{W W}\right]
$$

where: $\mathrm{P}_{\mathrm{ATM}}$ is the atmospheric pressure,

$\mathrm{T}_{2 \mathrm{M}} \quad$ is the measured temperature at the run air turbine meter or rotameters,

$\mathrm{P}_{\mathrm{A} 2 \mathrm{M}} \quad$ is the air partial pressure at the run turbine meter or rotameters,

$\mathrm{P}_{\mathrm{V} 2 \mathrm{M}} \quad$ is the vapor partial pressure at the run turbine meter or rotameters.

The value of $\mathrm{P}_{\mathrm{A} 2 \mathrm{M}} / \mathrm{P}_{\mathrm{ATM}}$ is given by 


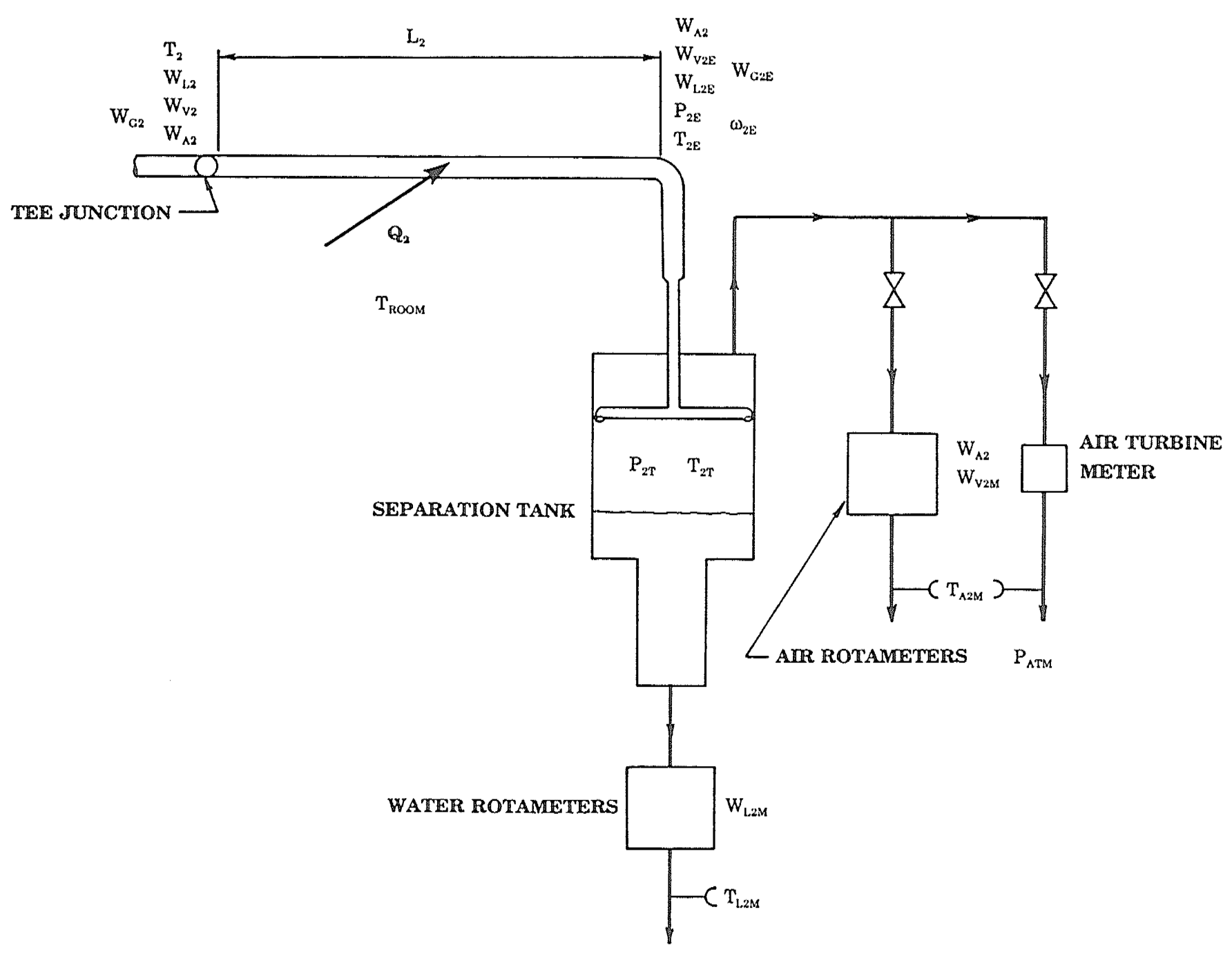

Figure A.4 Relevant parameters for the calculation of flow conditions in the run 


$$
\frac{P_{A 2 M}}{P_{A T M}}=\left[1+\frac{M_{A}}{M_{V}} \omega_{2 M}\right]^{-1}
$$

and $\mathrm{P}_{\mathrm{V} 2 \mathrm{M}} / \mathrm{P}_{\mathrm{ATM}}$ by

$$
\frac{P_{V Z M}}{P_{A T M}}=\frac{\omega_{2 M}}{\left[\frac{M_{V}}{M_{A}}+\omega_{2 M}\right]},
$$

where $\omega_{2 M}$ is the humidity ratio at the run turbine meter or rotameters. Since no condensation of water vapor occurred between the separation tank and the run turbine meter or rotameters, $\omega_{2 \mathrm{M}}$ is equal to $\omega_{2 \mathrm{~T}}$, and is given by equation (A.29).

The flow rate of vapor exiting the separation tank can be shown to be given by

$$
W_{V 2 M}=\left[\frac{\omega_{2 T}}{1+\omega_{2 T}}\right] W_{G 2 M} .
$$

Thus, the run air flow rate can be found using

$$
W_{A 2}=W_{G 2 M}-W_{V 2 M} \text {. }
$$

The fraction of run gas is defined as

$$
F_{R G}=\frac{W_{G 2}}{W_{G I}},
$$

where $\mathrm{W}_{\mathrm{G} 2}$ is the total gas flow rate in the run at the outlet of the tee junction. The flow rate $\mathrm{W}_{\mathrm{G} 2}$ is given by

$$
W_{G 2}=W_{A 2}+W_{V 2}
$$

where $\mathrm{W}_{\mathrm{v} 2}$ is the flow rate of vapor in the run at the outlet of the tee junction. If it is assumed that the humidity ratio of the gas does not change at the tee 
junction, that is $\omega_{1}=\omega_{2}\left(=\omega_{3}\right)$ at the tee junction, then it follows that

$$
F_{R G}=F_{R V}=F_{R A},
$$

where $F_{R V}$ is the fraction of run vapor given by

$$
F_{R V}=\frac{W_{V 2}}{W_{V_{1}}},
$$

and $F_{R A}$ is the fraction of run air given by

$$
F_{R A}=\frac{W_{A 2}}{W_{A 1}} .
$$

The value of $F_{R A}$ can be calculated using equations (A.8) and (A.34). The flow rate $\mathrm{W}_{\mathrm{V} 2}$ can then be found using equation (A.38) with $\mathrm{F}_{\mathrm{RV}}=\mathrm{F}_{\mathrm{RA}}$ and $\mathrm{W}_{\mathrm{G} 2}$ using equation (A.36). A mass balance for water (liquid and vapor) yields

$$
W_{L 2}=W_{L 2 M}+W_{V 2 M}-W_{V 2} \text {. }
$$

Equations (A.29) through (A.40) can be used to calculate the run flow rates $\mathrm{W}_{\mathrm{G} 2}$ and $\mathrm{W}_{\mathrm{L} 2}$. Unfortunately, the parameters $\mathrm{P}_{2 \mathrm{~T}}$ and $\mathrm{T}_{2 \mathrm{~T}}$ were never measured and, therefore, must be estimated.

An energy balance (neglecting kinetic energy terms) over length $L_{2}$ yields (refer to figure A.4)

$$
\frac{Q_{2}}{W_{A 2}}+C_{P}\left(T_{2}-T_{2 E}\right)+\frac{W_{L 2}}{W_{A 2}}\left(h_{L 2}-h_{L 2 E}\right)+\omega_{2}\left(h_{V 2}-h_{L 2 E}\right)+\omega_{2 E}\left(h_{L 2 E}-h_{V 2 E}\right)=0,
$$

where $Q_{2}$ is the net heat transfer rate to the air-vapor-water mixture and the subscript $2 \mathrm{E}$ refers to the inlet to the run separation tank. The temperature $\mathrm{T}_{2}$ was assumed to be equal to $\mathrm{T}_{1}$. Assuming the air to be saturated with water vapor at the inlet to the separation tank, $\omega_{2 \mathrm{E}}$ is given by 


$$
\omega_{2 E}=0.622 \frac{P_{S A T}}{P_{2 E}-P_{S A T}},
$$

where $P_{\mathrm{SAT}^{\prime} \mathrm{is}}$ evaluated at $\mathrm{T}_{2 \mathrm{E}}$ and $\mathrm{P}_{2 \mathrm{E}}$ is the pressure at the inlet to the separation tank. The pressure $\mathrm{P}_{2 \mathrm{E}}$ was calculated by extrapolating the measured pressure gradient in the run to the inlet to the separation tank. The rate of heat transfer $Q_{2}$ was calculated using equations (A.24) through (A.28) with $\mathrm{T}_{\mathrm{MIX}}=\left(\mathrm{T}_{2}+\mathrm{T}_{2 \mathrm{E}}\right) / 2$.

Equations (A.24), (A.41), and (A.42) can be used to calculate $\omega_{2 \mathrm{E}}$ and $\mathrm{T}_{2 \mathrm{E}}$. The flow rate $\mathrm{W}_{\mathrm{v} 2 \mathrm{E}}$ is found using

$$
W_{V 2 E}=\omega_{2 E} W_{A 2},
$$

and $\mathrm{W}_{\mathrm{G} 2 \mathrm{E}}$ using

$$
W_{G 2 E}=W_{A 2}+W_{V 2 E}
$$

Finally, a mass balance for water (liquid and vapor) yields

$$
W_{L 2 E}=W_{L 2}+W_{V 2}-W_{V 2 E} \text {. }
$$

The temperature $\mathrm{T}_{2 \mathrm{~T}}$ can be found using an energy balance between location $2 \mathrm{E}$ and the inside of the separation tank. Equation (A.29) gives the humidity ratio inside the separation tank. The equation analogous to equation (A.41) is

$$
C_{P}\left(T_{2 E}-T_{2 T}\right)+\frac{W_{L 2 E}}{W_{A 2}}\left(h_{L 2 E}-h_{L 2 T}\right)+\omega_{2 E}\left(h_{V 2 E}-h_{L 2 T}\right)+\omega_{2 T}\left(h_{L 2 T}-h_{V 2 T}\right)=0
$$

where the heat transfer rate to the mixture was assumed to be zero and the subscript $2 \mathrm{~T}$ refers to the inside of the run separation tank. Equations (A.29) 
and (A.46) were solved iteratively to give $\omega_{2 \mathrm{~T}}$ and $\mathrm{T}_{2 \mathrm{~T}}$ (see following paragraphs for estimates of $P_{2 T}$ ).

Equation (A.29) requires knowledge of the run separation tank pressure $P_{2 T}$. This pressure was slightly smaller than $P_{2 E}$ due to pressure losses which occurred in the separation tank piping. A schematic diagram of the separation tank is shown in figure 3.8. The inlet piping consisted of a number of different components: a $90^{\circ}$ elbow, a contraction from $37.6 \mathrm{~mm}$ to $25.4 \mathrm{~mm}$ dia., a dividing tee junction, and two nozzles. Although the pressure losses through these components were small, they were estimated.

Chisholm [A.3] presented a correlation for the prediction of pressure drops through pipe fittings during two-phase flow. The correlation is given by

$$
\frac{\Delta P_{T P}}{\Delta P_{L O}}=1+\left(\frac{\rho_{L}}{\rho_{G}}-1\right)\left(B x+(1-B) x^{2}\right),
$$

where: $\Delta \mathrm{P}_{\mathrm{TP}}$ is the pressure drop due to the pipe fitting during two-phase flow,

$\Delta \mathrm{P}_{\mathrm{LO}}$ is the pressure drop if all of the mixture flows as liquid,

$\rho_{\mathrm{G}}$ is the gas density,

$\rho_{\mathrm{L}} \quad$ is the liquid density,

$\mathrm{X}$ is the quality of the two-phase mixture,

$\mathrm{B}$ is a coefficient which varies for different pipe fittings.

The quality $\mathrm{x}$ was calculated at the inlet to the separation tank (location $2 \mathrm{E}$ ). Values of B recommended by Chisholm [A.3] for a $90^{\circ}$ elbow and a sudden contraction are 4.2 and 1.0 , respectively. For the $90^{\circ}$ elbow, $\Delta \mathrm{P}_{\mathrm{LO}}$ was calculated using an equivalent length procedure. For the sudden contraction, $\Delta \mathrm{P}_{\mathrm{LO}}$ is given by [A.4]: 


$$
\Delta P_{L O}=\Delta P_{R E V, L O}+\Delta P_{I R R, L O},
$$

where

$$
\Delta P_{R E V, L O}=\frac{1}{2} \rho_{L}\left(\frac{A_{I}^{2}}{A_{O}^{2}}-1\right) V_{I}^{2},
$$

and

$$
\Delta P_{I R R, L O}=0.42\left(1-\frac{A_{O}}{A_{I}}\right) \frac{A_{I}^{2}}{A_{O}^{2}} \frac{\rho_{L} V_{I}^{2}}{2}
$$

In the above equations, $A_{I}$ is the cross-sectional area at the inlet to the contraction, $A_{O}$ is the cross-sectional area at the outlet of the contraction, and $V_{I}$ is the velocity at the inlet to the contraction if all of the mixture flowed as liquid. The velocity $\mathrm{V}_{\mathrm{I}}$ is given by

$$
V_{I}=\frac{\left(W_{L 2 E}+W_{G 2 E}\right)}{A_{I} \rho_{L}} .
$$

The nozzles were treated as $90^{\circ}$ elbows, and the pressure drop through the dividing tee junction was ignored since no suitable correlation exists for its calculation.

Finally, the separation tank pressure $\left(\mathrm{P}_{2 \mathrm{~T}}\right)$ was calculated using

$$
P_{2 T}=P_{2 E}-\sum \text { LOSSES },
$$

where $\Sigma$ LOSSES is the sum of the pressure losses occurring in the separation tank piping ( $90^{\circ}$ elbow, contraction, and nozzles).

The use of the Chisholm correlation [A.3] can lead to significant error in calculating $\Sigma$ LOSSES. However, given the current lack of understanding in 
predicting pressure losses through pipe fittings during two-phase flow, the Chisholm correlation [A.3] was accepted as being adequate. As well, a sensitivity analysis was undertaken as part of the error analysis. The parameter LLOSSES was found to be insignificant for nearly all of the test runs. This is discussed in more detail in Appendix E.

An iterative procedure was required for calculating the run conditions. This procedure can be summarized as follows:

1. Calculate $\mathrm{P}_{2 \mathrm{E}}$ by extrapolating the measured pressure gradient in the run.

2. Assume $\mathrm{T}_{2 \mathrm{~T}}=\mathrm{T}_{1}$ and $\mathrm{P}_{2 \mathrm{~T}}=\mathrm{P}_{2 \mathrm{E}}$.

3. Calculate $\omega_{2 \mathrm{~T}}$ using equation (A.29).

4. Calculate $\rho_{\mathrm{G} 2 \mathrm{M}}$ using equations (A.30), (A.31), and (A.32) with $\omega_{2 \mathrm{M}}=$ $\omega_{2 \mathrm{~T}} \cdot$

5. Calculate $\mathrm{W}_{\mathrm{G} 2 \mathrm{M}}$ using the calibration curves to the run air turbine meter or rotameters.

6. Calculate $\mathrm{W}_{\mathrm{V} 2 \mathrm{M}}$ using equation (A.33) and $\mathrm{W}_{\mathrm{A} 2}$ using equation (A.34).

7. Calculate $\mathrm{F}_{\mathrm{RA}}$ using equation (A.39), $\mathrm{F}_{\mathrm{RV}}$ using (A.37), $\mathrm{W}_{\mathrm{V} 2}$ using (A.38), $\mathrm{W}_{\mathrm{G} 2}$ using (A.36), and $\mathrm{W}_{\mathrm{L} 2}$ using (A.40).

8. Solve equations (A.24), (A.41), and (A.42) iteratively with $\mathrm{T}_{\mathrm{MIX}}=\left(\mathrm{T}_{2}+\mathrm{T}_{2 \mathrm{E}}\right) / 2$ to give $\omega_{2 \mathrm{E}}$ and $\mathrm{T}_{2 \mathrm{E}}$.

9. Calculate $\mathrm{W}_{\mathrm{V} 2 \mathrm{E}}$ using equation (A.43), $\mathrm{W}_{\mathrm{G} 2 \mathrm{E}}$ using equation (A.44), and $\mathrm{W}_{\mathrm{L} 2 \mathrm{E}}$ using equation (A.45).

10. Calculate $\mathrm{P}_{2 \mathrm{~T}}$ using equations (A.47) through (A.52). 
11. Solve equations (A.29) and (A.46) iteratively to give new values of $\omega_{2 \mathrm{~T}}$ and $\mathrm{T}_{2 \mathrm{~T}}$

12. Calculate the convergence criterion $\varepsilon$ defined by

$$
\epsilon=\frac{\left(\omega_{2 T}-\omega_{2 T, O L D}\right)}{\omega_{2 T, O L D}},
$$

where $\omega_{2 T, \text { OLD }}$ is the value of $\omega_{2 \mathrm{~T}}$ found in step 3 . If $\varepsilon>0.001$ then go to step 4, otherwise, convergence has been achieved.

The above procedure gave values of $\mathrm{W}_{\mathrm{A} 2}, \mathrm{~W}_{\mathrm{G} 2}, \mathrm{~W}_{\mathrm{V} 2}$, and $\mathrm{W}_{\mathrm{L} 2}$. Equation (A.36) can also be expressed as

$$
W_{G 2}=\operatorname{CORR}_{G 2} \times W_{G 2 M},
$$

where the multiplicative correction factor is given by

$$
\operatorname{CORR}_{G 2}=\left[\frac{1+\omega_{2}}{1+\omega_{2 T}}\right] \text {. }
$$

As well, equation (A.40) can be re-written as

$$
W_{L 2}=W_{L 2 M}+\operatorname{CORR}_{L 2} \text {, }
$$

where

$$
\operatorname{CORR}_{L 2}=W_{A 2}\left(\omega_{2 T}-\omega_{2}\right) .
$$

The parameters $\mathrm{CORR}_{\mathrm{G} 2}$ and $\mathrm{CORR}_{\mathrm{L} 2}$ are the correction factors for the measured run mass flow rates.

It should be emphasized that in this thesis all of the flow rates reported have been corrected for evaporation as outlined in this appendix. As well, other parameters such as superficial velocities, qualities, $\mathrm{F}_{\mathrm{BG}}, \mathrm{F}_{\mathrm{BL}}, \mathrm{x}_{3} / \mathrm{x}_{1}$, and $\mathrm{W}_{3} / \mathrm{W}_{1}$ were calculated using the corrected flow rates, not the measured flow rates. However, it should be noted again that these correction factors were 
generally small. Only for $\mathrm{J}_{\mathrm{G} 1}=40 \mathrm{~m} / \mathrm{s}$ with $\mathrm{J}_{\mathrm{L} 1} \leq 0.0023 \mathrm{~m} / \mathrm{s}$ were the corrections due to evaporation significant. The procedure outlined in this appendix was applied to all two-phase flow tests only for the sake of consistency.

Finally, in Appendix $\mathrm{C}$ tabulated values of the mass balance errors are given. These mass balance errors were calculated using the equations given below. For air:

$$
E_{A I R}=\frac{\left(W_{A 2}+W_{A 3}-W_{A I}\right)}{W_{A I}} \times 100 \%,
$$

and for water:

$$
E_{\text {WATER }}=\left[\frac{\left(W_{L 2 M}+W_{V 2 M}+W_{L 3 M}+W_{V 3 M}\right)-\left(W_{L I M}+W_{V I M}\right)}{\left(W_{L I M}+W_{V I M}\right)}\right] \times 100 \% .
$$

\section{REFERENCES FOR APPENDIX A}

A.1 Van Wylen, G.J., and Sonntag, R.E., "Fundamentals of Classical Thermodynamics", 3rd Ed., John Wiley \& Sons, Inc., New York, pp. 412$427,1985$.

A.2 Kuehn and Goldstein as quoted in Kays, W.M., and Crawford, M.E., "Convective Heat and Mass Transfer", 2nd. Ed., McGraw-Hill, Inc., New York, pp. 328, 1980.

A.3 Chisholm, D., "Prediction of Pressure Drop at Pipe Fittings During TwoPhase Flow", Proc. 13th Int. Inst. Refrig. Cong., Washington, Vol. 2, pp. 781-789, 1971.

A.4. Gerhart, P.M., and Gross, R.J., "Fundamentals of Fluid Mechanics", 1st. Ed., Addison-Wesley Publishing Co., Reading, Massachusetts, pp. 457461, 1985. 


\section{Appendix B}

\section{DETERMINATION OF $\Delta \mathbf{P}_{12}$ AND $\Delta \mathbf{P}_{13}$ FROM THE MEASURED PRESSURE DISTRIBUTION}

The pressure drops $\Delta \mathrm{P}_{12}$ and $\Delta \mathrm{P}_{13}$ were calculated by extrapolating the fully developed pressure gradients in the inlet, run, and branch to the centre of the tee junction. It was extremely important that the extrapolated values of $\mathrm{P}_{1}, \mathrm{P}_{2}$, and $\mathrm{P}_{3}$ were obtained from data which were fully developed. The following describes the procedure used to obtain the linear regression equations in the inlet, run, and branch.

Figure B.1 shows the regression line for a typical pressure distribution in the run. For the following discussion, the pressure taps used in obtaining the regression line are labelled from 1 through $\mathrm{n}$. In should be noted that this is different than the actual pressure tap numbers given in figure 3.7. As outlined in Chapter 3, all of the pressure taps in the run were sampled with the high pressure sides of the pressure transducers connected to tap 1 in the inlet. Thus, the run pressure-distribution data consisted of

\section{슬}

$$
\Delta P_{1-i}=P_{T A P 1}-P_{T A P i},
$$

where $\mathrm{P}_{\text {TAP } 1}$ is the pressure at tap $1, \mathrm{P}_{\mathrm{TAP}} \mathrm{i}$ is the pressure at tap $\mathrm{i}$, and $\mathrm{i}=12$ to 32. Least squares analysis of these data gave the following equation for the run: 


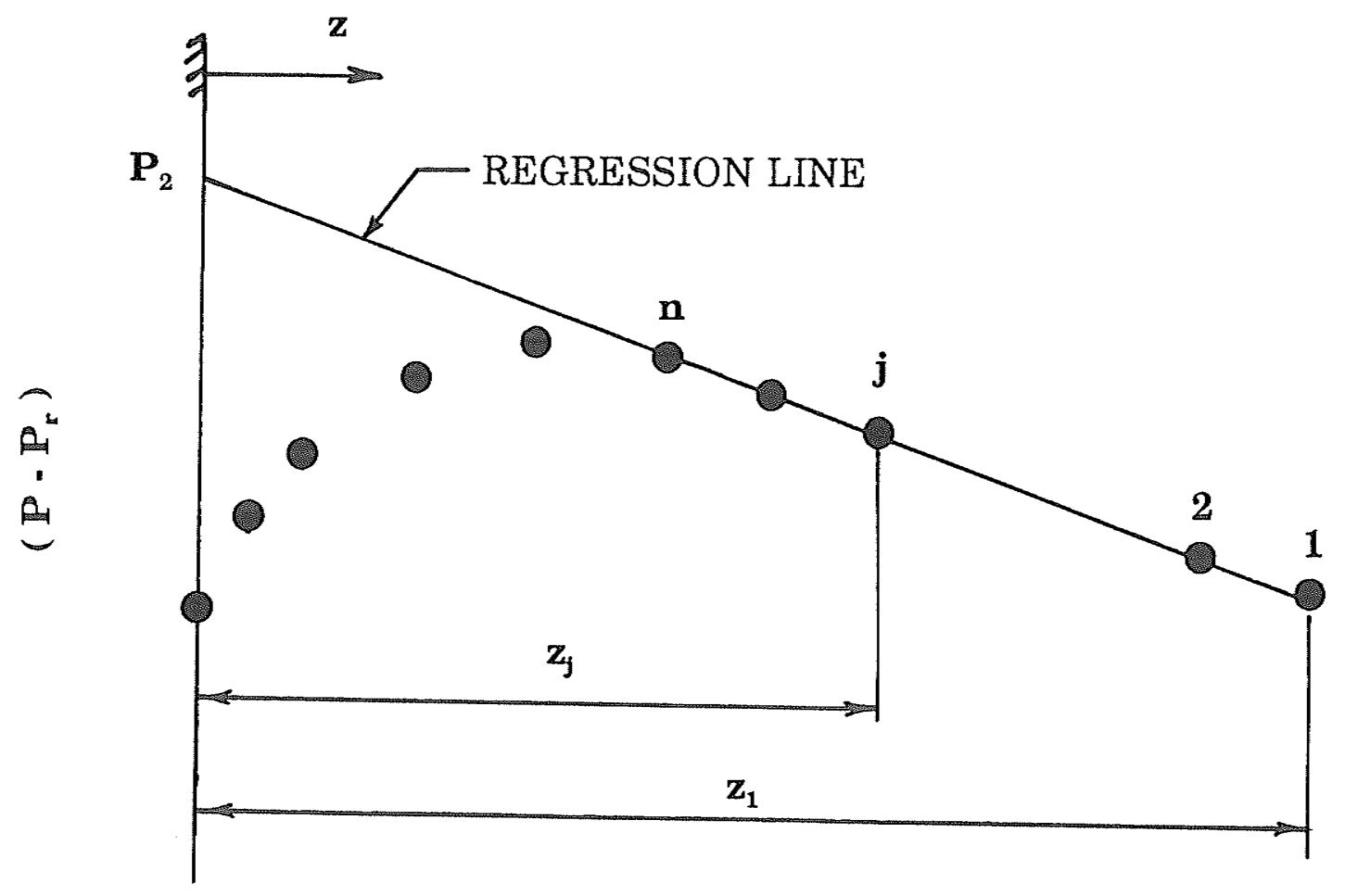

Figure B.1 Regression line for run pressure-distribution data 


$$
P_{R U N}=P_{2}+\frac{d P_{R U N}}{d z} z
$$

where $P_{\text {RUN }}$ is the pressure in the run, $P_{2}$ is the $y$-intercept, $d P_{R U N} / d z$ is the slope of the regression line, and $\mathrm{z}$ is the distance from the junction centre. The intercept $\mathrm{P}_{2}$ can be expressed as [B.1]

$$
\left.P_{2}=P_{2} \text { (measured }\right) \pm\left(8 P_{2}\right)_{0},
$$

where $\mathrm{P}_{2}$ (measured) is the $\mathrm{y}$-intercept given in equation (B.2) and $\left(\delta \mathrm{P}_{2}\right)_{0}$ is the uncertainty in $\mathrm{P}_{2}$ due to the scatter of the pressure distribution data about the regression line. The uncertainty $\left(\delta \mathrm{P}_{2}\right)_{0}$ can be estimated using the following equation [B.2]:

$$
\left(\delta P_{2}\right)_{0}=\frac{t_{0.95} s \sqrt{\sum_{j=1}^{n} z_{j}^{2}}}{\sqrt{n S_{z z}}},
$$

where $t_{0.95}$ is the value of the Students t-distribution with n-2 degrees of freedom and $\mathrm{s}$ is the standard deviation of the experimental data (taps 1 through $\mathrm{n}$ ) about the regression line. The parameter $\mathrm{S}_{z z}$ is calculated using

$$
S_{z z}=\sum_{j=1}^{n}\left(z_{j}-z_{A V E}\right)^{2},
$$

where $z_{A V E}$ is the average value of $z_{j}$ for taps 1 through $n$. A 95\% confidence interval was chosen for $\left(\delta \mathrm{P}_{2}\right)_{0}$. In other words, the statement given by equation (B.3) should be interpreted to mean the odds are 20 to 1 against the uncertainty in $\mathrm{P}_{2}$ being larger than $\pm\left(\delta \mathrm{P}_{2}\right)_{0}$ (see Appendix $\mathrm{E}$ ).

In general, the more pressure taps used to obtain the regression line ( $\mathrm{n}$ increasing), the smaller $\left(\delta \mathrm{P}_{2}\right)_{0}$ became. However, if $\mathrm{n}$ was increased too much, 
then pressure taps corresponding to data that were not fully developed were included in the linear regression. This had the effect of increasing $\left(\delta \mathrm{P}_{2}\right)_{0}$ because the data which were not fully developed lie below the correct regression line. Therefore, the value of $n$ used in calculating the linear regression line was the value of $n$ which minimized $\left(\delta \mathrm{P}_{2}\right)_{0}$. Taps 1 through $n$ were then assumed to correspond to fully developed flow.

The procedure used to obtain the regression line for the branch was similar to the above procedure for the run. The inlet pressure distribution data were obtained with the low pressure sides of the transducers connected to tap 32 in the run, or tap 33 in the branch. Thus, the inlet data consisted of

$$
\Delta P_{i-32}=P_{T A P i}-P_{T A P 32},
$$

or

$$
\Delta P_{i-33}=P_{T A P i}-P_{T A P 33},
$$

where $\mathrm{i}=1$ to 11 . The inlet data were then shifted using the following equations:

$$
\Delta P_{1-i}=\Delta P_{1-32}-\Delta P_{i-32},
$$

or

$$
\Delta P_{1-i}=\Delta P_{1-33}-\Delta P_{i-33},
$$

where $\mathrm{i}=1$ to $11, \Delta \mathrm{P}_{1 \cdot 32}$ is the pressure at tap 32 in the run relative to the pressure at tap 1 , and $\Delta \mathrm{P}_{1 \cdot 33}$ is the pressure at tap 33 in the branch relative to the pressure at tap 1 . Using the above equations, the inlet pressuredistribution data relative to tap 1 in the inlet were obtained. The inlet 
pressure-distribution data were now consistent with the run and branch data. This procedure gave independent measurements of the inlet pressure distribution. For most test runs, the data given by equation (B.8) were used in obtaining the inlet regression line. However, equation (B.9) was used when the reliability of the data from equation (B.8) were in question (see Appendix D for these data).

A computer program was written to calculate the values of $\Delta \mathrm{P}_{12}$ and $\Delta \mathrm{P}_{13}$ for all single-phase and two-phase test runs. The program calculated the $\mathrm{y}$ intercepts $\mathrm{P}_{1}, \mathrm{P}_{2}$, and $\mathrm{P}_{3}$ by minimizing the corresponding uncertainty intervals $\left(\delta \mathrm{P}_{1}\right)_{0},\left(\delta \mathrm{P}_{2}\right)_{0}$, and $\left(\delta \mathrm{P}_{3}\right)_{0}$.

For all tests, the regression equations found using the above procedure were verified by examining, for each test, a computer-generated plot of the experimental pressure-distribution data and the regressing equation generated for that test.

\section{REFERENCES FOR APPENDIX B}

B.1 S.J. Kline, and F.A. McClintock, "Describing the Uncertainties in SingleSample Experiments", Mechanical Engineering, Vol. 75, pp. 3-8, 1953.

B.2 Walpole, R.E., and Myers, R.H., "Probability and Statistics for Engineers and Scientists", 3rd Ed., Macmillan Publishing Co., New York, pp. 328$331,1985$. 


\section{Appendix C}

\section{PRESSURE-DROP AND PHASE-DISTRIBUTION DATA}

Table C.1 provides a listing of the operating conditions and corresponding phase-distribution and pressure-drop data for all two-phase flow test runs. In this table, observed flow regimes in the inlet, run, and branch are given; however, due to failure of the glass tube in the branch visual section, and the unavailability of a replacement tube, flow regimes in the branch are not given for all test runs. The single-phase operating conditions and pressure-drop data are given in Table C.2. Table C.3 provides a listing in which the present numbering scheme of the test runs is related to the previous numbering scheme used by the author (but does not appear in this thesis) during data acquisition. Finally, Table C.4 gives a listing of the mass flow rates of gas and liquid in each of the inlet, run, and branch. These mass flow rates are corrected for evaporation as outlined in Appendix A.

\section{Legend}

$\begin{array}{ll}\text { Test } & \text { Test number } \\ \mathrm{J}_{\mathrm{G} 1} & \text { Inlet superficial gas velocity }(\mathrm{m} / \mathrm{s}) \\ \mathrm{J}_{\mathrm{L} 1} & \text { Inlet superficial liquid velocity }(\mathrm{m} / \mathrm{s}) \\ \mathrm{G}_{1} & \text { Inlet mass flux }\left(\mathrm{kg} / \mathrm{m}^{2} \mathrm{~s}\right) \\ \mathrm{P}_{1} & \text { Inlet pressure (bar absolute) } \\ \mathrm{T}_{1} & \text { Temperature at the tee junction inlet }\left({ }^{\circ} \mathrm{C}\right) \\ \mathrm{x}_{1} & \text { Inlet quality }(\%) \\ \mathrm{W}_{3} / \mathrm{W}_{1} & \text { Extraction rate } \\ \mathrm{x}_{3} / \mathrm{x}_{1} & \text { Ratio of branch to inlet quality } \\ \mathrm{F}_{\mathrm{BG}} & \text { Fraction of total gas entering branch } \\ \mathrm{F}_{\mathrm{BL}} & \text { Fraction of total liquid entering branch } \\ \Delta \mathrm{P}_{12} & \text { Pressure drop from inlet to run (Pa) } \\ \Delta \mathrm{P}_{13} & \text { Pressure drop from inlet to branch (Pa) }\end{array}$




\section{Legend (continued)}

Error \% :

Air Mass balance error for air, given by equation (A.58) (\%)

Water Mass balance error for water, given by equation (A.59) (\%)

Flow Regime :

Inlet Observed inlet flow regime

Run Observed run flow regime

Branch - Observed branch flow regime

$\mathrm{V}_{1} \quad$ Inlet liquid velocity for single-phase-flow test runs $(\mathrm{m} / \mathrm{s})$

Re Inlet Reynolds number for single-phase-flow test runs

Error \% Mass balance error for single-phase water (\%) 
Table C.1

Two-Phase Pressure-Drop and Phase-Distribution Data

\begin{tabular}{|c|c|c|c|c|c|c|c|c|c|c|c|c|c|c|c|c|c|}
\hline \multirow[t]{2}{*}{ Test } & \multirow{2}{*}{$\mathrm{JgA}_{\mathrm{m} / \mathrm{s}}$} & \multirow{2}{*}{$\begin{array}{l}J_{1 / d} \\
m / s\end{array}$} & \multirow{2}{*}{$\underset{\mathrm{lg} / \mathrm{m}^{2} \mathrm{~s}}{\mathrm{G}_{1}}$} & \multirow{2}{*}{$\begin{array}{c}\mathbb{P}_{1} \\
\text { bar }\end{array}$} & \multirow{2}{*}{$\begin{array}{l}\mathbb{T}_{1} \\
{ }^{\circ} \mathbb{C}\end{array}$} & \multirow{2}{*}{$\begin{array}{l}x_{1} \\
\%\end{array}$} & \multirow{2}{*}{$W_{3} / W_{1}$} & \multirow{2}{*}{$x_{3} / x_{1}$} & \multirow{2}{*}{$\mathbb{F}_{\mathrm{n}:}$} & \multirow{2}{*}{$\mathbb{F}_{\mathrm{II}}$} & \multirow{2}{*}{$\begin{array}{c}\Delta \mathbf{P}_{12} \\
\mathbf{P a}_{\mathbf{a}}\end{array}$} & \multirow{2}{*}{$\underset{P_{a}}{\Delta \mathbb{P}_{13}}$} & \multicolumn{2}{|c|}{ Error \% } & \multicolumn{3}{|c|}{ Flow Regime: } \\
\hline & & & & & & & & & & & & & Air & Water & Inlet & Run & Branch \\
\hline $1-1$ & 10.8 & 0.0398 & 59 & 1.51 & 22.5 & 32.5 & 0.104 & 1.39 & 0.14 & 0.09 & -52 & -30 & -1.0 & -1.4 & W & W & St \\
\hline $1-2$ & 11.0 & 0.0398 & 59 & 1.49 & 21.7 & 32.6 & 0.300 & 1.46 & 0.44 & 0.23 & -136 & 4 & -3.4 & -1.5 & W & W & W \\
\hline $1-3$ & 10.9 & 0.0397 & 59 & 1.50 & 21.8 & 32.5 & 0.513 & 1.42 & 0.73 & 0.41 & -156 & 76 & -6.3 & 0.0 & W & St & $\mathrm{W}$ \\
\hline $1-4$ & 10.8 & 0.0397 & 59 & 1.50 & 21.9 & 32.5 & 0.716 & 1.30 & 0.93 & 0.61 & -146 & 133 & -4.8 & -1.7 & W & St & W \\
\hline $1-5$ & 10.8 & 0.0401 & 59 & 1.51 & 22.1 & 32.3 & 0.735 & 1.30 & 0.95 & 0.63 & -144 & 138 & -4.8 & -1.8 & W & $\mathrm{St}$ & W \\
\hline $1-6$ & 10.1 & 0.0399 & 58 & 1.51 & 21.6 & 31.0 & 0.897 & 1.08 & 0.97 & 0.86 & -152 & 153 & -2.8 & 1.4 & W & $\mathrm{St}$ & \\
\hline $2-1$ & 10.9 & 0.0093 & 29 & 1.52 & 21.4 & 67.6 & 0.108 & 1.15 & 0.12 & 0.08 & -39 & -23 & 1.2 & 0.9 & W & St-W & St \\
\hline $2-2$ & 10.9 & 0.0092 & 29 & 1.51 & 21.8 & 67.8 & 0.309 & 0.96 & 0.30 & 0.34 & -73 & -14 & -1.3 & 1.0 & W & St & $\mathrm{St}$ \\
\hline $2-3$ & 10.9 & 0.0092 & 29 & 1.51 & 21.1 & 67.8 & 0.499 & 0.98 & 0.49 & 0.52 & -99 & 7 & -0.5 & -0.7 & W & $\mathrm{St}$ & St \\
\hline $2-4$ & 10.9 & 0.0092 & 29 & 1.51 & 20.3 & 67.9 & 0.706 & 0.96 & 0.67 & 0.77 & -98 & 43 & -1.3 & 3.5 & W & St & W \\
\hline $2-5$ & 11.0 & 0.0092 & 29 & 1.49 & 19.6 & 68.0 & 0.906 & 0.94 & 0.85 & 1.02 & -96 & 96 & -0.5 & 4.9 & $\mathrm{~W}$ & St & W \\
\hline $3-1$ & 2.7 & 0.0399 & 45 & 1.50 & 21.2 & 10.6 & 0.100 & 0.00 & 0.00 & 0.11 & & 0 & -4.3 & 0.6 & W & W & \\
\hline $3-2$ & 2.7 & 0.0400 & 45 & 1.51 & 21.2 & 10.7 & 0.299 & 0.56 & 0.17 & 0.32 & & 5 & -3.6 & 2.2 & W & W & \\
\hline $3-3$ & 2.7 & 0.0398 & 44 & 1.49 & 21.2 & 10.7 & 0.502 & 1.11 & 0.56 & 0.50 & & 7 & 3.9 & 3.1 & $W$ & $\mathrm{St}$ & \\
\hline $3-4$ & 2.7 & 0.0398 & 44 & 1.50 & 21.1 & 10.6 & 0.692 & 1.39 & 0.97 & 0.66 & & 22 & -0.8 & 1.5 & W & St & \\
\hline $3-5$ & 2.7 & 0.0397 & 44 & 1.49 & 21.2 & 10.7 & 0.898 & 1.10 & 0.98 & 0.89 & -9 & 20 & -1.6 & 0.7 & W & $\mathrm{St}$ & \\
\hline $4-1$ & 10.9 & 0.1796 & 198 & 1.49 & 21.2 & 9.7 & 0.102 & 1.63 & 0.17 & 0.10 & -85 & -45 & -2.1 & -1.7 & $\mathrm{~S}$ & W & $\mathrm{St}$ \\
\hline $4-2$ & 10.9 & 0.1801 & 199 & 1.49 & 21.2 & 9.6 & 0.307 & 2.67 & 0.82 & 0.25 & & 181 & -2.6 & -2.0 & $\mathrm{~S}$ & $\mathrm{~S}$ & W \\
\hline $4-3$ & 11.0 & 0.1793 & 198 & 1.51 & 21.0 & 9.8 & 0.490 & 1.92 & 0.94 & 0.44 & -272 & 347 & -5.5 & -2.5 & $\mathrm{~S}$ & St & $\mathrm{W}$ \\
\hline $4-4$ & 10.8 & 0.1802 & 199 & 1.50 & 21.2 & 9.6 & 0.699 & 1.35 & 0.94 & 0.67 & & 519 & -5.4 & -2.5 & $\mathrm{~S}$ & $\mathrm{St}$ & $\mathrm{S}$ \\
\hline $4-5$ & 10.4 & 0.1797 & 197 & 1.48 & 21.0 & 9.2 & 0.898 & 1.05 & 0.94 & 0.89 & -337 & 514 & -5.7 & 0.1 & $\mathrm{~S}$ & & \\
\hline
\end{tabular}


Table C.1 (continued)

\begin{tabular}{|c|c|c|c|c|c|c|c|c|c|c|c|}
\hline Test & $\begin{array}{l}\mathbb{J}_{\mathrm{G1}} \\
\mathrm{m} / \mathrm{s}\end{array}$ & $\begin{array}{l}J_{L, 1} \\
\mathrm{~m} / \mathrm{s}\end{array}$ & $\underset{\mathrm{kg} / \mathrm{m}^{2} \mathrm{~s}}{\mathbb{G}_{1}}$ & $\begin{array}{c}\mathbb{P}_{1} \\
\text { bar }\end{array}$ & $\begin{array}{l}\mathrm{T}_{1} \\
{ }^{\circ} \mathrm{C}\end{array}$ & $\begin{array}{l}\mathbf{x}_{1} \\
\%\end{array}$ & $W_{9} / W_{1}$ & $\mathbf{x}_{3} / \mathbf{x}_{1}$ & $\mathbb{F}_{\mathrm{BG}}$ & $\mathrm{F}_{\mathrm{Bi}}$ & $\begin{array}{c}\Delta \mathbb{P}_{12} \\
\mathbf{P a}\end{array}$ \\
\hline $5-1$ & 4.4 & 0.1800 & 187 & 1.50 & 20.9 & 4.2 & 0.105 & 2.40 & 0.25 & 0.10 & -33 \\
\hline $5-2$ & 4.4 & 0.1807 & 188 & 1.52 & 21.0 & 4.2 & 0.311 & 2.94 & 0.91 & 0.29 & -207 \\
\hline $5-3$ & 4.5 & 0.1796 & 187 & 1.48 & 21.3 & 4.2 & 0.500 & 1.84 & 0.92 & 0.48 & -182 \\
\hline $5-4$ & 4.1 & 0.1797 & 186 & 1.49 & 21.5 & 3.8 & 0.693 & 1.37 & 0.95 & 0.68 & -234 \\
\hline $5-5$ & 4.0 & 0.1798 & 186 & 1.51 & 21.0 & 3.8 & 0.902 & 1.07 & 0.97 & 0.90 & -230 \\
\hline $6-1$ & 2.7 & 0.1803 & 185 & 1.51 & 20.9 & 2.6 & 0.099 & 0.86 & 0.09 & 0.10 & \\
\hline $6-2$ & 2.7 & 0.1793 & 184 & 1.54 & 21.0 & 2.6 & 0.301 & 2.77 & 0.83 & 0.29 & \\
\hline $6-3$ & 2.7 & 0.1806 & 185 & 1.50 & 20.9 & 2.6 & 0.510 & 1.77 & 0.91 & 0.50 & -183 \\
\hline $6-4$ & 2.7 & 0.1801 & 184 & 1.50 & 20.9 & 2.6 & 0.703 & 1.38 & 0.97 & 0.70 & -182 \\
\hline $6-5$ & 2.7 & 0.1801 & 184 & 1.51 & 21.0 & 2.6 & 0.899 & 1.10 & 0.99 & 0.90 & -185 \\
\hline $7-1$ & 10.9 & 0.0022 & 22 & 1.51 & 20.0 & 89.8 & 0.096 & 1.00 & 0.10 & 0.10 & -24 \\
\hline $7-2$ & 10.8 & 0.0022 & 22 & 1.51 & 20.0 & 89.8 & 0.298 & 0.85 & 0.25 & 0.70 & -50 \\
\hline $7-3$ & 10.1 & 0.0021 & 20 & 1.49 & 16.6 & 89.6 & 0.504 & 0.87 & 0.44 & 1.07 & \\
\hline $7-4$ & 11.0 & 0.0022 & 22 & 1.51 & 20.0 & 89.8 & 0.684 & 0.94 & 0.64 & 1.07 & \\
\hline $7-5$ & 11.2 & 0.0022 & 22 & 1.49 & 19.6 & 89.8 & 0.884 & 0.98 & 0.87 & 1.04 & \\
\hline $8-1$ & 4.4 & 0,0094 & 17 & 1.50 & 19.2 & 45.5 & 0.098 & 1.26 & 0.12 & 0.08 & \\
\hline $8-2$ & 4.4 & 0.0095 & 17 & 1.51 & 18.8 & 45.3 & 0.297 & 1.10 & 0.33 & 0.27 & \\
\hline $8-3$ & 4.5 & 0.0094 & 17 & 1.48 & 21.4 & 45.4 & 0.505 & 1.01 & 0.51 & 0.50 & \\
\hline $8-4$ & 4.4 & 0.0094 & 17 & 1.51 & 22.6 & 45.4 & 0.694 & 1.01 & 0.70 & 0.69 & \\
\hline $8-5$ & 4.5 & 0.0094 & 17 & 1.49 & 22.4 & 45.2 & 0.883 & 0.99 & 0.88 & 0.89 & \\
\hline
\end{tabular}

\begin{tabular}{|c|c|c|c|c|c|}
\hline \multirow{2}{*}{$\begin{array}{c}\Delta \mathbf{P}_{13} \\
\mathbf{P a}\end{array}$} & \multicolumn{2}{|c|}{ Error \% } & \multicolumn{3}{|c|}{ Flow Regime: } \\
\hline & Air & Water & Inlet & IRun & Branch \\
\hline-37 & 1.9 & -1.4 & S & S & St \\
\hline 64 & -2.6 & -2.3 & S & St & W \\
\hline 115 & -4.1 & -2.3 & $\mathrm{~S}$ & St-W & $\mathrm{S}$ \\
\hline 140 & -5.1 & -1.8 & $\mathrm{~S}$ & W & \\
\hline 218 & -3.6 & 0.1 & $S$ & $W$ & \\
\hline & -8.6 & 1.4 & $\mathrm{~S}$ & $S$ & \\
\hline & -3.0 & 0.7 & S & W & \\
\hline 93 & -0.9 & 0.6 & $S$ & W & \\
\hline 150 & -1.3 & 1.4 & $\mathrm{~S}$ & $W$ & \\
\hline 167 & -1.0 & 2.6 & S & St & \\
\hline-16 & 0.9 & 3.3 & St-W & St & \\
\hline-17 & 0.9 & 3.9 & St-W & St & \\
\hline 1 & -5.1 & 6.2 & St-W & & \\
\hline 32 & -1.5 & 6.8 & St-W & & \\
\hline 89 & -1.7 & 3.8 & St-W & & $W$ \\
\hline & 0.4 & 3.9 & St-W & St & \\
\hline & 0.8 & 0.2 & St-W & St & \\
\hline & -0.2 & 1.5 & St-W & St & \\
\hline & 2.6 & -0.5 & St-W & St & \\
\hline & -1.0 & 2.9 & St-W & St & \\
\hline
\end{tabular}


Table C.1 (continued)

\begin{tabular}{|c|c|c|c|c|c|c|c|c|c|c|c|c|c|c|c|c|}
\hline \multirow{2}{*}{ Test } & \multirow[b]{2}{*}{$\begin{array}{l}\mathbb{J}_{\mathrm{GI}} \\
\mathrm{m} / \mathrm{s}\end{array}$} & \multirow{2}{*}{$\underset{m / s}{\mathbb{J}_{1,1}}$} & \multirow{2}{*}{$\underset{\mathrm{lg} / \mathrm{m}^{2} \mathrm{~g}}{\mathrm{G}_{\mathrm{1}}}$} & \multirow{2}{*}{$\begin{array}{c}P_{1} \\
\text { bar }\end{array}$} & \multirow{2}{*}{$\begin{array}{l}\mathbb{T}_{1} \\
{ }^{\circ} \mathbb{C}\end{array}$} & \multirow{2}{*}{$\begin{array}{l}\mathbf{x}_{1} \\
\%\end{array}$} & \multirow{2}{*}{$W_{3} / W_{1}$} & \multirow{2}{*}{$x_{3} / x_{1}$} & \multirow{2}{*}{$F_{\mathrm{IC:}}$} & \multirow{2}{*}{$\mathbb{F}_{\text {mit }}$} & \multirow{2}{*}{$\begin{array}{c}\Delta \mathbb{P}_{12} \\
\mathbf{P a}\end{array}$} & \multirow{2}{*}{$\frac{\Delta \mathbf{P}_{13}}{P_{\mathfrak{a}}}$} & \multicolumn{2}{|c|}{ Error \% } & \multicolumn{2}{|c|}{ Flow Regime: } \\
\hline & & & & & & & & & & & & & Air & Water & Inlet & Pun Branch \\
\hline $9-1$ & 2.7 & 0.0023 & 7 & 1.51 & 22.0 & 67.4 & 0.094 & 0.96 & 0.09 & 0.10 & & & -4.6 & 3.7 & $S t$ & St \\
\hline $9-2$ & 2.7 & 0.0023 & 7 & 1.50 & 23.2 & 67.9 & 0.278 & 0.95 & 0.26 & 0.31 & & & -1.7 & 3.0 & St & $\mathrm{St}$ \\
\hline $9-3$ & 2.7 & 0.0022 & 7 & 1.51 & 21.7 & 68.1 & 0.451 & 0.90 & 0.41 & 0.55 & & & -0.5 & 2.6 & St & St \\
\hline $9-4$ & 2.7 & 0.0023 & 7 & $\mathbb{1 . 5 1}$ & 21.6 & 67.5 & 0.538 & 0.89 & 0.48 & 0.67 & & & -0.4 & 0.8 & St & St \\
\hline $9-5$ & 2.7 & 0.0023 & 7 & $\mathbb{1} .52$ & 22.0 & 67.4 & 0.658 & 0.89 & 0.59 & 0.81 & & & -4.5 & 3.8 & $\mathrm{St}$ & St \\
\hline $9-6$ & 2.7 & 0.0023 & 7 & 1.49 & 21.7 & 67.5 & 0.847 & 0.93 & 0.79 & 0.96 & & & -6.2 & 1.9 & St & St \\
\hline $10-1$ & 2.7 & 0.0094 & 14 & 1.51 & 23.8 & 33.3 & 0.100 & 0.60 & 0.06 & 0.12 & & & -6.0 & 1.0 & St & St \\
\hline $10-2$ & 2.7 & 0.0094 & 14 & 1.50 & 22.4 & 33.5 & 0.284 & 1.03 & 0.29 & 0.28 & & & -3.3 & 1.0 & St & St \\
\hline $10-3$ & 2.7 & 0.0094 & 14 & 1.50 & 22.0 & 33.5 & 0.491 & 1.07 & 0.53 & 0.47 & & & -6.4 & -1.7 & St & St \\
\hline $10-4$ & 2.7 & 0.0094 & 14 & 1.50 & 21.8 & 33.5 & 0.685 & 0.94 & 0.64 & 0.71 & & & -7.1 & 0.5 & St & St \\
\hline $10-5$ & 2.7 & 0.0095 & 14 & 1.50 & 21.5 & 33.4 & 0.857 & 1.08 & 0.93 & 0.82 & & & -6.4 & 1.1 & St & St \\
\hline $11-1$ & 18.3 & 0.0098 & 42 & 1.50 & 22.2 & 76.6 & 0.104 & 0.88 & 0.09 & 0.14 & -68 & -33 & 0.5 & 0.0 & SA & $W$ \\
\hline $11-2$ & 18.3 & 0.0098 & 42 & 1.51 & 22.4 & 76.7 & 0.300 & 0.94 & 0.28 & 0.36 & -180 & -41 & -0.8 & -2.3 & $\mathrm{SA}$ & $W$ \\
\hline $11-3$ & 18.2 & 0.0098 & 42 & 1.49 & 21.3 & 76.6 & 0.501 & 0.96 & 0.48 & 0.57 & -232 & 29 & -2.6 & 0.2 & SA & W \\
\hline $11-4$ & 18.4 & 0.0098 & 42 & 1.49 & 22.6 & 76.8 & 0.699 & 0.99 & 0.69 & 0.72 & -267 & 133 & -1.5 & 1.1 & $\mathrm{SA}$ & St \\
\hline $11-5$ & 18.4 & 0.0098 & 42 & 1.49 & 22.2 & 76.7 & 0.894 & 0.97 & 0.87 & 0.99 & -251 & 269 & -1.2 & 3.8 & SA & St \\
\hline $12-1$ & 40.9 & 0.0018 & 73 & 1.49 & 23.2 & 97.5 & 0.101 & 0.89 & 0.09 & 0.54 & -343 & -120 & -3.8 & 0.9 & An & $W$ \\
\hline $12-2$ & 40.5 & 0.0019 & 73 & 1.50 & 22.1 & 97.4 & 0.298 & 0.94 & 0.28 & 0.97 & -705 & -148 & -3.6 & -2.4 & An & W \\
\hline $12-3$ & 40.3 & 0.0017 & 72 & 1.51 & 24.6 & 97.6 & 0.498 & 0.97 & 0.48 & 1.06 & -981 & 86 & -3.9 & 3.1 & An & St \\
\hline $12-4$ & 40.4 & 0.0018 & 73 & 1.50 & 22.6 & 97.5 & 0.699 & 0.99 & 0.69 & 1.06 & -1172 & 591 & -4.4 & 3.3 & An & St \\
\hline $12-5$ & 40.9 & 0.0018 & 73 & 1.49 & 21.6 & 97.6 & 0.899 & 1.00 & 0.90 & 1.04 & -993 & 1444 & -5.4 & 1.4 & An & St \\
\hline
\end{tabular}


Table C.1 (continued)

\begin{tabular}{|c|c|c|c|c|c|c|c|c|c|c|c|c|c|c|c|c|}
\hline \multirow[t]{2}{*}{ Test } & \multirow{2}{*}{$\begin{array}{l}\mathbb{J}_{G t} \\
\mathrm{~m} / \mathrm{s}\end{array}$} & \multirow{2}{*}{$\begin{array}{l}J_{t, 1} \\
\mathrm{~m} / \mathrm{s}\end{array}$} & \multirow{2}{*}{$\underset{\mathrm{lg} / \mathrm{m}^{2} \mathrm{~g}}{\mathrm{G}_{1}}$} & \multirow{2}{*}{$\begin{array}{l}P_{1} \\
\text { bar }\end{array}$} & \multirow{2}{*}{$\begin{array}{l}\mathbb{T}_{1} \\
{ }^{\circ} \mathrm{C}\end{array}$} & \multirow{2}{*}{$\begin{array}{l}\mathrm{x}_{1} \\
\%\end{array}$} & \multirow[t]{2}{*}{$W_{3} / W_{1}$} & \multirow[t]{2}{*}{$x_{0} / x_{1}$} & \multirow[t]{2}{*}{$\mathbb{F}_{\mathrm{nc}}$} & \multirow[t]{2}{*}{$\mathbb{F}_{131}$} & \multirow{2}{*}{$\underset{\mathbb{P}_{12}}{\Delta \mathbb{P}_{12}}$} & \multirow{2}{*}{$\begin{array}{c}\Delta \mathbb{P}_{13} \\
\mathbb{P}_{\mathbf{a}}\end{array}$} & \multicolumn{2}{|c|}{ Error \% } & \multicolumn{2}{|c|}{ Flow Regime: } \\
\hline & & & & & & & & & & & & & Air & Water & Inlet & Run Branch \\
\hline $13-1$ & 40.5 & 0.0096 & 81 & 1.51 & 23.5 & 88.2 & 0.100 & 0.71 & 0.07 & 0.32 & -324 & -99 & & & An & An \\
\hline $13-2$ & 39.2 & 0.0096 & 82 & 1.58 & 22.4 & 88.4 & 0.301 & 0.89 & 0.27 & 0.55 & -860 & -120 & -2.7 & 0.0 & An & $\mathrm{SA}$ \\
\hline $13-3$ & 40.8 & 0.0096 & 82 & 1.50 & 21.5 & 88.3 & 0.499 & 0.90 & 0.45 & 0.87 & -1132 & 121 & -3.0 & 2.4 & An & $\mathrm{SA}$ \\
\hline $13-4$ & 41.1 & 0.0096 & 82 & 1.49 & 21.8 & 88.3 & 0.701 & 0.95 & 0.67 & 0.96 & -1212 & 725 & -3.2 & 2.4 & An & W \\
\hline $13-5$ & 40.8 & 0.0095 & 81 & 1.50 & 22.3 & 88.3 & 0.895 & 0.99 & 0.88 & 0.98 & -1064 & 1574 & -4.0 & 2.6 & An & St \\
\hline $14-1$ & 40.3 & 0.0394 & 112 & 1.51 & 16.3 & 64.9 & 0.098 & 0.49 & 0.05 & 0.19 & -318 & -104 & -4.5 & 4.8 & An & An \\
\hline $14-2$ & 40.7 & 0.0394 & 111 & 1.49 & 17.5 & 64.7 & 0.297 & 0.93 & 0.28 & 0.34 & -1019 & 0 & -3.6 & 4.7 & An & $\mathrm{SA}$ \\
\hline $14-3$ & 40.6 & 0.0396 & 111 & 1.49 & 21.2 & 64.3 & 0.495 & 1.05 & 0.52 & 0.45 & -1421 & 451 & -3.1 & 2.0 & An & $\mathrm{SA}$ \\
\hline $14-4$ & 40.2 & 0.0395 & 110 & 1.50 & 21.3 & 64.2 & 0.702 & 1.07 & 0.75 & 0.62 & -1474 & 1251 & -3.4 & 2.9 & An & W \\
\hline $14-5$ & 40.3 & 0.0396 & 112 & 1.54 & 22.6 & 64.8 & 0.900 & 1.09 & 0.98 & 0.75 & -1366 & 2412 & & & An & St \\
\hline $15-1$ & 38.1 & 0.1791 & 259 & 1.80 & 22.5 & 31.1 & 0.101 & 0.93 & 0.09 & 0.10 & -688 & -79 & -3.9 & 1.5 & An & An \\
\hline $15-2$ & 40.2 & 0.1797 & 252 & 1.50 & 17.2 & 28.7 & 0.299 & 1.67 & 0.50 & 0.22 & -2666 & 715 & -4.3 & 1.5 & An & An \\
\hline $15-3$ & 39.8 & 0.1795 & 252 & 1.55 & 22.0 & 28.8 & 0.506 & 1.70 & 0.86 & 0.36 & -2619 & 2574 & & & An & W \\
\hline $15-4$ & 33.9 & 0.1792 & 250 & 1.78 & 22.0 & 28.4 & 0.700 & 1.43 & 1.00 & 0.58 & -2162 & & & & An & St \\
\hline
\end{tabular}


Table C.2

Single-Phase Pressure-Drop Data

$\begin{array}{ccccccccc}\text { Test } & \begin{array}{c}\mathbf{V}_{1} \\ \mathbf{m} / \mathbf{s}\end{array} & \begin{array}{c}\mathbf{G}_{1} \\ \mathbf{k g} / \mathbf{m}^{2} \mathbf{s}\end{array} & \mathbf{R e} & \begin{array}{c}\mathbf{T}_{1} \\ { }^{\circ} \mathbf{C}\end{array} & \mathbf{W}_{3} / \mathbf{W}_{1} & \begin{array}{c}\Delta \mathbf{P}_{12} \\ \mathbf{P a}\end{array} & \begin{array}{c}\Delta \mathbf{P}_{13} \\ \mathbf{P a}\end{array} & \begin{array}{c}\text { Error } \\ \%\end{array} \\ \text { S-1 } & 0.180 & 168 & 6451 & 21.1 & 0.000 & 0.3 & -0.7 & -0.9 \\ \text { S-2 } & 0.180 & 168 & 6451 & 21.2 & 0.100 & -3.3 & -0.9 & -1.2 \\ \text { S-3 } & 0.180 & 168 & 6451 & 21.1 & 0.299 & -7.9 & -0.4 & -2.0 \\ \text { S-4 } & 0.180 & 168 & 6447 & 21.2 & 0.501 & -10.2 & 1.7 & -2.5 \\ \text { S-5 } & 0.180 & 168 & 6458 & 21.2 & 0.699 & -11.7 & 6.7 & -1.1 \\ \text { S-6 } & 0.180 & 168 & 6456 & 21.1 & 0.899 & -11.0 & 13.3 & -0.2 \\ \text { S-7 } & 0.180 & 168 & 6457 & 21.1 & 1.001 & -10.6 & 17.1 & 0.1\end{array}$


Table C. 3

Previous Numbering Scheme for Two-Phase Flow Test Runs

\begin{tabular}{|c|c|c|c|}
\hline & & & \\
\hline Present & Previous & Present & Previous \\
\hline $1-1$ & 5 & 9.1 & 27 \\
\hline $1-2$ & 4 & $9-2$ & 22 \\
\hline $1-3$ & 1 & $9-3$ & 24 \\
\hline $1-4$ & 2 & 9.4 & 23 \\
\hline $1-5$ & 3 & 9.5 & 25 \\
\hline 1.6 & 72 & $9-6$ & 26 \\
\hline $2-1$ & 17 & $10-1$ & 28 \\
\hline $2-2$ & 16 & $10-2$ & 29 \\
\hline $2-3$ & $15 \mathrm{R} 2$ & $10-3$ & 30 \\
\hline $2-4$ & 14 & $10-4$ & 31 \\
\hline $2-5$ & 13 & $10-5$ & 32 \\
\hline $3-1$ & 42 & $11-1$ & 52 \\
\hline $3-2$ & 41 & $11-2$ & 51 \\
\hline $3-3$ & 38 & $11-3$ & 48 \\
\hline $3-4$ & 39 & 11.4 & 49 \\
\hline $3-5$ & 40 & $11-5$ & 50 \\
\hline $4-1$ & 8 & $12-1$ & 66 \\
\hline $4-2$ & 9 & $12-2$ & 65 \\
\hline $4-3$ & 6 & $12-3$ & 64 \\
\hline $4-4$ & 7 & $12-4$ & 63 \\
\hline 4-5 & 75 & $12-5$ & 62 \\
\hline $5-1$ & 12 & $13-1$ & 71 \\
\hline $5-2$ & 11 & $13-2$ & 53 \\
\hline $5-3$ & 10 & $13-3$ & 54 \\
\hline $5-4$ & 73 & $13-4$ & 55 \\
\hline $5-5$ & 74 & $13-5$ & 56 \\
\hline $6-1$ & 43 & $14-1$ & 60 \\
\hline $6-2$ & 44 & $14-2$ & 59 \\
\hline $6-3$ & 45 & $14-3$ & 57 \\
\hline $6-4$ & 46 & $14-4$ & 58 \\
\hline $6-5$ & 47 & $14-5$ & 70 \\
\hline $7-1$ & 20 & $15-1$ & 67 \\
\hline $7-2$ & 19 & $15-2$ & 61 \\
\hline $7-3$ & 77 & $15-3$ & 68 \\
\hline $7-4$ & 21 & $15-4$ & 69 \\
\hline $7-5$ & 18 & & \\
\hline $8-1$ & 37 & & \\
\hline $8-2$ & 36 & & \\
\hline $8-3$ & 33 & & \\
\hline $8-4$ & 34 & & \\
\hline 8-5̃ & 35 & & \\
\hline
\end{tabular}


Table C.4

Two-Phase and Single-Phase Mass Flow Rates at the Tee Junction

\begin{tabular}{|c|c|c|c|c|c|c|c|c|c|c|c|c|c|}
\hline & & & & Mas: & flow r & 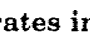 & & & & & & & \\
\hline Test & $\mathbf{W}_{\mathrm{L1}}$ & $W_{G 1}$ & $w_{L 2}$ & $W_{G 8}$ & $W_{L S}$ & $W_{G 9}$ & Test & $\mathrm{W}_{\mathrm{Ll}}$ & $W_{\mathrm{Gl}}$ & $W_{L, 2}$ & $W_{G Q}$ & $W_{L S}$ & $\mathrm{~W}_{\mathrm{GS}}$ \\
\hline $1-1$ & 158.6 & 76.31 & 142.9 & 64.58 & 13.46 & 11.01 & 9.1 & 9.177 & 18.94 & 8.597 & 16.37 & 0.933 & 1.696 \\
\hline $1-2$ & 158.9 & 76.87 & 119.4 & 40.57 & 37.04 & 33.67 & $9-2$ & 9.012 & 19.03 & 6.518 & 13.68 & 2.771 & 5.027 \\
\hline $1-3$ & 158.3 & 76.15 & 3.55 & 15.86 & 64.83 & 55.52 & 9.3 & 8.937 & 19.05 & 4.256 & 11.25 & 4.918 & 7.717 \\
\hline $1-4$ & 158.3 & 76.29 & 58.53 & 1.867 & 97.15 & 70.78 & $9-4$ & 9.140 & 18.97 & 3.135 & 9.834 & 6.076 & 9.054 \\
\hline $1-5$ & 159.9 & 76.30 & 56.01 & 0.000 & 100.9 & 72.65 & $9-5$ & 9.208 & 19.00 & 2.158 & 7.016 & 7.411 & 11.14 \\
\hline $1-6$ & 159.1 & 71.63 & 24.02 & 0.000 & 137.3 & 69.64 & $9-6$ & 9.130 & 18.93 & 0.531 & 2.778 & 8.790 & 14.99 \\
\hline $2-1$ & 37.14 & 77.38 & 34.68 & 68.72 & 2.802 & 9.610 & $10-1$ & 37.43 & 18.66 & 33.35 & 16.42 & 4.468 & 1.120 \\
\hline $2-2$ & 36.64 & 77.14 & 24.65 & 53.27 & 12.36 & 22.85 & $10-2$ & 37.50 & 18.91 & 27.34 & 12.78 & 10.53 & 5.515 \\
\hline $2-3$ & 36.70 & 77.26 & 17.51 & 38.90 & 18.94 & 37.95 & $10-3$ & 37.63 & 18.93 & 19.18 & 7.787 & 17.82 & 9.933 \\
\hline $2-4$ & 36.67 & 77.59 & 9.654 & 24.26 & 28.33 & 52.29 & 10.4 & 37.65 & 18.93 & 11.24 & 5.449 & 26.60 & 12.14 \\
\hline $2-5$ & 36.58 & 77.80 & 1.221 & 11.01 & 37.17 & 66.45 & 10.5 & 37.75 & 18.97 & 7.218 & 0.135 & 30.98 & 17.62 \\
\hline $3-1$ & 159.1 & 18.84 & 142.3 & 18.03 & 17.74 & 0.0 & $11-1$ & 39.22 & 128.7 & 33.55 & 117.5 & 5.641 & 11.78 \\
\hline $3-2$ & 159.5 & 19.08 & 112.8 & 15.19 & 50.18 & 3.209 & $11-2$ & 39.19 & 128.8 & 24.12 & 91.55 & 14.16 & 36.22 \\
\hline $3-3$ & 158.5 & 19.01 & 84.88 & 9.217 & 78.56 & 10.55 & $11-3$ & 38.89 & 127.7 & 16.97 & 62.92 & 22.01 & 61.43 \\
\hline $3-4$ & 158.7 & 18.87 & 56.42 & 0.514 & 104.7 & 18.22 & $11-4$ & 38.90 & 128.6 & 11.20 & 37.69 & 28.17 & 88.95 \\
\hline $3-5$ & 158.5 & 19.06 & 18.94 & 0.000 & 140.7 & 18.75 & $11-5$ & 39.08 & 128.8 & 1.954 & 15.92 & 38.69 & 111.3 \\
\hline $4-1$ & 16.1 & 76.6 & 35.7 & 62.33 & 68.13 & 12 & 12 & 7.267 & 284.6 & 8 & 248.3 & 3. & 25.45 \\
\hline $4-2$ & 718.2 & 76.49 & 522.7 & 11.78 & 181.1 & 62. & $2-2$ & 7.578 & 284.5 & 0.043 & 194.5 & 7.371 & 79.79 \\
\hline $4-3$ & 714.9 & 77.91 & 381.8 & 0.272 & 315.3 & 73. & $12-3$ & 6.836 & 282.4 & 0.007 & 134.7 & 7.273 & 136.8 \\
\hline $4 \cdot 4$ & 718.5 & 76.42 & 217.1 & 0.130 & 483.3 & 72.1 & 12.4 & 7.175 & 284.2 & 0.012 & 75.76 & 7.627 & 196.1 \\
\hline $4-5$ & 716.4 & 72.30 & 77.18 & 0.000 & 639.9 & 68.18 & $12-5$ & 7.126 & 286.2 & 0.016 & 14.54 & 7.399 & 256.3 \\
\hline $5-1$ & 717.8 & 31.31 & 37.0 & 24.06 & 70.52 & 7.8 & $3-1$ & 38.11 & 285.0 & 25.94 & 265.0 & 12.15 & 20.03 \\
\hline $5-2$ & 720.7 & 31.27 & 499.2 & 1.953 & 205.1 & 28.5 & $13-2$ & 38.08 & 289.2 & 17.24 & 203.9 & 20.89 & 77.65 \\
\hline $5-3$ & 716.3 & 31.20 & 355.0 & 1.258 & 345.2 & 28.6 & $13-3$ & 38.11 & 288.0 & 5.981 & 149.9 & & 129.5 \\
\hline $5-4$ & 716.4 & 28.68 & 214.1 & 0.000 & 489.3 & 27.24 & $13-4$ & 38.09 & 287.6 & 2.681 & 86.55 & 36.50 & 191.8 \\
\hline $5-5$ & 716.8 & 28.41 & 72.62 & 0.000 & 644.6 & 27.40 & $13-5$ & 38.02 & 287.2 & 1.890 & 22.05 & 37.30 & 253.6 \\
\hline $0-1$ & 18.8 & 19.23 & 87.2 & 10. & & & & & 291.0 & & & & 13.99 \\
\hline $6-2$ & 715.0 & 19.22 & 515.0 & 2.640 & 205.2 & 16. & $14-2$ & 157.2 & 288.2 & 112.1 & 198.1 & 52.72 & 79.70 \\
\hline $6-3$ & 720.2 & 18.97 & 364.6 & 1.634 & 359.9 & 17. & $14 \cdot 3$ & 158.0 & 284.5 & 90.45 & 127.3 & 70.80 & 148.4 \\
\hline $6-4$ & 718.3 & 19.02 & 228.4 & 0.371 & 499.9 & 18. & $14-4$ & 157.5 & 283.0 & 64.87 & 61.71 & 97.40 & 211.8 \\
\hline $6-5$ & 718.4 & 18.87 & 93.29 & 0.000 & 643.9 & 18.69 & $14-5$ & 157.8 & 290.1 & 40.24 & 4.580 & 117.5 & 285.5 \\
\hline $7-1$ & 8.770 & 77.62 & 8.212 & 70.86 & 0.858 & 7.4 & & & 321.5 & & & & 29.97 \\
\hline $7-2$ & 8.829 & 77.33 & 2.998 & 58.49 & 6.191 & 19. & 15.2 & 717.3 & 288.4 & 571.5 & 131.8 & 156.5 & 144.2 \\
\hline $7-3$ & 8.374 & 72.03 & 0.010 & 36.82 & 8.942 & 31. & $15 \cdot 3$ & 715.6 & 289.7 & 460.4 & 41.10 & 259.6 & 248.7 \\
\hline $7-4$ & 8.873 & 77.91 & 0.015 & 26.91 & 9.517 & 49. & $15-4$ & 714.4 & 283.4 & 299.6 & 0.000 & 414.8 & 283.4 \\
\hline $7-5$ & 8.904 & 78.71 & 0.016 & 9.139 & 9.260 & 68.22 & & & & & & & \\
\hline & & & & & & & $\mathrm{S}$ & & & & & & \\
\hline $8-1$ & 37.49 & 31.3 & 36.10 & 27. & 2.8 & & $S$ & 671.5 & & & & & \\
\hline $8-2$ & 37.84 & 31.37 & 27.63 & 21.31 & 10.29 & 10.3 & S- & 671.9 & & 457.3 & & 201.1 & \\
\hline $8-3$ & 37.58 & 31.23 & 19.31 & 15.22 & 18.82 & 15.94 & S-4 & 670.9 & & 317.9 & & 336.1 & \\
\hline $8-4$ & 37.32 & 31.06 & 11.40 & 10.10 & 25.71 & 21.77 & S-5 & 672.1 & & 195.2 & & 469.9 & \\
\hline $8-5$ & 37.52 & 30.94 & 5.271 & 3.543 & 33.36 & 27.09 & S-6 & 672.8 & & 67.12 & & 604.5 & \\
\hline & & & & & & & S-7 & 672.8 & & 0.000 & & 673.3 & \\
\hline
\end{tabular}




\section{Appendix D}

\section{SAMPLE PROBLEMS IN MEASURED PRESSURE DISTRIBUTIONS}

As mentioned in Chapter 4, values of $\Delta \mathrm{P}_{12}$ and $\Delta \mathrm{P}_{13}$ could not be measured for all test runs. In this appendix, examples of the problems encountered in the measurement of the pressure distribution are given.

Figure D.1 gives the measured pressure distribution for test 7-4. Both the inlet and branch pressure distributions were properly measured; however, the run data show severe scatter with no observable trends. Most of the run data lie below the expected values. Test 7-4 corresponded to an inlet flow regime of stratified-wavy flow. Table C. 1 indicates that for this test all of the liquid was removed through the branch. Therefore, the run was completely dry of any liquid. Tests 7-3 and 7-5 also showed severe scatter of the run data. Similarly, for tests $7-3$ and $7-5$ all of the liquid was removed through the branch, and the run was completely dry.

Since the flow through the run side was dry, then a meniscus may have developed at each pressure tap. Because of surface tension, a pressure difference would exist across the meniscus. This pressure difference can be approximated by 


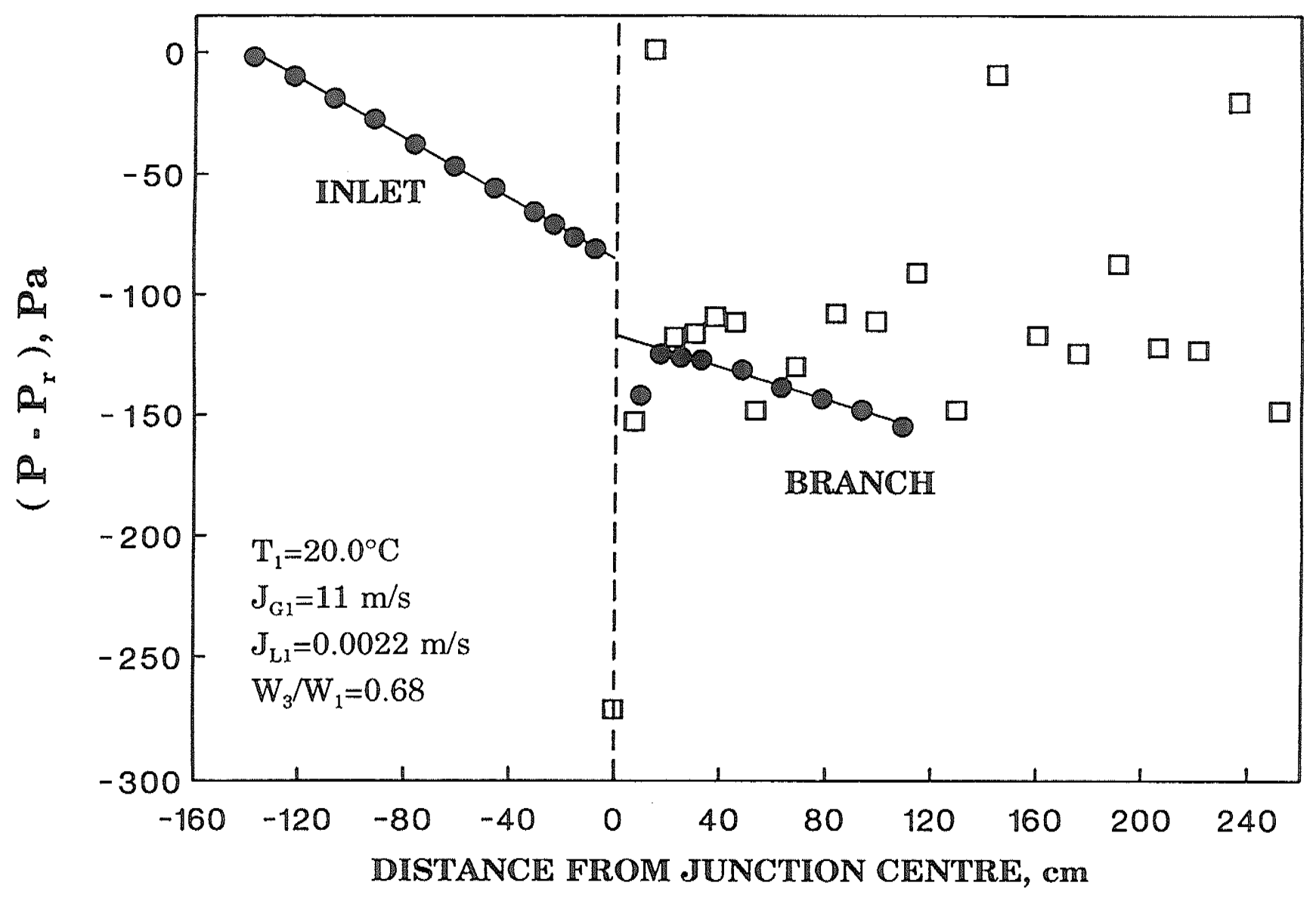

Figure D.1 Pressure distribution for test $7-4$ 


$$
\Delta P=\frac{20}{R},
$$

where $R$ is the radius of curvature of the meniscus and $\sigma$ is the surface tension $(\mathrm{N} / \mathrm{m})$. Using the above equation, $\Delta \mathrm{P}$ was calculated to be approximately 180 $\mathrm{Pa}$. This estimate of $\Delta \mathrm{P}$ appears to be of the proper order of magnitude. However, due to uncertainty, no value was recorded for $\Delta \mathrm{P}_{12}$.

Figure D.2 gives the measured pressure distribution for test $4-2$ and figure D. 3 the measured pressure distribution for test 4-4. Both of these tests were performed with the same inlet conditions. For both tests, the flow in the run never became fully developed. For test $4-2$ the extraction rate was 0.307 , and for test 4-4 the extraction rate was 0.699 . Table C.1 reveals that for the same inlet conditions, values of $\Delta \mathrm{P}_{12}$ were obtained at extraction rates of 0.102 , 0.490 , and 0.898 (tests $4-1,4-3$, and $4-5$, respectively). It is not understood why fully developed flow in the run was not achieved for tests 4-2 and 4-4, while it was achieved for tests 4-1, 4-3, and 4-5.

The measured pressure distribution for test 3-2 is given in figure D.4. For this test, fully developed flow existed in the branch; however, the flow in the run never became fully developed. Again, the reason for this is not known. Tests $3-1,3-3$, and $3-4$ also gave the same characteristic shape for the run pressure distribution. Tests 3-1 through 3-4 were all obtained at the same inlet conditions. 


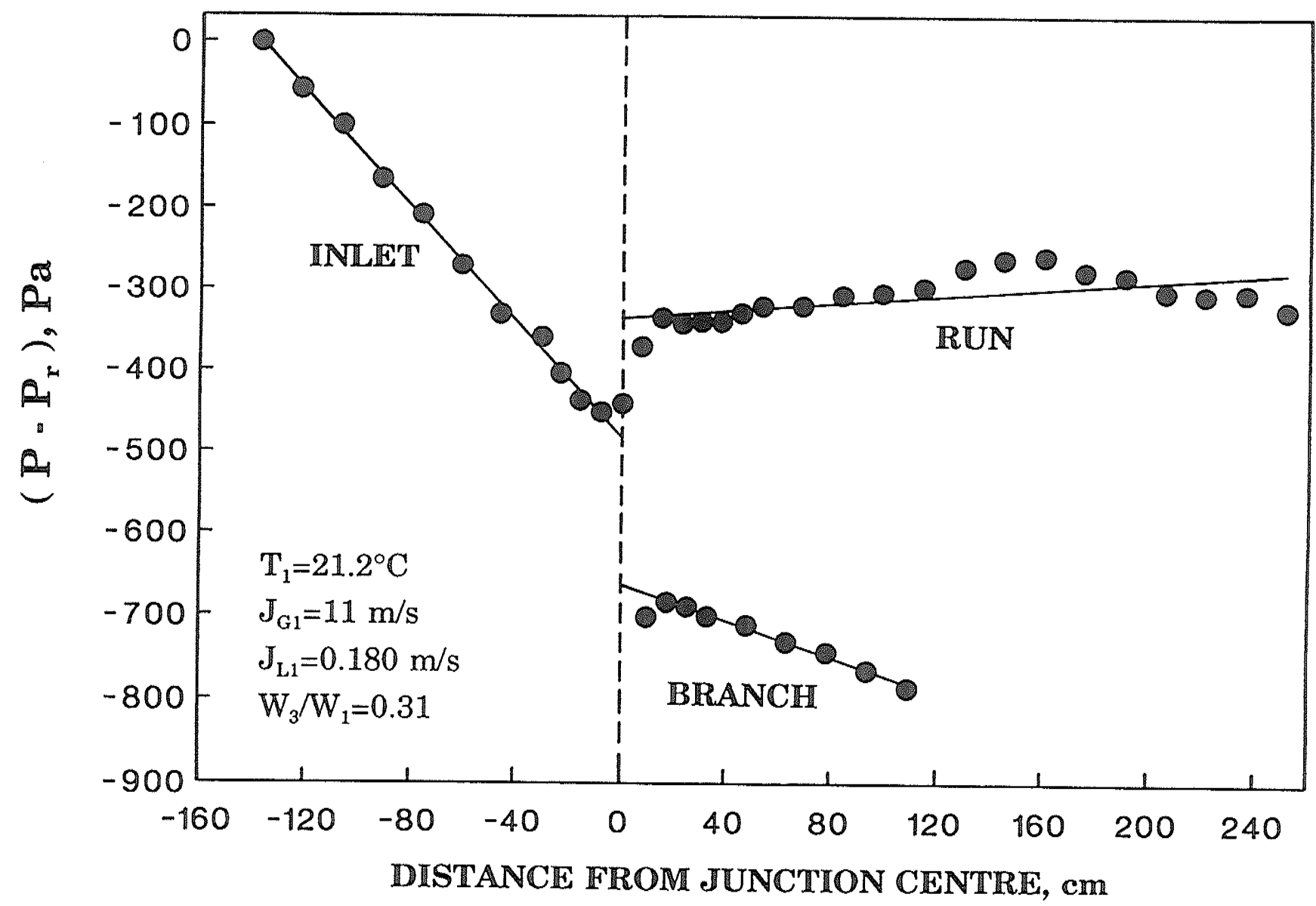

Figure D.2 Pressure distribution for test 4-2 


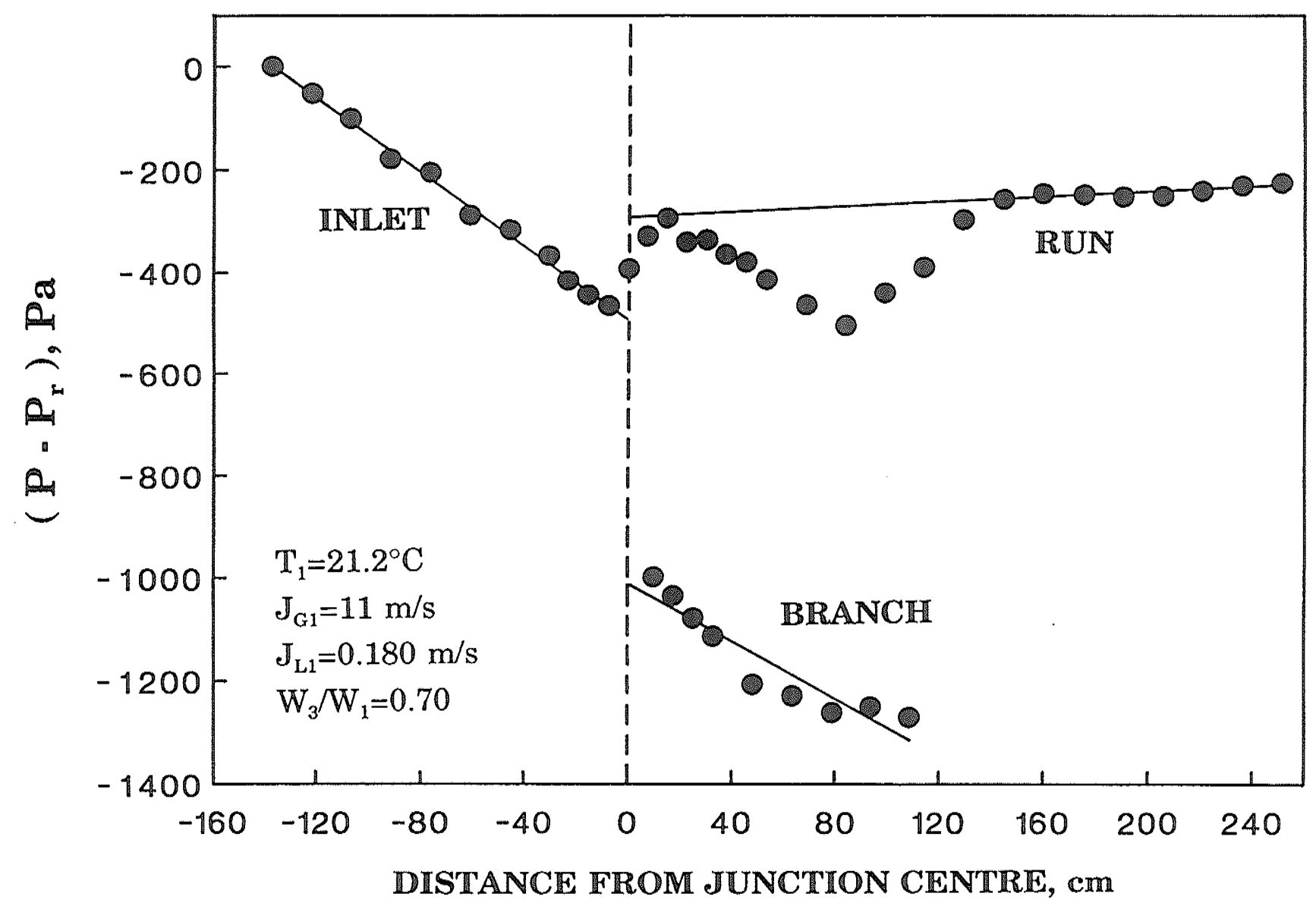

Figure D.3 Pressure distribution for test $4-4$ 


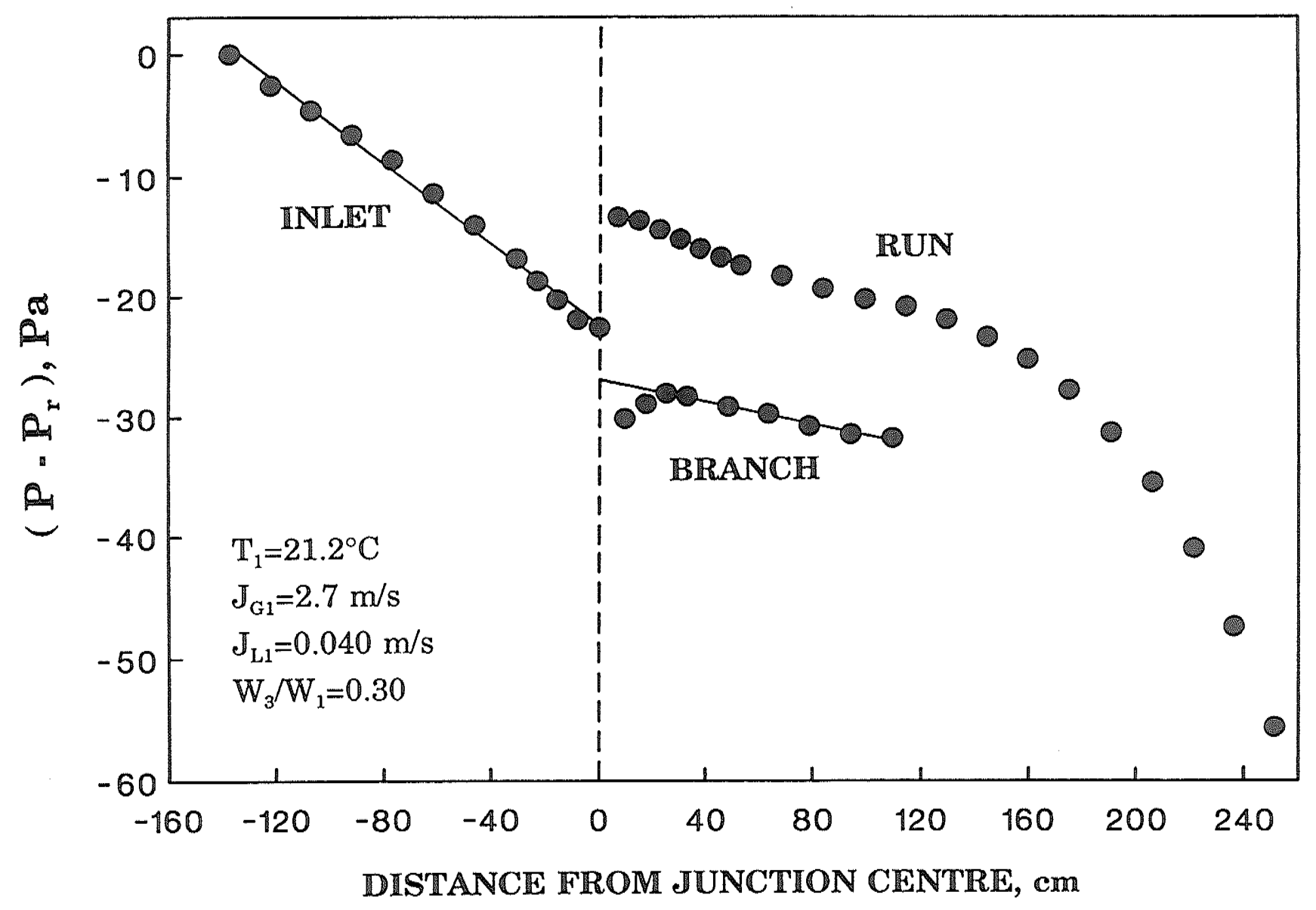

Figure D.4 Pressure distribution for test 3-2 
Values of $\Delta \mathrm{P}_{12}$ and $\Delta \mathrm{P}_{13}$ could not be obtained for tests 8-1 through 10-5 since, at low $J_{\mathrm{G} 1}$ and $J_{\mathrm{L} 1}$, the pressure gradients and pressure drops were too small to be measured accurately. The pressure drops $\Delta \mathrm{P}_{12}$ and $\Delta \mathrm{P}_{13}$ were also not obtained for tests $6-1$ and $6-2$ due to scatter of the data in the inlet, run, and branch. These two tests corresponded to an inlet flow regime of slug flow. In general, slug flow resulted in more scatter in the inlet, run, and branch pressure-distribution data compared with other flow regimes. This was shown previously in figure 4.24. For tests $6-1$ and $6-2$, the scatter in the data was too large to allow for accurate estimates of $\Delta \mathrm{P}_{12}$ and $\Delta \mathrm{P}_{13}$.

Finally, $\Delta \mathrm{P}_{13}$ was not obtained for test $15-4$. For this test, $\Delta \mathrm{P}_{13}$ was too large to be measured by the present pressure transducers. 


\section{Appendix E}

\section{ESTIMATES OF EXPERIMENTAL UNCERTAINTY}

This appendix deals with an analysis of the experimental errors in both measured quantities and calculated results. As well, a brief discussion of experimental repeatability is given. Three sections are presented:

E.1 Experimental Uncertainty in the Pressure-Drop Data

E.2 Experimental Uncertainty in the Phase-Distribution Data

E.3 Experimental Repeatability.

The method of analysis proceeds according to the method of Kline and McClintock [E.1]. These authors defined the term "uncertainty" as a possible value the "error" might have, where the error is the difference between the true value and the observed value for a single observation. If a "result" $\mathbf{R}$ is a function of variables $\mathbf{V}_{1}, \mathbf{V}_{2}, \ldots, \mathbf{V}_{n}$, then the uncertainty interval $\delta \mathbf{R}$ in the result can be obtained from

$$
\delta \boldsymbol{R}=\left\{\left(\frac{\partial R}{\partial V_{1}} \delta V_{1}\right)^{2}+\left(\frac{\partial R}{\partial V_{2}} \delta V_{2}\right)^{2}+\ldots+\left(\frac{\partial R}{\partial V_{n}} \delta V_{n}\right)^{2}\right\}^{1 / 2},
$$

where $\delta \mathbf{V}_{1}, \delta \mathbf{V}_{2}, \ldots, \delta \mathbf{V}_{\mathrm{n}}$ are the uncertainty intervals in the variables $\mathbf{V}_{1}$, $\mathbf{V}_{2}, \ldots, \mathbf{V}_{n}$. For the variable $\mathbf{V}_{i}(i=1,2, . ., n)$, the uncertainty interval $\delta \mathbf{V}_{i}$ must be calculated or estimated based on specific odds. The "odds" are the odds that the experimenter is willing to wager that any given reading lies within $\pm \delta \mathbf{V}_{\mathrm{i}}$ of the true value. In the present analysis, the uncertainty interval in each variable is quoted at odds of approximately 20 to 1 . Application of equation 
(E.1) gives odds for the uncertainty interval $\delta \mathbf{R}$ equal to the odds for the $\delta \mathbf{V}_{i}^{\prime}$ s of the individual $V_{i}$ 's.

\section{E.1 Experimental Uncertainty in the Pressure-Drop Data}

Appendix B gave the procedure for the calculation of the extrapolated pressures $\mathrm{P}_{1}, \mathrm{P}_{2}$, and $\mathrm{P}_{3}$. The pressure drops due to the tee junction were calculated using equation (3.12). Applying equation (E.1), the uncertainty intervals for $\Delta \mathrm{P}_{12}$ and $\Delta \mathrm{P}_{13}$ are given by

$$
8\left(\Delta P_{1 i}\right)=\left\{8 P_{1}^{2}+8 P_{i}^{2}\right\}^{1 / 2}, i=2,3
$$

\section{Calculation of $\delta \mathbf{P}_{i}$}

Considering the run, the pressure at each pressure tap was obtained using the calibration equation for the appropriate pressure transducer, that is,

$$
\Delta P_{1-i}=K \cdot V_{i},
$$

where $\mathrm{i}=12$ to $32, \mathrm{~V}_{\mathrm{i}}$ is the average voltage from the transducer corresponding to tap $i$, and $\mathbb{K}$ is the coefficient found from the calibration of the transducer. Each of the six differential pressure transducers were calibrated individually to give values of $\mathbf{K}$. The parameter $\Delta \mathrm{P}_{1 \cdot \mathrm{j}}$ was defined in Appendix $\mathrm{B}$ as the 
pressure difference between tap 1 in the inlet and tap $i$ in the run. These tap numbers were shown previously in figure 3.7.

The regression line for the run is calculated as described in Appendix B. In this appendix, the uncertainty in the extrapolated pressure $P_{2}$ was calculated using equation [B.4], namely

$$
\left(8 P_{2}\right)_{0}=\frac{t_{0.95} s \sqrt{\sum_{j=1}^{n} z_{j}^{2}}}{\sqrt{n S_{z z}}},
$$

where $\mathrm{S}_{z \mathrm{z}}$ is given by equation (B.5). The parameter $\left(\delta \mathrm{P}_{2}\right)_{0}$ represents the uncertainty in $\mathrm{P}_{2}$ due to the scatter of the run pressure-distribution data about the regression line. The uncertainty in $\mathrm{P}_{2}$ is further increased by the uncertainty in the calibration of the pressure transducer used in obtaining the run pressure-distribution data. The uncertainty in $\mathrm{P}_{2}$ due to the uncertainty in the pressure transducer calibration can be shown to be given by

$$
\left(8 P_{2}\right)_{T}=P_{2}\left(\frac{8 K}{K}\right) \text {. }
$$

In other words, the relative uncertainty in $\mathrm{P}_{2}$ due to the uncertainty in the transducer calibration $\left(\left(\delta \mathrm{P}_{2}\right)_{\mathrm{T}} / \mathrm{P}_{2}\right)$ is equal to the relative uncertainty in the transducer calibration $(\delta \mathbf{K} / \mathbf{K})$. The uncertainty interval for $\mathrm{P}_{2}$ is the root-sumsquare of $\left(\delta \mathrm{P}_{2}\right)_{0}$ and $\left(\delta \mathrm{P}_{2}\right)_{\mathrm{T}}$; thus,

$$
8 P_{2}=\left\{P_{2}^{2}\left(\frac{8 K}{R}\right)^{2}+\left(8 P_{2}\right)_{0}^{2112} .\right.
$$

The uncertainty given by equation (E.4) dominates the uncertainty in the extrapolated pressure $\mathrm{P}_{2}$. 
For a particular test run, the uncertainty in $\mathbf{K}$ is a fixed error. The value of $\delta \mathbf{K} / \mathbf{K}$ can be estimated from the calibration of the appropriate pressure transducer. For the present analysis, $\delta \mathbf{K} / \mathbf{K}$ was estimated to be 0.02 , for all six Validyne pressure transducers. This value includes any errors due to the calibration of the transducer, as well as any errors due to drifting of the calibration (changes in $\mathbf{K}$ ) over long periods of time.

The procedure used to obtain $\delta \mathrm{P}_{3}$ is similar to the above procedure for $\delta \mathrm{P}_{1}$, and will not be shown here.

Appendix $B$ also gives the procedure for calculating $P_{1}$. This procedure is nearly identical to that used to obtain $\mathrm{P}_{2}$ and $\mathrm{P}_{3}$. However, an additional step given by equations (B.8) and (B.9) was required in order to obtain the inlet pressure distribution relative to tap 1 . This additional step resulted in a greater uncertainty in $\mathrm{P}_{1}$, due to the uncertainty in the values of $\Delta \mathrm{P}_{1-32}$ and $\Delta \mathrm{P}_{1-33}$. The uncertainty in $\mathrm{P}_{1}$ can be shown to be given by

$$
8 P_{1}=\left\{8\left(\Delta P_{1-i}\right)^{2}+\left(8 P_{1}\right)_{1}^{2}\right\}^{1 / 2},
$$

where $i=32$ or 33 , and $\left(\delta P_{1}\right)_{1}$ is given by

$$
\left(\delta P_{1}\right)_{1}=\left\{P_{1}^{2}\left(\frac{\delta K}{K}\right)^{2}+\left(\delta P_{1}\right)_{0}^{2}\right\} 1 / 2 .
$$

The value of $\left(\delta \mathrm{P}_{1}\right)_{0}$ can be estimated using equation (B.4).

For test runs, $\Delta \mathrm{P}_{1-32}$ and $\Delta \mathrm{P}_{1-33}$ were average values obtained from the sampling of a particular pressure transducer. For the calculation of average values, 12000 samples were taken. The uncertainty $\delta\left(\Delta \mathrm{P}_{1-32}\right)$ can be found by 
applying equation (E.1) to equation (E.3), thus

$$
8\left(\Delta P_{1-32}\right)=\left\{V^{2} 8 K^{2}+\mathbb{K}^{2} 8 V^{2}\right\}^{1 / 2},
$$

where $\mathrm{V}$ is the average voltage. The value of $\mathbf{K}$ varies depending on which pressure transducer was used. The uncertainty in the average voltage $\mathrm{V}$ is found using [E.2]

$$
8 V=\frac{t_{0.95} s_{V}}{\sqrt{M}},
$$

where $s_{v}$ is the standard deviation of the measured voltages, and $M=12000$. $\delta\left(\Delta \mathrm{P}_{1-33}\right)$ can be found in a similar manner.

Typically, $\delta\left(\Delta \mathrm{P}_{1-32}\right)$ and $\delta\left(\Delta \mathrm{P}_{1-33}\right)$ were small and therefore, contributed little to the uncertainty in $P_{1}$. This was a consequence of the large number of samples used in calculating the average.

\section{Results}

The relative uncertainty intervals for $\Delta \mathrm{P}_{12}$ and $\Delta \mathrm{P}_{13}$ are given in Table E.1 for both the two-phase flow tests and the single-phase flow tests. The test numbers shown in the table correspond to those given in Appendix C. In general, the uncertainties in $\Delta \mathrm{P}_{12}$ were smaller than those for $\Delta \mathrm{P}_{13}$. For the two-phase $\Delta \mathrm{P}_{12}$ data, $94 \%$ of the data had relative uncertainties less than $\pm 17 \%$. For the two-phase $\Delta \mathrm{P}_{13}$ data, $76 \%$ of the data had relative uncertainties less than $\pm 30 \%$. These figures for $\Delta \mathrm{P}_{13}$ do not include tests $3-1,7-3$, and 14-2 where the value of $\Delta \mathrm{P}_{13}$ was 0,1 , and $0 \mathrm{~Pa}$, respectively. At these extremely 
Table E.1

Uncertainty Intervals for Reduced Data

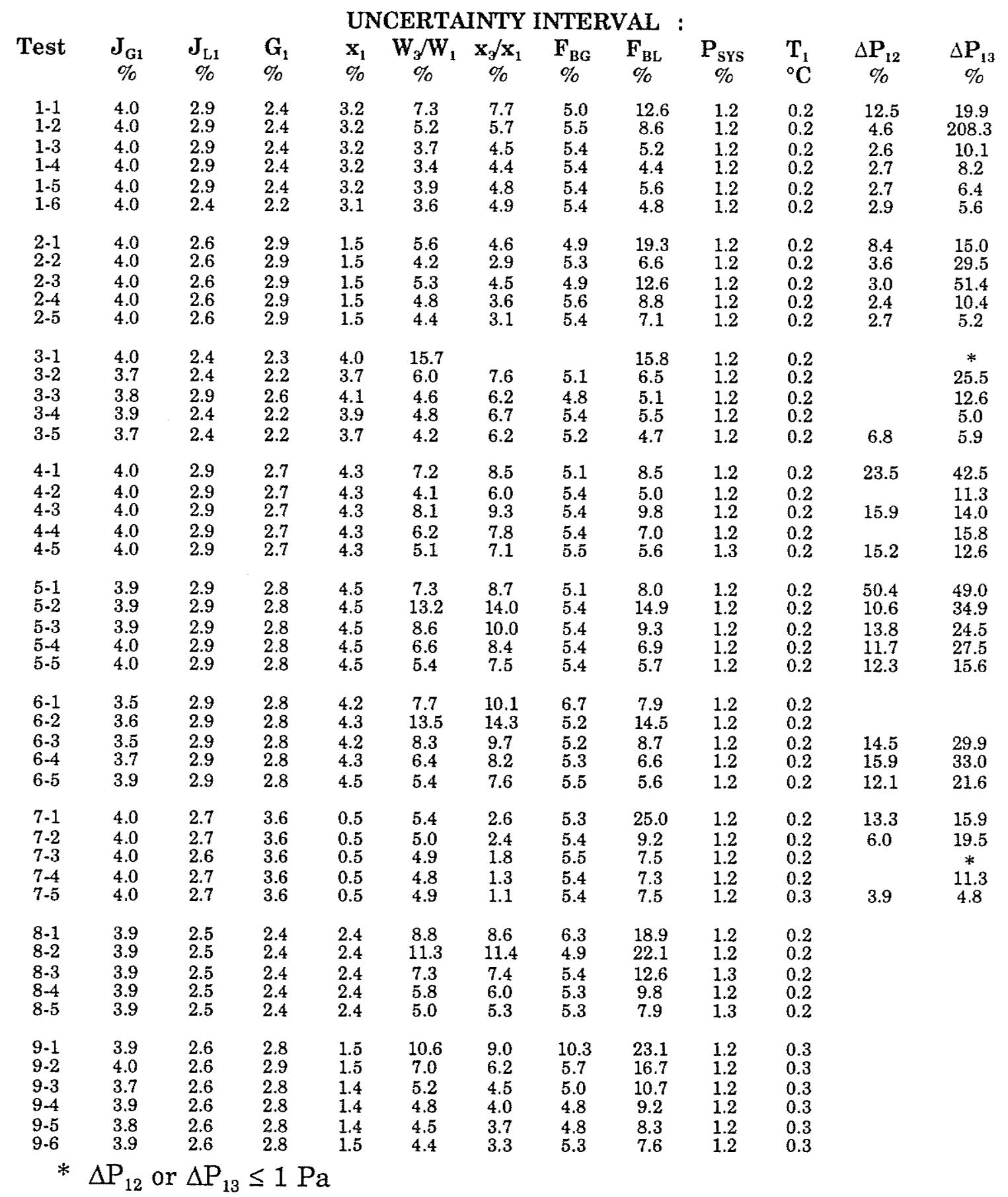


Table E.1 (continued)

\begin{tabular}{|c|c|c|c|c|c|c|c|c|c|c|c|c|}
\hline & & & & & CERTA & INTY & NTEI & $7 \mathrm{AL}$ & & & & \\
\hline Test & $\begin{array}{c}\boldsymbol{J}_{\mathrm{G} 1} \\
\%\end{array}$ & $\underset{\%}{\mathbf{J}_{\mathrm{L1}}}$ & $\begin{array}{l}\mathbf{G}_{\mathbf{1}} \\
\%\end{array}$ & $\begin{array}{l}\mathbf{x}_{1} \\
\%\end{array}$ & $\underset{\%}{\mathbf{W}_{\mathfrak{3}} / \mathbf{W}_{1}}$ & $\begin{array}{c}\mathbf{x}_{3} / \mathbf{x}_{1} \\
\%\end{array}$ & $\begin{array}{c}\mathbf{F}_{\mathrm{BG}} \\
\%\end{array}$ & $\underset{\%}{\mathbf{F}_{\mathrm{BL}}}$ & $\mathbf{P}_{\text {SYS }}$ & $\begin{array}{l}\mathrm{T}_{1} \\
{ }^{\circ} \mathrm{C}\end{array}$ & $\begin{array}{c}\Delta \mathbf{P}_{12} \\
\%\end{array}$ & $\underset{\%}{\Delta \mathbf{P}_{13}}$ \\
\hline $\begin{array}{l}10-1 \\
10-2\end{array}$ & $\begin{array}{l}4.0 \\
4.0\end{array}$ & $\begin{array}{l}2.9 \\
2.5\end{array}$ & $\begin{array}{l}2.4 \\
2.3\end{array}$ & $\begin{array}{l}3.2 \\
3.0\end{array}$ & $\begin{array}{c}10.8 \\
5.0\end{array}$ & $\begin{array}{l}15.7 \\
6.0\end{array}$ & $\begin{array}{c}14.9 \\
5.6\end{array}$ & $\begin{array}{c}13.0 \\
7.1\end{array}$ & $\begin{array}{l}1.2 \\
1.2\end{array}$ & $\begin{array}{l}0.2 \\
0.2\end{array}$ & & \\
\hline $10-3$ & 4.0 & 2.5 & 2.3 & 3.0 & 8.8 & 9.2 & 4.9 & 13.5 & 1.2 & 0.2 & & \\
\hline $\begin{array}{l}10-4 \\
10-5\end{array}$ & $\begin{array}{l}4.1 \\
4.0\end{array}$ & $\begin{array}{l}2.5 \\
2.5\end{array}$ & $\begin{array}{l}2.3 \\
2.3\end{array}$ & $\begin{array}{l}3.1 \\
3.0\end{array}$ & $\begin{array}{l}6.6 \\
5.6\end{array}$ & $\begin{array}{l}7.2 \\
6.4\end{array}$ & $\begin{array}{l}5.1 \\
5.5\end{array}$ & $\begin{array}{l}9.3 \\
8.2\end{array}$ & $\begin{array}{l}1.2 \\
1.2\end{array}$ & $\begin{array}{l}0.2 \\
0.2\end{array}$ & & \\
\hline $11-1$ & 4.0 & 2.5 & 3.2 & 1.1 & 5.0 & 3.7 & 5.0 & 10.7 & 1.2 & 0.2 & 14.5 & 29.5 \\
\hline $11-2$ & 4.0 & 2.5 & 3.2 & 1.0 & 6.2 & 5.0 & 5.3 & 17.1 & 1.2 & 0.2 & 4.6 & 22.2 \\
\hline $11-3$ & 4.0 & 2.5 & 3.2 & 1.0 & 5.0 & 3.2 & 5.4 & 11.0 & 1.2 & 0.2 & 3.1 & 34.3 \\
\hline $11-4$ & 4.0 & 2.5 & 3.2 & 1.0 & 4.7 & 2.5 & 5.4 & 8.9 & 1.2 & 0.2 & 2.7 & 9.0 \\
\hline $11-5$ & 4.0 & 2.5 & $3 . \overline{2}$ & 1.0 & 4.4 & 2.2 & 5.3 & 7.1 & 1.2 & 0.2 & 2.9 & 5.5 \\
\hline $12-1$ & 3.9 & 3.7 & 3.8 & 0.1 & 5.2 & 1.7 & 5.3 & 12.9 & 1.2 & 0.2 & 7.6 & 23.5 \\
\hline $12 \cdot 2$ & 3.9 & 3.5 & 3.8 & 0.1 & 5.1 & 0.8 & 5.4 & 8.7 & 1.2 & 0.2 & 6.5 & 25.6 \\
\hline $12 \cdot 3$ & 3.9 & 3.9 & 3.8 & 0.1 & 4.2 & 0.4 & 4.4 & 8.9 & 1.2 & 0.1 & 4.7 & 37.8 \\
\hline $12-4$ & 3.9 & 3.6 & 3.8 & 0.1 & 5.3 & 0.4 & 5.4 & 8.6 & 1.2 & 0.2 & 2.9 & 7.1 \\
\hline 12.5 & 3.9 & 3.6 & 3.8 & $0 . \overline{1}$ & 5.3 & 0.3 & 5.4 & 8.8 & 1.2 & 0.2 & 2.4 & 4.0 \\
\hline $\begin{array}{l}13-1 \\
13-2\end{array}$ & $\begin{array}{l}4.0 \\
3.9\end{array}$ & 2.6 & 3.5 & 0.5 & 8.3 & 7.5 & 5.3 & 19.6 & 1.2 & 0.2 & 12.6 & $\begin{array}{l}43.8 \\
373\end{array}$ \\
\hline 13.3 & 3.9 & 2.6 & 3.5 & 0.5 & 4.1 & 1.7 & 4.4 & 8.0 & 12 & 0.2 & $\begin{array}{l}4.4 \\
3.2\end{array}$ & 39.7 \\
\hline $13-4$ & 3.9 & 2.6 & 3.5 & 0.5 & 4.8 & 1.4 & 5.5 & 7.3 & 1.2 & 0.2 & $\begin{array}{l}3.0 \\
3.0\end{array}$ & 8.1 \\
\hline $13-5$ & 3.9 & 2.6 & 3.5 & 0.5 & 4.9 & 1.1 & 5.5 & 7.2 & 1.2 & 0.2 & 3.2 & 4.5 \\
\hline $14-1$ & 3.7 & 2.5 & 2.6 & 1.5 & 7.0 & 7.1 & 5.0 & 9.8 & 1.2 & 0.1 & 21.5 & 66.4 \\
\hline $14-2$ & 3.7 & 2.6 & 2.6 & 1.5 & 4.1 & 3.1 & 5.2 & 6.3 & 1.3 & 0.2 & 5.7 & * \\
\hline $14-3$ & 3.9 & 2.4 & 2.8 & 1.6 & 3.6 & 2.4 & 4.9 & 5.2 & 1.2 & 0.1 & 3.8 & 16.3 \\
\hline $14-4$ & 3.9 & 2.4 & 2.8 & 1.6 & 3.9 & 2.3 & 5.4 & 4.4 & 1.2 & 0.1 & 3.6 & 6.9 \\
\hline $14-5$ & 3.9 & 2.4 & 2.8 & 1.6 & 3.9 & 2.2 & 5.4 & 4.4 & 1.2 & 0.1 & 3.9 & 4.5 \\
\hline $15-1$ & 3.7 & 2.9 & 2.4 & 3.1 & 5.7 & 6.6 & 5.2 & 7.7 & 1.2 & 0.2 & 16.1 & 133.0 \\
\hline $15-2$ & 3.7 & 2.9 & 2.4 & 3.2 & 3.6 & 4.3 & 4.7 & 5.4 & 1.2 & 0.2 & 3.8 & 16.3 \\
\hline $15-3$ & 3.9 & 2.9 & 2.4 & 3.3 & 7.5 & 8.0 & 5.9 & 13.7 & 1.2 & 0.2 & 3.0 & 5.5 \\
\hline $15 \cdot 4$ & 3.9 & 2.9 & 2.4 & 3.4 & 5.6 & 6.3 & 5.4 & 8.6 & 1.2 & 0.2 & 4.2 & \\
\hline S-1 & & & & & & & & & & & * & * \\
\hline S-2 & & & & & & & & & & & 19.4 & * \\
\hline $\mathrm{S}-\overline{3}$ & & & & & & & & & & & 7.3 & \\
\hline S.4 & & & & & & & & & & & 5.2 & 42.7 \\
\hline S-5 & & & & & & & & & & & 5.4 & 19 \\
\hline S-6 & & & & & & & & & & & 5 & 8.6 \\
\hline S-7 & & & & & & & & & & & 8.8 & 7.5 \\
\hline
\end{tabular}


small values, the relative uncertainty would be expected to be very large. Values of $\Delta \mathrm{P}_{12}$ and $\Delta \mathrm{P}_{13}$ were not obtained for all tests for reasons discussed in Appendix D. As a result, uncertainties are not given for test runs in which the values of $\Delta \mathrm{P}_{12}$ and/or $\Delta \mathrm{P}_{13}$ were not obtained. Slug flow generally resulted in larger uncertainties due to the increased scatter of the pressure-distribution data.

Similar comments can be made concerning the relative uncertainties in the single-phase pressure-drop data. For $\Delta \mathrm{P}_{12}$, six single-phase tests had relative uncertainties less than $\pm 20 \%$. Only test $\mathrm{S}-1$ had a relative uncertainty greater than $\pm 20 \%$; however, for this test the value of $\Delta \mathrm{P}_{12}$ was only $0.3 \mathrm{~Pa}$. For $\Delta \mathrm{P}_{13}$, four single-phase tests had relative uncertainties less than $\pm 43 \%$. Tests S-1, S-2, and S-3 had values of $\Delta \mathrm{P}_{13}$ equal to $-0.7,-0.9$, and $-0.4 \mathrm{~Pa}$, respectively. Again, at these extremely small values, the relative uncertainty would be expected to be very large. Considering both $\Delta \mathrm{P}_{12}$ and $\Delta \mathrm{P}_{13}$, the absolute uncertainties were within $\pm 1.3 \mathrm{~Pa}$ for all single-phase tests.

\section{E.2 Experimental Uncertainty in the Phase-Distribution Data}

The main results of the error analysis on the phase-distribution data are given in Table E.1. The uncertainty intervals for the following variables were calculated with the application of equation (E.1): $\mathrm{J}_{\mathrm{G} 1}, \mathrm{~J}_{\mathrm{L} 1}, \mathrm{G}_{1}, \mathrm{x}_{1}, \mathrm{x}_{3} / \mathrm{x}_{1}, \mathrm{~F}_{\mathrm{BG}}, \mathrm{F}_{\mathrm{BL}}$, and $\mathrm{W}_{3} / \mathrm{W}_{1}$. For example, the uncertainty interval for $\mathrm{J}_{\mathrm{G} 1}$ is given by 


$$
\delta\left(J_{G I}\right)=\left\{\frac{1}{\rho_{G I}^{2} A^{2}} \delta W_{G I}^{2}+\frac{W_{G I}^{2}}{A^{2} \rho_{G I}^{2}}\left(\frac{\delta \rho_{G I}}{\rho_{G I}}\right)^{2}+\frac{W_{G I}^{2}}{\rho_{G I}^{2} A^{2}}\left(\frac{8 A}{A}\right)^{2}\right\} 1 / 2 .
$$

This equation was found by applying equation (E.1) to equation (3.8). Thus, a method is required in order to calculate the uncertainty intervals for the test section mass flow rates and densities. The uncertainty in the diameter of the test section tube was assumed to be $\pm 1 \%$. This corresponds to $\pm 0.4 \mathrm{~mm}$.

Appendix A outlined the procedure for the calculation of test section mass flow rates and temperature. Test-section flow rates were calculated using the measured mass flow rates, temperatures, and pressures by taking into account evaporation within the mixer, test section, and separation tanks. A computer program was written to facilitate the reduction of the measured data. Due to the complexity of the data reduction procedure, the differentials given in equation (E.1) were difficult or impossible to calculate. Therefore, a computer-executed uncertainty analysis was undertaken. The method used here was presented by Moffat [E.2]. The computer-executed uncertainty analysis was accomplished by sequentially perturbing the input variables and accumulating the individual uncertainty contributions. Thus, the data reduction program itself was used to generate the uncertainty analysis. The details of the procedure will be described as required. Much of the terminology used in the following discussion was defined in Appendix A.

The data reduction program was divided into five parts:

1. Calculation of $\mathrm{W}_{\mathrm{L} 1 \mathrm{M}}$. 
2. Calculation of $\mathrm{W}_{\mathrm{GIM}}$.

3. Calculation of inlet flow rates and temperature.

4. Calculation of run flow rates.

5. Calculation of branch flow rates.

Thus, the computer-executed uncertainty analysis proceeds in a similar manner. The procedure for estimating the errors in the branch flow rates is identical to the procedure for the run. Thus, it is not explained here.

\section{Uncertainty in $W_{\text {LIM }}$}

The liquid flow rate entering the two-phase mixer was measured by a turbine meter. The calibration curve for the low-range water turbine meter (model FTO-4C1YW-LHC-1) is given in figure E.1. The calibration curve consists of $\mathrm{K}^{*}$ versus the Reynolds number of the flow through the turbine meter. The parameter $\mathrm{K}^{*}$ is defined as the average voltage output from the flow meter divided by the volume flow rate through the flow meter. The calibration can be expressed as $\mathrm{K}^{*}=\mathrm{fnc}(\mathrm{Re})$. The uncertainty in the calibration curve was estimated to be $\delta \mathrm{K}^{*}= \pm 0.762 \mathrm{Volts} /\left(\mathrm{m}^{3} / \mathrm{s}\right)$, for the entire range of Re. This value corresponds to approximately $\pm 2.3 \%$ of the full-scale value of $\mathrm{K}^{*}$. Similarly, for the high-range water turbine meter, $\delta \mathrm{K}^{*} / \mathrm{K}^{*}$ was estimated to be $\pm 0.247 \mathrm{Volts} /\left(\mathrm{m}^{3} / \mathrm{s}\right)$. This corresponds to approximately $\pm 2.8 \%$ of the full-scale value of $\mathrm{K}^{*}$. 


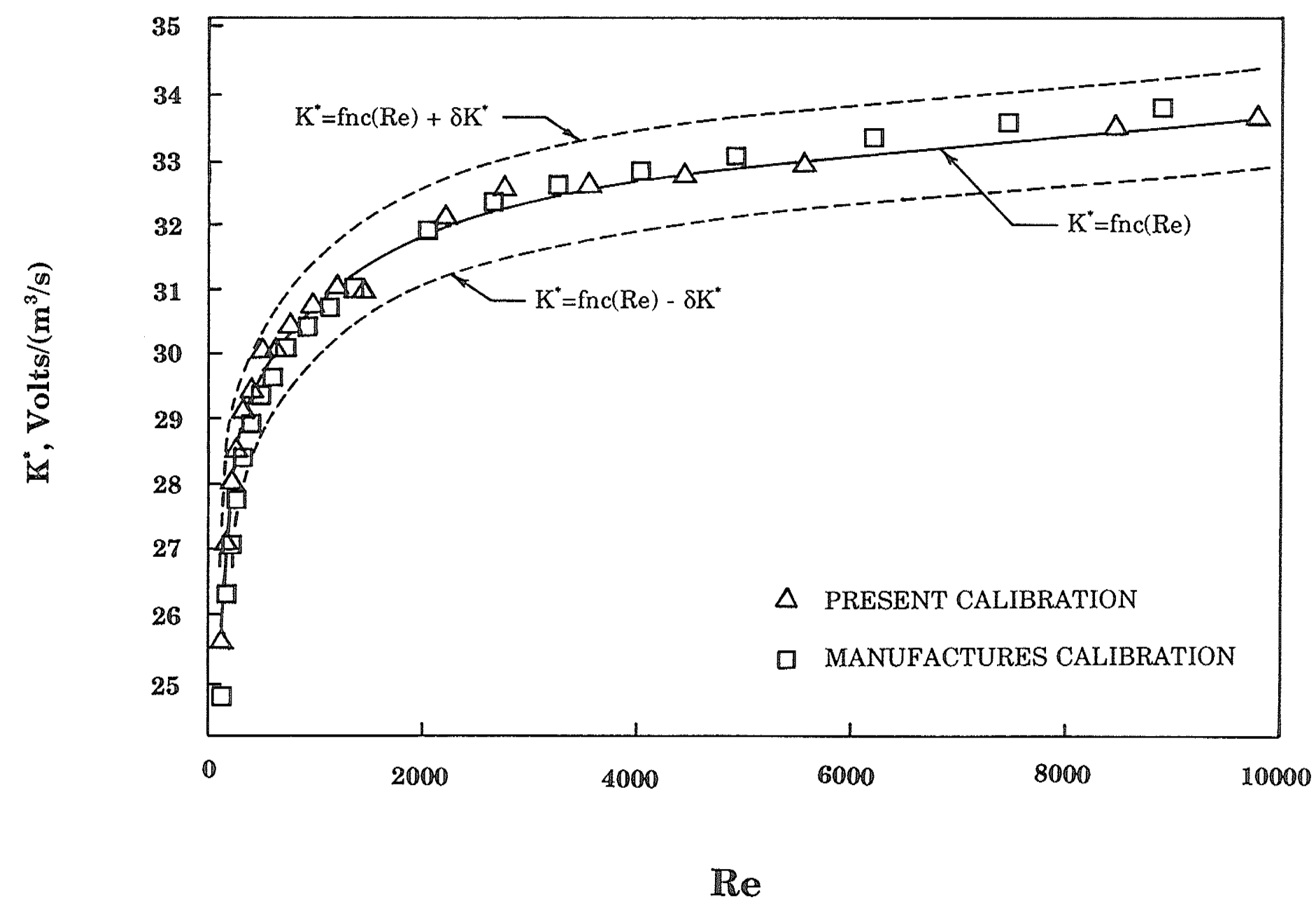

Figure E.1 Calibration of low-range water turbine meter 
During experimental test runs, the voltage output from the turbine meter was sampled for 30 seconds at a rate of 10 samples per second, and then the average voltage was calculated. The uncertainty interval for the average voltage is given by equation (E.10) with $\mathrm{M}=300$.

The temperature of the flow through the turbine meter $\mathrm{T}_{\mathrm{L} 1 \mathrm{M}}$ was measured using an iron-constantan thermocouple connected to the digital thermometer. Calibration of the thermocouples and digital thermometer indicated a maximum error of less than $\pm 0.1^{\circ} \mathrm{C}$. Therefore, $\delta\left(\mathrm{T}_{\mathrm{LIM}}\right)$ was taken to be $\pm 0.1^{\circ} \mathrm{C}$.

Figure E.2(a) summarizes the variables required in order to calculate $\delta\left(\mathrm{W}_{\mathrm{LIM}}\right)$ and figure E.2(b) illustrates the procedure for the calculation of $\delta\left(\mathrm{W}_{\mathrm{L} 1 \mathrm{M}}\right)$. Values of $\mathrm{T}_{\mathrm{LIM}}, \mathrm{V}$, and $\mathrm{K}^{*}=\mathrm{fnc}(\mathrm{Re})$ were perturbed sequentially by their corresponding uncertainty intervals, and their contributions to the uncertainty in $\mathrm{W}_{\mathrm{L} 1 \mathrm{M}}$ were recorded. In detail, the procedure is as follows:

1. $\mathrm{W}_{\mathrm{L} 1 \mathrm{M}}$ was calculated using the measured (nominal) values of $\mathrm{T}_{\mathrm{L} 1 \mathrm{M}}$ and $\mathrm{V}$, and the calibration curve given by $\mathrm{K}^{*}=\mathrm{fnc}(\mathrm{Re})$.

2. The value of $\mathrm{T}_{\mathrm{L} 1 \mathrm{M}}$ was perturbed by $0.1^{\circ} \mathrm{C} . \mathrm{W}_{\mathrm{L} 1 \mathrm{M}}$ was re-calculated with $\mathrm{V}$ and $K^{*}=f n c(R e)$ at their nominal values. The difference between the new value of $W_{L 1 M}$ and the nominal value is the contribution to the uncertainty of $\mathrm{W}_{\mathrm{L} 1 \mathrm{M}}$ caused by the uncertainty in $\mathrm{T}_{\mathrm{L} 1 \mathrm{M}}$.

3. The value of the average voltage $\mathrm{V}$ was perturbed by $\delta \mathrm{V}$, and $\mathrm{W}_{\mathrm{LIM}}$ was recalculated with $\mathrm{T}_{\mathrm{L} 1 \mathrm{M}}$ and $\mathrm{K}^{*}=\mathrm{fnc}(\mathrm{Re})$ at their nominal values. The difference between the new value of $\mathrm{W}_{\mathrm{L} 1 \mathrm{M}}$ and the nominal value is the contribution 


\section{INPUT}

OUTPUT

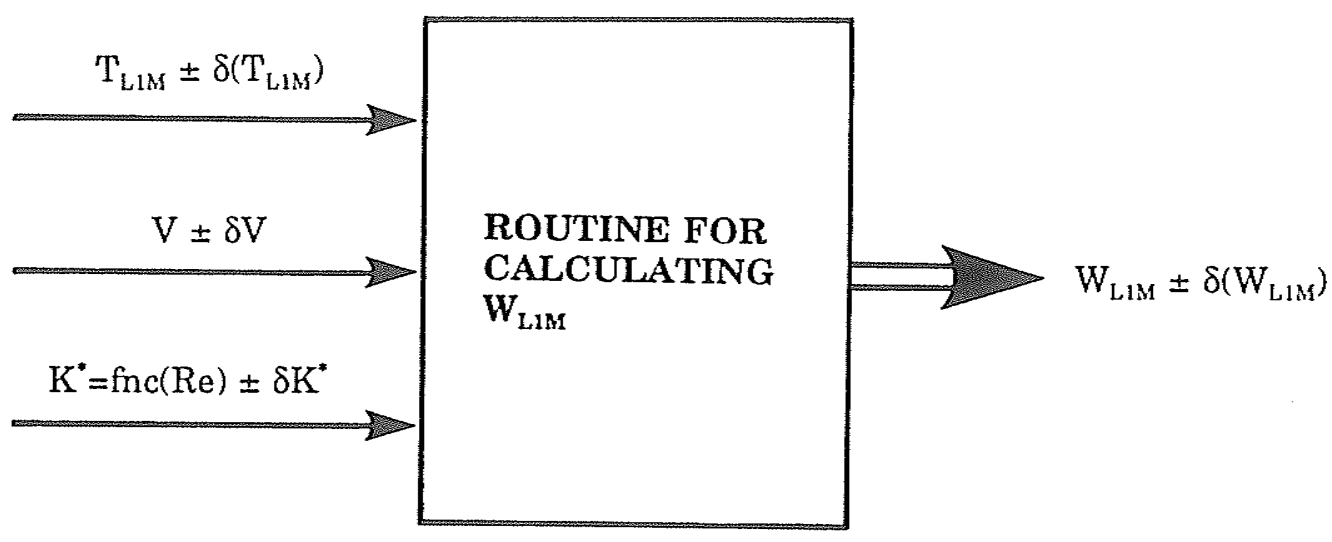

(a)

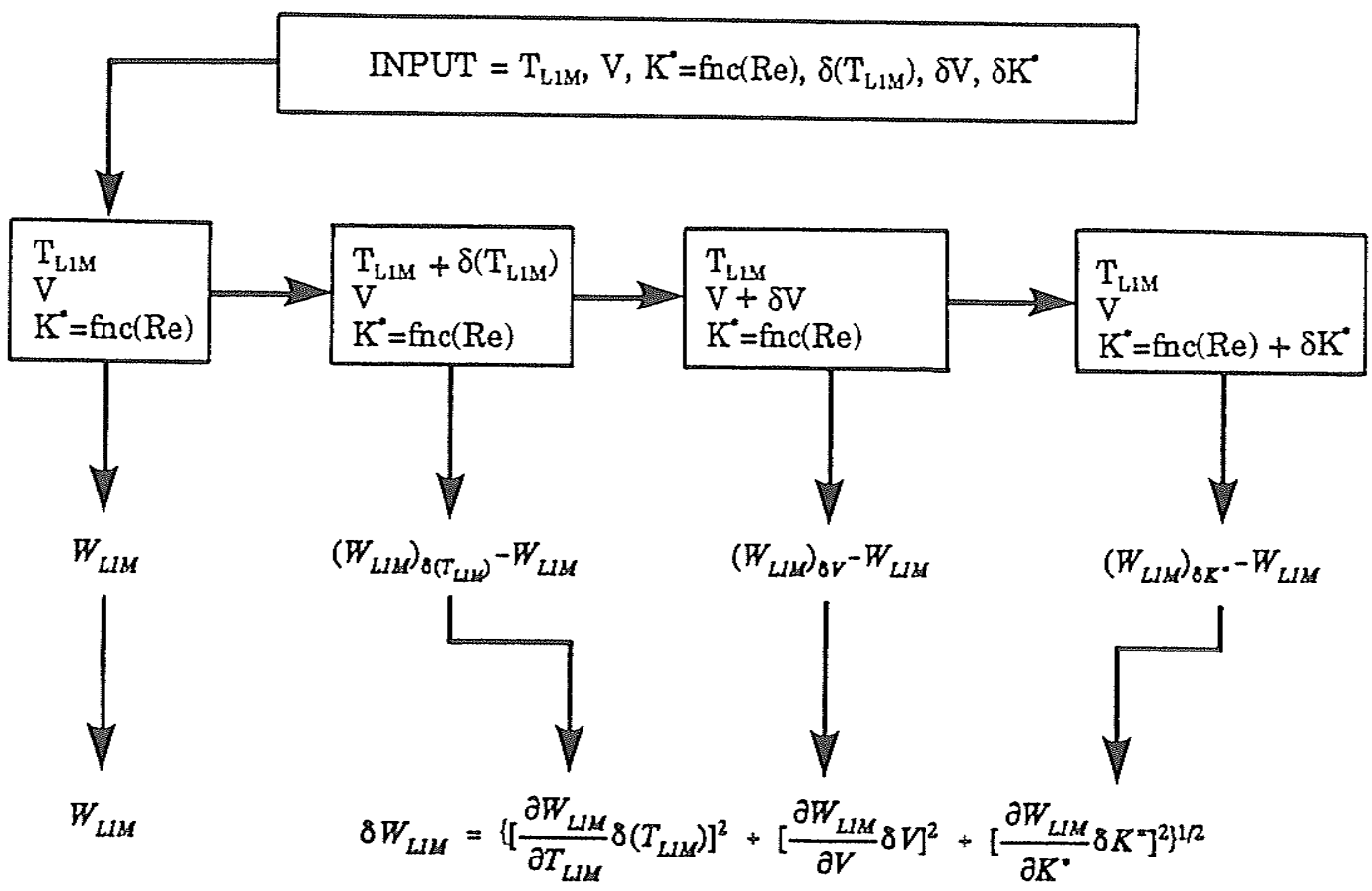

(b)

Figure E.2 Procedure for the calculation of $\delta\left(\mathrm{W}_{\mathrm{L} 1 \mathrm{M}}\right)$ 
to the uncertainty of $\mathrm{W}_{\mathrm{L} 1 \mathrm{M}}$ caused by the uncertainty in $\mathrm{V}$.

4. $\mathrm{W}_{\mathrm{L} 1 \mathrm{M}}$ was calculated with the nominal values of $\mathrm{T}_{\mathrm{LIM}}$ and $\mathrm{V}$, and the calibration curve shifted by $\delta \mathrm{K}^{*}$, that is, $\mathrm{K}^{*}=\mathrm{fn} \mathrm{c}(\mathrm{Re})+\delta \mathrm{K}^{*}$. The difference between the new value of $\mathrm{W}_{\mathrm{L} 1 \mathrm{M}}$ and the nominal value is the contribution to the uncertainty of $\mathrm{W}_{\mathrm{L} 1 \mathrm{M}}$ caused by the uncertainty in the turbine meter calibration.

5. $\delta\left(\mathrm{W}_{\mathrm{L} 1 \mathrm{M}}\right)$ was calculated as the root-sum-square of the individual uncertainty contributions.

It was found that the uncertainty in the average voltage and the uncertainty in $\mathrm{T}_{\mathrm{L} 1 \mathrm{M}}$ were negligible compared with the uncertainty in the calibration of the turbine meter.

\section{Uncertainty in $W_{G M}$}

The flow rate $\mathrm{W}_{\mathrm{G} 1 \mathrm{M}}$ was also measured using a turbine meter. Figure E.3 shows the variables which are required for the calculation of $\mathrm{W}_{\mathrm{G} 1 \mathrm{M}}$. The procedure for calculating $\delta\left(\mathrm{W}_{\mathrm{G} 1 \mathrm{M}}\right)$ is similar to the procedure for finding the uncertainty in $\mathrm{W}_{\mathrm{L} 1 \mathrm{M}}$. The input variables shown in figure $\mathrm{E} .3$ were perturbed sequentially and their contributions to the uncertainty in $\mathrm{W}_{\mathrm{GM}}$ recorded. Again, the uncertainty in the measured temperature $\mathrm{T}_{\mathrm{A} 1 \mathrm{M}}$ was taken to be $\pm 0.1^{\circ} \mathrm{C}$. The gauge pressure at the turbine meter $P_{1 M, G}$ was measured using a mercury manometer. The uncertainty $\delta\left(\mathrm{P}_{1 \mathrm{M}, \mathrm{G}}\right)$ was estimated conservatively to be $\pm 1 \mathrm{~cm}$ of mercury. This uncertainty was mainly due to oscillations of the 


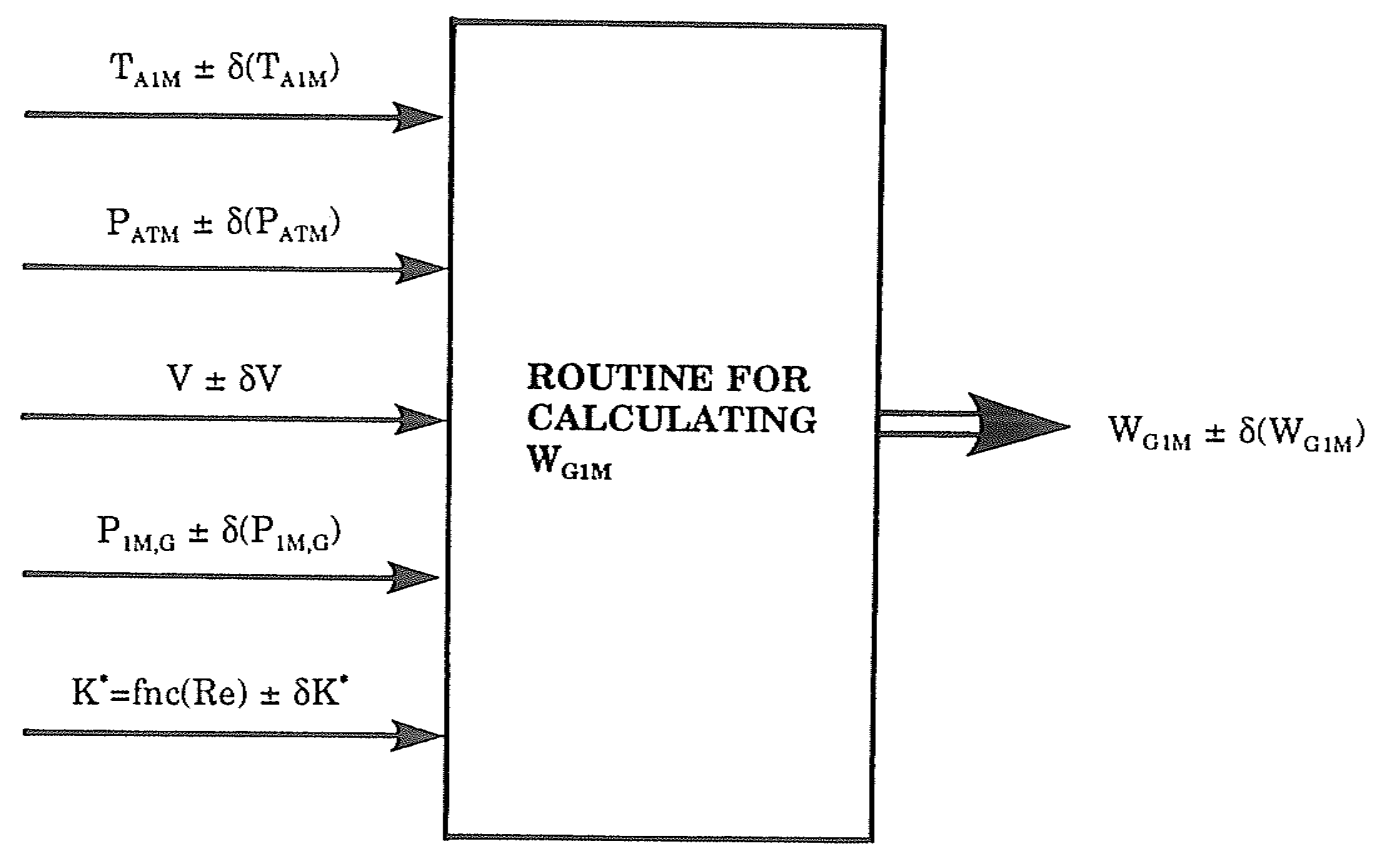

Figure E.3 Variables required for the calculation of $\delta\left(\mathrm{W}_{\mathrm{G} 1 \mathrm{M}}\right)$ 
mercury level in the manometer. For most tests, $\delta\left(\mathrm{P}_{1 \mathrm{M}, \mathrm{G}}\right)$ was much smaller than $\pm 1 \mathrm{~cm}$ of mercury. The ambient pressure in the laboratory $\mathrm{P}_{\mathrm{ATM}}$ was measured with a mercury barometer. The uncertainty $\delta\left(\mathrm{P}_{\mathrm{ATM}}\right)$ was given by the barometer manufacturer to be less than $\pm 1 \mathrm{~mm} \mathrm{Hg}$. Finally, $\delta \mathrm{K}^{*}$ was estimated to be \pm 0.002 volts $/\left(\mathrm{m}^{3} / \mathrm{s}\right)$, which corresponds to $\pm 3.5 \%$ of the full-scale value of $\mathrm{K}^{*}$ for the air turbine meter. Again, the uncertainty in the turbine meter calibration was found to be the most significant factor affecting the uncertainty in $\mathrm{W}_{\mathrm{G} 1 \mathrm{M}}$.

\section{Uncertainty in the Flow Rates and Temperature at the Tee Junction Inlet}

The procedure for calculating the mass flow rates and temperature at the tee junction inlet was described in Appendix A. The variables affecting the inlet flow conditions and their associated uncertainty intervals are shown in figure E.4. Again, the input variables were perturbed sequentially and their effect on the inlet conditions recorded. Values of $\delta\left(\mathrm{W}_{\mathrm{L} 1 \mathrm{M}}\right)$ and $\delta\left(\mathrm{W}_{\mathrm{L} 1 \mathrm{M}}\right)$ were calculated using the procedures described above. The temperatures $\mathrm{T}_{\mathrm{AM}}$ and $\mathrm{T}_{\mathrm{L} 1 \mathrm{M}}$ were perturbed by $0.1^{\circ} \mathrm{C}$. The value of $\mathbf{Q}_{1}$ was estimated using an empirical correlation. It was found that the value of $\mathbf{Q}_{1}$ had little effect on the calculation of the inlet flow rates and temperature. However, $\delta \mathbf{Q}_{1} / \mathbf{Q}_{1}$ was estimated to be \pm 0.5 , and was included in the error analysis. The gauge pressure at the tee junction $\mathrm{P}_{\mathrm{SYS}, \mathrm{G}}$ was measured using the Rosemount 


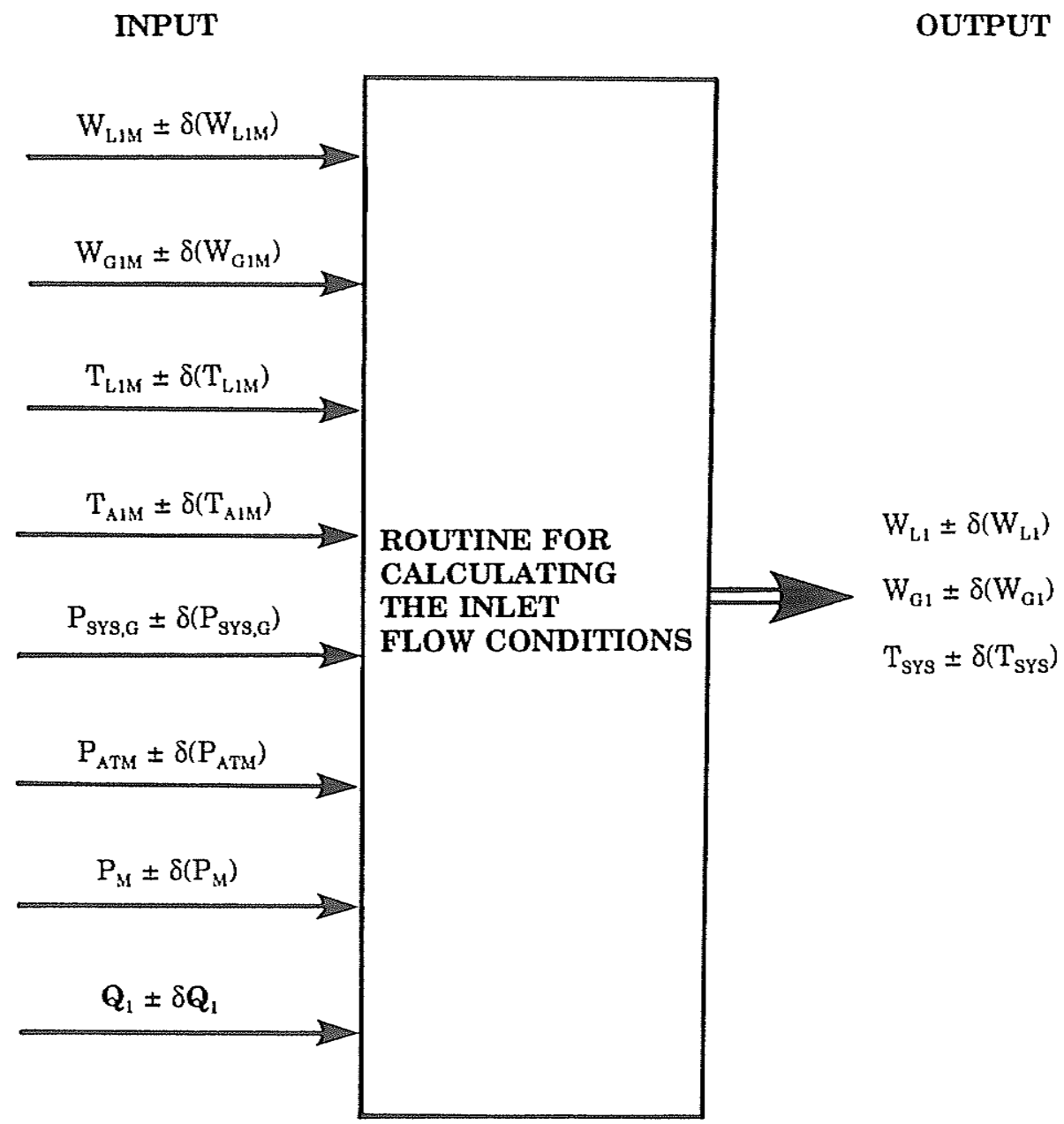

Figure E.4 Variables required for the calculation of inlet flow conditions 
pressure transducer. The calibration of this transducer was found to be near linear, and is given by

$$
P_{S Y S, G}=a+b V,
$$

where $a$ and $b$ are coefficients found from the calibration of the transducer, and $\mathrm{V}$ is the average voltage output from the transducer. Applying equation (E.1) to the above equation gives

$$
8 P_{S Y S, G}=\left\{8 a^{2}+V^{2} 8 b^{2}+b^{2} 8 V^{2}\right\}^{1 / 2} .
$$

From the calibration of the transducer, $\delta a / a$ and $\delta b / b$ were estimated to be $\pm 3.3 \%$ and $\pm 1.0 \%$, respectively. During experimental test runs, the voltage output from the transducer was sampled for 30 seconds at a rate of 10 samples per second. Thus, $\delta \mathrm{V}$ was found using equation (E.8) with $\mathrm{M}=300$. The uncertainty in the absolute pressure at the test section was found using

$$
8 P_{S Y S}=\left\{8 P_{S Y S, G}^{2}+8 P_{A T M}^{2}\right\}^{1 / 2},
$$

with $\delta \mathrm{P}_{\mathrm{ATM}}= \pm 1 \mathrm{~mm} \mathrm{Hg}$. Table $\mathrm{E} .1$ gives tabulated values of $\delta \mathrm{P}_{\mathrm{SYS}} / \mathrm{P}_{\mathrm{SYS}}$. Finally, the value of $\mathrm{P}_{M}$ was estimated by extrapolating the measured pressure distribution in the test section inlet to the mixer outlet. The uncertainty in $\mathrm{P}_{M}$ was estimated from the uncertainties in the regression line coefficients. For all tests, $\delta \mathrm{P}_{M}$ was found to be insignificant. 


\section{Uncertainty in the Run Flow Rates}

Figure E.5 shows the variables required in order to calculate the mass flow rates in the test section run. The gas flow rate exiting the separation tank was measured by either a turbine meter or a bank of rotameters. If the turbine meter was being used, then the procedure for estimating $\delta\left(\mathrm{W}_{\mathrm{G} 2 \mathrm{M}}\right)$ was similar to the procedure for estimating $\delta\left(\mathrm{W}_{\mathrm{G} 1 \mathrm{M}}\right)$. However, if the air rotameters were being used, then $\delta\left(\mathrm{W}_{\mathrm{G} 2 \mathrm{M}}\right)$ was estimated using the procedure described in the next paragraph.

The calibration equation for a particular rotameter is given by

$$
Q_{i}=a_{i}+b_{i} R_{i}
$$

where $Q_{i}$ is the volume flow rate through the rotameter, $a_{i}$ and $b_{i}$ are coefficients found from the calibration of the rotameter, and $R_{\mathrm{j}}$ is the rotameter reading. Applying equation (E.1) gives

$$
8 Q_{i}=\left\{8 a_{i}^{2}+R_{i}^{2} 8 b_{i}^{2}+b_{i}^{2} 8 R_{i}^{2}\right\}^{1 / 2},
$$

where $\delta a_{i}$ and $\delta b_{i}$ are estimated from the calibration of the rotameter. The uncertainty in the rotameter reading was estimated to be $\pm 2 \mathrm{~mm}$ (the rotameter float height is measured in $\mathrm{mm}$, full scale is $150 \mathrm{~mm}$ ). This uncertainty is mainly a result of fluctuations in the float height, due to fluctuations in the flow rate through the rotameter. The uncertainty in the total volume flow rate of gas through the bank of rotameters $\left(\delta\left(\mathrm{Q}_{\mathrm{G} 2 \mathrm{M}}\right)\right)$ is the 
INPUT

OUTPUT

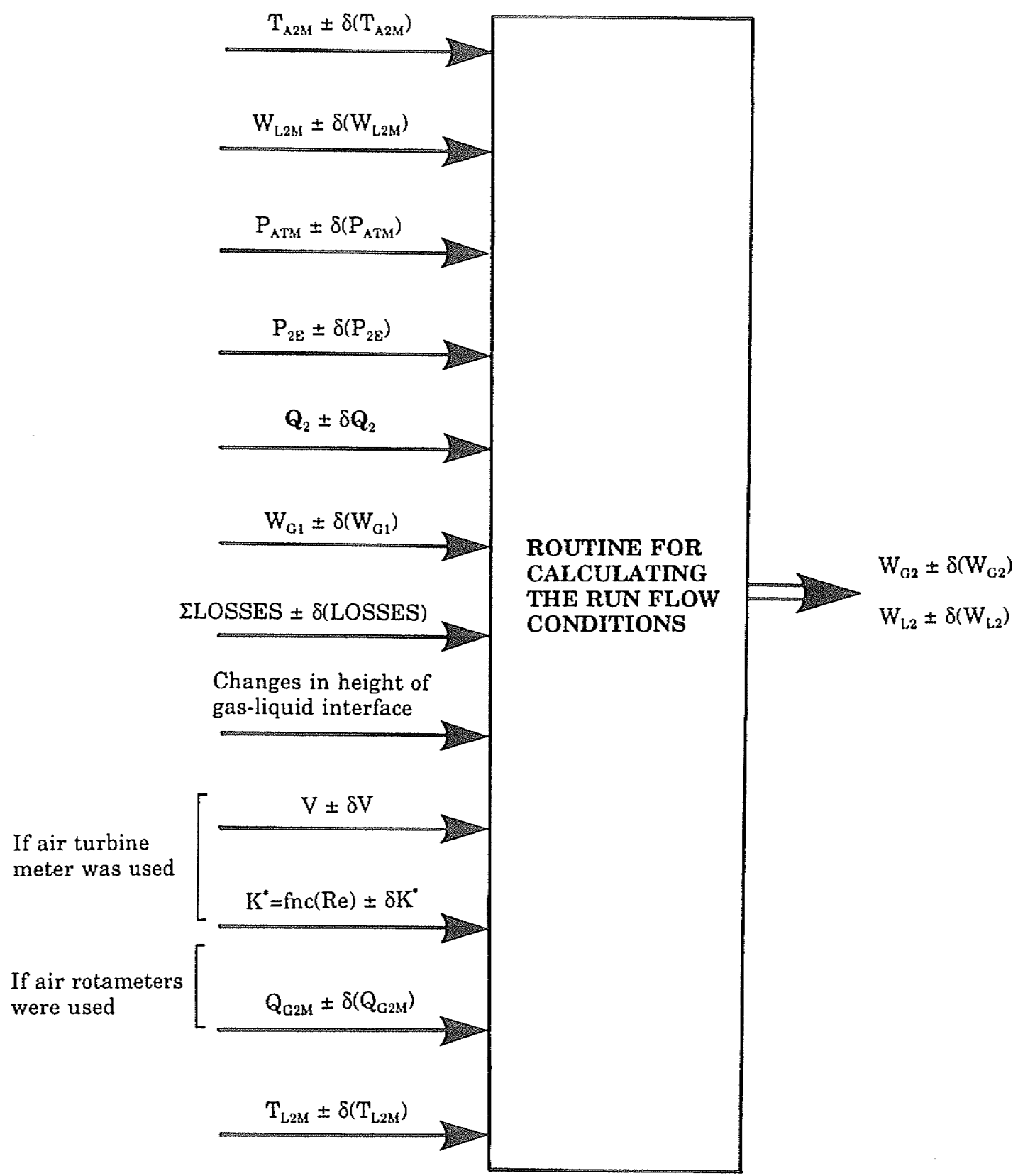

Figure E.5 Variables required for the calculation of $\delta\left(\mathrm{W}_{\mathrm{G} 2}\right)$ and $\delta\left(\mathrm{W}_{\mathrm{L} 2}\right)$ 
root-sum-square of the individual $\delta Q_{i}$. The flow rate $\mathrm{W}_{\mathrm{G} 2 \mathrm{M}}$ was calculated using the gas density $\rho_{\mathrm{G} 2 \mathrm{M}}$ calculated using equation (A.30). A procedure to estimate $\delta\left(\rho_{\mathrm{G} 2 \mathrm{M}}\right)$ was included within the computer-executed uncertainty analysis.

The liquid flow rate $\mathrm{W}_{\mathrm{L} 2 \mathrm{M}}$ was measured by a bank of rotameters. The procedure to estimate $\delta\left(\mathrm{W}_{\mathrm{L} 2 \mathrm{M}}\right)$ is similar to the above procedure for the air rotameters.

Changes in height of the gas-liquid interface in the separation tank were found to be the most significant factor affecting the uncertainty in $\mathrm{W}_{\mathrm{L} 2}$. A mass balance for the liquid and gas entering and leaving the separation tank yields

$$
\left|W_{L 3 M}-W_{L 3}\right|=A_{C S} \rho_{L 2 T} \frac{\Delta h}{\Delta t}
$$

and

$$
\left|W_{G 2 M}-W_{G 2}\right|=A_{C S} \rho_{G 2 T} \frac{\Delta h}{\Delta t},
$$

where $A_{C S}$ is the cross-sectional area of the separation tank, $\rho_{\mathrm{L} 2 \mathrm{~T}}$ is the liquid density in the separation tank, $\rho_{\mathrm{G} 2 \mathrm{~T}}$ is the gas density in the separation tank, and $\Delta \mathrm{h}$ is the change in height of the gas-liquid interface over time $\Delta t$. The value of $A_{C S}$ depends on the gas-liquid interface height. For most tests, the interface was maintained within the smaller diameter section. To estimate the effect of changes in height of the gas-liquid interface on the run flow rates, the values of $\mathrm{W}_{\mathrm{G} 2 \mathrm{M}}$ and $\mathrm{W}_{\mathrm{L} 2 \mathrm{M}}$ were perturbed sequentially by the amount given in 
equations (E.15) and (E.16), respectively. Values of $\Delta \mathrm{h} / \Delta \mathrm{t}$ were estimated individually for each test. In general, values for $\Delta \mathrm{h} / \Delta \mathrm{t}$ were largest during slug flow due to unsteadiness of this flow regime. Values of $\Delta \mathrm{h} / \Delta \mathrm{t}$ ranged between $0.2 \mathrm{~mm} / \mathrm{min}$ for small $\mathrm{W}_{\mathrm{L} 2}$ and an inlet flow regime of stratified flow, to 6 $\mathrm{mm} / \mathrm{min}$ for large $\mathrm{W}_{\mathrm{L} 2}$ and an inlet flow regime of slug flow.

The value of $\mathrm{P}_{2 \mathrm{E}}$ was estimated by extrapolating the measured pressure distribution in the test section run to the separation tank inlet. The uncertainty in $\mathrm{P}_{2 \mathrm{E}}$ was estimated from the uncertainties in the regression line coefficients. For all tests, $\delta \mathrm{P}_{2 \mathrm{E}}$ was found to be insignificant. The value of $\mathbf{Q}_{2}$ was estimated using an empirical correlation. Again, it was found that the value of $\delta \mathbf{Q}_{2}$ had little effect on the uncertainty for $\mathrm{W}_{\mathrm{L} 2}$ and $\mathrm{W}_{\mathrm{G} 2}$. However, $\delta \mathbf{Q}_{2} / \mathbf{Q}_{2}$ was estimated to be \pm 0.5 , and was included in the error analysis.

The parameter $\Sigma$ LOSSES was estimated using an empirical correlation. A sensitivity analysis of the value of $\delta$ (LLOSSES) typically showed little effect on the uncertainty in $\mathrm{W}_{\mathrm{L} 2}$ and $\mathrm{W}_{\mathrm{G} 2}$. For $\mathrm{J}_{\mathrm{G} 1}=40 \mathrm{~m} / \mathrm{s}$ and $\mathrm{J}_{\mathrm{L} 1}=0.0022 \mathrm{~m} / \mathrm{s}$, the effect of $\delta$ (LLOSSES) was most significant. However, even at these conditions the effect of errors in LLOSSES on the run flow rates are estimated to be smaller than $\pm 1 \%$ for $\mathrm{W}_{\mathrm{G} 2}$, and $\pm 3 \%$ for $\mathrm{W}_{\mathrm{L} 2}$. For the present analysis, $\delta(\Sigma$ LOSSES $) / \Sigma$ LOSSES was estimated to be \pm 2.0 . 


\section{Results}

As previously mentioned, the results of the above analysis are shown in Table E.1 for all of the two-phase flow test runs. The ranges of the uncertainty intervals for each variable can be summarized as follows:

\begin{tabular}{|c|c|c|}
\hline Variable & $\begin{array}{l}\text { Range in } \\
\text { Uncertainty }\end{array}$ & Comments \\
\hline $\mathrm{J}_{\mathrm{G} 1}$ & $3.5-4.1 \%$ & $\begin{array}{l}\delta\left(J_{G 1}\right) \text { is dominated by the uncertainty in the } \\
\text { calibration of the inlet air turbine meter. }\end{array}$ \\
\hline $\mathrm{J}_{\mathrm{L} 1}$ & $2.4-3.9 \%$ & $\begin{array}{l}\delta\left(J_{L 1}\right) \text { is dominated by the uncertainty in the } \\
\text { calibration of the inlet water turbine meters. }\end{array}$ \\
\hline $\mathrm{G}_{1}$ & $2.2-3.8 \%$ & $\begin{array}{l}\text { Only the uncertainties in } \mathrm{W}_{\mathrm{L} 1 \mathrm{M}} \text { and } \mathrm{W}_{\mathrm{G} 1 \mathrm{M}} \text { are } \\
\text { significant. Largest relative uncertainties } \\
\text { occurred at the smallest } \mathrm{W}_{\mathrm{L} 1 \mathrm{M}} \text {. }\end{array}$ \\
\hline $\mathrm{x}_{1}$ & $0.1-4.5 \%$ & $\begin{array}{l}\delta\left(x_{1}\right) \text { is very small for } x_{1} \text { near unity, while, } \\
\text { largest uncertainties occur for } x_{1} \text { near zero. }\end{array}$ \\
\hline $\mathrm{W}_{3} / \mathrm{W}_{1}$ & $3.4-15.7 \%$ & $\begin{array}{l}\text { Dominated by the uncertainty in } \mathrm{W}_{\mathrm{L} 3} \text {. Largest } \\
\text { relative uncertainties generally occur at the } \\
\text { smallest } \mathrm{W}_{3} / \mathrm{W}_{1} \text {. }\end{array}$ \\
\hline $\mathrm{x}_{3} / \mathrm{x}_{1}$ & $0.3-15.7 \%$ & $\begin{array}{l}\text { In general, } \delta\left(x_{3} / x_{1}\right) \text { is dominated by the } \\
\text { uncertainty in } x_{3} \cdot \delta\left(x_{3}\right) / x_{3} \text { is very small for } x_{3} \\
\text { near unity, while, largest uncertainties occur for } \\
x_{3} \text { near zero. }\end{array}$ \\
\hline$F_{B G}$ & $4.4-14.9 \%$ & $\begin{array}{l}\text { Typical values for } \delta\left(\mathrm{F}_{\mathrm{BG}}\right) / \mathrm{F}_{\mathrm{BG}} \text { are near } \pm 5.0 \% \text {. } \\
\text { The largest relative uncertainties occur at the } \\
\text { smallest } \mathrm{F}_{\mathrm{BG}} \text { and } \mathrm{W}_{\mathrm{G} 3} \text {. }\end{array}$ \\
\hline $\mathrm{F}_{\mathrm{BL}}$ & $4.4-25.0 \%$ & $\begin{array}{l}\text { Dominated by the uncertainty in the steadiness } \\
\text { of the branch separation tank gas-liquid } \\
\text { interface. Typically, the largest relative } \\
\text { uncertainties occur at the smallest } \mathrm{F}_{\mathrm{BL}} \text { and } \mathrm{W}_{\mathrm{L} 3} \text {. }\end{array}$ \\
\hline
\end{tabular}


$\mathrm{P}_{\mathrm{SYS}} \quad 1.2-1.3 \% \quad \delta\left(\mathrm{P}_{\mathrm{SYS}}\right)$ is near $\pm 1850 \mathrm{~Pa}$ for all tests. Both the uncertainty in the calibration of the Rosemount pressure transducer and the uncertainty in the average voltage from the transducer are significant.

$\mathrm{T}_{1} \quad 0.1-0.3^{\circ} \mathrm{C} \quad$ Largest uncertainties occur at the smallest $\mathrm{G}_{1}$, while, smallest uncertainties occur at the largest $\mathrm{G}_{1}$.

As a final comment, the present error analysis was undertaken with the assumption that the data reduction procedure described in Appendix A introduces no uncertainties in the reduced data. In other words, any idealizations in the data reduction equations were assumed to have no effect on the reduced data. It was pointed out that for most tests the effect of evaporation was small. As a result, the test section flow rates were near their respective measured flow rates, and the data reduction procedure to account for evaporation, and any errors due to this procedure, were therefore negligible. The main assumption in the data reduction procedure was that the flow of air in the test section was assumed to be saturated with water vapour. Although this assumption could not be verified, it does seem most reasonable.

\section{E.3 Experimental Repeatability}

Throughout the experimental investigation, several test runs were repeated by re-running the tests at conditions similar to the original tests. For most of these repeat tests, the data were only displayed on a computer 
monitor, with good agreement. However, for three two-phase flow tests and one single-phase flow test the repeat data were recorded. Table E. 2 presents the original data and the repeat data for these tests. For test 2-3, repeat data were obtained for both the phase distribution and the pressure drops $\Delta \mathrm{P}_{12}$ and $\Delta \mathrm{P}_{13}$. For test $4-4$, both the original and repeat data could not be obtained for $\Delta \mathrm{P}_{12}$, and for test 9-2, no pressure-drop data were obtained for both the original and repeat tests; for reasons discussed in Appendix D.

In general, values of $\mathrm{F}_{\mathrm{BG}}, \mathrm{F}_{\mathrm{BL}}$, and $\mathrm{x}_{3} / \mathrm{x}_{1}$ repeated within approximately $\pm 2 \%$ of the original value. Repeat values of $\Delta \mathrm{P}_{13}$ obtained for tests 2-3 and 4-4 agreed well with the original data. For test $2-3, \Delta \mathrm{P}_{12}$ repeated within $9 \%$ of the original value.

Single-phase pressure-drop data were repeated for test S-2. For this test, $\Delta \mathrm{P}_{12}$ and $\Delta \mathrm{P}_{13}$ repeated within $1 \mathrm{~Pa}$.

For tests 9-2 and S-2, the repeat data were obtained immediately after the original tests were performed. For tests 2-3 and 4-4, the repeat data were obtained at the end of the experimental program. 
Table E.2

Repeatability of Experimental Data

\begin{tabular}{|c|c|c|c|c|c|c|c|c|c|}
\hline $\begin{array}{c}\text { Test } \\
\#\end{array}$ & $\begin{array}{l}\text { Original } \\
(\mathrm{O}) \\
\text { or } \\
\text { repeat } \\
(\mathrm{R})\end{array}$ & $\begin{array}{l}\mathbf{J}_{\mathrm{LI}} \\
\mathbf{m} / \mathbf{s}\end{array}$ & $\begin{array}{l}\mathbf{J}_{G 1} \\
\mathbf{m} / \mathbf{s}\end{array}$ & $W_{3} / W_{1}$ & $\mathbf{F}_{\mathrm{BG}}$ & $\mathbf{F}_{\mathrm{BL}}$ & $\mathbf{x}_{9} / \mathbf{x}_{1}$ & $\begin{array}{l}\Delta \mathbf{P}_{13} \\
\mathbf{P a}_{\mathbf{a}}\end{array}$ & $\underset{\mathrm{Pa}_{12}}{\Delta \mathrm{P}}$ \\
\hline $2-3$ & $\begin{array}{l}0 \\
\mathrm{R}\end{array}$ & 0.0092 & 10.9 & 0.50 & $\begin{array}{l}0.49 \\
0.49\end{array}$ & $\begin{array}{l}0.52 \\
0.51\end{array}$ & $\begin{array}{l}0.98 \\
0.98\end{array}$ & $\begin{array}{l}7 \\
5\end{array}$ & $\begin{array}{l}-99 \\
-90\end{array}$ \\
\hline $4-4$ & $\begin{array}{l}0 \\
\mathrm{R}\end{array}$ & 0.180 & 10.8 & 0.70 & $\begin{array}{l}0.94 \\
0.96\end{array}$ & $\begin{array}{l}0.67 \\
0.68\end{array}$ & $\begin{array}{l}1.35 \\
1.38\end{array}$ & $\begin{array}{l}519 \\
490\end{array}$ & \\
\hline $9-2$ & $\begin{array}{l}\mathrm{O} \\
\mathrm{R} \\
\end{array}$ & 0.0023 & 2.7 & 0.28 & $\begin{array}{l}0.26 \\
0.27\end{array}$ & $\begin{array}{l}0.31 \\
0.30\end{array}$ & $\begin{array}{l}0.95 \\
0.96\end{array}$ & & \\
\hline $\mathrm{S} \cdot 2$ & $\begin{array}{l}O \\
\mathrm{R}\end{array}$ & 0.180 & 0 & 0.30 & & & & $\begin{array}{l}-0.4 \\
-0.2\end{array}$ & $\begin{array}{r}-7.9 \\
-8.8\end{array}$ \\
\hline
\end{tabular}

\section{REFERENCES FOR APPENDIX E}

E.1 S.J. Kline, and F.A. McClintock, "Describing the Uncertainties in Single-Sample Experiments", Mechanical Engineering, Vol. 75, pp. 3-8, 1953.

E.2 Moffat, R.J., "Describing the Uncertainties in Experimental Results", Experimental Thermal and Fluid Science, Vol. 1, pp. 3-17, 1988. 